UNIVERSIDADE DE SÃO PAULO

FACULDADE DE FILOSOFIA CIENCIAS E LETRAS

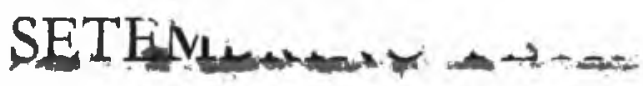

\title{
Foraminíferos Fósseis da Bacia do Marajó
}

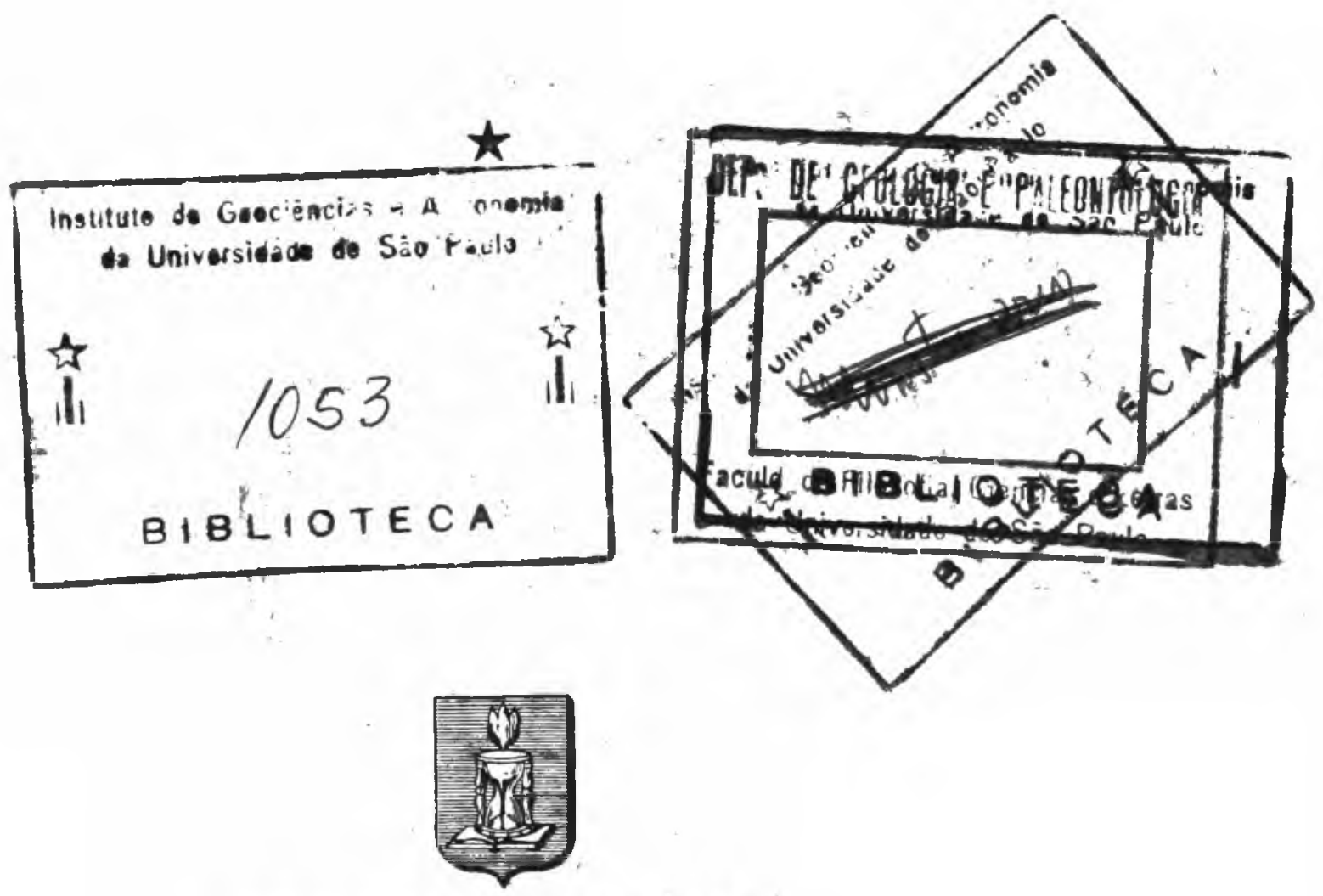

S Ã O P A UL O-B R A S I L

1954 
Os Boletins da Faculdade de Filosofia, Ciências e Letras da Universidade de São Paulo, são editadas pelos Departamentos das suas diversas secçöes.

Tôda correspondência deverá ser dirigida para o Departamento respectivo da Faculdade de Filosofia, Ciências e Letras - Caixa_Postal 8105, S. Paulo-Brasil.

The "Boletins da Faculdade de Filosofia Ciências e Letras da Universidade de Sáo Paulo" are edited by the different departments of the Faculty.

All correspondence should be addressed to the Department concerned. Caixa Postal 8105, S. Paulo-Brasil.

\title{
UNIVERSIDADE DE SÃO PAULO
}

Reitor:

Prof. Dr. José de Mello Morais

FACULDADE DE FILOSOFIA, CIENCIAS E LETRAS

Diretor:

Prof. Dr. Eurípedes Simões de Paula

\author{
$=$ \\ DEPARTAMENTO DE GEOLOGIA E PALEONTOLOGIA \\ Diréfor : \\ Prof. Viktor Leinz, Ph. D.
}

Prof. Colaborador Josué Camargo Mendes, D. Sc.

Assistentes:

Sérğto Estanislau do Amaral, Lic. Sc.

Reinholt Ellert .

Alfredo J. Simon Bjornberg

Auxiliar de Ensino:

Ana Maria Vieira de Carvalho, Lic. Sc. 
FACULDADE DE FILOSOFIA CIENCIAS E LETRAS

\section{SETEMBRINO PETRI}

\section{Foraminíferos Fósseis da Bacia do Marajó}
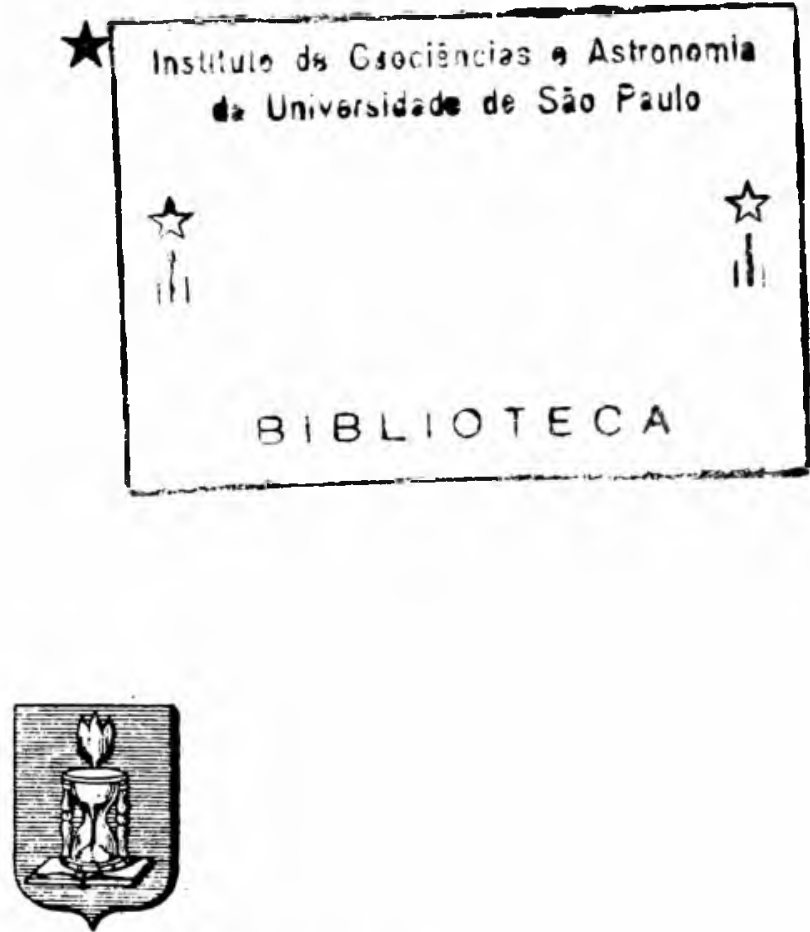

$$
\begin{gathered}
\text { S I P A UL O - B R A S IL } \\
1954
\end{gathered}
$$





\section{APRESENTAÇÃO}

Foi com grande prazer que recebemos do Dr. Setembrino Petri o trabalho constante do presente boletim.

O autor, antigo Assistente nosso e atualmente do quadro do Conselho Nacional do Petróleo, tem apresentado relevantes contribuições no campo da Micropaleontologia, de que o seu trabalho ora publicado é mais um atestado.

Aplaudimos, outrossim, ao Dr. Plinio Cantanhede, Presidente do Conselho Nacional do Petróleo, por incentivar seus técnicos a trabalhos dêste gênero e ainda custear a publicação dêste boletim, iniciando assim uma nova forma de colaboração entre institutos universitários e de pesquisa aplicada.

\section{VIKTOR LEINZ}

Diretor do Departamento de Geologia e Paleontologia 



\section{R E S T M O}

No presente trabalho são descritos foraminíferos fósseis separados de testemunhos de sondagem e amostras de calla da sondagem do Conselho Nacional do Petróleo localisada no vale do rio Cururú, Ilha de Marajó (Sondagem CR-1-PA). (Fig. 1). Esta sondagem foi localisada na bacia sedimentar limitada por falhas, conhecida como fóssa do Marajó, compreendendo a ilha de Marajó e regiões circunvizinhas. Foi depositado, nesta bacia, espêsso pacote de sedimentos, atingindo, em alguns lugares, mais de $4.000 \mathrm{~m}$ de espessura.

A existência desta fóssa até bem pouco tempo atrás (1946) não era suspeitada, admitindo-se que a regrião cra ocupada por sedimentos terciários (série Barreira!) e aluvião de espessura relativamente pequena. A verificação de una bacia de intensa sedimentação na região só foi revelada graças a trabalhos do Geofísiea feitos por intermédio do Conselho Nacional do Petróleo, pois a inexistência de afloramentos não permitem estudos de Geologia de superfície.

A maior parte dos foraminíferos descritos provém do intervalo de $245 \mathrm{~m} 740 \mathrm{~m}$, existindo contudo, foraminíferos fósseis até a profundidade de 2.425 metros.

A idade dêsses fósseis é miocênica na parte superior e eocênina e cretácica na parte inferior. Contudo os foraminíferos do Eoceno e do Cretáceo estão retrabalhados.

Também foi discuticla a estratiorafia da sondagem de Cururú, bem como de duas outras existentes na mesma fóssa, Limoeiro (LM-1-PA) e Badajós (B.J-1-PA). As correlacooes dos sedimentos dêsses três poços são incertas não só derido aos ambientes de sedimentação diferentes, como também as distáncias gengráficas que os separam.

\section{$A B S T R A C T$}

Fossil Foraminiferal Famas from a well drilled in the Marajó Island, Brazil are deseribed in the presente paper. This island is located in the State of Pará, between the months of the Amazon and Tocantins river's (Fig. 1).

The Marajo Island and lands nearby are covered with thick forests and soils, showing only allurium deposits. No outcrops of old rocks are seen. This region was thought to have been filled with 
a shallow sedimentary basin. Intensive researches are beeing made by the Brazilian Petroleum Council (Conselho Nacional do Petróleo) in this area in order to find out eventually oil reserves. Until recently the nature of these researches was only geophysical because the absence of outcrops prevented superficial geologic studies. We got an idea of the mature of the sediments in this basin, only in 1950 , when the first well was drilled in this region, and then subsuperficial Geology was possible. Even the geophysical researches were started only in 1946. These researches revealed the presence of a graben in the region not suspected before. The faults limiting this graben have the general direction southeast-northwest. This graben has no definite limitations only in the direction of the ocean. Its outline is a large basin between $47^{\circ} 30^{\prime}$ and $51^{\circ} \mathrm{W}$ Long. and from the north coast to about $3^{\circ} 30^{\prime} \mathrm{s}$ Lat. with a north-south trending through, the center of which is over 4000 meters in depth. It is included in this graben the Marajo island and the borderland between the Tocantins and the Amazon rivers and beyond the Tocantins northeastward reaching the lower Capim river then turning northwestward to the coast, in the entry of the Guajara bay. There are two structural highs in this basin, in the neighbourhood of the city of Balem and near the main course of the Amazon River. A complex of faults striking mostly in the southeast-northwest direction was detected around the mouth of the Tocantins and Para rivers.

To the East and Northeast of the Marajó graben, lays a small sedimentary basin which sediments are mostly of Miocene age, known as Pirabas formation (Silva e Petri 1952) (See also map fig. 1 of the present paper). The relationships between the Marajo basin and the Pirabas basin are doubtful; probably there is a fault zone between them.

- So far three wells were drilled in the Marajó basin, in structures revealed by geophysical methods. These wells vielded the first fossils found out so far in the region.

The first well drilled, was in the locality linown as Iimoeiro, at the left margin of the Tocantins river near its mouth in the Guajara bay. It is located about 180 kilometers southrest of the city of Belém. This well known as LM-1-PA was abandoned at the depth of 4027 meters withont reaching the cristaline basement. The fossils vielded by it were few, only some sponges spieules, Diatomaceae, plant fragments and reworked Foraminifera. Continental conditions prevailed through all the time of deposition of these sediments.

The second well known as CR-1-PA was located in the raller of the Cururú river in the northern side of the Marajo island and about 150 kilometers $\mathrm{N} 9^{\circ} \mathrm{W}$ of the Limoeiro well. It reached the cristaline basement at the depth of 3848 meters. This was the most fossiliferous well in the region: Foraminifera, Sponge spicules. 
Corals, Bryozoa, Pelecypoda, Gastropoda, fragments of Echinodermata, fish bones and teeth, trails and burrows of uncertain origins and spores and fragments of plants. The sediments of the well were deposited in marine and continental environments.

The third well was located near the locality of Badajós right margin of the Capim river and about 170 kilometers $S 19^{\circ} \mathrm{E}$ of the Limoeiro well. It was located near the flank of the Marajo basin, so the thickness of sediments is here smaller than in other wells. Quartzite believed to represent cristaline basement was reached at the depth of 2159 meters. Most of the fossils yielded here come from non marine environments: Sponge spicules, Ostracoda, fragments of fish bones and teeth (ostheichthi) and fragments of bones and teeth of selachii and possibly reptils, oogonias of Charophyta algae, spores and plant fragments and trails and burrows of uncertain origins.

The description of the Foraminifera found out in the Cururu well was the main purpose of this paper. Problems of correlations and Stratigraphy and the enviromment of deposition of the different formations were also discussed.

As shown by the fossils of the Marajo basin, most of its sediments must be refered to the Cenozoic, and the oldest beds possibly belong to the Cretaceous.

The correlation of the three wells is difficult to inake up not only because of the different environments of depositions but also because the distances separating these three wells are great. The Fig. 5 shows possible lines of correlations.

The Stratigraphy of the Cururu well is given below in an abridged way. The interval $3848 \mathrm{~m} 3507 \mathrm{~m}$ is characterized by red-brown shales and siltites which probably is not younger than Cretaceous because of diabase intrusion cutting these sediments. The youngest diabase in Brazil cuts possibly Cretaceous rocks with dycotiledoneous leaves as shown in the basin of São Manuel river (Moura 1938 p. 65). The Rhaetic age is more common for the Brazilian diabase. Of course these sediments could be older than Cretaceous. Furthermore there is no proof that this diabase has a Rhaetic or Cretaceous age. A thick arenaceous formation was drilled between $3507 \mathrm{~m}$ and $2580 \mathrm{~m}$. Small fossils, possibly oogonias of the Charophyta algae Clavatoraceae are found in this formation. These algae belong to the Cretaceous going down doubtly to the Triassic. We infer therefore a Cretaceous age for this formation. The environment was possibly a coastal one.

From $2580 \mathrm{~m}$ to $2020 \mathrm{~m}$ we find an argillaceous black shale. very rich in carbonaceous plant remains and coal. Dark siltite and fine to medium grained gray sandstone are also found. Few rewor- 
ked Cretaceous and Eocene Foraminifera were found in these beds. The following were classified:
1) Globigerina cretacea d'Orbigny
2) G. cf. triangularis White
3) Globorotalia compressa (Plummer)
4.) G. cf. crassata (Cushman)
5) Gümbelina globulosa (Ehrenherg)

The age of these beds is uncertain inasmuch as these fossils are reworked. We consider them Eocene. As for the environment, we think it was an environment of marginal lagoons with poor circulation or marine swamps because of the black shales containing pyrite. It is significant that the fossils listed above are all planktonic Foraminifera with light shells which can be easily transported.

In the next interval, $2020 \mathrm{~m} 1692 \mathrm{~m}$ we have grayish red silts and clays with only fragments of plants and spores so the age is uncertain.

In the $1692 \mathrm{~m} 740 \mathrm{~m}$ interval the plant remains are very abundant. Here we find also few Foraminifera badly preserved (Quinqueloculina, Globigerina, Elphidium). We may have here also a marine swamp environment and the age could be Miocene because its Foraminifera bear some resemblance with the Miocene ones found in the next interval. However no index fossils were found.

In the interval $740 \mathrm{~m} 460 \mathrm{~m}$ we find also abundant carbonaceous plant remains and coal and the Foraminifera appear in larger numbers than in the preceding interval. It looks like a continuation of the preceding conditions, only a more marked marine inset. The marine conditions become more dominant in the interval $460 \mathrm{~m} 245 \mathrm{~m}$ where we find index fossils for the Miocene (Orbulina suturalis Bromnimann, Globoquadrina quadraria (Cusman and Ellisor) var. advena Bermudez etc.). Besides Foraminifera we find other fossils in this interval: Sponge spicules, Corals, Bryozoa, Echinodermata fragments, Pelecrpoda, Gastropoda, Ostracoda and fish teeth and bone fragments. The enrironment, infered by the fossils, were marine, shallow warm clear water near reefs. The large Foraminifera Amphistegina and Peneroplidae which are common here, besides corals, are characteristics of reef conditions. However the high percentage of planktonic Foraminifera brings the suspection of thanatocoenosis, and the rather coarse foraminiferal-bearing sediments suggest near shore enviromment with supplies of terrestrial sediments.

The interval $245 \mathrm{~m}-0 \mathrm{~m}$ is characterized by the disappearance of the fossils of the preceding interval, and only plant remains 


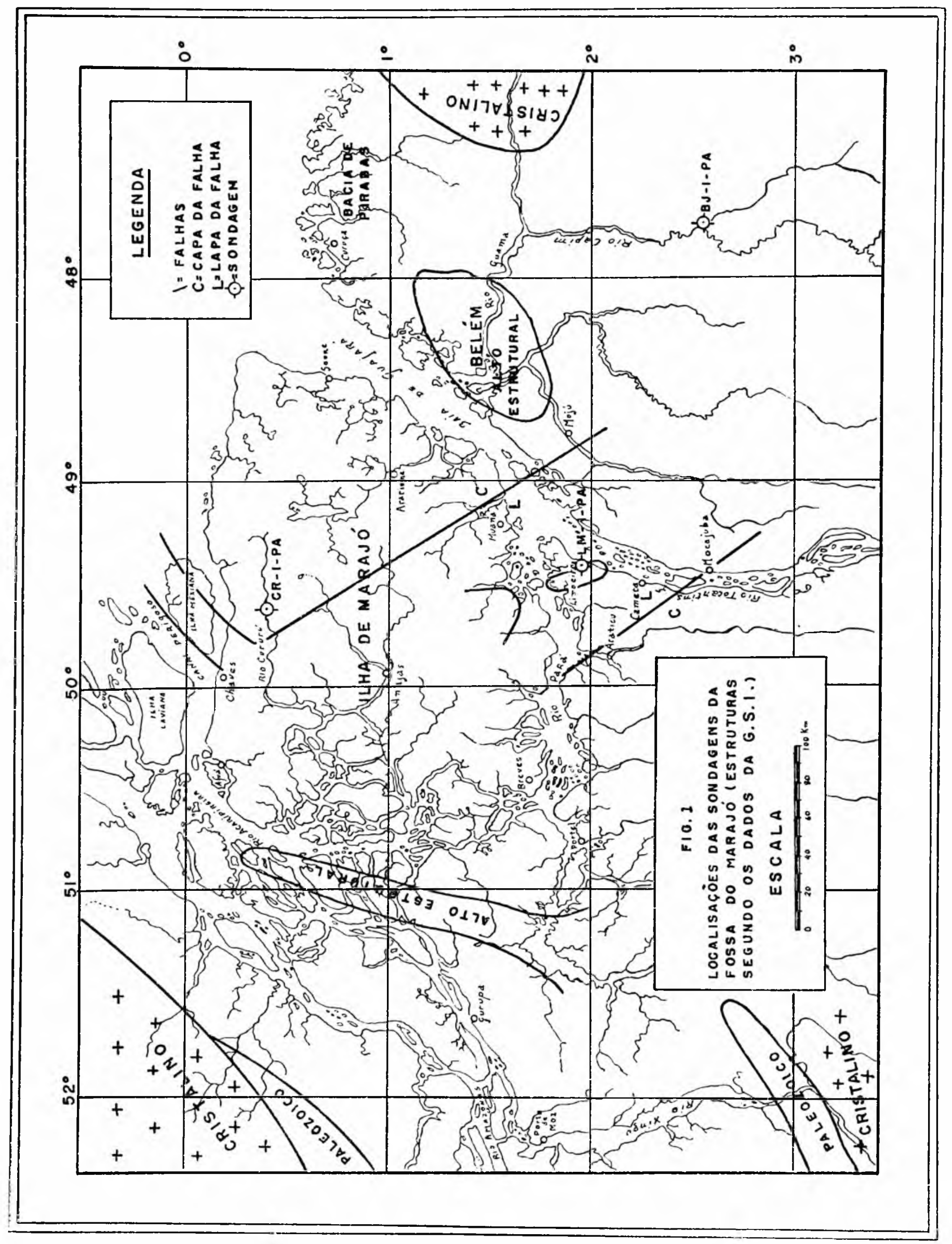


appear therein. The sediments represent perhaps the Recent or Pleistocene period of deposition and they possible are of fluvial nature.

The Foraminifera described come mainly from the interval $740 \mathrm{~m} 245 \mathrm{~m}$. 'This interral can be divided in different paleontological zones which cannot be precisely defined because they were based mainly on ditch samples inasmuch as the coring were very sparse.

The following zones were recognised:

1) Amphistegina lessonii d'Orbigny

zone $245 \mathrm{~m} \cdot 259 \mathrm{~m}$

2) Bolivina plicatella Cushman

zone $259 \mathrm{~m} \cdot 330 \mathrm{~m}$

3) Elphidium poeyanum d'Orbigny var. elongata

Petri zone $330 \mathrm{~m} \cdot 460 \mathrm{~m}$

4) Quinqueloculina lamarckiana d'Orbigny

zone $460 \mathrm{~m} \cdot 740 \mathrm{~m}$

\section{I T ROD L C I O}

No presente trabalho são descritos foraminiferos fósseis provenientes de uma sondagem do Conselho Nacional do Petróleo na ilha do Marajó, região de Cururú. Esta ilha está situada no Estado do Pará, Brasil, entre a fóz do rio Amazonas e a do rio Tocantins (Fig. 1).

A ilha do Marajó e terrenos lindeiros do continente são cobertos por espêssa vegetação e por sólo, mostrando sòmente algumas exposições de aluvião. Não há afloramentos de rochas mais antigas. Admitia-se a presença ali de uma bacia rasa de sedimentos. Esta região tem sido objeto de intensos estudos feitos por intermédio do Conselho Nacional do Petróleo que está pesquisando a área com o fito de procurar depósitos de petróleo. Essas pesquisas se resumiam, até há pouco tempo, a trabalhos de Geofísica, visto que a inexistência de afloramentos impede estudos de Geologia de superfície. Sòmente em 1950, quando o primeiro poço foi perfurado na região, tornou-se possivel ter idéia da natureza dos sedimentos que ocupam esta bacia e iniciar-se estudos de Geologia subsuperficial. Mesmo os trabalhos de Geofísica datam de pouco tempo tendo sido iniciados em 1946. Graças a êsses trabalhos foi revelada a presença de uma fóssa de sedimentos na região do Marajó, até então não suspeitada. Esta fóssa é limitada por falhas na direção sudestenoroeste, tanto no seu limite léste como no limite oéste. O limite sul também é provàvelmente zona de falhamentos. A fóssa não tem limites definidos no lado do oceano. Ela compreende uma larga bacia entre $47^{\circ} 30^{\prime}$ e $51^{\circ}$ oéste de longitude e do litoral até cêrca de $3^{\circ} 30^{\prime}$ sul de latitude, atingindo os sedimentos, no centro da bacia, mais de 4.000 metros de espessura. Ela inclui a ilha do 
Marajó e terrenos lindeiros do continente que ficam entre os rios Tocantins e Amazonas, estendendo-se também para a região nordeste do Tocantins, atingindo o curso inferior do rio Capim e infletindo daí para noroeste até atingir o Atlântico na entrada da baía do Guajará. Há dois altos estruturais nesta fóssa, um na circunvizinhança da cidade de Belém e outro próximo ao curso principal do rio Amazonas. A região da fóz dos rios Tocantins e Pará na baía do Guajará, apresenta um complexo de falhas cuja direção predominante é sudeste-noroeste. Devemos lembrar também eviclências de falhas próximo à Belém, $30 \mathrm{~km}$ a léste desta cidade, na fóz do igarapé Caraparú no rio Guamá, onde aflora calcáreo com evidências de fraturas possivelmente de origem tectônica (Petri, 1952 p. 25). A maioria dêsses falhamentos da fóssa do Marajó, segundo informações do sr. Herman J. Koch, não atinge a superfície, desaparecendo a $1.500 \mathrm{~m}$ de profundidade. Contudo, a falha que passa pelo lado oéste da ilha de Mexiana, ating'e a superfície, mostrando a reativação de falhamentos, provàvelmente no Quaternário.

A léste e a nordeste da fóssa do Marajó, existe uma bacia de sedimentos de idade miocênica, conhecida como formação Pirabas. (Silva e Petri 1952) (Fig. 1). As relações entre a fóssa do Marajó e a bacia de Pirabas são incertas, havendo provàvelmente relações de falhamento.

Três sondagens foram feitas até agora pelo Conselho Nacional do Petróleo, na fóssa do Marajó, em estruturas determinarlas pela Geofísica. Estas sondagens revelaram os primeiros fósseis até agora conhecidos da região. A primeira sondagem, em ordem cronológica, foi feita próximo a localidade chamada Limoeiro, à margem esquerda do rio Tocantins, próximo à fóz dêste rio na baía do Guarajá e a 180 quilômetros a sudoeste da cidade de Belém. Esta sondagem foi abandonada quando a profundidade alcançou 4.027 metros, não tendo, contudo, sido atingido o embasamento cristalino. Ela é conhecida por LII-1-PA. Poucos fósseis forneceu esta sondagem, revelando sòmente a presença de espiculas de esponjas, diatomaceas, fragmentos de vegetais e foraminíferos retrabalhados. Parece que prevaleceram aqui condições continentais na deposição dos sedimentos.

O segundo poço foi localisado no vale do rio Cururú, na ilha do Marajó na parte norte e distante do poşo de Limoeiro, cêrca de 150 quilômetros na direção N $9^{\circ} \mathrm{W}$. Esta sondagem atingin o cmbasamento cristalino a profundidade de 3.848 metros. Ela é conhecida por CR-1-PA. Esta sondagem foi a que fornecen maior número de fósseis. Além de foraminíferos, foram encontrados Ostracoda, Bryozoa, Pelecypoda, Gastropoda, Corais, Espiculas de esponjas, fragmentos de Echinodermata, fragmentos de ossos e dentes de peixes, rastros e tubos de natureza indeterminada e fragmentos e 
espóros de plantas. Os sedimentos dêsse poço foram depositados em ambientes continentais e marinhos.

O terceiro poço foi localisado próximo a localidade de Badajós, à margem direita do rio Capim a a cêrea de 170 quilômetros a $\mathrm{S} 19^{\circ} \mathrm{E}$ do poço de Limoeiro. Esste poço foi localisado próximo a borda da fóssa e possui, por conseguinte, espessura bem menor de sedimentos tendo sido atingido um quartzito a profundidade de 2.159 metros, que se crê pertencer ao embasamento cristalino. Esta sondagem forneceu fósseis predominantemente de água dôce. Foram encontrados dentes e fragmentos de ossos de peixes teleosteos e de outros vertebrados, Ostracoda, espículas de esponjas, oogónias de algas Charophyta, espóros e fragmentos de plantas e rastros e tubos de origem indeterminada.

A descrição dos foraminíferos fósseis encontrados na sondagem de Cururú constitui o objeto principal dêste trabalho. Abordam-se também problemas de correlação e de Estratigrafia. Os ambientes de sedimentação das diversas formações das sondagens de Cururú e Badajós são discutidos.

Os fósseis encontrados na fóssa do Marajó mostram que a maior parte dos sedimentos que preenchem essa fóssa deve ser referida ao Cenozoico sendo que os sedimentos mais antigos, provàvelmente foram depositados durante o Cretaceo.

Agradecemos ao Eng. Décio Savério Oddone, Chefe do Serviço Regional da Amazonia, do Conselho Nacional do Petróleo, pelas atenções e boa rontade que sempre demonstrou permitindo que o Laboratório de Paleontologia do CNP em Belém, Estado do Pará, fôsse aparelhado com o material necessário para levar adiante o trabalho óra apresentado. Agradecemos também ao sr. Herman .J. Koch da 'Geophysical Service Incorporation' pelos dados que nos forneceu relativos às estruturas da fóssa do Marajó. Êsses agradecimentos são também extensiros ao si. Francisco Mota Bezerra da Cunha pela valiosa contribuição para as ilustrações aqui apresentadas e asos srs. Otávio Benedito de Carvalho Melo e Carlos Olímpio da Gama Malcher de Araújo que nos auxiliaram na coléta de microfósseis.

ESTRATI $\mathrm{T}$ R A F I A

\section{Sondagem de Limoeivo -- Litologia e Litótopos}

A Estratigrafia da sondagem de Limoeiro é tratada aqui de maneira mais breve. Assim procedemos devido a raridade de fósseis. encontrados neste poço o que permite poucas deduções sôbre idade e ambiente de sedimentação. 
Além de restos de plantas e espóros de difícil classificação, e portanto sem grande valor para a Estratigrafia, encontrados em diversos testemunhos de sondagem, os únicos fósseis dêste poço que permitem que se tenha alguma idéia sôbre a idade e ambiente de sedimentacão são os do intervalo $2453 \mathrm{~m} 3394 \mathrm{~m}$. Foram encontrados neste intervalo, por Mrs. Katherine Gilmore, do 'Dallas Stratigraphic and Paleontologic Laboratory', de Dallas, Texas, globigerinas que se assemelham a $G$. increbescens Bandy ou G. ouachitensis Howe e Wallace do Eoceno dos Estados Unidos (intervalo $2453 \mathrm{~m}$ $2573 \mathrm{~m}$ ) e algumas formas arenosas duvidòsamente identificadas como Gaudryina, Haplophragmoides e Ammobaculites (intervalo $2864 \mathrm{~m}-3394 \mathrm{~m}$ ). Êsses fósseis estão retrabalhados, tendo portanto os sedimentos que os contém, idade incerta, sendo aqui duvidòsamente considerados do Eoceno. Quanto ao ambiente de sedimentação parece ser de água salobra; restos de regetais carbonisados e presença comum de pirita indicam ambiente redutôr. $O$ sr. Sérgio Estanislau do Amaral, do Departamento de Geologia e Paleontologia da Faculdade de Filosofia, Ciências e Letras da Universidade de São Paulo, encontrou no testemunho n1. ${ }^{\circ} 166$ e em outros, abundantes diatomaceas (comunicação verbal). Como o testemunho $n^{\circ}{ }^{\circ} 166$ $(4026 \mathrm{~m}-4027 \mathrm{~m})$ pertence a base da secção, esta descoberta tem grande valor para a avaliaçãa da idade_dêsses sedimentos basais. Como as diatomaceas aparecem no registro geológico sòmente no Jurássico, vemos que mesmo a profundidade de 4027 metros não temos sedimentos mais antigos que o Jurássico.

Predominam neste poço, sedimentos grosseiros. De uma maneira geral os sedimentos de Limoeiro podem ser divididos da seguinte maneira: 1) Silte vermelho-amarelado e vermelho pintalgado e silte e areia fina cinzentos $0 \mathrm{~m} 1200 \mathrm{~m}$; 2) Siltito e argilito vermelho-marrons, limoníticos e arenito fino cinzento a vermelhomarron, limonítico. Êsses sedimentos possuem as vêzes cimento calcáreo; $1200 \mathrm{~m} 2000 \mathrm{~m}$; 3) Leitos espêsssos de siltito vermelho a cinzento intercalados com arenito branco fino a grosso. No intervalo $2453 \mathrm{~m} 2573 \mathrm{~m}$, formado por siltito vermelho e cinzento, foram encontradas as globigerinas citadas acima. F̂sse intervalo parece ser transicional entre o intervalo superior $(1200 \mathrm{~m} 2000 \mathrm{~m})$ e o inferior $(2600 \mathrm{~m} 4027 \mathrm{~m})-2000 \mathrm{~m} 2600 \mathrm{ml}$; 4) Arenito fino a grosseiro, branco, com leitos conglomeráticos e estratificação cruzada de corrente em alguns testemunhos e pacotes de siltito cinzento subordinados. Na parte superior, onde a rocha é mais fina, foram encontrados os foraminíferos arenosos pèssimamente conservados. eitados acima, Gaudryina, Haplophragmoides e Ammobaculites -$2600 \mathrm{~m} 4027 \mathrm{~m}$.

Na figura 2, damos com maior detalhe a sucessão litológica encontrada nesse poço. Quanto ao ambiente de sedimentação não 
podemos nos alongar devido a raridade de fósseis. A inconstância de tipos litológicos e raridade de fósseis sugerem ambientes continentais para a maioria dêsses sedimentos. A espêssa sedimentação arenosa da base talvez reflita ambiente costeiro.

\section{Sondagem de Cururú - Litologia e Litótopos}

Nota-se, de uma maneira geral, nesta sondagem, predomínio de sedimentos clásticos relativamente grosseiros (siltitos e arenitos). Contudo sedimentos argilosos são aqui mais freqüentes que nas outras duas sondagens da fóssa do Marajó (Limoeiro e Badajós). Esta situação corresponde a esperada se considerarmos a fóssa do Marajó com declive regional para o mar, tendo, por conseguinte, os sedimentos de Limoeiro e Badajós, características mais continentais que os de Cururú. Esta situação é corroborada pelos dados paleontológicos. Outra consideração que vem a favor da citada hipótese, é a seguinte: Grande parte dos sedimentos que preenchem a fóssa do Marajó foi depositada durante a éra Cenozoica e sabemos que já desde o comêço do Cenozoico a costa brasileira estava mais ou menos delineada razão porque sedimentos marinhos do Cenozoico só encontramos próximo à costa.

- De uma maneira geral nota-se, com exceção do intervalo $460 \mathrm{~m}$ $245 \mathrm{~m}$, onde aparece rica fauna marinha, grande quantidade de fragmentos de vegetais e de carvão, mostrando que durante a maior parte do tempo de deposição dos sedimentos de Cururú, a região foi pantanosa ou situando-se próxima a pântanos, provàvelmente mangues de água salobra. Essa dedução é reforçada pela presença comum de pirita nesses sedimentos.

A sondagem de Cururú alcançou a profundidade de $4048 \mathrm{~m}$, tendo atingido o embasamento cristalino a profundidade de $3848 \mathrm{~m}$ (granitos e dioritos) (Ver fig. 3).

De $3848 \mathrm{~m}$ a $3507 \mathrm{~m}$, foram perfurados follêlhos e siltitos vermelho-marrons, parcialmente com cimento calcáreo e abundantes espêlhos tectônicos. Êstes sedimentos são atravessados por 15 metros de intrusiva básica, (de $3725 \mathrm{~m}$ a $3740 \mathrm{~m}$ ) a qual foi classificada na Seccão de Petrografia do Departamento Nacional da Produção Mineral, pelo dr. Evaristo Penna Scorza, como basaltito, rocha filiada a magma basáltico, de textura porfirítica, constituída dos seguintes elementos: Plagioclásio (labradorita), augita, ilmenomagnetita e apatita. Os fenocristais são de plagioclásio e augita.

A idade dêsses sedimentos vermelho-marrons é incerta visto não terem sido encontrados fósseis. Devido ao fato dêles terem sofrido intrusão de magma basáltico, consideramos êstes sedimentos de idade cretácica ou mais antiga. A maioria das intrusões básicas do Brasil, é considerada de idade rética. Contudo Moura (1938 
p. 65) cita diabásio intrusivo em sedimentos considerados por êle como cretácicos, com fôlhas fósseis de dicotiledôneas, na bacia do rio São Manuel, afluente do rio Tapajós. 0 ambiente de sedimentạção do intervalo aqui considerado é incerto devido a ausência de fósseis como também à incertesa se a côr vermelho-marron dêsses sedimentos é original ou não, visto que algumas amostras dêsse intervalo mostram manchas irregulares de côr cinzenta, côr esta mais comum em sedimentos que o vermelho-marron. Em virtude da pouca seleção dêsses sedimentos, consideramotos continentais, depositados próximo a rocha matriz.

De $3507 \mathrm{~m}$ a $2580 \mathrm{~m}$, o poço atravessa uma espêssa formação arenosa, constituída de arenitos grosseiros a finos, em parte com estratificação cruzada, com alguns leitos conglomeráticos, friáveis, feldspáticos, com raros leitos irregulares de matéria carbonosa e algumas intercalações finas de siltito einzento e folhêlho arenoso, micáceo, cinzento-claro. A matéria carbonosa citada acima é constituída de restos de vegetais, que se dispõe en leitos irregulares e contrasta com o arenito branco, sem evidência de restos orgânicos, tendo sido evidentemente transportada. Além dêsses fragmentos de regetais aparecem também aqui corpúsculos que aparentam esporos. Êsses corpúseulos que foram encontrados no testemunho n. ${ }^{\circ} 88$, $3011 \mathrm{~m} 3014 \mathrm{~m}$, foram enviados ao dr. Friedrich Wilhelm Sommer do Departamento Nacional da Produção Mineral o qual nos comunicou, por carta, que êles são possìvelmente algas carófitas da família Clavatoraceae, boa família estratigráfica, até agora só conhecida do Cretáceo para baixo, duvidòsamente até o Triássico. Baseado nesses fósseis consideramos êsses sedimentos como de idade entre (retácica e triássica, mais provável cretácica. Quanto ao ambiente de sedimentação êste é incerto. O log elétrico sugere alta salinidade para esta secção do poço, contudo esta salinidade, se existe realmente, deve-se, provàvelmente, a migração de água salgada de outras regiões. A espessura do arenito em consideração (927 metros) torna provável ambiente de região costeira para a sua deposição.

De $2580 \mathrm{~m} 2020 \mathrm{~m}$, a secção é caracterisada por folhêlho argiloso prêto, brilhante, untuoso ao tacto, riquíssimo em fragmentos de vegetais e carvão brilhante. Além dessa rocha, aparecem, ainda, interealados, siltito esenro e arenito fino a médio, cinzento. Raros foraminíferos do Cretáceo e do Eoceno, retrabalhados contudo, foram encontrados em Dallas. Texas. Dêsses foraminíferos, foram rlassificados os seguintes:

1) Globigerina cretacea d'Orbigny

2) G. cf triangularis White

3) Globorotalia compressa (Plummer)

4) G. cf crassata (Cushman)

5) Gümbelina glcbulosa (Ehrenberg) 
Como êsses fósseis estão retrabalhados, é incerta a idade de deposição dêsses sedimentos. Nós os referimos, tentativamente, ao Eoceno, idade a que pertence a maioria dêsses fósseis. Os restos de vegetais são muito abundantes neste pacote. A carbonisação dêsses restos, aliados à presença de carvão e de pirita também abundantes, fazem com que suspeitemos que êsses sedimentos foram depositados em lagunas costeiras com pequena circulação de água ou então em regiões de mangue, onde haveria pouco acesso de oxigênio, responsável pelas características redutôras dos sedimentos. Os fósseis acima mencionados poderiam ter sido transportados por correntes fortes de marés ou por tempestade. Crêmos que é significativo que só se tenha encontrado foraminíferos planctônicos nesses sedimentos (globigerinideos e globorotalideos) além do fóssil Gümbelina que também é considerado planctônico não só pelas câmaras infladas como pelo registro fóssil em associação com outros foraminíferos planctônicos. O gênero Gümbelina parece que foi extinto no Oligoceno. Os foraminiferos planctônicos, pelas câmaras infladas ocasionando pequeno pêso especifico para a testa e pelo fato de viverem boiando no meio líquido são mais fàcilmente transportados que outros foraminíferos.

De $2020 \mathrm{~m} 1692 \mathrm{~m}$, a secção é caracterisada por silte e argila cinzento-avermelhados, côr esta devida a abundante presença de limonita. Foram encontrados sòmente raros fragmentos e espóros de plantas, sendo a idade dêsses sedimentos, por conseguinte incerta. Também o ambiente de sedimentação é incerto devido a côr avermelhada dêsses sedimentos ser, provàvelmente, secundária. Visto estar, êsse pacote, entre sedimentos possivelmente do Eoceno, e certamente do Mioceno, nós o consideramos, tentativamente, como depositado no Eoceno ou Oligoceno. Acima dêsse pacote, no intervalo de $1692 \mathrm{~m}$ a $740 \mathrm{~m}$, aparecem sedimentos onde os restos de vegetais são abundantes, aparecendo também raríssimos foraminíferos mal conservados, nenhum indice acima do Eoceno (Quinqueloculina, Globigcrina, Elphidium). A idade é portanto incerta. Devido a ausência de foraminíferos do Terciário Inferior e devido a êsses foraminiferos apresentarem certa semelhança com os que aparecem acima, de idade miocênica indubitável, consideramos esta seccão como depositada no Mioceno. Os restos de vegetais abundantes aliados aos foraminíferos raros permitem a suposição de deposição em ambiente de água salôbra ou alternância de água dôce e salôbra com pequenas invasões marinhas. Este pacote de sedimentos, litològicamente não é uniforme. Assim de $1692 \mathrm{~m}$ a $1368 \mathrm{~m}$, a secção é caracterisada por arenito de muito fino a grosseiro, de côr variada ; no intervalo $1368 \mathrm{~m}$ a $1172 \mathrm{~m}$ predomina argila cinzenta e de $1172 \mathrm{~m}$ a $740 \mathrm{~m}$ a rocha consiste predominantemente de arenito fino a grosseiro, feldspático, de côr variável. No intervalo de $740 \mathrm{~m}$ a 
$460 \mathrm{~m}$, os foraminiferos tornam-se regularmente comuns e restos de vegetais carbonisados, carvão e pirita tormam-se mais abundantes. Começam a aparecer aqui fósseis característicos do Mioceno (Orbulina suturalis Bronnimann, Globoquadrina quadraria (Cushman e Ellisor) var. advena Bermudez, etc.). As rochas predominantes são silte cinzento-claro, argila cinzento-amarelada e areia muito fina. Mergulhados na massa do silte encontram-se, esparsos, grãos de quartzo de $1 / 8$ a $1 / 4$ de milímetro. Os foraminíferos predominam no silte e na areia fina. Parece que o ambiente de sedimentação foi aqui marinho, de águas turvas, próximo a rios que trariam os restos de vegetais tão abundantes nesta secção. É possível que os fósseis marinhos aí encontrados tenham também sido transportados. Acima, no intervalo de $460 \mathrm{~m}$ a $245 \mathrm{~m}$, as características marinhas são mais marcantes. Os restos de vegetais são ausentes ou muito raros e os fósseis marinhos são abundantes, foraminíferos, ostracodas, ossos e dentes de peixes seláquios, lamelibrânquios marinhos (Cardium, Ostraea, Pecten, Glycymeris e Tellina?), briozoários, corais e espículas de esponjas. Baseados na fauna seríamos levados a dedução de que o ambiente de sedimentação dêsse intervalo, é marinho de águas bem rasas, límpidas e quentes, próximo a zona de recifes. Favorece esta suposição as seguintes considerações: 1) Presença de corais; 2) A fauna é rica em diversos gêneros de Peneroplidae e Amphistegina, gêneros êstes característicos de regiões de recifes dos trópicos. (Cushman 1931 p. 79). Êstes foraminiferos formam mais de $80 \%$ do número de indivíduos de foraminíferos nas camadas superiores dêste intervalo. Segundo ainda Cushman (1948 p. 301), o gênero Amphistegina, como aliás outros foraminíferos grandes, muito provàvelmente têm a sua distribuição nos oceanos, limitada a cêrca de 30 braças de profundidade (66 metros), isto devido as algas comensais que os acompanham, assim limitadas devido a penetração da luz solar, circunscrita a esta profundidade; 3) O gênero Orbulina é comum na fauna dêste intervalo. Segundo Bronnimann (1951 p. 136) êste gênero, como fóssil em Trinidad, é comum em sedimentos depositados em ambientes de recife e águas rasas, claras e próximas à costa; 4) As espécies Rotalia beccarii (Lineu), Elphidium poeyanum (d'Orbigny) e Reussella spinulosa (Reuss) comuns na fauna dêste intervalo são características de águas rasas e quentes. Rotalia beccarii (Lineu) se encontra, na região das Caraíbas, das praias a 29 metros de profundidade, Elphidium poeyanum (d'Orbigny) até 110 metros de profundidade e Reussella spinulosa (Reuss) entre 10 metros e 110 metros de profundidade (Renz 1948 p. 75). O gênero Elphidium tão comum em nossa fauna, aparece em maior frequiência em águas rasas, até 100 metros de profundidade (Phleger 1951 p. 46). 
As porcentagens das diversas famílias de foraminíferos dêste pacote de sedimentos (Fig. 6), reforçam a idéia de ambiente de sedimentação de águas rasas.

Para que a nossa dedução do ambiente de sedimentação das rochas dêsse intervalo seja válida, é preciso que admitamos que a fauna não tenha sido transportada e sim que tenha vivido no local onde foi fossilisada. Parte dêsses fósseis não mostram sinais de transporte e alguns Pelecypoda foram encontrados com ambas as valvas. Contudo cremos que houve transporte se bem que pequeno, para os Pelecypoda bentônicos e corais, talvez por fortes correntes. A razão de nossa dedução é o fato dêsses fósseis aparecerem $\mathrm{cm}$ rochas clásticas relativamente grosseiras (silte com seixos de quartzo esparsos e areia fina). Contudo mesmo assim cremos que nossas deduções de ágnas rasas não se alteram visto ter êsse transporte sido, provàvelmente, em direção a costa devido ao acúmulo de sedimentos de origem terrestre. Já a respeito de presença de águas límpidas não podemos estar tão seguros. Êsses sedimentos certamente foram depositados em águas mais límpidas que no intervalo anterior $(740 \mathrm{~m}-460 \mathrm{~m})$, pois os restos de vegetais são muito raros no intervalo em consideração. Os foraminíferos planctônicos trazem maior evidência de transporte. F̂les são abundantes nos sedimentos da sondagem em consideração, a partir de 259 metros. A porcentagem dêsses foraminíferos no intervalo $259 \mathrm{~m}-460 \mathrm{~m}$ varia de 20 a $56 \%$. Segundo Parker (1948 pp. 234-235) que estudon a distribuição dos foraminíferos na plataforma continental do Golfo do Maine a MLaryland, Estados Unidos da América do Norte, os foraminíferos planctônicos só aparecem em porcentagem maior que $2.6 \%$ em águas mais profundas que 121 metros, sendo insignificante a porcentagem em 50 metros. Temperatura e mudanças de salinidade parecem ser os principais fatôres que causăm o desaparecimento dêsses foraminíferos em direção a costa. Contudo ainda Parker (Idem pp. 226-227) ressalta que na primeira estação do 'Cape Cod Light Traverse', na profundidade de 5 metros, uma fauna inesperada para esta profundidade aparece, caracterisada por grande porcentagem de foraminíferos planctônicos. A explicação da presença dessa fauna a essa profundidade é de que ela foi transportadia por fortes correntes de maré que correm ao longo da costa. Parker nota que êsses foraminíferos planctônicos são todos pequenos para as espécies a que são referidos. É interessante notar que também no Cururú êsses foraminíferos se caracterisam pelo pequeno tamanho. Os foraminíferos planctônicos são muito fáceis de serem transportados devido possuírem as câmaras infladas e serem providos de espinhos dando como resultado grande aumento de volume e diminuição do pêso específjeo. 
As fortes correntes que teriam causado o transporte dos foraminíferos planctônicos desaparecem acima de 259 metros ocasionando forte queda no número dêsses foraminíferos e grande aumento no número de Amphistegina e Peneroplidae, havendo portanto no intervalo de $245 \mathrm{~m} 259 \mathrm{~m}$, características de recife mais marcantes.

Pelo expôsto, vê-se que a fauna de foraminíferos do intervalo $740 \mathrm{~m} 245 \mathrm{~m}$, não é inteiramente uniforme podendo ser dividida em zonas paleontológicas. Estas zonas serão tratadas mais adiante.

O intervalo de $245 \mathrm{~m} 0 \mathrm{~m}$ caracterisa-se pelo desaparecimento de foraminiferos, sendo que os fósseis consistem apenas de restos de plantas de aparência recente. A rocha é constituída predominantemente de silte cinzento-claro. Consideramos êsses sedimentos como representando o período atual de deposicão on o Pleistoceno sendo possivelmente depósitos fluviais. () log elétrico pode ser interpretado como indicativo de água dôce.

Em liuhas gerais, a história da região é portanto a seguinte: Possìvelmente durante o Cretáceo, iniciou-se a deposição dos sedimentos na área que iria constituir futuramente a fóssa do Marajó, sedimentação esta talvez de origem fluvial. Posteriormente, possìrelmente ainda no Cretáceo, a sedimentação tornou-se, ao que parece, de natureza deltaica, e grande espessura de sedimentos arenosos foram depositados (aproximadamente 1.000 metros) auxiliados talvez por lento morimento epirogênico negativo. Durante o Eoceno a regetação foi invadindo a região transformando-a em extenso mangue, depositando-se cutão os sedimentos argilosos escuros, carbonosos, do intervalo $2580 \mathrm{~m} 2020 \mathrm{~m}$. Os arenitos intercalados dêste intervalo talvez tenham sido depositados por rios eujos meandros provorariam freqüientes mudanças de seus cuisos. Os siltes e argilas cinzento-arermelhados do intervaic $2020 \mathrm{~m} 1682 \mathrm{~m}$ seriam depósitos originados por rios que se estabeleceram na região talvez devido a pequeno movimento epirogênico positivo. A partir de $1692 \mathrm{~m}$, há contínua subsidência, cada vez mais acentuada, até que depósitos puramente marinhos se formaram no interralo de $460 \mathrm{~m} 245 \mathrm{~m}$. Novo lerantamento trouxe como resultado a deposicão de sedimentos com caracteristicas mais continentais do intejralo $245 \mathrm{~m} 0 \mathrm{~m}$.

Na tabela n. 1 está expressa a distribuicãa dos for aminíferos do posgo de Cururú de acôrdo com a profundidade. Com o fito de facilitar a apresentação do gráfico, omitiu-se as ocoriências de foraminíferos, aliás esparsas, a profundidades inferiores a 1.550 metros. Essas ocorrências são as seguintes:

1) Quinqueloculina seminula (Lineu). Amostra de calha. intervalo $1580 \mathrm{~m} 1610 \mathrm{~m}$

2) Globigerina cf triangularis White - Testemunho $\mathrm{n}^{0} 55.2198 \mathrm{~m}-2201 \mathrm{~m}$

3) Gümbelina globulosa (Ehrenberg) -- Testemunho n. ${ }^{0} 51.2082 \mathrm{~m}-2085 \mathrm{~m}$ e testemunho n. ${ }^{\circ} 65,2376 \mathrm{~m}-2379 \mathrm{~m}$ 
4) Globigerina cretacea d'Orbigny - Testemunho ${ }^{0}{ }^{\circ} 65,2376 \mathrm{~m}-2379 \mathrm{~m}$

5) Globorotalia compressa (Plummer) - Testemunho n. ${ }^{\circ} 65,2376 \mathrm{~m}-2379 \mathrm{~m}$

6) G. cf crassata (Cushman) - Testemunho n. ${ }^{\circ} 65,2376 \mathrm{~m} \cdot 2379 \mathrm{~m}$

\section{Sondagem de Badajós - Litologia e Litótopos}

Nota-se, de uma maneira geral, nesta sondagem, o predomínio de sedimentos clásticos relativamente grosseiros (siltitos e arenitos). A porcentagem de sedimentos grosseiros é aproximadamente igual a do poço LM-1-PA, sendo que no poço CR-1-PA a porcentagem de sedimentos argilosos é maior.

Da superfície até $283 \mathrm{~m}$ de profundidade, os únicos fósseis encontrados foram espículas de esponjas silicosas Tetractinellidae as quais podem ocorrer tanto em água dôce como salgada, e alguns fragmentos de vegetais terrestres os quais também nada dizem sôbre o ambiente de sedimentação visto terem sido, òbviamente transportados. Consideramos esta secção como representando o período atual de deposição e portanto ambiente de água dôce, possivelmente fluvial.

A partir de $283 \mathrm{~m}$ começam a aparecer ossos e dentes de peixe os quais são muito abundantes. Aparecem também aqui, fragmentos de vegetais. Apesar dêsses ossos e dentes de peixe não serem raros, extranha-se a ausência de escamas que deveriam acompanhar os restos acima mencionados. A ausência de escamas e o estado fragmentário dos ossos não permitem que se faça idéia da natureza dos peixes em consideração. Os dentes, por outro lado, estão mais perfeitos, sendo de tamanho pequeno, em média de 270 microns de comprimento. A ausência de escamas permite a suposição de que se trata de peixes actinopterigeos cujas escamas são finíssimas e por conseguinte mais difíceis de se conservarem em contraste com as espêssas escamas ganoides de paleoniscídeos, holósteos, etc., cujos restos fósseis são predominantemente de escamas. Os paleoniscídeos são os peixes teleósteos predominantes do Paleozoico, os holósteos do Mesozoico e os actinopterígeos do Cenozoico. Êsses restos de peixe sugerem, portanto, a idacle Cenozoica para êsses sedimentos do poço BJ-1-PA. Quanto ao ambiente de sedimentação, trata-se, provàvelmente, de sedimentos de água dôce; os actinopterígeos habitam tanto água dôce com água salgada.

$O$ intervalo de $483 \mathrm{~m}$ a $570 \mathrm{~m}$ é caracterisado por espículas de esponjas do tipo das que aparecem no intervalo $0 \mathrm{~m} 283 \mathrm{~m}$. Aparecem também, aqui, dentes de peixes seláquios, peixes êstes exclusivamente marinhos. Êsses dentes são raros e talvez tenham sido transportados por marés. Consideramos êsses sedimentos, portanto, como depositados em água salôbra. 
O intervalo de $570 \mathrm{~m}$ a $724 \mathrm{~m}$, é caracterisado por abundantes Ostracoda e oogônias de algas de água dôce carófitas, do gênero Nitella, gênero êste jovem e que pouco se conhece abaixo do Quaternário. Baseado neste gênero Nitella, consideramos todo o pacote de sedimentos de $0 \mathrm{~m} 724 \mathrm{~m}$, como do Cenozoico Superior (considerando-se Cenozoico Superior os sedimentos do Mioceno a Recente).

Quanto aos Ostracoda, êles aparecem bruscamente neste intervalo, e em grande quantidade. Êles pertencem a diversos gêneros distribuídos entre as famílias Cypridae e Cytheridae. Êstes últimos são alongados com comprimento em média de $0.17 \mathrm{~mm}$, dotados de linha cardinal reta e com 3 lobos separados por sulcos profundos. Pequenos tubérculos aparecem na região marginal. Os Cytheridae são característicos do Mesozoico e C'enozoico. Os representantes dos Cypridae têm linha cardinal curva. Êsses Ostracoda, ocorrem, em maior abundância, em ambiente de água salôbra, razão porque consideramos os sedimentos dêste intervalo como depositados em água salôbra.

O intervalo de $724 \mathrm{~m}$ a $1000 \mathrm{~m}$ é caracterisado por abundantes restos e espóros de plantas. Os testemunhos ns. 25, 26 e 27 que provém dêste intervalo, são caracterisados por restos de vegetais rarbonisados muito comuns, aparecendo também grande quantidade de pirita, a qual, juntamente com os vegetais carbonisados, indicam ambiente redutôr, isto é, sedimentação em bacia fechada, água parada, de maneira a não haver oxidação dos sedimentos que estavam sendo depositados no fundo. Talvez êste intervalo possa ser correlacionado com a seção da sondagem de Cururú caracterisada por folhêlhos escuros carbonosos, com as mesmas características redutôras e com raros fósseis do Eoceno (intervalo $2020 \mathrm{~m}-2580 \mathrm{~m}$ ). A base para a correlação é, contudo, frágil.

Abaixo de $1000 \mathrm{~m}$ até $1688 \mathrm{~m}$, a secção é predominantemente de arenito. $O$ único fóssil encontrado neste intervalo foi um dente, possivelmente de réptil, no testemunho $n .^{\circ} 44(1452 \mathrm{~m} 1458 \mathrm{~m})$. De $1688 \mathrm{~m}^{\prime}$ a $2005 \mathrm{~m}$, a secção é caracterisada por folhêlho e siltito cinzento-escuros com rastros e tubos de vermes, marcas de ondas e grêtas de contração. Os testemunhos ns. 49 a 54 (1692 m $1936 \mathrm{~m}$ ) mostram maior concentração dêsses tubos de vermes. Os sedimentos estão revolvidos por animais e correntes mostrando estratificações muito irregulares. O testemunho $\mathrm{n}^{0} 55$ (2001 m $2004 \mathrm{~m}$ ) é constituído de folhêlhos parecidos com folhêlhos da formação Longá, Devoniano da bacia do Maranhão. Infelizmente não conseguimos encontrar fósseis índices nesses sedimentos. Abaixo de $2005 \mathrm{~m}$ até $2159 \mathrm{~m}$, a secção é caracterisada por arenito cinzento-claro fino a grosseiro com alguma estratificação cruzada. Um dique de diabásio foi atingido a $2159 \mathrm{~m}$, e quartzito de $2182 \mathrm{~m}$ a $2185 \mathrm{~m}$, quando o poço foi abandonado. 
A idade dos sedimentos abaixo de $724 \mathrm{~m}$, é incerta devido a precarieclade de docmmentação paleontológrica. A Sísmica verificou para os sedimentos da profundidade de $1500 \mathrm{~m}$, velocidade de $3692 \mathrm{~m}$ por segundo. V'elocidade desta natureza são mais comuns em sedimentos de idacle paleozoica. Contudo há exceçōes a esta regra; além disto é possível que o diabásio que ocorre no intervalo $2159 \mathrm{~m}$ $2182 \mathrm{~m}$, tenha afetado os sedimentos superiores. () quartzito que aparece a profundidade de $2182 \mathrm{~m}$ foi tomado como embasamento cristalino.

\section{CORRELACTOO DAS SONDAGENS PERFIRADAS NA FÓSSA DO MARAJÓ}

A correlação dos sedimentos existentes nas três sondagens acima mencionadas é difícil não só devido ao ambiente de sedimentação diferente nos três poços como também as distâncias que separam os mesmos. (Fig. 5). A rltitude das bôcas dos três poços acima do nível do mar é sempre muito pequena. A sondagem de Limoeiro. está a cêrca de $2 \mathrm{~m}$ acima do nível do mar, a sondargem de Cururú cêrea de $1 \mathrm{~m}$ e a sondagem de Badajós, cềrea de $6 \pm \mathrm{m}$.

Uma possível limha de correlação é a presença de fósseis, infelizmente retrabalhados, do Eoceno e Cretaceo (Irlade Eoceno?) em Limoeiro (2453 m $3394 \mathrm{~m}$ ) e Cururú (2083 m 2376 m). Contudo êsses fósseis, apesar de serem aproximadamente da mesma idade. não são idênticos. Mesmo adnitindo esta correlação como certa teríamos ainda duas maneiras para explicar as relacoes entre essas sondagens: 1) Mergulho das camadas de Cururú para Limoeiro; 2) Falhamento com elevação do embasamento cristalino na zona de Cururí ou abaixamento do embasamento na zona de Limoeiro. (O embasamento aparece em Cururú a $3848 \mathrm{~m}$ de profundidade não tendo siclo atingido em Limoeiro, apesar do poço ter alcançado a profundidade de $4027 \mathrm{~m}$ ). Poderíamos ainda correlacionar os sedimentos de Badajós con características redutôras, do intervalo $724 \mathrm{~m} 1000 \mathrm{~m}$, com os intervalos de Cururú e Limoeiro acima citados (2083 m $2376 \mathrm{~m}$ e $2453 \mathrm{~m} 33.94 \mathrm{~m}$ ), com as mesmas características redutôras.

Favoreceria esta linha de correlação o espêsso pacote de sedimentos arenosos, com intercalaçóes de siltito cinzento, próximo a base da secção dos três pocos, o culal em Badajós, aparece no inter. valo $2005 \mathrm{~m} 2159 \mathrm{~m}$, em Limoeiro no intervalo $2612 \mathrm{~m}-4027 \mathrm{~m}$, e em Cururú, no intervalo $2580 \mathrm{~m} 3507 \mathrm{~m}$.

Verificamos portanto, que segundo esta hipótese de correlação, Limoeiro representaria a região mais profunda da fóssa com os sedimentos mergulhando para esta região tanto a partir de Badajós 
como de Cururú. Há um argumento que favorece por outro lado a hipótese de mergulho dos sedimentos para Cururú tanto de Limoeiro como de Badajós. Nestes dois pocos, há predominância de sedimentos arenosos enquanto em Cururú, pelo contrário, a porcentagem de sedimentos argilosos é maior. Ora o que acontece em uma bacia de sedimentação é que quanto mais afastada da borda da bacia maior deposição de sedimentos finos ocorre. O mergulho dos sedimentos sempre se dá da borda para o centro das bacias de sedimentação a não ser que haja distúrbios tectônicos que alterem esta situação. O geólogo Arthur Palmer, do Conselho Nacional do Petróleo (informação verbal) correlaciona sedimentos vermelho-marrons que aparecem na sondagem de Badajós, no intervalo $483 \mathrm{~m}$ $724 \mathrm{~m}$, na sondagem de Limoeiro no intervalo $2264 \mathrm{~m} 2612 \mathrm{~m}$ e na sondagem de Cururú no intervalo $3507 \mathrm{~m} 3848 \mathrm{~m}$. Teríamos então mergulho das camadas de Badajós para Limoeiro e dêste para Cururú, o embasamento estando mais raso em Cururú que em Limoeiro devido a falhamento. Segundo Palmer, os logs elétricos concordam, aparentemente, com esta correlação. O pacote de sedimentos vermelho-marrons de Badajós (483 m 724 m) tem idade Cenozoica Superior bem estabelecida pelos espóros de carófitas do gênero Nitclla enquanto o pacote de sedimentos rermelho-marrons de Limoeiro ( $2264 \mathrm{~m} 2612 \mathrm{~m}$ ) possui fósseis do Cretaceo? e Eoceno? Contudo além cós fósseis de Limoeiro estarem mal conservados sendo portanto duvidosa a idade a êles atribuída, êles estão retrabalhados podendo, portanto, terem sido depositados em sedimentos mais jovens. Quanto a Cururú, êsses sedimentos vermelho-marrons estão abaixo do pacote do intervalo $2020 \mathrm{~m} 2580 \mathrm{~m}$, onde os fósseis do Eoceno são bem mais característicos que os de Limociro. Contudo aqui também estão êsses fósseis retrabalhados podendo, portanto, terem sido depositados em sedimentos de idade mais jovem.

Não obstante essas considerações, o ponto de vista do greólogo Palmer não tem, a nosso ver, base segura, pois podemos por em dúvida se êsses sedimentos vermelho-marrons possuem a côr original oll foram secundàriamente coloridos por limonita, não havendo portanto razão alguma para que essa coloração se desse sòmente $\mathrm{em}$ determinados pacotes da coluna estratioráfica. Temos essas suspeitas de coloração secundária devido a algums testemmonos desta secção possuírem manchas irregulares de côr cinzenta. côr esta mais comum como côr original de sedimentos.

Os sedimentos de Cururú são muito moles e todos os testemu. nhos de sondagem foram facilmente desintegrados merculhando-os simplesmente na água. Quanto ans testemunhos de Limoeiro e Badajós, ao contrário, são fàcilmente desintegráveis somente os da parte superior (os dos primeiros 700 a 800 metros), encuanto os outros são muito difíceis de serem desintegrados havendo mesmo 


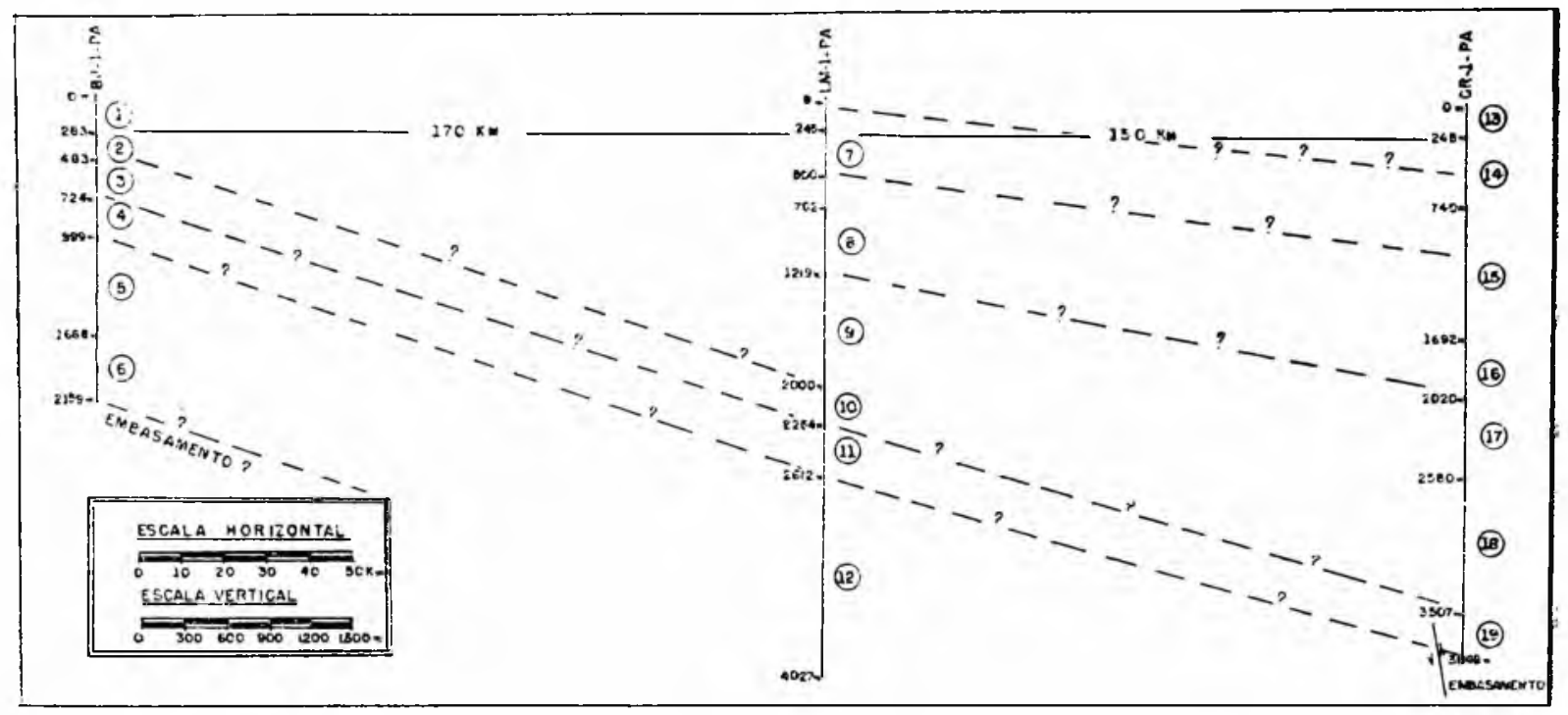

FIG. 5-Possiveis correlaçöes entre os poços da tossa do Marajó.

(1) Quaternário (?) - Espiculas de esponjas + fragmentos de vegetais.

(2) Cenozoico Superior (?) - Areia fina + silte + argila - ossos e dentes de peixe + vegetais.

(3) Cenozoico Superior - Argila + silte vermelho marron - Ostracoda, Charophyta Nitella - espículas de esponjas ossos e dentes de peixes teleosteos e selaquios.

(4) Idade incerta - Arenito fino + siltito - esporos e restos de plantas.

(5) Idade incerta (Cretaceo?) - Arenito fino + siltito - dente possivelmente de reptil.

(6) Idade incerta - Arenito médio à grosseiro + siltito + folhelho arenoso.

(7) Idade incerta - Silte + areia + argila.

(8) Idade incerta - Siltito $\div$ argilito vermelho marron limonítico.

(9) Idade incerta - Arenito + siltito.

(10) Idade incerta - Arenito branco + siltito vermelho marron.

(11) Siltito vermelho marron com fósseis do Eoceno (?) e Cretaceo (?) retrabalhados (globigerinas e outros foraminíferos mal conservados)

12) Arenito feldspático, fino à grosseiro às vêzes com estratificação cruzada, com foraminíferos mal conservados na parte superior onde o sedimento é mais fino (Cretaceo?).

(13) Quaternário - Silte cinzento.

(14) Mioceno - Silte e argila cinzentos com rica fauna.

(15) Mioceno (?) - Arenito feldspático com argila - sem fósseis índices (fragmentos de vegetais).

(16) Oligoceno (?) - Siltito e argila cinzentos avermelhados, limoníticos sem fósseis indices.

(17) Eoceno (?) -- Folhelho escuro carbonoso com foraminíferos - Gümbelina. globigerinas, globorotalias.

(18) Creiáceo (?) - Arenito feldspático com fócseis do Cretáceo - Triássico (Charophytas Clavatoraceae).

(19) Triássico (?) - Jurássico (?) - Siltito vermelho + intrusão diabásio. 
alguns cuja desintegração é impossível tendo que ser estudados por seç̧ões delgadas.

Pesquisas de minerais pesados realisadas em São Paulo por Viktor Leinz e Sérgio Estanislau do Amaral (comunicação verbal) trouxeram como resultado correlações seguras entre os sedimentos de Limoeiro e de Cururú. Foi possível, assim, verificar que as camadas mergulham de Limoeiro para Cururú, ou pelo menos, camadas correspondentes aparecem em Limoeiro em níveis mais altos do que em Cururú. A fig. 5 se baseia nesses estudos na parte que se refere a êsses dois poços.

Os depósitos miocênicos da fóssa do Marajó aparecem na sondagem de Cururú entre as profundidades de $245 \mathrm{~m}$ e $760 \mathrm{~m}$. Êles não podem ser correlacionacios com segurança com os depósitos do Mioceno da formação Pirabas (Fig. 1), visto que a fauna de Cururú consiste principalmente de foraminíferos e a fauna de foraminíferos da formação Pirabas ainda não foi descrita, sendo a idade desta formação deduzida tendo por base os seus moluscos. Conseguimos coletar foraminíferos da formação Pirabas provenientes de diversas localidades daquela bacia. A comparação com os fósseis de Cururú é dificultada devido ao estado de conservação dos foraminíferos daquela formação não ser, em geral, muito bom. Na fauna da formação Pirabas proveniente de Salinópolis (Silva e Petri 1952 Planta da situação), os gêneros Archaias e Amphistegina, são comuns como acontece também na fauna do Mioceno de Cururú, mas em geral não há semelhança estreita entre as faunas das duas formações, devido talvez a ambientes diferentes de deposição. Existem mesmo diferenças entre as associações de foraminíferos provenientes de diversas localidades da formação Pirabas. Pretendemos tratar com mais minúcia dos foraminíferos da formação Pirabas em trabalho posterior. Adiantamos, contudo, que a formação Pirabas tomada em conjunto possui muitos foraminíferos fósseis em comum com o Mioceno da fóssa do Marajó, embora as faunas dos diversos afloramentos em separado, tenham poucos elementos em comum, permitindo a suposição que parte dêsses sedimentos miocênicos da sondagem possa ser correlacionadas com os daquela formação.

\section{BIOSTRATIGRAFIA DO MIOCENO DE CURURÚ}

Idade da fauna do intervalo $245 \mathrm{~m} 740 \mathrm{~m}$

A idade da fauna que ocorre na sondagem de Cururú, no intervalo de $245 \mathrm{~m} 740 \mathrm{~m}$ é miocênica. As características dessa fauna que permitem a sua colocaçăo no Mioceno são as seguintes:

1) Presença comum de Peneroplidae (Archaias, Peneroplis e Taberina) e da espécie Amphis.egina lessonii d'Orbigny, associa- 
ção esta que só se torna comum na fauna caraíbica, a partir do Mioceno até hoje.

2) Presença de espécies altamente ornamentadas de Elphidium (E. lens Galloway e Heminway, E. sagrai d'Orbigny) só conhecidas a partir do Oligoceno Médio até hoje.

3) Presença de uma espécie do gênero Laticarinina com a carena bem desenvolvida. Espécies primitivas do gênero, com a carena estreita existem dêsde o Cretaceo; contudo, espécies com os caracteres do gênero completamente desenvolvidos só foram encontrados do Mioceno até hoje.

4) Presença de espécies tais como 'Rotalia' beccarii (Lineu), Clavulina tricarinata d'Orbigny, Elphidium advenum Cushman, etc., espécies que se estendem do Oligoceno ou Mioceno a Recente.

5) Associação de foraminíferos planctônicos diferentes da atual, e presença de espécies planctônicas características do Mioceno (Globoquadrina quadraria (Cushman e Ellisor) e Orbulina suturalis Bronnimann).

6) Ausência de foraminíferos grandes, orbitoides, que na fauna caraíbica só se encontram no Terciário Inferior (EocenoOligoceno).

Para a determinação da idade destas camadas deve-se dar grande pêso as espécies planctônicas Orbulina suturalis Brommimann e Globoquadrina quadraria (Cushman e Ellisor), espécies estas fàcilmente reconhecíveis; além disso sendo planctônicas, elas são fàcilmente transportadas por correntes para diversos ambientes de sedimentação sendo, por conseguinte, encontradas em sedimentos de diversos fácies, o que as tornam excelentes fósseis índices.

Eliminando-se as formas não descritas específicamente da associação faunística aqui em discussão e considerando-se espécies e variedades como constituindo uma única forma, obteremos 64 formas distintas. Dessas 64 formas, 40 são ainda formas viventes no Oceano Atlântico, 2 são viventes na região Indo-Pacífica (Astacolus cf insolitus (Schwager) e Discorbis patelliformis Brady), totalisando portanto 42 formas viventes. Das 22 formas que ocorrem somente como fósseis, 18 são registradas no Mioceno, 2 (Angulogerina of rugoplicata Cushman e Elphidium lens Galloway e Heminway) tinham sido registradas anteriormente só no Oligoceno, uma é afim a uma espécie descrita anteriormente do Eoceno (Talvulineria aff scrobiculata (Schwager), e mma, Lagena perlucida (Montagu), timha sido descrita anteriormente no Plioceno. A porcentagem de formas viventes na famna em consideração pode, portanto, ser aproximadamente tomarla como $52.4 \%$

Renz (1948 pp. 1-76), tratando da Estratiorafia das formações oligocênicas e miocênicas da Venezuela, divide estas formacões em zonas caracterisadas por foraminiferos. Assim êle considera as seguintes zonas do Mioceno e ()ligoceno Superior. 
Formação Ojo de Agua - Mioceno Superior - Não estudada por êle.

Luciano

Mioceno Médio
Zônula de Elphidinm pocyanum - Reussclla spinulosa - Mais de $60 \%$ de formas viventes.

Zônula de T'ertularia panamensis - $60 \%$ de formals viventes.

Zônula de Tagimulinopsis superbus T'rochammina ef pacifica $55.3 \%$ de formas viventes.

Zona de Robulus senmi - $41.2 \%$ de formas viventes.

Zond de Marginulinopsis basispinosus $40.8 \%$ de formas viventes.

Zona de Valvulineria herricki - $41.5 \%$ de formas viventes.

Zona de Globorotalia fohsi - $44.1 \%$ de formas riventes.

Zona de siphogenerina transversa - 40\% de formas viventes.

Zona de Robulus wallacei - $39.4 \%$ de formas virentes.

Comparando a nossa Assembléia (intervalo 245 m $T 40 \mathrm{~m}$ ) com as fâunulas acima, vemos que ela se enquadraria entre a zona de Robulus senni e a zônula de Vaginulinopsis superbus-Trochammina ef pacifica, portanto no Mioceno Médio.

Estas considerações por si só não são suficientes, naturalmente, para considerarmos esta fauna como pertencente ao Mioceno Médio.

Com o fito de têrmos uma idéia sôbre a colocação clêsses sedimentos dentro do Mioceno, levamos a comparação da sua fauna com outras de diversas regiões das Antilhas, bem como da Venezuela e Colômbia (Tabela n. ${ }^{\circ}$ 2). Estas comparações dão um quadro disforme das verdadeiras relaçóes de nossa fauna não só porque as faumas de foraminíferos fósseis do Mioceno de certas rexiões como por exemplo da Colômbia são ainda ineompletamente conhecidas e certas associações são de ambientes de sedimentacão diferentes, ambientes êstes nem sempre especificados nas descriçoes das faunas, como também pelo fato da nossa fanina não representar uma secção restrita do intervalo $245 \mathrm{~m} 740 \mathrm{~m}$, havendo, portanto, possibilidade dela compreender diversos ambientes de sedimentarão. As condições de recifes por exemplo são mais marcantes na zona Amphistegina lessonii d'Orbigny (245 m $259 \mathrm{~m}$ ) do (nue nos inter- 
valos inferiores. Infelizmente a pobresa de testemunhagem na sondagem de Cururú, neste intervalo, não permite que tenhamos idéia mais precisa sôbre as diversas associações faunísticas. Além disso a fauna de Cururú apresenta evidências de transporte, sendo portanto um depósito de 'thanatocoenose' podendo, portanto, ser mistura de diferentes 'biocoenoses' Apesar dessas considerações, essas comparações sugerem relações mais estreitas com o Mioceno Médio. Abaixo é dada uma relação de diversas regiões onde aparecem camadas de diversos estágios do Mioceno e suas comparações com a nossa fauna em relação ao número de espécies comuns. Os globigerinídeos não foram considerados devido ao estado caótico da sistemática desta família.

Número de espécies comuns com Cururú:

\begin{tabular}{|c|c|c|c|}
\hline Colômbia & $\begin{array}{l}\text { Mioceno } \\
\text { Mioceno } \\
\text { Mioceno }\end{array}$ & $\begin{array}{l}\text { Superior } \\
\text { Médio } \\
\text { Inferior }\end{array}$ & $\begin{array}{l}\text { Usiacuri } \\
\text { Tubara } \\
\text { Las Perdices }\end{array}$ \\
\hline Venezuela & $\begin{array}{l}\text { Mioceno } \\
\text { Mioceno } \\
\text { Mioceno }\end{array}$ & $\begin{array}{l}\text { Superior } \\
\text { Médio } \\
\text { Inferior }\end{array}$ & $\begin{array}{l}\text { Ojo de Agua } \\
\text { Luciano } \\
\text { Araguatiano }\end{array}$ \\
\hline Trinidad & $\begin{array}{l}\text { Mioceno } \\
\text { Mioceno } \\
\text { Mioceno }\end{array}$ & $\begin{array}{l}\text { Superior } \\
\text { Médio } \\
\text { Inferior }\end{array}$ & $\begin{array}{l}\text { Springvale } \\
\text { Los Atajos } \\
\text { Navarro }\end{array}$ \\
\hline Jamaica & Mioceno & Médio & $\begin{array}{l}\text { Bowden } \\
\text { Buff Bay }\end{array}$ \\
\hline Cuba & $\begin{array}{l}\text { Mioceno } \\
\text { Mioceno } \\
\text { Mioceno }\end{array}$ & $\begin{array}{l}\text { Superior } \\
\text { Médio } \\
\text { Inferior }\end{array}$ & $\begin{array}{l}\text { El Abra } \\
\text { Canimar } \\
\text { Güines }\end{array}$ \\
\hline Pôrto Rico & Mioceno & Inferior & $\begin{array}{l}\text { Quebradillas } \\
\text { Los Puertos }\end{array}$ \\
\hline Haití & Mioceno & Médio & Pourt-au-Prince \\
\hline São Domingos & $\begin{array}{l}\text { Mioceno } \\
\text { Mioceno } \\
\text { Mioceno }\end{array}$ & $\begin{array}{l}\text { Superior } \\
\text { Médio } \\
\text { Inferior }\end{array}$ & $\begin{array}{l}\text { Mao } \\
\text { Gurabo } \\
\text { Cercado }\end{array}$ \\
\hline
\end{tabular}

Pela relação acima verifica-se que sempre que aparece em uma região outros estágios do Mioceno além do Médio, a fauna do Mioceno Médio apresenta maior identidade de fósseis com a fauna de Cururú. Destas formações, a que apresenta maior número de caracteres comuns com Cururú é a formação Gurabo, Mioceno Médio de 


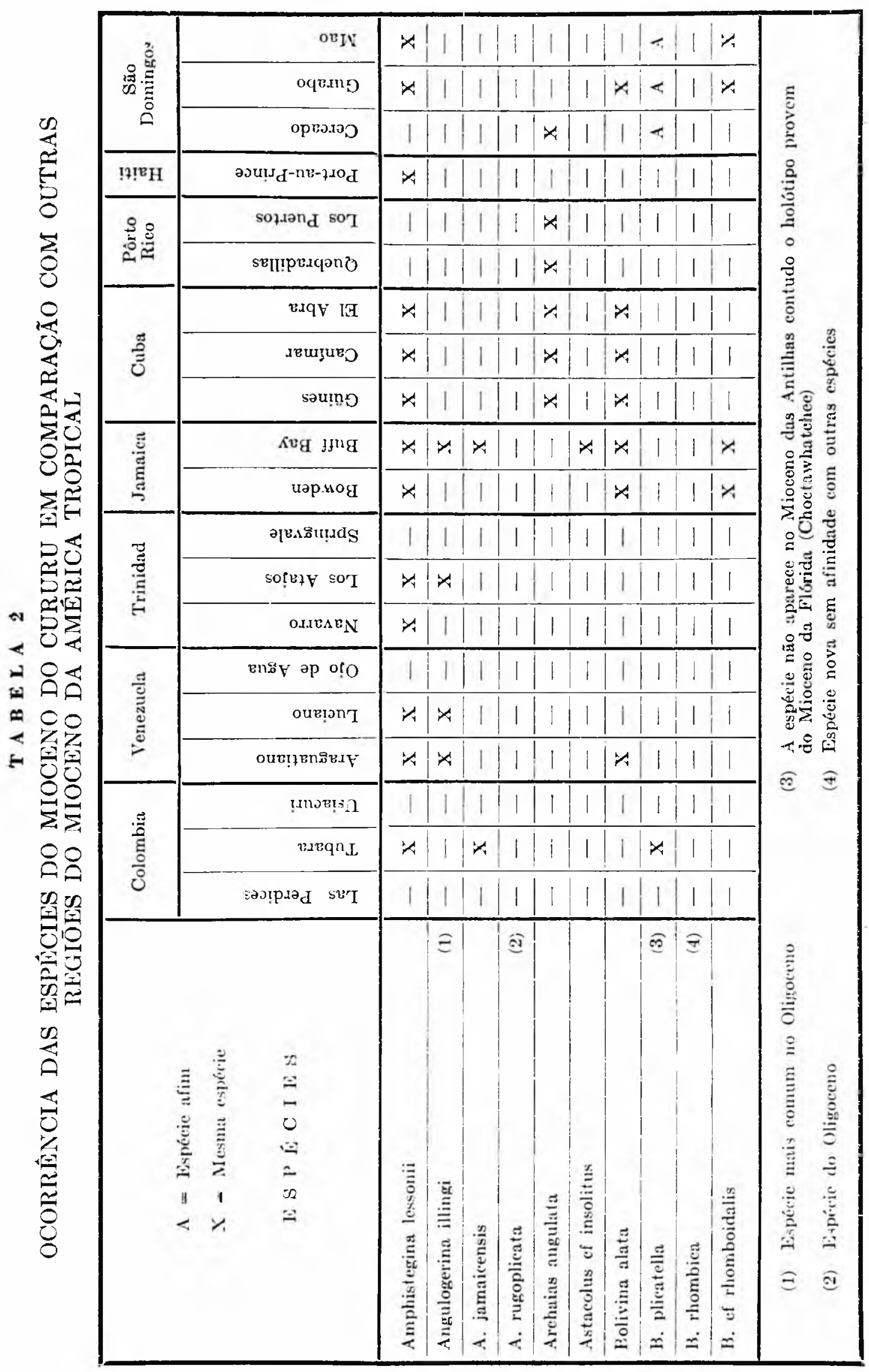


BOL. FAC. FIL. CIEN. LETR. N. 176, GEOLOGIA N. 11

\begin{tabular}{|c|c|c|c|c|c|c|c|c|c|c|c|c|c|c|c|c|}
\hline \multirow{3}{*}{ 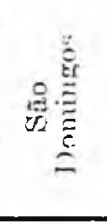 } & orin & -1 & & 1 & H & 1 & $\mathcal{H}$ & $x$ & 1 & 4 & $r$ & A & 1 & 1 & 1 & 1 \\
\hline & oq $1 . .111\}$ & 1 & 一 & 1 & W & $r$ & 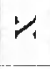 & $A$ & . & $\div$ & $<$ & $A$ & $x$ & $i 4$ & $1 / 4$ & is \\
\hline & (1) & 1 & - & 1 & 1 & 1 & 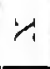 & $x$ & 1 & $<$ & $\because$ & $B$ & 1 & 11 & 1 & 1 \\
\hline$!+!{ }^{*} \mathrm{H}$ & 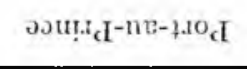 & 11 & 1 & 二 & 1 & 1 & 1 & 1 & 1 & 1 & 1 & 1 & 1 & 11 & 1 & 1 \\
\hline \multirow{2}{*}{ 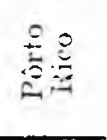 } & sol:əind $: C T$ & 1 & 1 & 1 & 1 & $n$ & 1 & 1 & i & - & $\div$ & H & 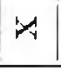 & 1 & 1 & 1 \\
\hline & 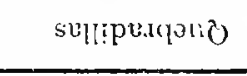 & 1 & 1 & 1 & 1 & i & 1 & 1 & 1 & ? & $1 \div$ & 11 & 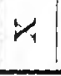 & 11 & 1 & 1 \\
\hline \multirow{3}{*}{ 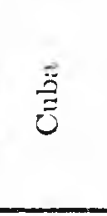 } & MqF & 11 & 1 & 1 & 11 & 1 & 1 & 1 & 1 & $\mid$ & 11 & 11 & $x$ & 1 & & I \\
\hline & 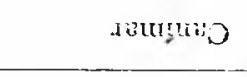 & 1 & 1 & 1 & 1 & 1 & 1 & 1 & 1 & 1 & 1 & $\infty$ & $M 1$ & $A$ & 11 & I \\
\hline & soung & 11 & 1 & 1 & 1 & 1 & 1 & 1 & I & 1 & 11 & 11 & 4 & $\times 1$ & 1 & 1 \\
\hline \multirow{2}{*}{ 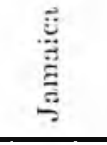 } & 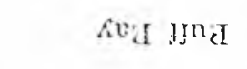 & 4 & 1 & 15 & i & $r$ & $r_{1}$ & 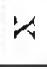 & 1 & $i$ & 1 & $B$ & 1 & $r .1$ & 1 & I \\
\hline & I:pp: & $i$ & - & $<$ & in & 以 & 4 & 1 & i & T & 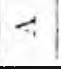 & 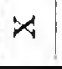 & is & $H_{4}$ & 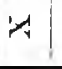 & 1 \\
\hline \multirow{3}{*}{ 胥 } & 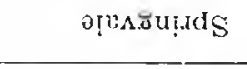 & 11 & 1 & 1 & 1 & 1 & 1 & 1 & 1 & 1 & 11 & 11 & $!$ & 1 & 1 & 1 \\
\hline & $\operatorname{sor} 3 \dot{r} \leq 0^{\circ} I$ & i & 1 & 1 & 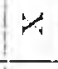 & $x$ & $x$ & 1 & 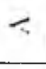 & 1 & 1 & 1 & 1 & 1 & 1 & 1 \\
\hline & $0.11 \omega_{N}$ & 1 & 1 & 11 & ir & $x$ & 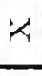 & 1 & $\div$ & 1 & 11 & 11 & 1 & 1 & 1 & 1 \\
\hline \multirow{3}{*}{ 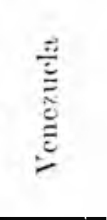 } & c1.45 әp ofo & 11 & 1 & 1 & 11 & 1 & 1 & 1 & 1 & 1 & 1 & 1 & 1 & 1 & 1 & 1 \\
\hline & ous?:Jn'T & 1 & 1 & 1 & ix & $x$ & 1 & 1 & $<$ & 1 & 1 & 1 & 1 & 1 & 1 & 1 \\
\hline & outratusus & 1 & 1 & 1 & 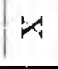 & $x$ & 1 & 1 & - & 1 & 11 & 11 & 1 & I & 1 & I \\
\hline \multirow{3}{*}{ 吾 } & !un, & 1 & 1 & 1 & 1 & 1 & 1 & 1 & 1 & 1 & 1 & 11 & $!$ & । & 1 & 1 \\
\hline & virequin $L$ & 1 & 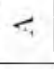 & 1 & is & $i$ & 1 & 1 & 4 & 1 & 11 & 11 & 1 & I & 1 & 1 \\
\hline & 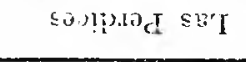 & $i$ & 1 & 1 & 1 & 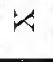 & $A$ & 1 & 1 & 1 & i & 1 & 1 & 1 & 1 & 1 \\
\hline & 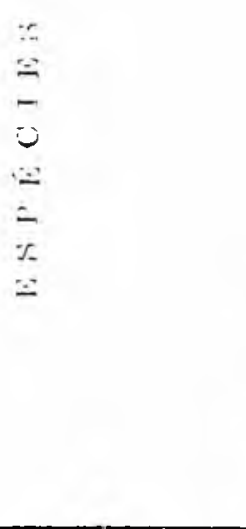 & 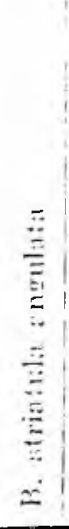 & 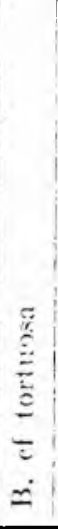 & 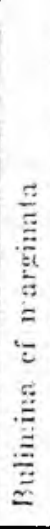 & 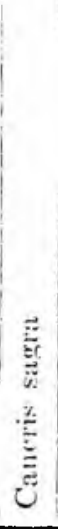 & 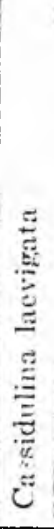 & 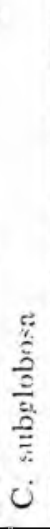 & 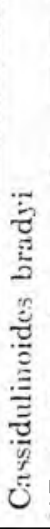 & 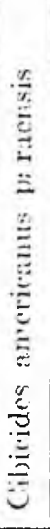 & 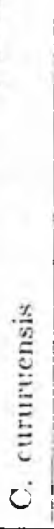 & 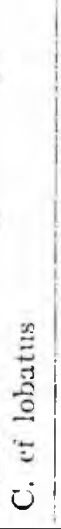 & 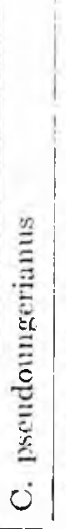 & 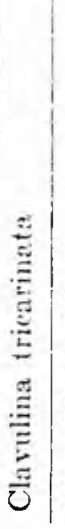 & 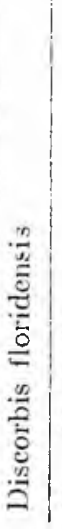 & 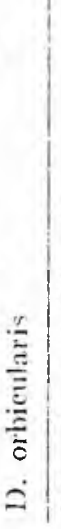 & 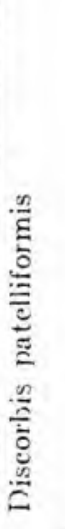 \\
\hline
\end{tabular}




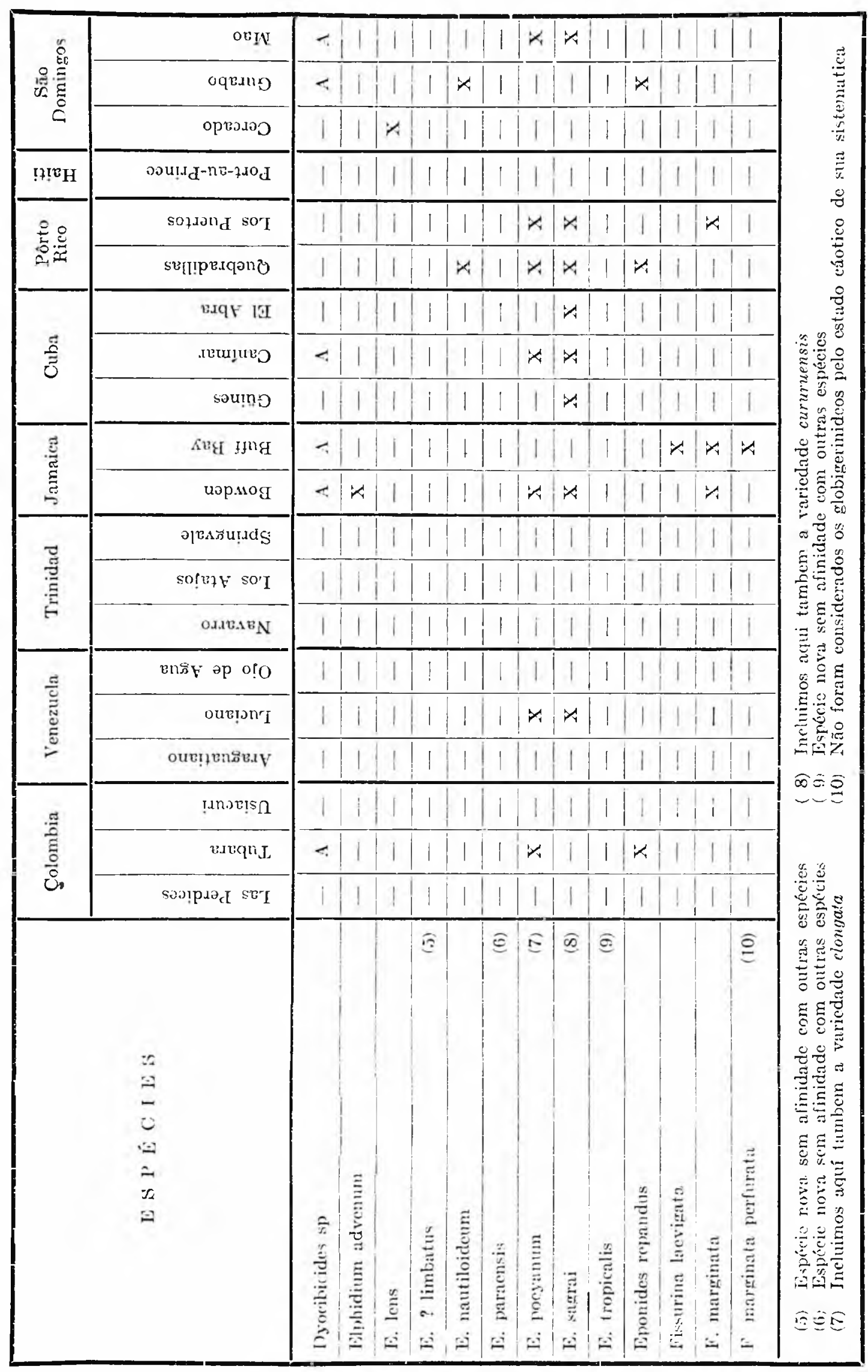




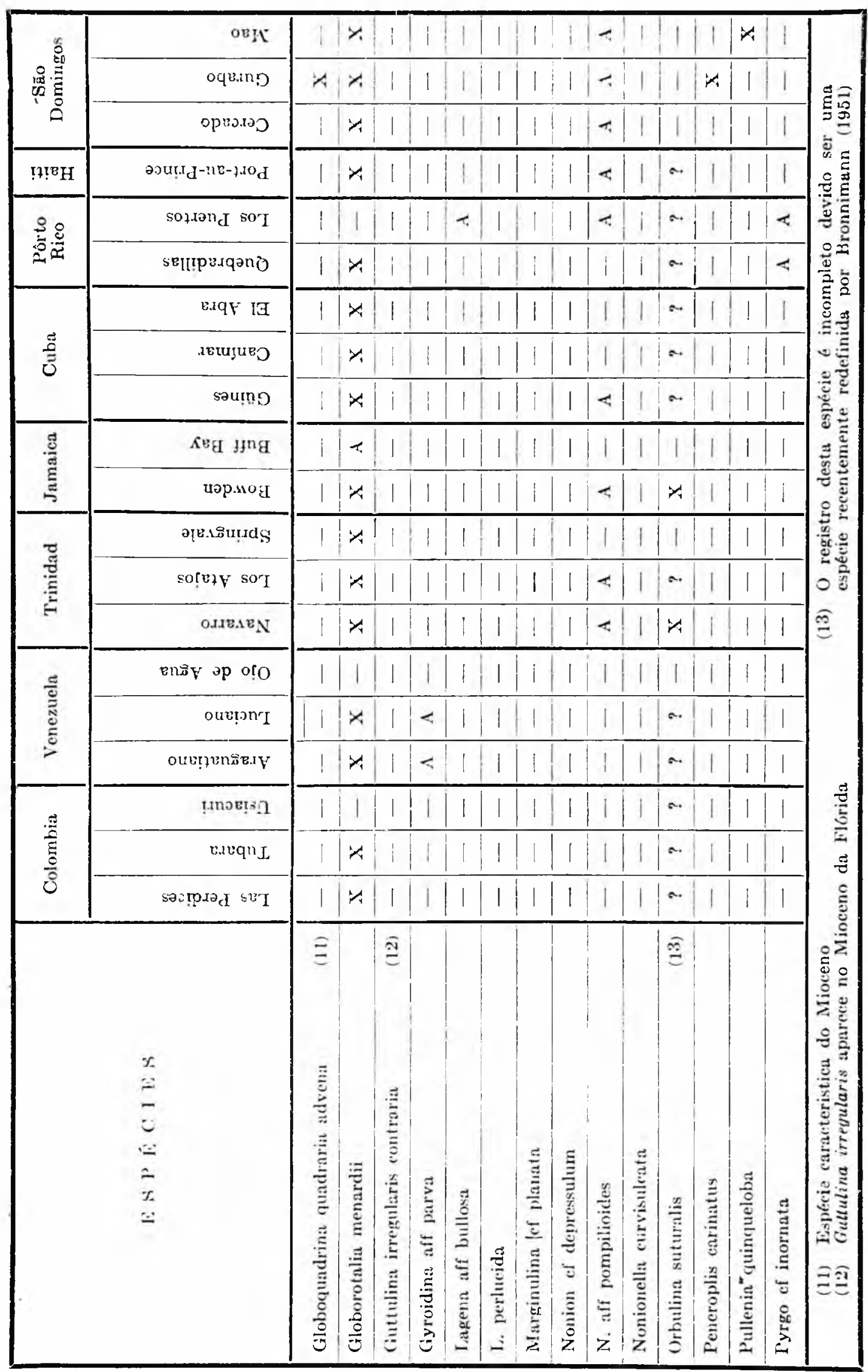




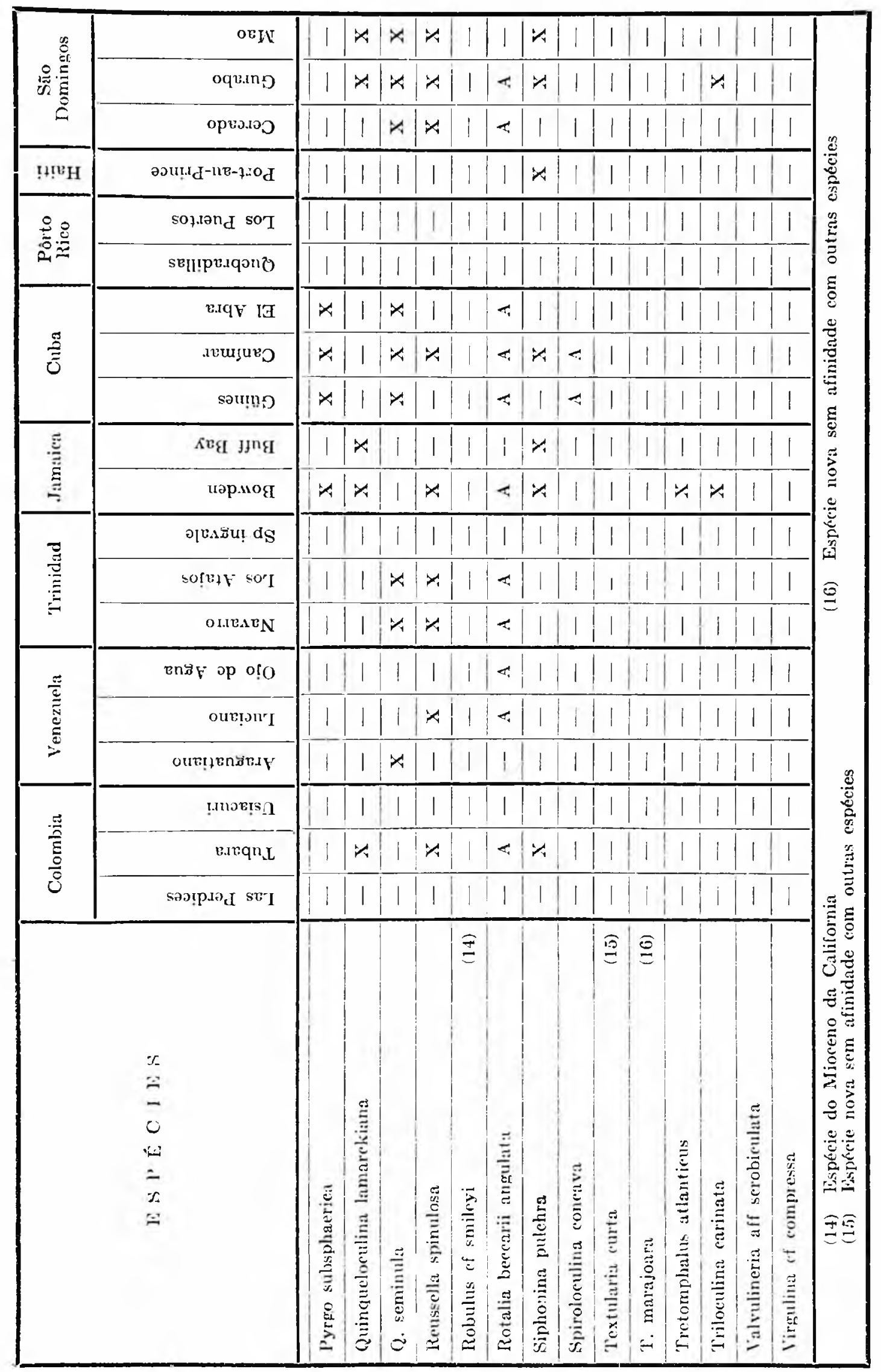




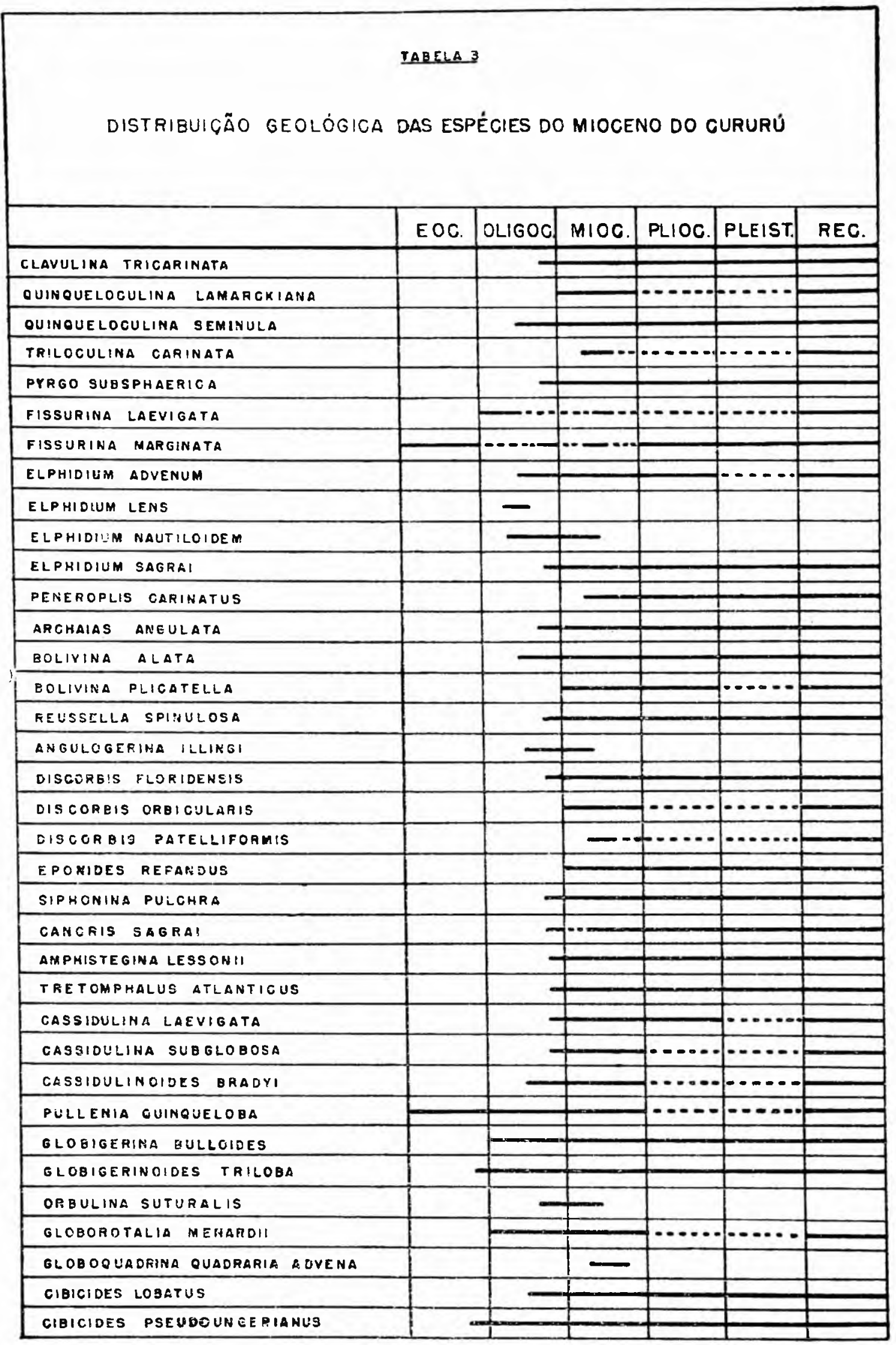


São Domingos. A formação Gurabo, segundo Bermudez (1949 pp. 14-15), possue ambiente de sedimentação que varia de águas rasas para ambiente de águas moderadamente profundas.

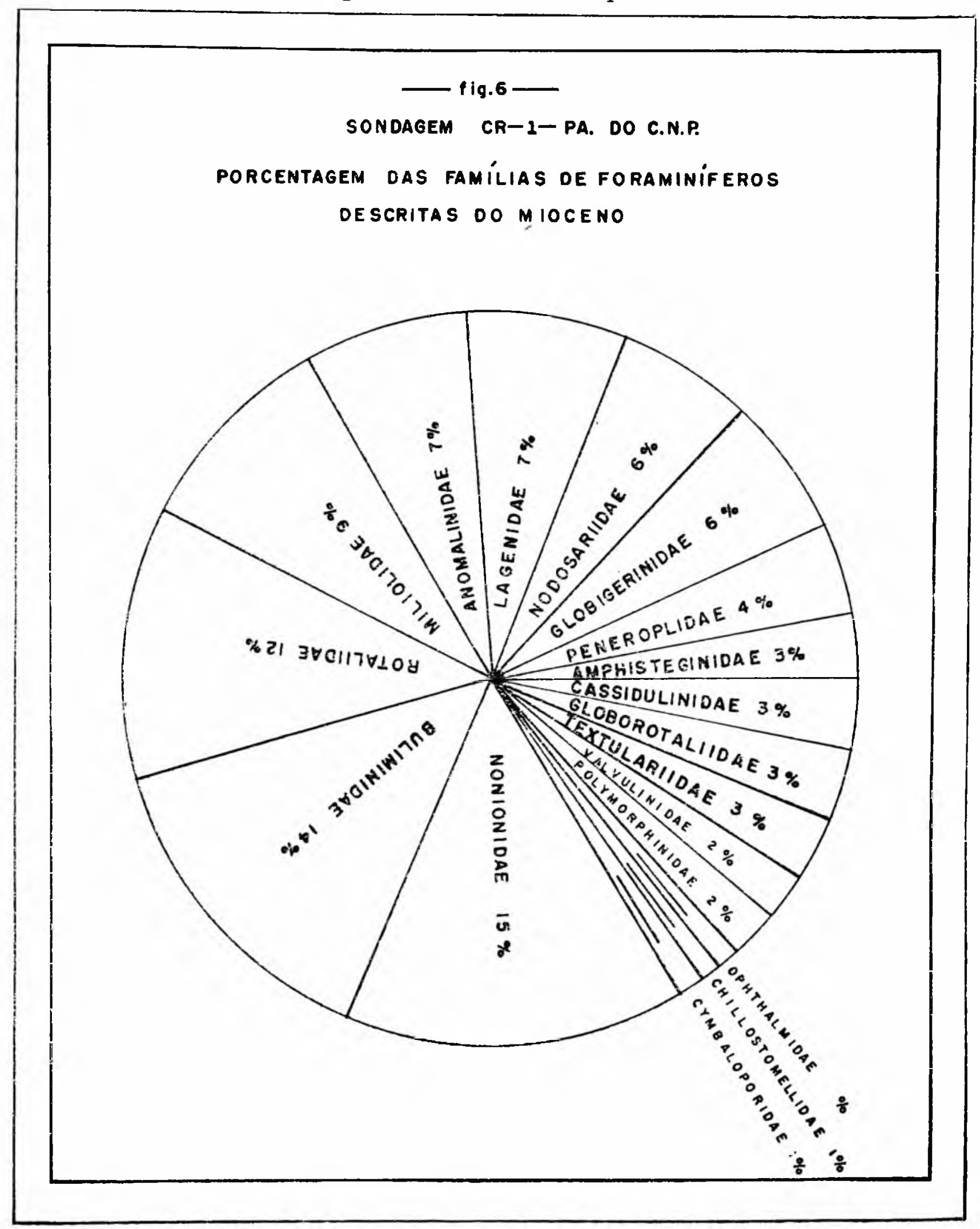




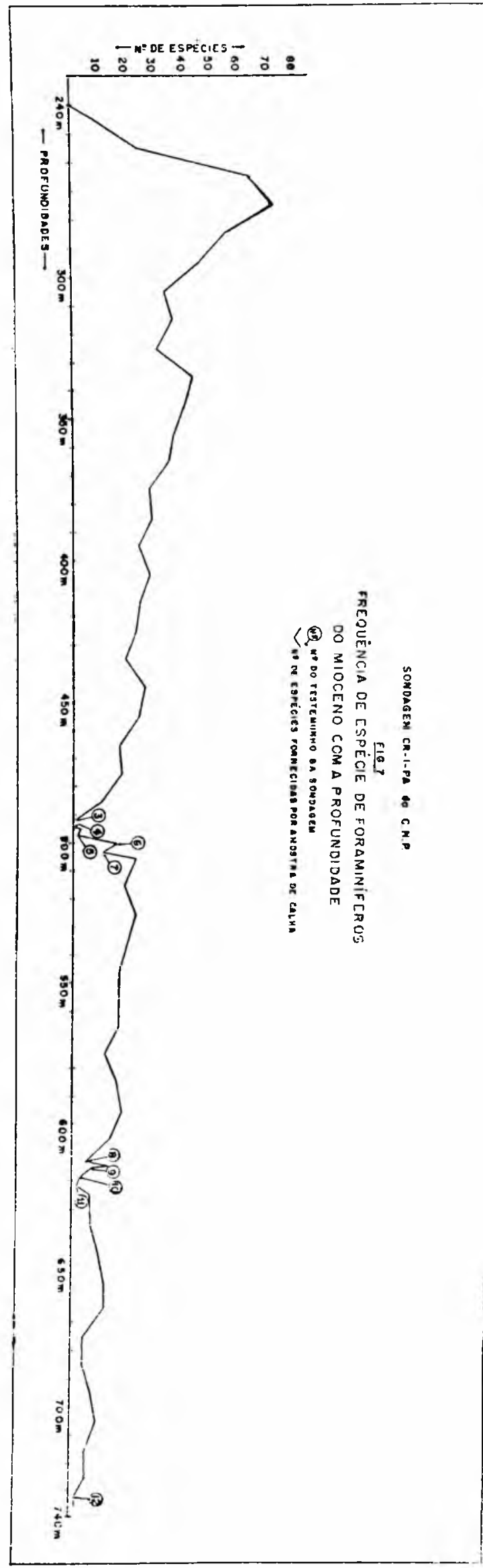

Não obstante as consideracooss acima, Orbulina suturalis Bronimann, tem em Trinidad, a sua distribuição estratigráfica limitada a parte superior do Mioceno Inferior o que nos leva a coloc'ar os sedimentos de C'ururń do intervalo aqui considerado nessa parte do Mioceno en lugar de no Mioceno Médio.

$\Lambda$ Tabela n. ${ }^{\circ} 3$ mostra a distribuição geologriea das espécies do Mioceno de Cururú. Eliminamos desta tabela as espécies novas a as não exatamente iclentificallas com espéciess pré-exiotentes. A iclade miorênica da famnd ressalta-se desta tabela.

\section{Comsideracties sôbre a fanma do Mioceno de rumuri}

()s foraminiferos fósseis do Mioceno de C'ururí são muito mais abundantes no intervalo $245 \mathrm{~m} 460 \mathrm{~m}$ do que no intervalo $460 \mathrm{~m} 740 \mathrm{~m}$. Infelizmente nenhum testemunho foi tiladlo nesta parte do poco de maneira que as nossas deducóes estratigraficas tiveram que ser baseadas em amostras de calha senclo, por conseguinte, imperfeitas devido a contaminação dias anostras por sedimentos superiores, por desmoronamentos a pela lâma circonlante. As nosisas idéias sôbre a distribuição dêsses fósseis só se tornam mais completas considerando-se a frepü̈ência dêsses fósseis por amostra de calha. A curva da Fig. $T$ foi obtida considerando- 


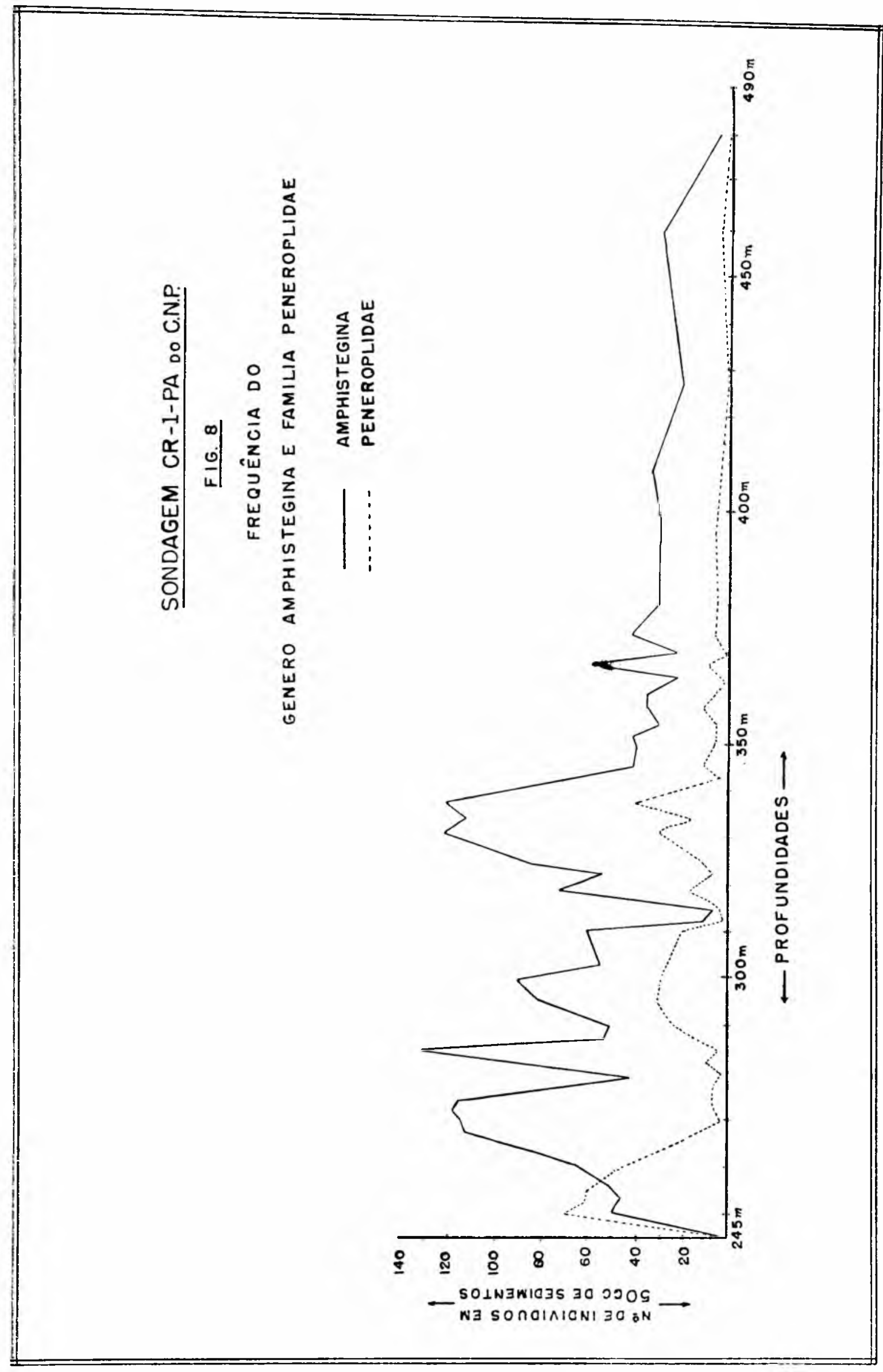


se o número de espécies de foraminíferos por profundidade, e a curva da Fig. 8 foi obtida considerando-se o número de indivíduos do gênero Amphistegina e da família Peneroplidae por profundidade, tomando-se $50 \mathrm{cc}$ de sedimento. Escolhemos o gênero Amphistegina e a família Peneroplidae por serem os foraminíferos mais abundantes e os que apresentam distribuição estratigráfica mais completa. Temos alguns testemunhos no intervalo $460 \mathrm{~m} 740 \mathrm{~m}$. A freqüiência dos foraminíferos é aqui bem menor. Parece que dentro dêsse intervalo fossilífero havia variações periódicas das condições ambientes produzindo-se variações na freqüiência das espécies. Veja-se por exemplo as supracitadas Figs. 7 e 8. A Fig. 7 mostra que de acôrdo com os dados fornecidos pelas amostras de calha, o desenvolvimento máximo da associação faunística dell-se no intervalo $274 \mathrm{~m}-277 \mathrm{~m}$ (Zona Bolivina plicatella Cushman). A curva é assimétrica crescendo bruscamente do intervalo $247 \mathrm{~m}-250 \mathrm{~m}$ ao intervalo $274 \mathrm{~m}$ $277 \mathrm{~m}$, caindo depois suavemente e com variações de certa monta. Talvez parte dessas irregularidades a partir de $277 \mathrm{~m}$ seja devido a contaminação das amostras de calha. Contudo a freqüiência de espécies nos testemunhos do intervalo $460 \mathrm{~m} 740 \mathrm{~m}$, se enquadram bem nesta curva geral, mostrando que os desvios são pequenos. Êsses dados fornecidos pelos testemunhos demonstram a periodicidade de freqüência de espécie com a profundidade, pois os testemunhos ns. 3 e $4(492 \mathrm{~m} 493 \mathrm{~m}$ e $493 \mathrm{~m} 4.97 \mathrm{~m})$ não forneceram foraminíferos fósseis. Já o testemunho n. ${ }^{\circ} 5(497 \mathrm{~m} 500 \mathrm{~m})$ forneceu uma única espécie, o testemunho n. ${ }^{\circ} 6(500 \mathrm{~m} 503 \mathrm{~m})$ forneceu 15 espécies caindo o número de espécies para 10 no testemunho n. ${ }^{0} 7(503 \mathrm{~m}$

$506 \mathrm{~m}$ ). Infelizmente faltou testemunhagem abaixo de $506 \mathrm{~m}$, pois o testemunho n. ${ }^{0} 8$ foi tirado do intervalo $614 \mathrm{~m} 617 \mathrm{~m}$.

Como já foi dito atrás, a maior parte dos foraminíferos descritos no presente trabalho, provém de amostras de calha devido a escassez de testemunhagem. Sòmente as seguintes espécies foram encontradas em testemunhos de sondagem.

1) Amphistegina lessonii d'Orbigny - test. 6, 7, 9 e 10.

2) Bulimina cf marginata d'Orbigny - test. 5 e 6.

3) Cibicides americanus Cushman var. paraensis Petri - test. 6 e 9.

4) C. pseudoungerianus (Cushman) - test. 6 e 8.

5) Clavulina tricarinata d'Orbigny - test. 6.

6) Eponides repandus (Fichtel e Moll) - test. 6 e 7 .

7) Globigerina sp - test. 9 e 12.

8) Globigerinoides triloba (Reuss) - test. 6, 7, 8 e 9.

9) G. triloba (Reuss) var. aspera Petri - test. 6, 7 e 8.

10) Lagena perlucida (Montagu) - test. 9.

11) L. sp - test. 6 .

12) Orbulina suturalis (Bronnimann) - test. 7.

13) Pyrgo subsphaerica (d'Orbigny) -- test. 6 e 7 . 
14) Quinqueloculina lamarchiana (d'Orbigny) - test. 6, 7. 9, 11 e 12 .

15) Q. seminula (Lineu) - test. 6 e 7.

16) Rotalia beccarii (Lineu) var. angulata Petri - test. 6.8 e 10.

17) Taberina sp - test. 6 e 7.

18) Textularia marajoara Petri - test. 6 e 7.

A descrição da fama de foraminíferos do Mioceno de Cururú não está esgotada no presente trabalho, pois algumas espécies raras e com testa fragmentária não foram descritas. Além disso a ausência de testemunhagem na secção mais rica em fósseis do poço faz com que muitas espécies tenham, possivelmente, passado desapercebidas.

As espécies citadas abaixo, não foram descritas, sendo que, devido ao estado fragmentário, são só duvidòsamente determinadas genèricamente.
1) Articulina? sp
2) Asterigerina? sp
3) Eponides sp
4) Globigerinita? $\mathrm{sp}$
5) Lagena sp
6) Pseudoglandulina? $\mathrm{sp}$
7) Siphogenerina? $\mathrm{sp}$
8) Siphoninoides? sp
9) Spiroloculina $\mathrm{sp}$
10) Tubulogenerina? sp
11) Valvulina? $\mathrm{sp}$

As seguintes espécies provenientes do Mioceno de C'ururú $(245 \mathrm{~m} 740 \mathrm{~m})$ foram descritas e figuradas.

1) Amphistegina lessonii d'Orbigny

2) A. lessonii d'Orbigny var. conica Petri var. nov.

3) A. lessonii d'Orbigny var. tumida Petri rar. nov.

4) Angulogerina illingi Cushman e Renz

5) A. jamaicensis Cushman e Todd

6) A. rugoplicata Cushman

7) Archaias angulata (Fichtel e Moll)

8) Astacolus ef insolitus (Schwager)

9) Bolivina alata (Seguenza)

10) B. plicatella Cushman

11) B. rhombica Petri sp nov.

12) B. cf rhomboidalis (Millett)

13) B. striatula Cushman var. angulatu Petri var. nov.

14) B. cf tortuosa Brady

15) Bolivina $\mathrm{sp}$ 
16) Bulimina ef marginata d'Orbigny

17) Cancris sagra d'Orbigny

18) Cassidulina laevigata d'Orbigny

19) C. subglobosa Brady

20) Cassidulinoides bradyi (Norman)

21) Cibicides americanus Cushman var. paraensis Petri var. nov.

22) C. cururuensis Petri sp nov.

23) C. cf lobatus (Walker e Jacob)

24) C. pseudoungerianus (Cushman)

25) Clavulina tricarinata d'Orbigny

26) Cornuspira sp

27) Cribrobulimina sp

28) Discorbis floridensis (Cushman)

29) D. orbicularis (Terquem)

30) D. patelliformis (Brady)

31) Discorbis sp

32) Dyocibicides sp

33) Elphidium advenum (Cushman)

34) E. ? limbatus Petri sp nov.

35) E. lens Galloway e Heminway

36) E. nautiloideum Galloway e Heminway

37) E. paraensis Petri sp nov.

38) E. poeyanum (d'Orbigny)

39) E. poeyanum (d'Orbigny) var. elongata Petri var. nov.

40) E. sagrai (d'Orbigny)

41) E. sagrai (d'Orbigny) var. cururuensis Petri var. nov.

42) E. tropicalis Petri sp nov.

43) E. sp

44) Eponides repandus (Fichtel e Moll)

45) Fissurina laevigata Reuss

46) F. marginata (Walker e Jacob)

47) F marginato-perfurata (Seguenza)

48) $F \mathrm{sp}$

49) Frondicularia $\mathrm{sp}$

50) Globigerina bulloides d'Orbigny

51) G. sp

52) Globigerinoides triloba (Reuss)

53) G. triloba (Reuss) var. aspera Petri var. nov.

54) G. sp

55) Globoquadrina quadraria (Cushman eEllisor) var. advena Bermudez

56) Globorotalia menardii (d'Orbigny)

57) $G . \mathrm{sp}$

58) Guttulina irregularis (d'Orbigny) var. contraria Petri var. nov.

59) Gyroidina aff parva Cüshman e Renz

60) Gyroidinoides sp 
61) Lagena aff bullosa Galloway e Heminway

62) L. perlucida (Montagu)

63) L. sp

64) Laticarinina ef pauperata (Parker e Jones)

65) Marginulina cf planata Phleger e Parker

66) Nodosaria sp

67) Nonion cf depressulum (Walker e Jacob)

68) N. aff pompilioides (Fichtel e Moll)

69) Nonionella curvisulcata Petri sp nov.

70) Orbulina suturalis Bronnimann

71) Peneroplis carinatus d'Orbigny

72) Planulina sp

73) Pseudopolymorphina sp

74) Pullenia quinqueloba (Reuss)

75) Pyrgo cf inornata (d'Orbigny)

76) P. subsphaerica (d'Orbigny)

77) Quinqueloculina lamarckiana (d'Orbigny)

78) Q. seminula (Lineu)

79) Q. sp

80) Reussella spinulosa (Reuss)

81) Robulus cf smileyi Kleinpell

82) $R$. cf smileyi Kleinpell var. pauciloculata Petri var. nov.

83) Rotalia beccarii (Lineu) var. angulata Petri var. nov.

84) Siphonina pulchra Cushman

85) Spirolina sp

86) Spiroloculina concava Petri nom. nov.

87) Taberina $\mathrm{sp}$

88) Textularia curta Petri sp nov.

89) T. marajoara Petri sp nov.

90) T. ? sp

91) Tretomphalus atlanticus Cushman

92) Triloculina carinata d'Orbigny

93) $T . \mathrm{sp}$

94) Valvulineria aff scrobiculata (Schwager)

95) Virgulina cf compressa (Bailey)

96) Uvigerina $\mathrm{sp}$

As seguintes espécies provenientes do Eoceno? (2033 m-2380 m), foram descritas e figuradas.

1) Globigerina cretacea d'Orbigny

2) G. cf triangularis White

3) Globorotalia compressa (Plummer)

4) G. cf crassata Cushman

5) Gümbelina globulosa (Ehrenberg) 
A Fig. 6, mostra, em forma de gráfico, a porcentagem das diversas famílias de foraminiferos provenientes do Mioceno de Curuxú.

$\mathrm{Na}$ descrição das espécies seguiu-se a ordem dada pelo tratado de Cushman (1948), de acôrdo com o uso corrente entre os micropaleontólogos. Para não nos estendermos na lista de referências que damos logo abaixo das espécies descritas, evitamos sempre que possível, citar as publicaçoes anteriores a Monografia de Cushman sôbre os foraminíferos do Oceano Atlântico (1918-1931). Indicamos a lacuna com a nota 'Referências', logo após a supracitadla publicação de Cushman, ou outras publicações que tratem dessas referências anteriores, de maneira que o leitor interessado poderá chegar as fontes das mesmas.

\section{Divisão do Mioceno em zonas paleontológicas}

Conforme já foi dito acima, o intervalo do poço de Cururú com fauna do Mioceno, pode ser dividido em zonas paleontológicas, se bem que grosseiramente, visto a pobresa de testemunhagem. Escolhemos as espécies mais características dessas diversas zonas, para as denominações, usando o conceito de Arkell (Em Renz 1948 p. 28) o qual afirma que o organismo escolhido para caracterisar uma zona não precisa necessàriamente ser confinado a esta zona ou encontrar-se distribuído em tôda a sua extensão. Estas zonas paleontológicas poderão, erentualmente, ser melhor precisadas com outros pocos que porventura forem perfurados na região.

As zonas paleontológicas distingüidas foram as seguintes:

1) zona Amphistegina lessonii d'Orbigny $(245 \mathrm{~m} \cdot 259 \mathrm{~m})$

2) zona Bolivina plicatella Cushman ( $259 \mathrm{~m}-340 \mathrm{~m}$ )

3) zona Elphidium poeyanum d'Orbigny var. elongata Petri $(340 \mathrm{~m} \cdot 460 \mathrm{~m})$

4) zona Quinqueioculina lamarchiana d'Orbigny $(460 \mathrm{~m} \cdot 740 \mathrm{~m}$ )

\section{Zona Amphistegina lessonii d'()rbigny}

Esta zona é caracterisada pelo seguinte:

a) A associação de foraminíferos é constituída na sua quase totalidade por Amphistegina e peneroplídeos sendo raros outros tipos de foraminíferos.

b) São muito comuns conchas de Pelecypoda, fragmentos de corais e dentes de peixes seláquios, fósseis êstes que são restritos a esta zona, enquanto os Ostracoda e Bryozoa vão até $460 \mathrm{~m}$.

c) As espécies de foraminíferos encontradas nesta zona são as seguintes: 
I) Amphistegina lessonii d'Orbigny

2) A. lessonii d'Orbigny var. tumida Petri var. nov.

3) Archaias angulata (Fichtel e Moll)

4) Bolivina striatula Cushman var. angulata Petri var. nov.

5) Elphidium nautiloideum Galloway e Heminway

6) E. poeyanum (d'Orbigny)

7) E. poeyanum (d'Orbigny) var. elongata Petri var. nov.

8) E. sagrai (d'Orbigny) var. cururuensis Petri var. nov.

9) Eponides repandus (Fichtel e Moll)

10) Frondicularia sp

11) Globigerina sp

12) Globigerinoides triloba (Reuss)

13) G. triloba (Reuss) var. aspera Petri var. nov.

14) Globoquadrina quadraria (Cushman e Ellisor) var. advena Bermudez

15) Peneroplis carinatus d'Orbigny

16) Pyrgo subsphaerica (d'Orbigny)

17) Quinqueloculina lamarckiana (d'Orbigny)

18) Q. seminula (Lineu)

19) Robulus cf smileyi Kleinpell

20) Rotalia beccarii (Lineu) var. angulata Petri var. nov.

21) Spiroloculina concava Petri var. nov.

22) Taberina sp

23) Textularia marajoara Petri sp nov.

24) Virgulina cf compressa (Bailey)

\section{Zona Bolivina plicatella (C'ushman)}

a) $O$ principal característico desta zona é o aparecimento brusco e em grande quantidade dos gêneros Angulogerina e Cvigerina e da espécie Bolivina plicatella Cushman as quais desaparecem na zona seguinte.

b) Aumento da porcentagem de outros foraminíferos em relação a associação Amphistegina --- peneroplídeos. Os peneroplídeos sofrem grande redução na sua freqüência mas o gênero Amphistegina ainda continua numeroso.

c) Aparecimento das espécies relacionadas abaixo, as quais se tornam muito frequientes nesta zona:

1) Angulogerina illingi Cushman e Renz

2) A. jamaicensis Cushman e Todd

3) A. rugoplicata Cushman

4) Astacolus cf insolitus (Schwager) (Rara'

5) Bolivina alata (Seguenza)

6) B. plicatella Cushman 
7) B. rhombica Petri sp nov.

8) B. cf rhomboidalis (Millett)

9) B. cf tortuosa Brady (Rara)

10) B. sp

11) Bulimina cf marginata d'Orbigny

12) Cancris sagra d'Orbigny

13) Cassidulina laevigata d'Orbigny

14) C. subglobosa Brady

15) Cassidulinoides bradyi (Norman)

16) Cibicides americanus Cushman var. paraensis Petri var. nov.

17) C. cururuensis Petri sp nov.

18) C. cf lobatus (Walker e Jacob)

19) C. pseudoungerianus (Cushman)

20) Clavalina tricarinata d'Orbigny

21) Cornuspira sp (Rara)

22) Discorbis floridensis (Cushman)

23) D. orbicularis (Terquem)

24) D. patelliformis (Brady)

25) D. $\mathrm{sp}$

26) Dyocibicides sp

27) Elphidium advenum (Cushman)

28) E. ? limbatus Petri sp nov.

29) E. lens Galloway e Heminway

30) E. paraensis Petri sp nov.

31) E. sagrai (d'Orbigny)

32) E. tropicalis Petri sp nov.

33) $E . \mathrm{sp}$

34) Fissurina laevigata Reuss

35) F marginata (Walker e Jacob)

36) F marginato-perfurata (Seguenza)

37) $F \mathrm{sp}$

38) Globigerina bulloides d'Orbigny

39) Globigerinoides sp

40) Globorotalia menardii (d'Orbigny)

41) G. sp (Rara)

42) Guttulina irregularis (d'Orbigny) var. contraria Petri var. nov.

43) Gyroidina aff parva Cushman e Renz

44) Gyroidinoides sp (Rara)

45) Lagena aff bullosa Galloway e Heminway

46) L. perlucida (Montagu)

47) L. sp

48) Marginulina of planata Phleger e Parker

49) Nodosaria sp

50) Nonion cf depressulum (Walker e Jacob)

51) N. aff pompilioides (Fichtel e Moll) 
52) Nonionella curvisulcata Petri sp nov.

53) Orbulina suturalis Bronnimann

54) Planulina sp (Rara)

55) Pseudopolymorphina sp (Rara)

56) Pullenia quinqueloba (Reuss)

57) Pyrgo cf inornata (d'Orbigny)

58) Quinqueloculina sp (Rara)

59) Reussella spinulosa (Reuss)

60) Robulus ef smileyi Kleinpell var. pauciloculata Petri var. nov.

61) Siphonina pulchra Cushman

62) Spirolina sp (Rara)

63) Textularia curta Petri sp nov.

64) T. ? sp

65) Tretomphalus atlanticus Cushman

66) Triloculina carinata d'Orbigny

67) T. sp

68) Valvulineria aff scrobiculata (Schwager)

69) Uvigerina sp

d) A espécie Frondicularia sp é a única exclusiva da zona anterior não encontrada na zona em consideração nem nas seguintes.

e) Grande riquesa de foraminíferos planctônicos especialmente globigerinídeos.

f) Redução do número de macrofósseis.

Zona Elphidium poeyamum d'Orbigny var. elongata Petri

a) Esta zona é caracterisada ùnicamente pelo desaparecimento de certas espécies da zona anterior não tendo aparecido nenhuma espécie nesta zona.

b) A porcentagem de foraminíferos planctônicos cai muito em relação aos bentônicos.

c) As espécies de Amphistegina, Quinqueloculina e Rotalia bem como Cibicides anericanus Cushman var. paraensis Petri, Elphidium nautiloideum Galloway e Heminway, E. poeyanum d'Orbigny var. elongata Petri e $E$. sagrai d'orbigny var. cururuensis Petri são as predominantes.

d) As seguintes espécies cla zona anterior não são encontraclas na presente zona bem como nia seguinte:
1) Angulogerina illingi Cushman e Renz
2) A. jamaicensis Cushman e Todd
3) A. rugoplicata Cushman
4) Bolivina alata (Seguenza)
5) B. plicatella Cushman 


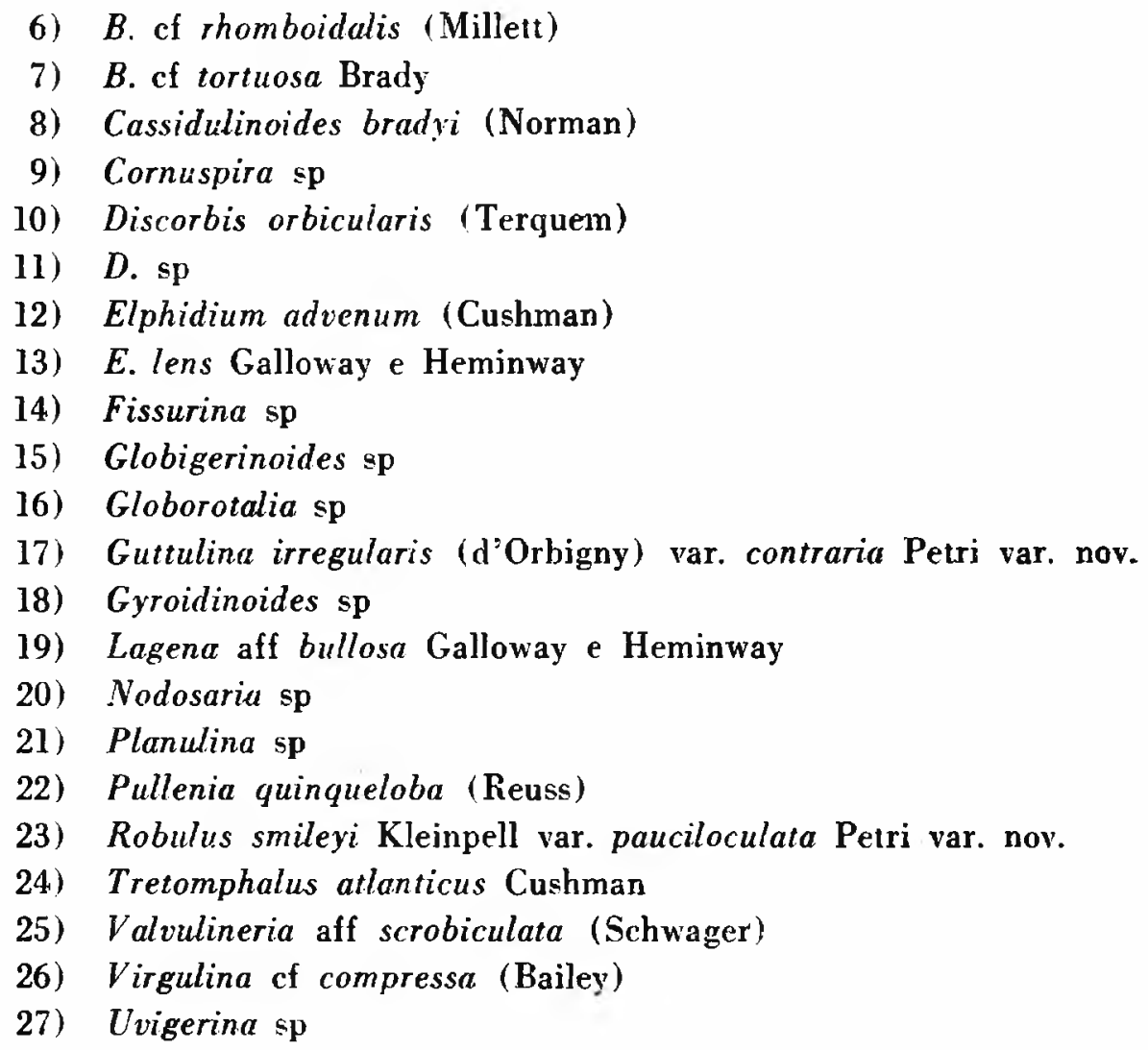

\section{Zona Quinqueloculina lamarckiana d'Orbigny}

a) Esta zona é caracterisada pelo predominio das espécies de Quinqueloculina.

b) As seguintes espécies, aliás raras, são restritas a esta zona.

1) Cribrobulimina ? sp

2) Laticarinina of pauperata (Parker e Jones)

c) As outras espécies são as que persistem da zona anterior.

\section{DESCRIÇA O D A S E S P ÉCIE S}

Textularia curta Petri sp nov.

Est. 1 - Figs. 1-2

Deschiç̃o - Testa largà e curta, um tanto comprimida; periferia subaguda, lados fortemente divergentes; câmaras distintas, relativamente ponco numerosas, bem mais largas que altas; suturas distintas, ligeiramente deprimidas, as laterais ligeiramente arqueadas formando ângulo quase reto com o eixo das suturas axiais as quais são em forma de zig-zag' bem fechado; parede finamente 
arenosa, finamente acabada; abertura alongada na base de uma depressão na margem interna da câmara formada por último.

OCoRRÊACIA - Relativamente commm no pogo CR-1-PA, ocorrendo em amostras de calha, nos seguintes intervalos: $267 \mathrm{~m} 276 \mathrm{~m}$, $282 \mathrm{~m} 288 \mathrm{~m}, 297 \mathrm{~m} 303 \mathrm{~m}, 318 \mathrm{~m}-321 \mathrm{~m}, 330 \mathrm{~m}-336 \mathrm{~m}, 342 \mathrm{~m}$ $351 \mathrm{~m}, 364 \mathrm{~m} 385 \mathrm{~m}, 411 \mathrm{~m}-475 \mathrm{~m}, 493 \mathrm{~m}-508 \mathrm{~m}, 522 \mathrm{~m}-544 \mathrm{~m}$, $560 \mathrm{~m}-566 \mathrm{~m}, 600 \mathrm{~m} 606 \mathrm{~m}, 1100 \mathrm{~m} 1109 \mathrm{~m}$.

Dimensões - Espécime figurado: Comprimento $0.62 \mathrm{~mm}$, largura $0.64 \mathrm{~mm}$, espessura $0.36 \mathrm{~mm}$.

Discussão - Os nossos exemplares apresentam alguns caracteres de T. gramen d'Orbigny, descrita do Mioceno da bacia de Viena, como a testa larga e curta, um tanto deprimida, periferia subaguda e a abertura na base de uma depressão na margem interna da última câmara. Contudo os nossos exemplares são muito mais largos que altos em relação ao exemplar típico daquela espécie e as câmaras também são muito mais largas que altas. Quanto a vista apertural ela é muito semelhante ao exemplar figurado por Cushman e Cahill (1933 figs. 9a, 9b) mas difere da vista apertural do holótipo figurado por d'Orbigny (Ellis e Messina, Catalogue of Foraminifera). Cushman (1930 p. 17), Cushman e Ponton (1932 p. 39) e Cushman e Cahill (1933 p. 7) citam a espécie gramen como pertencente ao gênero Textularia. Contudo Bermudez (1950 p. 362), cita a espécie gramen como pertencente ao gênero Spiroplectammina, gênero êste descrito por Cushman em 1927. Seccões delgadas de alguns de nossos exemplares feitos no Laboratório de Paleontologia do Conselho Nacional do Petróleo em Belém, Pará, indicam que a espécie aqui descrita pertence ao gênero Textularia e não ao sênero Śpiroplectammina, pois êles são bisseriais descle o ińúcio; portanto, admitindo a afiliação genérica da espécie gramen dada por Bermudez como certa, os nossos exemplares não podem ser referidos à aquela espécie; como êles não podem ser comparados a nenhuma outra espécie de Textularia, nós o consideramos como representando uma nova espécie a que damos o nome de $T$. curta.

\section{Holótipo - L. P - C. N.P 1-104* \\ Textularia narajoara Petri sp nov.}

Est. 1 - Figr. $3-4$

Descriçño - Testa alongada, não comprimida, a não ser a parte inicial, afinando-se gradualmente para ma extremidade arredon-

* L. P. - C. N. P. = Lahoratório de Paleontologia do Conselho Nacional. do Petríleo em Belém - Estado do Pará. 
dada, com 5 a 6 câmaras um tanto entumescidas de cada lado; periferia arredondada, ligeiramente lobulada em tôda a extensão; suturas distintas, deprimidas, as laterais retas, a mediana em zigzag; parede grosseiramente arenosa mas finamente acabada; abertura consistindo em uma estreita fenda na base da face apertural.

Ocorrência - Esta é, das espécies arenosas, a mais comum no poço CR-1-PA. Ela ocorre tanto em testemunhos de sondagem como em amostras de calha. Ela aparece nos seguintes testemunhos de sondagem: test. $n{ }^{\circ} 6,500 \mathrm{~m}-503 \mathrm{~m}$ e test. n ${ }^{\circ}{ }^{7} 7,503 \mathrm{~m}-506 \mathrm{~m}$. Nas amostras de calha, ela aparece nos seguintes intervalos: $255 \mathrm{~m}$ $304 \mathrm{~m}, 319 \mathrm{~m}-460 \mathrm{~m}, 522 \mathrm{~m} 528 \mathrm{~m}, 556 \mathrm{~m}-562 \mathrm{~m}, 587 \mathrm{~m}-605 \mathrm{~m}$, $655 \mathrm{~m} 664 \mathrm{~m}, \quad 780 \mathrm{~m} \quad 807 \mathrm{~m}, 968 \mathrm{~m}-986 \mathrm{~m}, 1300 \mathrm{~m} \quad 1312 \mathrm{~m}$.

Dunensões - O espécime figurado, o qual corresponde a um tipo médio de testa adulta possue as seguintes dimensóes: Comprimento $0.73 \mathrm{~mm}$, largura $0.45 \mathrm{~mm}$, espessiura $0.42 \mathrm{~mm}$.

Discussĩo - Esta espécie de Textularia pertence ao tipo formado por câmaras entumescidas e periferia arredondada dando como resultado uma vista apertural em forma de elípse. Êste tipo é o mais raro, sendo bem mais comum o tipo formado por câmaras não entumescidas com periferia aguda ou subaguda, dando como resultado uma vista apertural em forma de losângulo.

De tôdas as espécies de Textularia a que mais se aproximid de nossa espécie é $T$ hannai Daris, do Eoceno do Texas. A forma geral da testa, a atitude dos septos e o número de câmaras, etc., são idênticos. A nossa espécie é, contudo, mais alongada, as câmaras são proporcionalmente mais altas, aumentando ràpidamente de altura mas gradativamente de largura.

Ela difere de $T$ candeiana d'Orbigny descrita das costas de Cuba, por possuir, esta última espécie, câmaras muito mais baixas e largas e por possuir, a forma adulta, número maior de câmaras, sendo a testa mais curta e larga. Pela mesma razão difere de $T$. schencki Cushman e Valentine.

\section{HoLótiPo - L. P - C. N. P 1-105. \\ Textularia ? sp}

Est. 1 - Figr. 5

Descrição - Testa alongada e estreita, cêrua de 3 vêzes mais longa que larga, deprimida, afinando-se gradualmente para a extremidade inicial, possuindo a porção adulta, que forma a quase totalidade da testa, lados paralelos; câmaras visiveis, cêrca de 8 de cada lado, sendo que as 4 últimas formam mais de metade da testa, 
largas e curtas, havendo tendência, as últimas câmaras, a se tornarem relativamente mais longas; suturas distintas, deprimidas, as laterais quase retas em relação ao eixo das suturas axiais, sendo que estas formam um zig-zag aberto. A periferia é subagurla e a parede é grosseiramente arenosa com acabamento grosseiro produzido por grãos espalhados pela testa. A abertura é estreita, na base da face apertural, na região mediana, não se estendendo para os lados, sendo do tipo de T. adalta Cushman. Algumas perfurações grosseiras podem ser notadas na face apertural do exemplar figurado.

OCORRÊNCIA - A espécie é relativamente rara no poço CR-1-PA. ocorrendo em amostras de calha dos seguintes intervalos: $268 \mathrm{~m}$ $298 \mathrm{~m}, 344 \mathrm{~m} 362 \mathrm{~m}$.

Dnensões - As dimensões não são dadlas em virtude de estarem, os espécimes, quebrados.

Discussão - Infelimente os nossos exemplares estão quebrados na porção inicial da testa, de maneira que é duvidoso se êles realmente pertencem ao gênero Textularia on ao gênero Spiroplectammina. A forma geral da testa, a abertura e o caráter da parede dotada de grandes grãos escassos espalhados pela testa são caracteres que lembram a espécie T. adalta Cushman descrita do Eoceno do plano costal norte-americano. Contudo o caráter fragmentário dos espécimes não permite uma identificação segurura.

Espéchies tipos - L. P - C. N. P 1-106.

Clavulina tricarinata d'Orbigny

Est. 1 - Figs. 6-9

Clavulina tricarinata d'Orbigny, in De La Sagra, Hist. Phys. Pol. Nat. Cuba, Foraminifères, 1839, p. 111, pl. 2, figs. 16-18; Recente, Cuba e Jamaica. Cushman, Publ. 311, Carnegie Instit. Washington, 1922, pp. 29, 30, pl. 3, fig. 3; Recente, Oceano Atlântico. - U. S. Nat. Mus. Bull. 104, pt. 3, 1922, p. 89, pl. 17, figs. 3-4; Recente, Flórida - Cushman e Ponton, Flórida St. Geol. Surv. Bull. 9, 1932, p. 43, pl. 1, figs. 13 a, b; Mioceno, formação Chipola, Flórida. -- Galloway e Heminway, New York Acad. Sci., Sci. Survey Pôrto Rico and Virgin Ils; vol. 3, pt. 4, 1941, p. 326, pl. 7, fig. 8; Oligoceno Sup. e Mioceno Inf., formação Ponce, Porto Rico. - Palmer, Bull. Am. Pal., vol. 29, n. ${ }^{\circ} 115$, 1945, p. 24; Mioceno Médio, formação Bowden, Jamaica. - Bermudez, Cush. Lab. Foram. Res. Sp. Publ. 25, 1949, p. 79, pl. 4, figs. 11-12; Mioceno Médio, formação Gurabo, São Domingos. Mem. Soc. Cubana Hist. Nat., vol. XIX, n. ${ }^{0} 3$, 1950, p. 334, Mioceno-Recente, Cuba.

Descrição - Testa alongada, triangular em secção transversal, aumentando gradativamente em diâmetro para a extremidade apertural; câmaras largas e curtas, relativamente numerosas, as da porção trisserial obscuras, as da porção universal distintas, trian- 
gulares em secção, com lados ligeiramente côncavos e arestas um tanto projetantes e dirigidas para a porção inicial da testa. A porção trisserial é bem distinta da porção unisserial sendo separada desta por um estrangulamento da testa; ambas são triangulares em secção; suturas da porção unisserial distintas, curvando-se em direção a porção trisserial nas arestas, em direção a abertura nas faces; parede arenosa mas com fino acabamento; abertura circular, terminal, sem pescoço, central na face apertural e com um dente valvular bem distinto.

OCoRrêncra - Esta espécie aparece em freqüência regular no poço CR-1-PA, ocorrendo no testemunho n. ${ }^{\circ} 6$, intervalo de $500 \mathrm{~m}-503 \mathrm{~m}$, e em amostras de calha dos seguintes intervalos: $262 \mathrm{~m} 265 \mathrm{~m}, 274 \mathrm{~m} 289 \mathrm{~m}, 317 \mathrm{~m} 320 \mathrm{~m}, 332 \mathrm{~m} 387 \mathrm{~m}, 442 \mathrm{~m}$ $460 \mathrm{~m}, 497 \mathrm{~m} 503 \mathrm{~m}$.

Dimensões - As dimensões medidas nos espécimes figurados. provenientes de amostra de calha do intervalo $287 \mathrm{~m} 289 \mathrm{~m}$, representando o primeiro um indivíduo adulto completamente desenvolvido e o segundo um indivíduo jovem, são as seguintes: 1) Comprimento $1.34 \mathrm{~mm}$, largura entre duas arestas, $0,42 \mathrm{~mm}$, entre aresta e face, $0.40 \mathrm{~mm}$; 2) Comprimento $0.48 \mathrm{~mm}$, largura entre duas arestas, $0.22 \mathrm{~mm}$, entre aresta e face, $0.20 \mathrm{~mm}$.

Discussão - Os nossos espécimes concordam muito bem com as descrições e ilustrações da espécie $C$. tricarinata descrita por d'Orbigny de matorial recente das costas de Cuba. Esta espécie é característica da região das Antilhas. Segundo Cushman (1937 p. 23) ela é abundante em águas rasas da região das Antilhas, aparecendo em Bermuda, Flórida, Bahamas, Cuba, Jamaica e Martinica.

$$
\text { Plesiótipos - L. P. - C. N. P 1-27. }
$$

$$
\text { Cribrobulimina? sp }
$$

Est. I - Figs. 10-11

Descriçĩo - A testa é largamente cônica; nada pode ser dito sôbre o arranjo das primeiras câmaras porque estão ausentes devido a testa estar quebrada na sua parte inicial; as outras câmaras estão arranjadas em espiral alongada, sendo 4 câmaras e meia visíveis em uma volta, de um lado da testa, talvez 8 câmaras formando uma volta do corpo; câmaras distintas, infladas; suturas fortemente deprimidas; a parede parece ser finamente arenosa, com acabamento fino; abertura coberta por uma placa convexa, circular, crivada. 


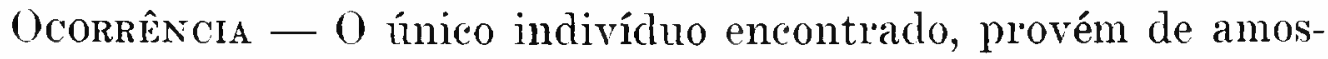
tra de calha, do intervalo de $512 \mathrm{~m}$ a $524 \mathrm{~m}$.

Dimensões - Comprimento $0.78 \mathrm{~mm}$, largura $0.42 \mathrm{~mm}$, espessura $0.44 \mathrm{~mm}$. Deve-se lembrar que o comprimento foi medido até a parte quebrada, tendo tido, a testa, antes de se quebrar, comprimento maior que $0.78 \mathrm{~mm}$.

Discussão - Êste gênero é duvidòsamente representado na fama do poço de Cururú sòmente por um indivíduo mal conservado, estando a porção inicial da testa quebrada; êle é representado na província caraíbica, sòmente por algumas espécies do Eoceno; contudo nas costas da Australia êle aparece nas associações do Plioceno, Pleistoceno e Recente. O indivíduo aqui em consideração apresenta sinais de ter sido retrabalhado e possivelmente provém de formacoões mais antigas. Êle se assemelha a espécie C. cushmani Applin e Jordan descrita do Eoceno Médio Superior (Calcareo Avon Park) dé Flórida.

Espécine tripo - L. P - C. N. P 1-29.

Quinqueloculina lamarckiana d'orbigny

Est. 1 - Figs. 19-17

Quinqueloculina lamarckiana d'Orbigny in De La Sagra, Hist. Phys. Pol. Nat. Cuba, Foraminifères, 1839, p. 189, pl. 11, figs. 14, 15; Recente, Cuba e Jamaica. Cushman, U. S. Nat. Mus., Bull. 104, pt. 6, 1929, p. 26. pl. 2, fig. 6; Recente, Região das Caraíbas. - Cushman e Moyer, Cush. Lab. Foram. Res. Cont. vol. 6, pt. 3, 1930, p. 52; Recente, Califórnia. - Cushman e Cahill, U. S. Geol. Surv. Prof. Paper 175-A, 1933, p. 9, pl. 2, figs. 2 a-c; Referências, Mioceno Inferior, formação Choctawhatchee, Flórida. - Palmer, Bull. Am. Pal., vol. 29, n. $^{0} 115,1945$, p. 29 , Mioceno Médio, formação Bowden, Jamaica. - Bermudez, Cush. Lab. Foram. Res. Sp. Publ. 25, 1949, p. 101, pl. 6, fig. 5; Mioceno Superior, formação Mao, São Domingos. - Redmond, Jour. Pal., vol. 27. n. ${ }^{\circ} 5$, 1953, p. 715, pl. 74, figs. 3 a-c; Mioceno Médio, formação Tubara, Colômbia.

Descriçĩo - A maior parte das quinqueloculinas do poço CR-1-PA, apresenta caracteres que permitem a classificação na espécie Q. lamarckiana d'Orbigny. Assim a testa possui o comprimento e a largura aproximadamente iguais, as cêumaras 10 tanto triangulares em secção transversal, com ângulos subaguclos; a parede é lisa, sem ornamentação e o dente é estreito e alongado.

OCORRÊncia - Esta espécie é comum no poco C'R-1-PA, ocorrendo nos seguintes testemumhos de sondagem: test. $n .^{\circ} 6$, intervalo $500 \mathrm{~m} 503 \mathrm{~m}$, test. n. $^{\circ} \overline{\mathrm{\gamma}}, 503 \mathrm{~m} 506 \mathrm{~m}$, test. n. ${ }^{\circ} 9,617 \mathrm{~m} 620 \mathrm{~m}$, test. n. ${ }^{\circ} 11,623 \mathrm{~m} 626 \mathrm{~m}$, test. n. ${ }^{\circ} 12,730 \mathrm{~m} 736 \mathrm{~m}$, e duvidòsamente nos test. n. ${ }^{\circ} 21,1158 \mathrm{~m} 1160 \mathrm{~m}$, e test. n. ${ }^{\circ} 23,1161 \mathrm{~m} 1162 \mathrm{~m}$. 
Ocorre também em amostras de calha dos seguintes intervalos: $253 \mathrm{~m}-602 \mathrm{~m}, 641 \mathrm{~m} 710 \mathrm{~m}, 735 \mathrm{~m} \quad 800 \mathrm{~m}, 848 \mathrm{~m}-876 \mathrm{~m}, 890 \mathrm{~m}$ $908 \mathrm{~m}, 930 \mathrm{~m} 950 \mathrm{~m}, 970 \mathrm{~m} 980 \mathrm{~m}, 990 \mathrm{~m} 994 \mathrm{~m}, 1010 \mathrm{~m} 1020 \mathrm{~m}$, $1100 \mathrm{~m} 1120 \mathrm{~m}$, e $1222 \mathrm{~m} 1240 \mathrm{~m}$.

Dimensões - As dimensões medidas em 3 espécimes são: 1) Comprimento $0.62 \mathrm{~mm}$, largura $0.59 \mathrm{~mm}$, espessura $0.48 \mathrm{~mm}$; 2) Comprimento $0.62 \mathrm{~mm}$, largura $0.53 \mathrm{~mm}$, espessura $0.48 \mathrm{~mm}$; 3) Comprimento $0.34 \mathrm{~mm}$, largura $0.25 \mathrm{~mm}$, espessura $0.32 \mathrm{~mm}$.

Discussão - Esta espécie é bem representada na região das Antilhas onde vive atualmente. Cushman (1929 a pp. 26-27) nota que, nas Antilhas, aparecem duas formas que talvez possam ser distintas. Uma delas tem o ângulo agúdo e a superfície polida e a outra é rombuda e a superfície é opaca. Os espécimes brasileiros possuem ângulos rombudos e superfície polida. Talvez os ângulos sejam rombudos devido a erosão.

Plesiótipos - L. P - C. N. P 1-88.

\section{Quinqueloculina seminula (Lineu)}

Est. I - Figs. 18-23

Serpula seminulum, Lineu, Syst. Nat. ed. 10, 1785, p. 786; Recente, Adriático.

Quinqueloculina seminulum (Lineu), d'Orbigny, Ann. Sci. Nat. vol. 7, 1826, p. 303; Recente, Mediterrâneo; Plioceno, Itália. - Cushman e Cahill, U. S. Geol. Surv., Prof. Paper 175-A, 1933, p. 9, pl. 2, figs. 2 a-c; Mioceno Inferior, formação Choctawhatchee, Flórida. - Galloway e Heminway, New York Acad. Sci., Sci. Survey Porto Rico and Virgin Ids., vol. 3, pt. 4, 1941, p. 305, pl. 2, fig. 8; Oligoceno, formações San Sebastian e Cibao, Porto Rico, Clapp, Maryland Dept. Geol. Mines and Water Res. Bull. 2, 1948, pp. 280-281, pl. XXIX, figs. 2 a-c; Referências, Mioceno, Maryland. - Bermudez, Cush. Lab. Foram. Res. Sp. Publ. 25, 1949, p. 102, pl. 6, fig. 6; Oligoceno Superior, São Domingos. - Mem. Soc. Cubana Hist. Nat., vol. XIX, n. ${ }^{\circ} 3,1950$, p. 356, Oligoceno Médio - Recente, Cuba.

Descriçĩo - Q. seminula (Lineu) foi redefinida por Cushman (1929 b pp. 59-60) e compreende formas lisas com a extremidade apertural truncada e abertura com um dente simples.

OCorrência - Esta espécie aparece no poço CR-1-PA, nos seguintes testemunhos de sondagem: test. n. ${ }^{0} 6,500 \mathrm{~m} 503 \mathrm{~m}$, test. n. $^{\circ} 7,503 \mathrm{~m} 506 \mathrm{~m}$. Ocorre também em amostras de calha, nos seguintes intervalos: $250 \mathrm{~m} 253 \mathrm{~m}, 261 \mathrm{~m} 286 \mathrm{~m}, 305 \mathrm{~m}-320 \mathrm{~m}$, $340 \mathrm{~m}-365 \mathrm{~m}, 404 \mathrm{~m} 502 \mathrm{~m}, 510 \mathrm{~m}-540 \mathrm{~m}, 552 \mathrm{~m}-570 \mathrm{~m}, 656 \mathrm{~m}$ $665 \mathrm{~m}, 684 \mathrm{~m} 703 \mathrm{~m}, 761 \mathrm{~m} 818 \mathrm{~m}, 840 \mathrm{~m}-871 \mathrm{~m}, 1080 \mathrm{~m} 1103 \mathrm{~m}$, $1140 \mathrm{~m} 1149 \mathrm{~m}, 1258 \mathrm{~m} 1270 \mathrm{~m}, 1318 \mathrm{~m} 1330 \mathrm{~m}, 1578 \mathrm{~m} 1596 \mathrm{~m}$. 
Dinessões - As dimensões medidas em 3 exemplares foram:

1) Comprimento $0.98 \mathrm{~mm}$, largura $0.48 \mathrm{~mm}$, espessura $0.44 \mathrm{~mm}$;

2) Comprimento $0.56 \mathrm{~mm}$, largura $0.31 \mathrm{~mm}$, espessura $0.21 \mathrm{~mm}$;

3) Comprimento $0.48 \mathrm{~mm}$, largura $0.25 \mathrm{~mm}$, espessura $0.17 \mathrm{~mm}$.

Discussĩo - As câmaras de alguns indivíduos de Cururú são ligeiramente angulares, enquanto na forma típica elas são arredondadas. Contudo o caráter ligeiramente angular das câmaras ainda está dentro da definição da espécie de acôrdo com Cushman. Esta espécie é espalhada por todo o Atlântico, sendo mais comum, entretanto, em zonas temperadas. No trabalho de Cushman e Parker (1931) sôbre a costa da América do Sul ela não é citada.

$$
\text { Plesiótipos - L. P - C. N. P 1-89. }
$$

\section{Quinqueloculina sp}

Est. 1 - Fig. 24 ; Est. 2 - Figs. 1-2

Descrição - Entre os indivíduos pertencentes ao gênero Quinqueloculina provenientes do poço CR-1-PA, existem espécimes que se caracterisam por serem muito alongados e deprimidos. $O$ estado de conservação não permite a avaliação de todos os seus caracteres.

OCORRÊNCIA - Êles ocorrem em amostras de calha dos seguintes intervalos: $262 \mathrm{~m} 265 \mathrm{~m}, 350 \mathrm{~m} 353 \mathrm{~m}, 594 \mathrm{~m} 600 \mathrm{~m}$.

Dimensões - As dimensões dos espécimes são: 1) Comprimento $0.73 \mathrm{~mm}$, largura $0.25 \mathrm{~mm}$, espessura $0.16 \mathrm{~mm}$; 2) Comprimento $0.56 \mathrm{~mm}$, largura $0.25 \mathrm{~mm}$, espessura $0.13 \mathrm{~mm}$; 3) Comprimento $0.50 \mathrm{~mm}$, largura $0.20 \mathrm{~mm}$, espessura $0.18 \mathrm{~mm}$.

Discessão - Esta espécie lembra Q. laevigata d'Orbigny especialmente os exemplares figurados por Cushman e Parker (1931 pl. I, figs. 5-6) proveniente da costa do Brasil. O pequeno número de indivíduos não permite classificação segura.

Além das espécies de Quinqueloculina aqui figuradas e descritas existem diversos indivíduos que não se incluem em nenhuma das espécies acima. Êles não foram considerados devido ao pequeno número de exemplares.

Espécimes tipos - L. P - C. N. P $1-90$.

Spiroloculina concava nom. nov.

Est. 2 - Figs. 3-6

Spiroloculina planulata Cushman (non Lamarck) - U. S. Nat. Mus. Bul. 104, pt. 6, 1929, pp. 41-42, pl. 8, figs. 2-5; Referências; Recente, Atlântico. 
Descriçio - Testa alongada, periferia truucada formando ângulo aproximadamente reto com os lados. Câmaras visíveis cêrea de 6 de cada ladlo, aumentando ràpidamente de comprimento e espessura de modo que os lados são fortemente côncaros. O aumento em largura, ao contrário, é gradativo; as câmaras são bem projetantes na extremidade basal e ligeiramente, na apertural, não existindo, contudo, um pescoço distinto; elas possuem um esbôco trapesoidal, diminuindo a espessura da periferia para dentro, ocasionalmente com traços de costas na região apertural; suturas distintas, ligeiramente deprimidas; parede lisa, polida; a abertura é elítica. achatada, dotada de um dente em forma de estilete.

OCORRÊNCIA - Esta espécie é relativamente rara no poco CR1-PA, ocorrendo em amostras de calha, nos seguintes intervalos:

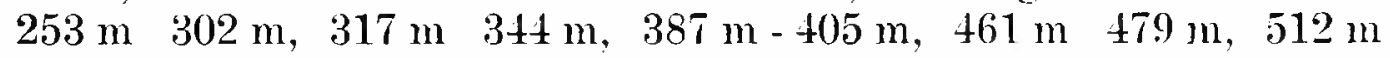
$529 \mathrm{~m}$.

Dinensões - As dimensões medidas em diversos espècimes são as seguintes: 1) Comprimento $1.40 \mathrm{~mm}$, largura $1.06 \mathrm{~mm}$, espessura $0.65 \mathrm{~mm}$; 2) Comprimento $1.23 \mathrm{~mm}$, largura $0.70 \mathrm{~mm}$, espessura $0.64 \mathrm{~mm}$; 3) Comprimento $1.01 \mathrm{~mm}$, largura $0.76 \mathrm{~mm}$, espessura $0.60 \mathrm{~mm}$; 4) Comprimento $0.87 \mathrm{~mm}$, largura $0.59 \mathrm{~mm}$, espessura $0.50 \mathrm{~mm}$; 5) Comprimento $0.42 \mathrm{~mm}$, largura $0.25 \mathrm{~mm}$, espessura $0.11 \mathrm{~mm}$; 6) Comprimento $0.28 \mathrm{~mm}$, largura $0.20 \mathrm{~mm}$, espessura $0.04 \mathrm{~mm}$.

Discussĩo - Esta espécie parece ser idêntica a descrita e figcurada por Cushman em sua monografia sôbre os foraminiferos do Oceano Atlântico (1929 a pp. 41-42, Est. 8, figs. 2-5) com o nome de S. planulata (Lamarck). Esta espécie tem sido citada em rrande número de localidades. Para cvitar estendermo-nos neste particular, indicamos a supracitada monografia de Cushman para referência completa das citações da espécie em trabalhos anteriores a 1929. Referências posteriores da espécie, na província caraíbica são as de Cushman (1930 p. 2, Est. 3, figs. 1 a, b), Cushman e Ponton (1932 p. 49) e Cushman e Cahill (1933 p. 10) que a citam no Mioceno de Flórida.

Em 1944, Cushman e Todd na monografia sôbre o gềnero Spiroloculina (1944 p. 76 ) adiantam que os tipos, descritos por Lamarck sob o nome de Miliolites plamulata, pertencem, realmente, ao gênero Quinqueloculina. Contudo êles silenciam sôbre as ilustrações de Cushman (1929 a Est. 8, figss. 2-4) "Spiroloculina planulata (Lamarck)", as quais pertencem realmente ao gênero spiroloculina e mereciam, por conseguinte, nome novo, e, que, são coespecíficas, a nosso ver, com a espécie do poso CR-1-PA. 
A espécie determinada por Parker, Jones e Brady, como $\$$. planulata (Lamarek), pertence, segundo Cushman (idem, p. 29) a S. depressa d'Orbigny, a qual, difere da nossa espécie, entre outros caracteres, por ser muito deprimida.

A espécie determinada por Cushman e Valentine como S. planulata (Lamarck), pertence, segundo Cushman (idem, p. 71) a S. dentata Cushman e Todd, a qual, difere da nossa espécie, entre outros caracteres, por possuir os lados achatados ou ligeiramente côncavos e ângulos da periferia distintamente carenados.

A espécie aqui considerada, a qual é idêntica a citada por Cushman (1929 a pp. 41-42) proveniente de material recente do Oceano Atlântico, bem como do Mioceno de Flórida (Cushman e Cahill 1933 p. 10), fica portanto sem denominação específica. Poderíamos manter o nome S. planulata, excluindo desta denominação específica, a espécie "Miliolites planulata Lamarck" Contudo esta maneira de proceder iria, a nosso ver, causar confusão com as citacões anteriores de $S$. planulata que davam como tipos, o material descrito por Lamarek. Preferimos, por conseguinte, adotar novo nome para esta espécie, ou seja, Spiroloculina concava.

Além desta espécie de Spiroloculina, aparecem ainda algumas formas do mesmo gênero as quais não tentamos determinação específica devido a raridade das mesmas.

\section{Plesiótipos - L. P - C. N. P 1-101. \\ Triloculina carinata d'Orbigny}

Est. 2 - Figs. 7-9

Triloculina carinata d'Orbigny in De La Sagra, Hist. Phys. Pol. Nat. Cuba, Foraminifères, 1839, p. 179, pl. 10, figs. 15.17; Recente, Cuba. - Cushman, Proc. U. S. Nat. Mus., vol. 59, 1921, p. 71, pl. 17, figs. 9, 10; Recente Jamaica. - Carnegie Instit. Washington, Publ. 311, 1922, p. 75, pl. 12, fig. 6; Recente, Tortugas. U. S. Nat. Mus., Bull. 104, pt. 6, 1929, p. 65, pl. 17, fig. 4; Recente, Atlântico. Palmer, Bull. Am. Pal., vol. 29, n. $^{\circ} 115,1945$, p. 31 ; Mioceno Médio, formação Bowden, Jamaica. - Bermudez, Cush. Lab. Foram. Res., Sp. Publ. 25, 1949, pp. 1l1-112, pl. 6, fig. 13; Mioceno Médio, formação Gurabo, São Domingos.

DESCRIÇão - Esta espécie é muito característica pela superfície reticulada, periferia carenadid, mas não truncada e abertura alongada, estreita, com um distinto lábio virado para fora e sem ornamentação e com um dente longo e estreito.

OCORRÊNCIA - Esta espécie é rara no poço CR-1-PA, tendo sido encontrados sòmente 3 indivíduos, em amostras de calha, respectivamente dos seguintes intervalos: $280 \mathrm{~m} 283 \mathrm{~m}, 342 \mathrm{~m} 345 \mathrm{~m}$, $350 \mathrm{~m} \quad 353 \mathrm{~m}$. 
Dimensões - As dimensões do indivíduo figurado foram as seguintes: Comprimento $1.00 \mathrm{~mm}$, largura $0.70 \mathrm{~mm}$, espessura $0.31 \mathrm{~mm}$.

Discussĩo - Esta espécie foi descrita por d'Orbigny de praias de Cuba. Cushman (1929 p. 66) adianta que ela é comum e largamente distribuída nas Antilhas. Ela é muito característica, não sendo conhecida em sedimentos mais antigos que o Mioceno, constituindo portanto mais $\mathrm{um}$ argumento para considerar os sedimentos. de Cururú que a contém, como do Cenozoico Superior.

Plesiótipos - L. P - C. N. P 1-108.

\section{Triloculina sp}

Est. 2 - Figs. 10-12

Descrição - As espécies de Triloculina que aparecem no poço de Cururú, são tôdas fracamente representadas na associação aqui descrita. Além da espécie descrita atrás (Triloculina carinata d'Orbigny), existem pelo menos 3 formas diferentes. Uma forma alongada e angular do tipo de $T$ tricarinata d'Orbigny, outra alongada e arredondada do tipo de $T$ oblonga (Montagu) e uma terceira forma curta e entumescida, do tipo de T. rotunda d'Orbigny. Estas formas além de serem raras estão imperfeitamente conservadas não sendo claro o caráter da abertura e do dente, razão porque não se tentou classificação específica. Figuramos a espécie do tipo de $T$ rotunda d'Orbigny por ser a que está melhor conservada.

OCORRÊNCia - Ela se distribue no poço CR-1-PA, nos seguintes intervalos, em amostras de calha: $265 \mathrm{~m} 268 \mathrm{~m}, 353 \mathrm{~m} 356 \mathrm{~m}$, $387 \mathrm{~m} \quad 409 \mathrm{~m}, 500 \mathrm{~m} \quad 503 \mathrm{~m}$.

Dinensões - $O$ comprimento do espécime figurado é de $0.29 \mathrm{~mm}$.

Espécimes tipos - L. P - C. N. P 1-109.

Pyrgo of inornata (d'Orbigny)

Est. 2 - Figs. 13-16

Biloculina inornata d'Orbigny, Foram. Foss. Vienne, 1846, p. 266, pl. 16, figs. 7-9; Mioceno Médio, Viena.

Pyrgo inornata (d'Orbigny) -- Howe e Wallace - Louisiana Geol. Bull., vol. 2, 1932, p. 21; Oligoceno, Mississippi. - Cushman e Mc Glamery, U. S. Geol. Surv. Prof. Paper 189-D, 1938, p. 104, pl. 24, figs. 6-7; Oligoceno, Alabama. Galloway e Heminway, The New York Acad. Sci., vol. III, pt. 4, 1941, p. 311, pl. 4, figs. 3 a-c; Mioceno Inferior, Porio Rico. - Cushman e Frizzell, Cush. Lab. Foram. Res., Contr. 1943, vol. 19, pt. 4, pp. 82-83, pl. 14, fig. 3; Oligoceno, Estado de Washington. - Cushman e Stainforth, Cush. Lab. Foram. Res., Sp. Publ. n.o 14, 1945, p. 21, pl. 2, fig. 21; Oligoceno, Trinidad. 
Descrição - Existem, no poço CR-1-PA, alguns indivíduos, pertencentes ao gênero Pyrıo, os quais pelo caráter alongado e entumeseido das câmaras, estreito na frente e alargado atrás e dente bifurcado cobrindo parcialmente a abertura, lembra a espécie descrita por d'Orbigny como Biloculina inornata, proveniente do Mioceno da bacia de Viena. Identificação mais segura não pode ser feita devido estar a maioria dos fósseis quebrados. Algumas testas estão deprimidas. Êste caráter talvez seja secundário sendo produzido por deformação.

OCORRÊAcIA - A espécie é rara no poço CR-1-PA, ocorrendo, em amostras de calha dos seguintes intervalos: $263 \mathrm{~m} 267 \mathrm{~m}$, $288 \mathrm{~m} 298 \mathrm{~m}, 314 \mathrm{~m}-317 \mathrm{~m}, 335 \mathrm{~m} 338 \mathrm{~m}, 354 \mathrm{~m} 357 \mathrm{~m}, 369 \mathrm{~m}-$ $372 \mathrm{~m}$.

Drmensões - As dimensões medidas em 2 espécimes foram: 1) Comprimento $0.53 \mathrm{~mm}$, largura $0.39 \mathrm{~mm}$, espessura $0.32 \mathrm{~mm}$;

2) Comprimento $0.45 \mathrm{~mm}$, largura $0.36 \mathrm{~mm}$, espessura $0.22 \mathrm{~mm}$.

$$
\text { Plesiótipos - L. P C. N. P 1-86. }
$$

\section{Pyrgo subsphaerica (d'Orbigny)}

Est. 2 - Figs. 17-19

Biloculina subsphaerica d Orbigny. in De La Sagra, Hist. Phys. Pol. Nat. Cuba, Foraminifères, 1839, p. 162, pl. 8, figs. 25.27; Recente, Cuba e Jamaica. Cushman, Publ. 311, Carnegie Instit. Washington, 1922, p. 77, Recente, Tortugas. Publ. 344, 1926, p. 83; Recente. Porto Rico.

Pyrgo subsphaerica (d'Orbigny), Cushman, U. S. Nat. Mus., Bull. 104, pt. 6, 1929. p. 68, pl. 18, figs. 1, 2; Recente, Caraibas. - Palmer, Bull. Arr. Pal., vol. 29, n. ${ }^{\circ} 115,1945$, p. 33; Mioceno Médio, formação Bowden, Jamaica. - Bermudez, Cush. Lab. Foram. Res., Sp. Publ. 25, 1949, p. 113, pl. 6, fig. 45; Oligoceno Superior, formação Trinchera, São Domingos. - Mem. Soc. Cubana Hist. Nat., vol. XIX, n. ${ }^{\circ}$ 3, 1950, p. 355; Mioceno - Recente, Cuba.

(Non) Pyrgo subsphaerica (d'Orhigny), Cushman e Parker, Proc. U. S. Nat. Mus., 1931, vol. 80 , Art. 3, p. 5, pl. I, figs. 13 a. b; Recente, costa atlântica da América do Sul. - Cushman e Gray, Cush. Lab. Foram. Res., Sp. Publ. 19, 1946, pp. 7, 10. - Cuvillier e Szakall, Foraminifères d'Aquitaine, pt. 1, 1949, p. 45, pl. 20, fig. 2; Mioceno, França.

Descrição - Esta espécie que é a mais característica do gêmero Pyrgo para a província caraíbica está regularmente representada na fauna do poço CR-1-PA. A forma bojuda. ligeiramente mais alongada que larga, com periferia arredondada, parede lisa sem ornamentação e dente bifurcado cobrindo só parcialmente a abertura longamente oval, são cararterísticos da espécie. 
Ocorrência - A espécie ocorre no poço CR-1-PA, tanto em testemunhos de sondagem como em amostras de calha. Ela aparece nos seguintes testemunhos de sondagem: Test. n. ${ }^{\circ} 6$, intervalo $500 \mathrm{~m} 503 \mathrm{~m}$, test. n. ${ }^{0} 7$, intervalo $503 \mathrm{~m} 506 \mathrm{~m}$. Ocorre também em amostras de calha, nos seguintes intervalos: $250 \mathrm{~m} 652 \mathrm{~m}$, $780 \mathrm{~m} 799 \mathrm{~m}, 1219 \mathrm{~m} 1233 \mathrm{~m}, 1310 \mathrm{~m} 1318 \mathrm{~m}, 1498 \mathrm{~m} 1525 \mathrm{~m}$.

Dimensões - As dimensões de 2 espécimes são: 1) Comprimento $1.06 \mathrm{~mm}$, largura $1.00 \mathrm{~mm}$, espessura $0.86 \mathrm{~mm}$; 2) Comprimento $0.25 \mathrm{~mm}$, largura $0.21 \mathrm{~mm}$, espessura $0.20 \mathrm{~mm}$.

Discussão - Cushman (1929 p. 68) cita a espécie como vivente em Jamaica, Cuba, Pôrto Rico, região das Tortugas, e em numerosas estações da costa da Flórida e das Bahamas. Cushman e Parker (1931 p. 5) citam a espécie como rara ao longo da costa da América do Sul até o Rio de Janeiro. A ilustração que êles dão para a espécie na América do Sul, (Idem, Est. I, fig. 13), indica uma forma um tanto mais alongada que a forma típica. Na relação das formas do Pacífico dada por Cushman (1932 pp. 61-67) não aparece a espécie. Ainda que Cushman e Gray (1946 pp. 7, 10) citem a espécie como rara (uџ único indivíduo) no Plioceno da Califórnia, o único espécime citado por êles não parece ser típico. Cuvillier e Szakall (1949 p. 45) citam a espécie como rara no Mioceno da França. Ela não parece contudo ser típica nesta última localidade. Ela só aparece portanto, sob sua forma típica, na província caraíbica onde é comum tanto como fóssil como forma vivente.

$$
\text { Plesiótipos - L. P - C. N. P. 1-8T. }
$$

\section{Cornuspira sp}

Est. 2 - Figs. 20-21

Descriçio - Testa pequena, planispiralmente enrolada, muito deprinida, com abertura elítica em seccão sendo a face apertural mais larga que alta, com os lados da testa ligeiramente convexos; a testa é constituída por poucas voltas visíveis (cêrca de 3 ) que aumentam ràpidamente de largura; periferia arredondada, suturas distintas, ligeiramente deprimidas; parede calcárea imperfurada.

OCoRrêncIa - O gênero Cormuspira é raro na província caraíbica, sendo representado por pequeno número de espécies. A fauna de Cururú não foge a regra. Somente 2 indivíduos foram obtidos no citado poco, ambos em amostras de calha, um no intervalo de $259 \mathrm{~m} 262 \mathrm{~m}$, e outro no intervalo $354 \mathrm{~m}-357 \mathrm{~m}$. 
Dimensões - As dimensões, medidas no indivíduo melhor conservado, o qual é o figurado são as seguintes: Diâmetro $0.20 \mathrm{~mm}$, espessura $0.08 \mathrm{~mm}$.

Discussão - A espécie de Cururú parece diferir das outras espécies conhecidas do mesmo gênero, contudo a raridade de espécimes obtidos não permite. identificação segura.

Espéchnes tipos - L. P - C. ^. P 1-28.

\section{Robulus ef snileyi Kleinpell}

Est. 3 - Figs. 1-2 14. a, b.

Robulus smileyi Kleinpell, Am. Ass. Petr. Geol., 1939, p. 202, pl. 15, figs.

Descrição - Testa grande, intimamente enrolada, involuta em ambos os lados, espêssa; periferia aguda, as vêzes não carenada, as vêzes com uma carena estreita ; área umbilical distintamente elevada, coberta por uma região clara, grande e transparente onde pode-se ver as voltas anteriores; câmaras distintas, geralmente 13 na última volta do corpo; suturas distintas, limbadas, retas ou gentilmente curvas na parte mais nova da testa, niveladas com a superfície da testa; parede lisa; a abertura não poude ser observada devido ao estado fragmentário do nosso material.

OCorrência - Esta espécie é relativamente comum no poço CR-1-PA, ocorrendo em amostras de ealha dos seguintes intervalos: $253 \mathrm{~m} 277 \mathrm{~m}, 298 \mathrm{~m} 301 \mathrm{~m}, 335 \mathrm{~m}-341 \mathrm{~m}, 354 \mathrm{~m} 357 \mathrm{~m}, 366 \mathrm{~m}$ $375 \mathrm{~m}, 442 \mathrm{~m}-460 \mathrm{~m}$.

Dimensões - As dimensões medidas no exemplar figurado são: Diâmetro menor $1.04 \mathrm{~mm}$, espessura $0.81 \mathrm{~mm}$. Não foi possível medir o diâmetro maior, devido estar, a concha, quebrada.

Discussĩo - $O$ estado fragmentário do material, não permite um seguro diagnóstico específico. Há contudo semelhança estreita com a espécie de Kleinpell.

Plesiótipos - L. P - C. N. P 1-94.

Robulus ef smileyi Kleinpell var. panciloculata Petri var. nov. Est. 3 - Figs. 3-4

Descriçio - Entre o material pertencente ao gênero Robulus foram separados 3 indivíduos, que diferem dos restantes, por pos. 
suírem sòmente 7 câmaras na última volta, enquanto em outros caracteres não diferem essencialmente dos outros exemplares.

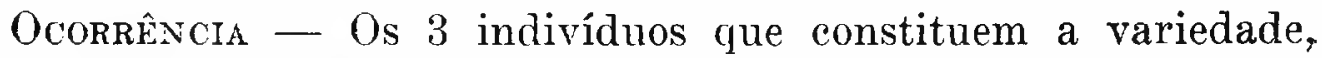
ocorrem em amostra de calha do intervalo $288 \mathrm{~m} 294 \mathrm{~m}$.

Dimensões -- As dimensões medidas no exemplar figurado são: Diâmetro menor $1.20 \mathrm{~mm}$, espessura $0.55 \mathrm{~mm}$. Não foi possível medir o diâmetro maior devido estar, o espécime, quebrado.

Holótipo - L. P - C. N. P 1-95.

Marginulina of planata Phleger e Parker

Est. 3 - Figs. 5-6

Marginulina planata Phleger e Parker, Geol. Soc. Am. Mem. 45, pt. II, 1951, p. 9, pl. 4, figs. 21,22 ; pl. 5, figs. 1-3.

Descrição - Testa pequena, deprimida, parte mais antiga da testa intimamente enrolada; parte mais jovem com uma ou duas. câmaras unisseriais; câmaras aumentando gradativamente de tamanho, cêrca de 7 na última volta do corpo; suturas limbadas, niveladas com o resto da testa, atravessadas por costelas longitudinais por tôda a extensão da testa, cêrca de 10 de cada lado, com os espaços intercostelares mais largos que as costelas. O desenvolvimento destas costelas são variáveis de acôrdo com o indivíduo. A periferia é dotada de uma carena estreita; abertura radial, periferal.

OCORRÊNCIA - Esta espécie é relativamente rara no poço CR1-PA, ocorrendo em amostras de calha dos seguintes intervalos: $268 \mathrm{~m} 277 \mathrm{~m}, 369 \mathrm{~m}-372 \mathrm{~m}, 405 \mathrm{~m}-423 \mathrm{~m}, 442 \mathrm{~m}-460 \mathrm{~m}, 473 \mathrm{~m}$ $482 \mathrm{~m}, 594 \mathrm{~m} 600 \mathrm{~m}$.

Dimensões - As dimensões, medidas no exemplar figurado, são: Comprimento $0.56 \mathrm{~mm}$, largura $0.31 \mathrm{~mm}$, espessura $0.13 \mathrm{~mm}$. O exemplar está quebrado sendo o comprimento um tanto incompleto.

Discussão - Os nossos exemplares pelo caráter comprimido da testa, com periferia dotada de uma carena fina, suturas limbadas e niveladas com o resto da testa e tipo de ornamentação se aproximam da espécie $M$. planata Phleger e Parker a qual foi descrita recentemente por aquêles autores (1951 p. 9), como espécie vivente do Gôlfo do México. Caso os nossos indivíduos pertençam realmente a esta espécie, é a primeira vez que ela é registrada como fóssil, o que não é de extranhar visto ser uma espécie só descrita 
recentemente sendo provável que tenha passado desapercebida no material fóssil descrito. Nenhuma das espécies fósseis de Marginulina descritas da província caraíbica se assemelha aos nossos exemplares.

$$
\text { Plesiótipos - L. P - C. N. P 1-it. }
$$

\section{Astacolus cf insolitus (Schwager)}

Est. 3 - Fig's. $7-8$

Cristellaria insolita Schwager, Novara Exped. Geol. Theil, vol. 2, 1866, p. 242, pl. 6, fig. 85; Plioceno, Kar Nikobar, India.

Cristellaria crepidula Brady, (non Fichtel e Moll), Rep. Voy. Challenger Zool. 9, 1884, pl. 67, fig. 17 (non 19, 20); Recente.

Astacolus insolitus (Schwager), Galloway e Heminway, The New York Acad. Sci., vol. III, pt. 4, 1941, p. 334, pl. 8, figs. 9 a, b; Oligoceno formação Ponce, Porto Rico.

Marginulina insolita (Schwager), Cushman e Todd, Cush. Lab. Foram. Res., Sp. Publ. 15, 1945, p. 19, pl.3, fig. 7; Mioceno Médio, formação Buff Bay Jamaica.

Descrição - Testa um tanto alongada, muito deprimida ; câmaras mais antigas intimamente enroladas, câmaras mais jovens tendendo a se tornar alargadas e desenroladas; periferia subangular, tendendo para arredondada nas últimas câmaras; câmaras distintas, cêrca de 9 visíveis, alargando-se consideràvelmente a medida que são adicionadas na forma adulta, e alongando-se menos ràpidamente; suturas distintas, ligeiramente deprimidas, ligeiramente limbadas e ligeiramente curvas; parede lisa, finamente perfurada; abertura radial, periferal.

OcorRÊncIA - Esta espécie é rara no poço CR-1-PA, ocorrendo em amostras de calha dos seguintes intervalos : $274 \mathrm{~m} 277 \mathrm{~m}, 387 \mathrm{~m}$ $405 \mathrm{~m}$.

Dumensões - As dimensões, mediclas no espécime figurado são: Comprimento $0.53 \mathrm{~mm}$, largura $0.28 \mathrm{~mm}$, espessura $0.12 \mathrm{~mm}$.

Discussão - A posição das suturas e a forma alongada e muito deprimida são muito características o que aproxima os nossos cxemplares, da espécie $A$. insolitus (Schwager). Êste gênero pôsto em sinonímia de Robulus, Lenticulina ou Marginulina por Cushman, tem sido revivido por diversos autores como Glaessner, Galloway, etc.

$$
\text { Plesiótipos - L. P - C. N. P } 1-9 .
$$




\section{Nodosaria sp}

Descrição - Foram achados, no poģo CR-1-PA, 2 fragmentos de foraminíferos de testa calcárea, unisserial; um dos fragmentos mostra sòmente 2 câmaras ainda assim fragmentadas, ornamentadas por costelas longitudinais grossas e relativamente numerosas, atravessando as suturas entre as câmaras sem sofrer interrupção. Elas são em número de 10. Os espaços intercostelares são mais largos que as costelas. A ornamentação é do tipo de $N$. affinis Reuss.

$O$ segundo fragmento mostra também 3 câmaras ornamentadas por costelas longitudinais também com espaços intercostais mais largos, contudo mais finos e numerosos do que o espécime acima citado, cêrea de 20. Elas são interrompidas nas suturas entre as câmaras. A ornamentação é do tipo de $N$ spinicosta d'Orbigny.

$O$ estado fragmentário dêsses fósseis não permite a verificação do caráter da abertura.

Como se deduz do expôsto o gênero Nodosaria é escassamente representado no poco CR-1-PA, podendo ser despresado do conjunto da associação faunística. Não ilustramos o material devido ao estado fragmentário do mesmo.

Ocorrência - Ambos os indivíduos encontrados, provém de amostras de calha, respectivamente, dos seguintes intervalos : $274 \mathrm{~m}$ $277 \mathrm{~m}, 333 \mathrm{~m}-335 \mathrm{~m}$.

Espéchues tipos - L. P - C. N. P 1-115.

\section{Frondicularia sp}

Est. 3 - Fig. 9

Descriçĩo - A testa é deprimida, ligeiramente mais longa que larga, com extremidade inicial oval; a extremidade apertural está quebrada.

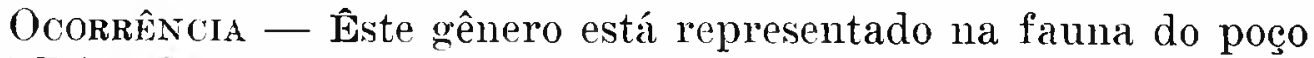
CR-1-PA, somente por um indivíduo, proveniente de amostra de calha, intervalo $250 \mathrm{~m} 253 \mathrm{~m}$.

Dimensões - Largura máxima $1.68 \mathrm{~mm}$. Não é possível medir o comprimento devido ao estado fragmentário do fóssil.

Discussĩo - As câmaras são largamente arredondadas na extremidade apertural, o que a diferencia da maioria das frondicularias descritas da região caraíbica, assemelhando-se neste particular a $F$ alazanensis Nuttall descrita do Oligoceno do México, ocorrendo 
também no Oligoceno da Venezuela e Trinidad. O único exemplar encontrado, ainda assim quebrado, não permite diagnose específica.

$$
\text { Espécime tipo - L. P - C. N. P } 1-51 .
$$

\section{Lagena aff bullosa Galloway e Heminway}

Est. 3 - Figs. 10-11

Lagena bullosa Galloway e Heminway, The New York Acad. Sci., vol III, pt. 4, 1941, pp. 345-346, pl. 11, figs. 10 a, b.

DESCRIÇÃo - Foram coletados em sedimentos do poço CR-1-PA, alguns indivíduos pertencentes ao gênero Lagena, eujos caracteres se aproximam dos da espécie L. bullosa descrita por Galloway e Heminway, de sedimentos do Oligoceno Superior e Mioceno Inferior de Pôrto Rico (1941 pp. 345-346). A ornamentação da testa, constituída por grânulos arredondados, é semelhante, apesar de que parece haver mais ordem na disposição dos grânulos em nossos espécimes. A testa é esferoidal sendo contudo mais alongada em nossos espécimes. Como na espécie supracitada, o pescoço é atravessado, em nossos espécimes, por curtas cristas transversais; contudo êle é muito mais curto nos exemplares brasileiros. Tôdas as pequenas diferenças apontadas acima parecem indicar que nossos espécimes pertencem a uma espécie distinta, afim contudo a $L$. bullosa Galloway e Heminway.

OCorrência - Esta espécie é rara no poego CR-1-PA, ocorrendo em amostra de calha do intervalo $262 \mathrm{~m} 2 \pi \mathrm{m}$.

Dhrensões - As dimensões medidas no espécime figurado, são: Comprimento $0.31 \mathrm{~mm}$, largura $0.22 \mathrm{~mm}$.

$$
\text { HoLótipo - L. P - C. N. P 1-70. }
$$

\section{Lagena cf perlucida (Montagu)}

Est. 3 - Figs. 12-13

Vermiculum perlucidum Montagu - Test. Brit. 1803, p. 525, pl. 14, fig. 3, Recente, costa da Inglaterra.

Lagena vulgaris Williamson var. perlucida Williamson, Rec. Foram. Great Britain, 1858, p. 5, pl. 1, figs. 7, 8; Recente, costa da Inglaterra.

Lagena perlucida (Montagu), Cushman, U. S. Nat. Mus., Bull. 104, pt. 4, 1923, p. 46, pl. 8, figs. 12, 13; Recente, costa da Irlanda. - Cushman e Gray, Cush. Lab. Foram. Res., Sp. Publ. 19, 1946, p. 18, pl. 3. figs. 17-20; Plioceno, Califórnia. 
Descriçĩo - Testa em forma de frasco, um tanto alongada, tendo na parte anterior um pescoço um tanto longo, estreitando-se gradativamente até o ápice, terminando por uma margem espessada e de diâmetro maior que o do pescoço. A maior parte da testa é lisa, brilhante, hialina e transparente, com exceção da parte basal, coberta por costas, aproximadamente em número de 20 , que se dirigem para cima, cêrca de um sexto do comprimento de tôda a testa. Esta parte basal é arredondada; a largura maior é no meio da testa.

OCORRÊncia - A espécie ocorre no poço CR-1-PA, no testemunho de sondagem número 9 , intervalo de $678 \mathrm{~m} 681 \mathrm{~m}$. Ela ocorre também em amostras de calha dos seguintes intervalos: $261 \mathrm{~m} 289 \mathrm{~m}, 306 \mathrm{~m}-319 \mathrm{~m}, 330 \mathrm{~m} 333 \mathrm{~m}$.

Dimensões - As dimensões, medidas no espécime figurado, são: Comprimento $0.34 \mathrm{~mm}$, largura $0.20 \mathrm{~mm}$.

Discussĩo - A nossa espécie parece ser idêntica a $L$. perlucida (Montagu), contudo as costelas basais são em nosso material mais desenvolvidas. Ela se assemelha também a $L$. vulgaris Williamson, forma vivente das costas da Inglaterra, principalmente a variedade semistriata Williamson, devido a ornamentação em costas sòmente na base da testa. Contudo as costas são muito mais numerosas e mais intimamente unidas em nossa espécie, o pescoço mais curto e a testa, proporcionalmente, mais entumescida. Ela se parece ainda com a espécie $L$. striata (Montagu) var. B. semistriata Williamsson também forma vivente descrita das costas da Inglaterra. A nossa espécie parece ser, proporcionalmente, mais entumescida, e o número de costelas basais é maior as quais são mais intinamente unidas.

Das espécies referidas da região caraíbica, não há nenhuma que se aproxime da nossa.

Plesiótipos - L. P - C. N. P 1-71.

\section{Lagena sp}

Est. 3 - Figs. 14-15

Descriçio - Foi coletado no poço CR-1-PA, um único indivíduo pertencente ao gênero Lagena o qual difere de outras lagenas do mesmo poço, pela ornamentação em costelas elevadas, cêrca de 20, as quais se estendem em todo o comprimento da testa.

OCorrîncia - O único indivíduo encontrado, provém de amostra de calha do poço CR-1-PA, do seguinte intervalo: $271 \mathrm{~m} 274 \mathrm{~m}$.

Dinensões -- Comprimento $0.17 \mathrm{~mm}$, largura $0.11 \mathrm{~mm}$. 
Discussĩo - Ela se assemelha a espécie $L$. amphora Reuss do Oligoceno germânico e L. ampulla Galloway e Heminway do Oligoceno Superior e Mioceno Inferior de Pôrto Rico. A semelhança é mais estreita com $L$. amphora Reuss devido ao número de costelas.

\section{EspécIMe tipo - L. P - C. N. P 1-72.}

No testemunho de sondagem $\mathbf{n}^{\circ}$ 6, do mesmo poço, intervalo $500 \mathrm{~m} 503 \mathrm{~m}$, foi encontrado um único indivíduo que parece também pertencer ao gênero Lagena. A testa é alongada, dotada de um pescoço curto e de um pequeno espinho na região basal, e a superfície é ornamentada por pequenos grânulos salientes. O fóssil não está bem conservado para ser fotografado.

\section{Fissmina laevigata Reuss}

$$
\text { Est. } 3 \text { - Figs. 16-17 }
$$

Fissurina laevigata Reuss, K. Akad. Wiss. Wien, Math - Nat. Cl., Denkschr., Viena, Austria, I850, vol. 1, p. 366 , pl. 46, figs. 1 a, b; Terciário, Alemanha.

Entosolaenia laevigata (Reuss), Cushman e Todd, Cush. Lab. Foram. Res., Sp. Publ. 15, 1945, p. 4l, pl. 6, fig. 17; Mioceno Médio, formação Buff Bay, Jamaica.

Lagena laevigata (Reuss) - Bermudez, Mem. Soc. Cubana Hist. Nat. vol. XIX, n. ${ }^{\circ}$ 3, 1950, p. 346; Oligoceno, formação Tinguaro, Cuba.

Descrição - Existem no poço CR-1-PA, diversas espécies que podem ser refericlas a êste gênero. A mais comum destas espécies é a que é referida acui a espécie $F^{r}$ laevigata Reuss. Ela pode ser distinguida prontamente das outras pela carena, estreita ou ausente, sendo a periferia, contudo, angular. Tôdas as outras espécies, provenientes do supracitado poço são distintamente carenadas. A testa é pequena, oval, larga e arredondada na base, afinando-se para a extremidade apertural. A abertura está situada na extremidade e é formada por uma estreita fenda transversal, cujas margens são espessadas. Ela se abre en num vestíbulo bem definido e separado do resto da testa.

Ocorrêxcia - Esta espécie é relativamente comum no poço CR-1-PA, ocorrendo, em amostras de calha, dos seguintes interralos: $262 \mathrm{~m} 289 \mathrm{~m}, 314 \mathrm{~m} 317 \mathrm{~m}, 329 \mathrm{~m}-354 \mathrm{~m}, 366 \mathrm{~m} \quad 369 \mathrm{~m}, 387 \mathrm{~m}$ $405 \mathrm{~m}, 503 \mathrm{~m} 511 \mathrm{~m}, 802 \mathrm{~m}-820 \mathrm{~m}$.

Dniensões - As dimensões mediclas em 2 espécimes são: Espécime figurado: comprimento $0.22 \mathrm{~mm}$, largura $0.18 \mathrm{~mm}$, espessura $0.17 \mathrm{~mm}$. Outro espécime : comprimento $0.14 \mathrm{~mm}$, largura $0.11 \mathrm{~mm}$, espessura $0.08 \mathrm{~mm}$. 
Discussĩo - o gênero Fissurina é aqui considerado de acôrdo com o conceito de Parr (1947 p. 128). O vestíbulo entre a abertura e o resto da testa é um tanto mais largo do que mostram as ilustrações de $F$ lacvigata Reuss, contudo os nossos espécimes são semelhantes a esta espécie em outros caracteres. Esta espécie vive atualmente no oceano Atlântico, tendo sido registrada próximo às costas da Inglaterra e do litoral norte-americano da Nova Inglaterra. Ela tem sido registrada como fóssil na região das Caraíbas desde o Oligoceno.

$$
\text { Plesiótipos - L. P. - C. N. P. 1-47. }
$$

\section{Fissurina marginata (Walker e Boys)}

$$
\text { Est. } 3 \text { - Figs. 18-19 }
$$

Serpula (Lagena) marginata Walker e Boys, Test. Minuta, 1784, p. 2, pl. 1, fig. 7; Recente.

Lagena marginata (Walker e Boys). Brady (Parte). Rep. Voy. Challenger. Zool., vol. 9, 1884, p. 476. pl. 59, fig. 22; Recente, Pacífico. - Bermudez, Mem. Soc. Cubana Hist. Nat. vol. 12, 1938, p. 14, Eoceno, Cuba. -- Idem, vol. XIX, n. ${ }^{\circ}$ 3, 1950, p. 346; Plioceno. Recente, Cuba. - Cush. Lab. Foram. Res.. Sp. Publ. 25, 1949, p. 117, pl. 10, figs. 56-58; Oligoceno Superior, formação Trinchera, São Domingos.

Lagena cf marginata (Walker e Boys) - Palmer, Bull. Am. Pal. vol. 29, n.o 115, 1945, p. 40; Mioceno Médio, formação Bowden, Jamaica.

Entosolaenia ef marginata (Walker e Boys), Cushman e Todd, Cush. Lab. Foram. Res., Sp. Publ. 15, 1945, p. 41. pl. 6, fig. 16; Mioceno Médio, formação Buff Bay, Jamaica.

Descriçĩo - A testa é quase circular, bem achatada, a extremidade basal largamente arredondada, extremidade apertural truncada; tôda a testa é circundada por uma carena moderadamente larga e transparente; parede lisa. abertura terminal, fissurina, dotada de nim lábio, sem peseogeo.

OCoRrênch - Esta espécie é relativamente rara no pogo CR-1-PA, ocorrendo em amostras de calha dos seguintes intervalos: $262 \mathrm{~m} 277 \mathrm{~m}, 341 \mathrm{~m} 344 \mathrm{~m}$.

Drinssões - As dimensões medidas no exemplar figurado são: Comprimento $0.21 \mathrm{~mm}$, largura $0.18 \mathrm{~mm}$, espessura $0.10 \mathrm{~mm}$.

Discussão - Os espécimes do poço CR-1-PA classificados como $F$ marginata (Walker e Boys) distinguem-se de outras espécies do mesmo gênero pela combinação do caráter liso da testa, a qual é deprimida, e pela presença de uma carena com desenvolvimento 
relativamente grande. Ela se aproxima das ilustrações dadas por Bermudez (1949, Est. 10, figs. 56-58) para a mesma espécie.

Convém notar que ela tem sido citada na literatura como espécie ora de autoria de Walker e Boys ora de autoria de Montagu. Cushman e Gray (1946 p. 30) cita, do Plioceno da Califórnia, Entosolaenia marginata (Montagu), espécie esta descrita em 1803 por Montagu com o nome de Vermiculum marginatum Montagu. 0 próprio Cushman juntamente com Todd (1945 p. 41) citam, do Mioceno de Jamaica, (Buff Bay), Entosolaenia marginata (Walker e Boys), espécie esta descrita por Walker e Boys em 1784 com o nome de Serpula (Lagena) marginata Walker e Boys. Parece que as duas citações se referem a mesma espécie. Deve-se manter, neste caso, o holótipo de Walker e Boys para esta espécie.

$$
\text { Plinsiótipos -- L. P - C. N. P 1-48. }
$$

Fissurina cf marginato-perfurata (Seguenza)

Est. 3 - Figs. 20-21

Lagena marginato-perfurata Seguenza, R. Accad. Lincei, Roma, Itália, ser. 3, vol. 6, 1880, p. 332, pl. 17, fig. 34; Plioceno, Itália. - Bermudez, Mem. Soc. Cubana, Hist. Nat. vol. XIX, n. ${ }^{\circ} 3,1950$, p. 346; Plioceno, Recente, Cuba.

Entosolaenia marginata-perfurata (Seguenza), Cushman, Flórida St. Geol. Surv. Bull. 4, 1930, p. 32 ; Mioceno, formação Choctawhatchee, Flórida. - Cushman e Todd, Cush. Lab. Foram. Res., Sp. Publ. 15, 1945, p. 41, pl. 6, fig. 18; Mioceno, Buff Bay, Jamaica.

DESCRIÇÃo - Testa deprimida, aproximadamente oval alongada com a maior largura próximo a base da testa; extremidade apertural ligeiramente projetante; periferia ligeiramente carenada; a parede da testa é coberta por grande número de perfurações bem visíveis, a parte central da testa sendo isenta de perfurações; a forma da testa e as perfurações bem visíveis tornam esta espécie bem distinta das outras do poço CR-1-PA.

OCorrência - Esta espécie é rara no poço CR-1-PA, ocorrendo em amostras de calha dos seguintes intervalos: $262 \mathrm{~m} 277 \mathrm{~m}$, $351 \mathrm{~m}-354 \mathrm{~m}$.

Dimensões - As dimensões medidas em 2 indivíduos são: Espécime figurado: Comprimento $0.28 \mathrm{~mm}$, largura $0.22 \mathrm{~m}$, espessura $0.11 \mathrm{~mm}$. Outro espécime: Comprimento $0.22 \mathrm{~mm}$, largura $0.17 \mathrm{~mm}$, espessura $0.13 \mathrm{~mm}$.

Plesiótipos - L. P - C. N. P 1-49. 


\section{Fissurina sp}

Est. 4 - Figs. 1-2

Descriçio - Testa pequena, oval em vista lateral, bem deprimida; extremidade apertural prolongada em um peseoco curto e grosso; periferia dotada de uma carena relativamente grande; a testa vista de perfil, mostra, na zona da periferia, uma crista central elevada, seguida, para os lados, por duas depressões marginadas, do lado de fora, por duas cristas; nota-se, portanto, três na periferia. Estas cristas são atravessadas transversalmente por estrias, as quais, provàvelmente são canais que atravessam a parede da carena. Êstes canais aparecem também na superfície da câmara. a qual vista de frente, mostra-se grosseiramente perfurada, sendo estas perfurações, provàvelmente, projeções dos supracitados canais. Estas perfurações são de densidade variável com o indivíduo, sendo que alguns possuem a parede quase isenta delas, apresentando-se. então, hialinas.

OCORRÊncia - Esta espécie é rara no poço CR-1-PA, ocorrendo em amostra de calha do intervalo $267 \mathrm{~m} 276 \mathrm{~m}$.

Dnrexsões - As dimensões medidas no exemplar figurado são: Comprimento $0.33 \mathrm{~mm}$, largura $0.2 \pm \mathrm{mm}$, espessura $0.08 \mathrm{~mm}$.

Discussĩo - Os nossos espécimes se aproximam da espécie descrita por Cushman como Lagena schwagcriana mas diferem pela carena mais estreita, pela periferia dotada de 3 cristas, pela parede com grossas perfuraçóes e por serem bem mais deprimidas. Pela periferia dotada de 3 cristas, se aproximam de $F$ subformosa Parr. descrita das costas da Antártida. Diferem desta espeécie, bem como da espécie afim $F$ formosa (Schwager), pelo pescoco bem mais curto e mais grosso, por serem mais deprimidos, pelas grossas perfurações da parede da testa e por serem menos alongados.

É possivel que os espécimes brasileiros representem uma nova espécie. Evitamos, contudo, dar-lhes um nome específico devido a raridade de espécimes a disposição. Êles podem ser imediatamente diferenciados de ontras fissurinas do poço CR-1-PA pela ornamentação característica.

Guttulina irregularis (d'orbigny) rar. contraria Petri var. nor.

Est. 4 - Figs. 3-5

Descriçĩo - Testa largamente piramidal a subdeltoidal formando um ânçulo obtuso na extremidade apertural, sendo largamente arredondada na base, onde está localisado o seu maior dîa- 
metro; o lado distal da última câmara possui um declive suave, enquanto o lado distal da penúltima câmara é mais largamente arredondado sendo o seu traçado quebrado pelo prolongamento da última câmara na direção da abertura. A testa, vista tanto do lado basal como apertural, é triangular, com lados e câmaras arredondados; câmaras alongadas, mais ou menos infladas, arranjadas de maneira contrária ao sentido dos ponteiros de relógio, cada câmara afastada muito pouco da base; suturas limbadas, um tanto deprimidas; parede um tanto espêssa, lisa; abertura radiada.

OCoRRÊncIa - Esta espécie é relativamente rara no poço CR1-PA, ocorrendo em amostras de calha dos seguintes intervalos: $274 \mathrm{~m} 280 \mathrm{~m}, 317 \mathrm{~m} 320 \mathrm{~m}, 328 \mathrm{~m}-334 \mathrm{~m}$.

Dimensões - As dimensões, medidas no exemplar figurado, são: Comprimento $0.64 \mathrm{~mm}$, largura $0.56 \mathrm{~mm}$, espessura $0.35 \mathrm{~mm}$.

Discussão - As guttulinas de Cururú parecem muito com os exemplares referidos a $G$. irregularis (d'Orbigny). A forma subdeltoidal é idêntica, as ristas basal e apertural são identicamente triangulares com ângulos e faces arredondados; os declives laterais das 2 últimas câmaras são idênticos sendo que o da penúltima câmara é identicamente quebrado pelo prolongamento da última câmara. Contudo, as câmaras em G. irregularis (d'Orbignỳ) são acrescentadas no sentido dos ponteiros do relógio enquanto na variedade brasileira elas são acrescentadlas em sentido contrário a dos ponteiros do relógio. Em outras palarras, a variedade contraria é especularmente idêntica a espécie $G$. irregularis (d'orbigny). Nesta última espécie, a abertura está a direita quando a vemos pelo lado que mostra as 4 últimas câmaras, enculunto na raviedarle contriria, está a esquerda.

$G$. irregularis (d'Orbigny) var. nippoensis Cushman e Ozawa do Plioceno do Japão, possue as câmaras acrescentaclas tanto no sentido dos ponteiros do relógio como no sentido inverso. Contudo ela difere da variedade brasileira pelo prolongamento de tôdas as câmaras até bem próximo da base havendo também tendência para as câmaras mais jovens envolverem as mais antigas. Êstes caracteres aproximam esta rariedade to gênero Sigmoidella. A julgar pela descrição e ilustraçoes, esta rariedade possue caracteres suficientemente distintos para se constituir como espécie a parte. A julgar pelo que acontece com outros foraminíferos, a indiferenca com que as câmaras são acrescentadas, no sentido dos ponteiros do relógio on no sentido inverso, nos indicaria estammos diante de uma espécie primitiva, sob ponto de vista da erolucão. inferior a espécie G. irregularis com um plano de enrolamento bem definido. 
Esta espécie é largamente distribuida tanto geográfica como geologicamente. Geològicamente ela se distribue do Cretaceo aos dias de hoje. Geograficamente ocorre em todo o mundo, sendo frequiente, na província caraíbica, do Eoceno aos dias de hoje.

$$
\text { Holótspo - L. P - C. N. P 1-67. }
$$

\section{Globulina sp}

Os exemplares aqui referidos ao gênero Globulina compreendem sòmente 2 indivíduos, um dos quais incompleto. têles provêm de amostra de calha, um dêles do intervalo $264 \mathrm{~m} 267 \mathrm{~m}$ e o outro do intervalo $274 \mathrm{~m} 277 \mathrm{~m}$. () primeiro possui a testa globular com secção transversal quase circular, podendo-se comparar com a espécie G. gibba d'Orbigny, enquanto o segundo é mais alongado, podendo-se comparar com $G$. inaequalis Cushman e Ponton. Contudo, a raridade dos exemplares e o estado de conservação dos mesmos, não permitem que se chegue a uma identificação segura. Pelas mesmas razões êles também não foram figurados.

Espéchmes - L. P - C. N. P 1-65.

\section{Pseudopolymorphina sp}

\section{Est. 4 - Figs. 6-8}

Descriçño - Testa alongada, um tanto deprimida; periferia arredondada; a largura maior está localisada no meio da testa afinando-se para as extremidades as quais são obtusas, sendo a extremidade basal a mais obtusa; câmaras alongadas, suturas niveladas com o resto da testa, limbadas; parede lisa, um tanto espêssa, as últimas câmaras não se afastam muito da base da testa.

Ocorrêncra - Esta espécie é rara no poro CR-1-PA, ocorrendo em amostras de calha dos seguintes intervalos: $261 \mathrm{~m} 270 \mathrm{~m}$, $386 \mathrm{~m} 404 \mathrm{~m}$.

Dramensóes - Dimensócs medidas em 2 indivíduos: Exemplar figurado: Comprimento $1.23 \mathrm{~mm}$, largura $0.56 \mathrm{~mm}$, espessura $0.23 \mathrm{~mm}$. Outro exemplar: Comprimento $0.16 \mathrm{~mm}$, largura $0.07 \mathrm{~mm}$, espessura $0.04 \mathrm{~mm}$.

Discussĩo - A fantilia Polymorphinidae é pobremente representada nos trabalhos que tratam dos foraminíferos da província caraíbica sendo também o caso na associacano de Cururú. Das poucas citações do gênero Pscudopolymorphina da província caraíbica. 
nenhuma se assemelha aos nossos fósseis. Das espécies provenientes de outras regiós, $P$. decora (Reuss) é a que mais se aproxima de nossos exemplares, pelo esbôço da testa, pelas câmaras alongadas e alternadas, quase bisseriais desde o princípio e pelas suturas não deprimidas, distintas. Na descrição de $P$ decora (Reuss) não está claro se as suturas são limbadas ou não. A espécie de Reuss é comum no Mioceno e Eoceno da França.

$$
\text { Fispécines tipos - L. P. - C. N. P 1-84. }
$$

\section{Nonion cf depressulum (Walker e Jacob)}

Est. 4 - Figs. 9-10

Nautilus depressulus Walker e Jacob in Adams Essays, Ed. Kanmacher 1798. p. 641, pl. 14, fig. 33; Recente, costas da Inglaterra.

Nonionina depressula Heron - Allen e Earland, Linnean Soc. London Trans., 1916, ser n.' 2, vol. 11, p. 279, pl. 43, figs. 4-7; Recente, costas da Inglaterra.

Nonion depressulum (Walker e Jacob), Cushman, U. S. Nat. Mus., Bull. 104, pt. 7, 1930, p. 3, pl. 1, figs. 3-6; Recente, Atlântico.

Descrição - Testa pequena, comprimida, completamente involuta; periferia subangular; câmaras distintas, geralmente em número de 12 na última volta do corpo, não infladas, aumentando progressivamente de tamanho; suturas distintas não limbadas, fortemente curvas; a região umbilical é ocupada por uma rôlha, as vêzes distinta, as vêzes indistinta; a abertura não é clara.

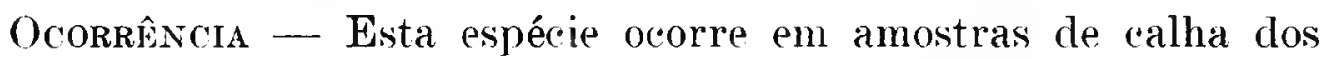
seguintes intervalos: $216 \mathrm{~m} 277 \mathrm{~m}, 310 \mathrm{~m} 313 \mathrm{~m}, 331 \mathrm{~m}-334 \mathrm{~m}$, $340 \mathrm{~m} 346 \mathrm{~m}, 368 \mathrm{~m} 374 \mathrm{~m}$.

Dimensões - Diâmetros medidos no exemplar figurado, cêrca de $0.31 \mathrm{~mm}$ e $0.25 \mathrm{~mm}$; espessura $0.08 \mathrm{~mm}$.

Discussĩo - Esta é a espécie de Tonion mais commmente encontrada no poco CR-1-PA. Ela se assemelha, principalmente pela forma das câmaras e suturas fortemente curvas, aos espécimes figurados por Heron-Allen e Earland (Em Cushman 1939, Est. 5, figs. 23-25) como $N$ depressulum (Walker e Jacob). Contudo, como nota Cushman (Idem, p. 21), os espécimes considerados por aquêles antores como $N$. depressulum diferem um tanto da figura do holótipo dada por Walker e Jacob (Em Cushman idem, Est. 5, figs. 22 a e b).

Os espécimes brasileiros são menos deprimidos, possuem periferia subangular e suturas sem evidêneia de serem limbadas, diferindo nesses caracteres, dos espécimes descritos de $N$ depressulum. Êles se distinguem de $N$. advenum (Cushman) e $T^{\top}$ havanense Cushman! 
e Bermudez principalmente pelo progressivo aumento do tamanho das câmaras.

A espécie $N$. depressulum vive atualmente nas costas do norte da Europa.

Plesiótipos - L. P. - C. N. P. 1-75.

Sonion aff pompilioides (Fichtel e Moll)

Est. 4 - Figs. 11-12

Nautilus pompilioides Fichtel e Moll, Test. Micr., 1798, p. 31, pl. 2, figs. a-c; Recente, Mediterrâneo.

Nonion pompilioides (Fichtel e Moll), Cushman, U. S. Nat. Mus., Bull. 104, pt. 7, 1930, p. 4, pl. 1, figs. 7-11; pl. 2, figs. 1, 2; Recente, Atlântico. - U. S. Geol. Surv. Prof. Paper 191, 1939, p 19, pl. 5, figs. 9-12; Referências. - Galloway e Heminway, New York Acad. Sci., vol. 3, pt. 4, 1941, p. 357, pl. 14, fig. 1; Oligoceno e Mioceno, Pôrto Rico. - Palmer, Bull. Am. Pal., vol. 29, n. ${ }^{\circ} 115$, 1945, p. 42; Mioceno Médio, formação Bowden, Jamaica. - Cushman e Stainforth, Cush. Lab. Foram. Res., Special Publ. 14, 1945, p. 35, pl. 5, fig. 8; Oligoceno, formação Cipero, Trinidad, B. W. I. - Bermudez, Cush. Lab. Foram, Res., Special Publ. 25, 1949, p. 167; Mioceno, São Domingos.

Descrição - Entre o nosso material proveniente do poço CR1-PA, existem alguns indivíduos que se assemelham a espécie $N$. pompilioides. A testa é planispiral, bilateralmente simétrica, inteiramente involuta, com umbílico profundamente excavado mas estreito, periferia largamente arredondada e com câmaras em número de 9 na última volta do corpo, de tamanho uniforme, aumentando gradualmente de tamanho. As suturas são niveladas com o resto da testa, limbadas, fundindo-se ao longo do umbílico para formar uma pequena área não elevada; parede lisa; a abertura é constituída por uma fenda larga e baixa na base da face apertural.

OCORRÊncra - A espécie aqui considerada, ocorre no poco CR-1-PA, em amostra de calha do intervalo $331 \mathrm{~m} 335 \mathrm{~m}$.

Dimensões - Diâmetros medidos no exemplar figurado: $0.3 \pm \mathrm{mm}$ e $0.28 \mathrm{~mm}$; espessura $0.16 \mathrm{~mm}$.

Discussĩo - Os espécimes brasileiros são mais deprimidos e a face apertural é um tanto mais alta que nos espécimes típicos, contudo esta espécie é conhecida como possuindo grande variação na espessura relativa da testa. A espécie $N$ pompilioides tem sido registrada, como vivendo atualmente, embora não sendo comum, na região do Mediterrâneo, em águas rasas, ocorrendo, espaçadamente, em águas profundas, no Atlântico, tanto do Norte como do Sul. Phleger e Parker (1951 p. 11) citam a espécie como vivendo no 
Gôlfo do México, a variedade bojuda em águas profundas e a deprimida em águas rasas.

$$
\text { TiPos - L. P - C. N. P 1-76. }
$$

Tonionella curvisulcata Petri sp nov.

Est. 4 - Figs. 13-15

DEscrição - São relativamente comuns no material do poço de Cururú, uma espécie de Nonionella que se assemelha a $N$. atlantica descrita por Cushman (1947 pp. 90-91).

A testa é deprimida, assimétrica, dotada de periferia arredondada, o lado dorsal mostrando as voltas anteriores, as quais são cobertas no lado ventral; as câmaras são em número de 10 a 12 na forma adulta, na última volta do corpo, podendo diminuir para 7 nas formas jovens; elas são ligeiramente infladas, aumentando gradualmente de tamanho; suturas distintas, ligeiramente deprimidas, distintamente curvas; parede lisa, exceto o lobo do lado ventral da câmara, que se dirige para o umbílico, que é papiloso; a abertura não é clara no nosso material.

OCorrência - Esta espécie ocorre, em amostras de calha do poço CR-1-PA, nos seguintes intervalos : $261 \mathrm{~m} 292 \mathrm{~m}, 344 \mathrm{~m}-347 \mathrm{~m}$, $365 \mathrm{~m} 368 \mathrm{~m}, 1408 \mathrm{~m} 1420 \mathrm{~m}$.

Dimensōes - Os diâmetros em média são: $0.29 \mathrm{~mm}$ e $0.23 \mathrm{~mm}$; espessura em média $0.15 \mathrm{~mm}$.

Discussĩo - Esta espécie se assemelha a $N$. atlantica Cushman. Contudo a testa em nosso material é menos alongada e as suturas são mais curvas que na espécie de Cushman. Êste gênero é pouco encontradiço, como fóssil, na província caraíbica.

HоLótIPo - L. P - C. N. P 1-7

Elphidium advenum (Cushman)

Est. 4 - Figs. 16-17

Polystomella subnodosa Brady (Non Von Münster), Challenger Rep., Zool., vol. 9, 1884, p. 734, pl. 110, figs. 1 a, b. - Chapman, Linnean Soc. London Jour., Zool., vol. 28, 1902, p. 203.

Polystomella advena Cushman, Carnegie Instit. Washington, Publ. 311, 1922, p. 56, pl. 9, figs. 11, 12; Recente, Tortugas, Flórida. - Publ. 342, 1924, p. 48; Recente, Samoa. - Publ. 344, 1926, p. 80; Recente, Pôrto Rico. 
Elphidium advenum (Cushman), Cushman, U. S. Nat. Mus., Bull. 104, pt. 7, 1930. p. 25, pl. 10, figs. 1, 2; Recente, Atlântico. - Flórida Geol. Surv. Bull. 4, 1930, p. 40, pl. 7, fig. 7; Mioceno Inferior, formação Choctawhatchee, Flórida. Palmer e Bermudez, Mem. Soc. Cubana Hist. Nat., vol. 9, 1935, p. 246; Mioceno Superior, Cuba. - Cushman, U. S. Geol. Surv., Prof. Paper 191. 1939, p. 60, pl. 16, figs. 31-35; Referências. - Palmer, Bull. Am. Pal., vol. 129, n. ${ }^{\circ} 115,1945$, p. 43; Mioceno Médio, formação Bowden, Jamaica. - Cushman e Ellisor, Jour. Pal., vol. 19, 1945 , p. 560 , pl. 75 , fig. 7, Oligoceno Médio, formação Anahuac, Texas. Bermudez, Cush. Lab. Foram. Res., Sp. Publ. 25, 1949, p. 167, pl. 11, fig. 35; Plioceno, formaçāo Jimani, São Domingos. - Mem. Soc. Cubana Hist. Nat. vol. XIX, n. 3, 1950, p. 338; Plioceno, formação Matanzas, Cuba.

Descriçĩo - Testa fortemente deprimida, periferia aguda com estreita carena, vista periferal em forma de losângulo, região umbilical com pequena rôlha de material claro a qual em vista periferal não se projeta além do contôrno da testa e câmaras, cêrca de 12 na última volta do corpo. Não foi possível saber o caráter da abertura.

OCorrência - Esta espécie é rara em amostras de calha do poço CR-1-PA, ocorrendo nos seguintes intervalos: $267 \mathrm{~m} 270 \mathrm{~m}$, $286 \mathrm{~m} 289 \mathrm{~m}$.

Dumessões - Os diâmetros no espécime figurado são cêrca de $0.26 \mathrm{~mm}$ e $0.23 \mathrm{~mm}$; espessura $0.14 \mathrm{~mm}$.

Discussio - Os caracteres apontados acima, tais como testa fortemente deprimida, periferia aguda com estreita carena, vista periferal, número de câmaras por rolta do corpo, etc. identificam a nossa forma com $E$. ad renum (Cushman).

Esta espécie vive atualmente nos oceanos Atlântico e Pacífico. Encontram-se, na literatura, notícias de ocorrência desta espécie descle a costa do Rio de Janeiro até Flórida. Como fóssil ela ocorre no Mioceno de Flórida, Carolina do Sul e Jamaica e no Plioceno de Cuba.

Plesiótipos - I. P - C. N. P 1-3.5.

$$
\begin{gathered}
\text { Elphidium lens Galloway e Heminway } \\
\text { Est. } 4 \text { - Figs. 18-21 }
\end{gathered}
$$

Elphidium lens Galloway e Heminway, The New York Acad. Sci., vol 3, pt. 4, 1941, p. 361, pl. 14. figs. 10 a, b; Oligoceno Médio, formação San Sebastian, Pôrto Rico.

DEscriç̃o - Testa aproximadamente cireular, um tanto deprimida, distintamente romboidal em vista periferal, umbonada; periferia inteira, não lobulada, aguda; câmaras distintas, muito nume- 
rosas, cêrea de 30 na última volta do corpo, de altura uniforme em tôda a volta, largas e baixas e ligejramente curvas; elas não são infladas; suturas distintas não deprimidas, niveladas com o resto da testa; processos retrais numerosos mas curtos e ponco distintos; parede lisa e polida; umbo grande, transparente, liso, sem granulações, aproximadamente $1 / 3$ do diâmetro da testa; face apertural estreita, em forma de arco; a abertura consiste de uma série de póros na base da face apertural.

OCorrência - Esta espécie é rara no poço CR-1-PA. Ocorre nos seguintes intervalos, em amostras de calha: $276 \mathrm{~m} 279 \mathrm{~m}$. $280 \mathrm{~m} 283 \mathrm{~m}, 294 \mathrm{~m} 297 \mathrm{~m}, 324 \mathrm{~m} 335 \mathrm{~m}$.

Dimensões - As dimensões dos exemplares figurados, provenientes da amostra de calha do intervalo $280 \mathrm{~m} 283 \mathrm{~m}$, são: 1) Diâmetro $0.72 \mathrm{~mm}$ e espessirura $0.32 \mathrm{~mm}$; 2) Diâmetro $0.22 \mathrm{~mm}$ e espessura $0.10 \mathrm{~mm}$.

Discussĩo - $A$ espécie do Marajó pertence a secção do gênero Elphidium caracterisada por espécies grandes, mais ou menos circulares, dotadas de grande número de câmaras largas e baixas, testa mais ou menos deprimida e umbonada, periferia aguda e abertura consistindo em uma série de póros na base da face apertural.

A nossa espécie parece ser idêntica a $E$. lens Calloway e Heminway do Oligoceno Médio de Pôrto Rico. Os espécimes de Pôrto Rico são maiores que os nossos espécimes.

$$
\text { Pr.esiótipos - L. P - C. N. P 1-36. }
$$

\section{Elphidium ? limbatus Petri sp nor.}

Est. 5 -- Figs. 1-2

Descriçio - Testa relativamente grande, subcircular, deprimida; periferia largamente arredondada, margem inteira não lobulada nem mesmo ligeiramente; face apertural semi-elítica; região umbilical deprimida, câmaras não infladas, cêrca de 8 na última volta do corpo; suturas não deprimidas, largas, caracteristicamente limbadas com processos retrais muito curtos e indistintos; a parede é lisa e grosseiramente perfurada ; a abertura consiste de uma fenda na base da face apertural.

Oconrêsecta - Esta espécie é rala no pogo (R-1-PA. ocorrendo em amostras de calha dos seguintes intervalos: $289 \mathrm{ml} 292 \mathrm{~m}$, $404 \mathrm{~m} \quad 423 \mathrm{~m}, 635 \mathrm{~m} \quad 641 \mathrm{~m}$.

Dimensóes - Os diâmetros em média são: $0.50 \mathrm{~mm}$ e $0.39 \mathrm{~mm}$ e a espessura $0.18 \mathrm{~mm}$. 
Discussio - O caráter limbado da sutura é a feicão mais característica da espécie. No caráter largo da sutura ela apresenta certa semelhança com o gênero Elphidiella e também com Elphidium lidoense Cushman, forma recente de Idido, Itália, mas ela difere desta última espécie em feições tais como umbílico liso, não papiloso e periferia inteira, não lobulosa. O citado caráter largo das suturas é uma feição não usual no gênero Elphidium. Os processos retrais aparentemente existem mas são indistintos o que faz com que se torne duvidosa a afiliação genérica dada aqui.

$$
\text { Holótipo - L. P - C. ․ P. 1-37. }
$$

\section{Elphidium nautiloideum Galloway e Heminway}

$$
\text { Est. } 5 \text { - Figs. 3-4 }
$$

Elphidium nautiloideum Galloway e Heminway, New York Acad. Sci., vol. 3, pt. 4, 1941, p. 362, pl. 14, fig. 5; Oligoceno Médio - Mioceno Inferior, Pôrto Rico. - Bermudez, Cush. Lab. Foram. Res., Sp. Publ. 25, 1949, p. 170, pl. 11, fig. 28; Mioceno Médio, formação Gurabo, São Domingos.

Descrição - Espécie pequena, deprimida, subcircular em vista lateral, com periferia largamente arredondada; margem inteira ou com as 2 ou 3 últimas câmaras ligeirarnente lobuladas; lados aproximadamente paralelos em rista periferal; região umbilical papilosa, geralmente com limites imprecisos; as câmaras não são infladas, cêrea de 12 na última volta do corpo; suturas ligeiramente curras, radiais, não deprimidas, marcadas por processos retrais muito curtos e inconspícuos; parede fina, translúcida, lisa, distinta mas finamente perfuradia a abertura consiste de diversos orifícios arredondados na base da face apertural.

OCoRrêxcra - Esta espécie é a mais comum de Elphidium do poço CR-1-PA, ocorrendo em amostras de calha de $2.58 \mathrm{~m}$ a $502 \mathrm{~m}$ rle profundidade.

Dinexsõrs - Os diâmetros da testa, em média, são de $0.34 \mathrm{~mm}$ e $0.31 \mathrm{~mm}$ e a espessura $0.1 .7 \mathrm{~mm}$.

Discussio - Esta espécie é muito próxima de $E$. pocyanum (d'Orbigny) de que difere pelo número maior de câmaras por volta do corpo e pela periferia menos lobulada. Bermudez (1949 p. 170) cita a espécie como frequiente na formação Gurabo, Mioceno Médio de São Domingos, sendo sempre encontrada em sedimentos depositados em águas rasas.

$$
\text { Plesiótipos - L. P - C. \. P 1-38. }
$$


Elphidium paraensis Petri sp nov.

Est. 5 - Figs. 5-6

Descriçĩo - Testa subcircular pequena, deprimida, completamente involuta; periferia largamente arredondada; região umbilical preenchida por material granuloso, a superfície da qual se apresenta sob a forma de pequenas saliências arredondadas; esta região umbilical ocupa de $1 / 4$ a $1 / 3$ da superfície de uma face da testa; câmaras distintas, ligeiramente entumescidas, de tamanho aproximadamente uniforme, aumentando muito ligeiramente em tamanho, geralmente em número de 12 na última volta do corpo; suturas distintas, limbadas, curvas; a ornamentação da região umbilical penetra em certa extensão pela sutura obtendo-se como resultado aspecto estrelado da mesma; parede lisa ou com sugestões de uma frágil ornamentação concêntrica na região umbilical, grosseiramente perfurada; a abertura não é clara, parecendo ser constituída por uma série de orifícios na base da face apertural.

OCORRÊncia - Esta espécie ocorre em amostras de calha do poço CR-1-PA, dos seguintes intervalos : $274 \mathrm{~m}-283 \mathrm{~m}, 298 \mathrm{~m}-301 \mathrm{~m}$, $328 \mathrm{~m} 331 \mathrm{~m}, 340 \mathrm{~m} 343 \mathrm{~m}, 350 \mathrm{~m}-353 \mathrm{~m}, 365 \mathrm{~m}-374 \mathrm{~m}, 553 \mathrm{~m}$ $559 \mathrm{~m}, 599 \mathrm{~m} 607 \mathrm{~m}, 635 \mathrm{~m} 641 \mathrm{~m}$.

Dimansões - Diâmetros do exemplar figurado, cêrca de $0.33 \mathrm{~mm}$ e $0.30 \mathrm{~mm}$; espessura cêrea de $0.14 \mathrm{~mm}$.

Discussĩo - Esta espécie é muito característica pela periferia lobada em tôda a extensão, câmaras aumentando gradualmente em tamanho e umbílico e suturas largas. Pelo esbôco circular, periferia lobada e câmaras aumentando gradativamente em tamanho ela lembra a espécie $E$. hughesi Cushman e Grant, do Plioceno da Califórnia. Ela difere desta última espécie, contudo, pelo umbílico mais desenvolviclo e suturas mais largas.

$$
\text { Holótipo - L. P - C. N. P 1-39. }
$$

\section{Elphidium ef poeyanum (d'Orbigny')}

Est. 5 - Figs. 7-8

Polystomella poeyana d'Orbigny, in De La Sagra, Hist. Phys. Pol. Nat. Cuba, Foraminifères, 1839. p. 55, pl. 6. figs. 25. 26; Recente. Cuba e Jamaica. - Cushman, Publ. 311, Carnegie Instit. Washington. 1922. p. 55. pl. 9. figs. 9. 10; Recente, Tortugas. 
Elphidium poeyanum (d'Orbigny), Cushman, U. S. Nat. Mus., Bull. 104, pt. 7. 1930, p. 25, pl. 10. figs. 4, 5; Recente, Antilhas. - Bermudez, Mem. Soc. Cubana, Hist. Nat. vol. 9. 1935, p. 187; Recente, Cuba. - Cushman, U. S. Geol. Surv., Prof. Paper 191, 1939, pp. 54-55, pl. 14, figs. 25. 26; Referências. -- Palmer, Bull. Am. Pal., vol. 29, n. ${ }^{\circ} 115,1945$, p. 44; Mioceno Médio, formação Bowden, Jamaica. Renz, Geol. Soc. Am., Mem. 32, 1948, p. 132, pl. 6, fig. 6; Mioceno, formação Luciano, Venezuela. -- Bermudez, Cush. Lab. Foram. Res., Sp. Publ. 25, 1949, p. 171, pl. 11, fig. 27; Mioceno Superior. formação Las Salinas, São Domingos. Mem. Soc. Cubana Hist. Nat., vol. XIX, n. ${ }^{\circ}$ 3. 1950, p. 339; Mioceno - Recente, Cuba.

Descriçĩo - Testa aproximadamente circular, de tamanho pequeno para o gênero, um tanto deprimida; periferia largamente arredondada; margem ligeiramente lobulada; lados paralelos $\mathrm{em}$ vista periferal; região umbilical deprimida; câmaras, cêrea de 10 , na última rolta do corpo, ligeiramente infladas, distintas; suturas deprimidas, marcadas por processos retrais curtos e largos; o número dêsses processos retrais por sutura é ao redor de 15 de cada lado; parede fina, translúcida. lisa, finamente perfurada; a abertura é obscura.

OCorkêxcia - Esta espécie é comum no poço CR-1-PA, ocorrendo em amostras de calha, de $258 \mathrm{ml}$ a $423 \mathrm{~m}$.

Dinensões - Os diâmetros são, em média, $0.37 \mathrm{~mm}$ e $0.33 \mathrm{~mm}$ no espécime figurado, e a espessura, $0.20 \mathrm{~mm}$.

Discussio - Os espécimes brasileiros diferem dos exemplares figurados por d'Orbigny e também por Cushman (1939, Est. 14, figs. 25-26), por serem mais bojudos.

Segundo Renz (1948 p. 132) esta espécie é índice de fácies e não de idade. Segundo êste autor, se em grande número, é excelente indicador ecológico para a zona nerítica lagunal. Seu habitat normal é em profundidade de menos de $180 \mathrm{~m}$. Na região das Caraíbas ela é registrada como vivente normalmente até $110 \mathrm{~m}$ de profundidade, havendo, contudo, registro até de $1098 \mathrm{~m}$ de profundidade. Mais para o Sul, na Baía de Guanabara, ela só aparece até $5 \mathrm{~m}$ de profundidade.

A espécie E. poeyanum (d'Orbigny) é comum na província caraíbiea. Na fauna do poço UR-1-PA ela não foge a regra sendo também comum. Além disto existem formas afins a $E$. poeyanum as quais são também comuns na fauna de Cururú. Estas formas são as seguintes: $E$. poeyanum (d'Orbigny) var. elongata Petri var. nov. e $E$. nautiloideum Galloway e Heminway.

$$
\text { Piesiótipos - L. P - C. N. P. 1-40. }
$$


Elphidium cf poeyanum (d'Orbigny) var. clongata Petri var. nov.

Est. 5 - Figs. 9-10

Descrição e Discussĩo - A rariedade elongata é mais alongada que a forma típica. O número de câmaras é de cêrca de 8 a 9 ; ela também é mais deprimida que as formas aqui referidas a espécie poeyanum, aproximando-se mais, neste sentido, a forma típica.

Ocorrência - Esta variedade aparece nas amostras de calha, de $258 \mathrm{~m}$ a $350 \mathrm{~m}$.

Dimensões - Os diâmetros são, em média, $0.28 \mathrm{~mm}$ e $0.22 \mathrm{~mm}$ e a espessura $0.11 \mathrm{~mm}$.

Holótipo da variedade - I. P. - C. N. P 1-41.

\section{Elphidium sagrai (d'Orbigny)}

Est. 5 -- Figs. 11-12

Polystomella sagra d'Orbigny, in De La Sagra, Hist. Phys. Pol. Nat. Cuba, Foraminifères, 1839, p. 55, pl. 6, figs. 19, 20; Recente, Cuba.

Elphidium sagrum (d'Orbigny). Cushman, U. S. Nat. Mus., Bull. 104, pt. 7, 1930. p. 24, pl. 9, figs. 5, 6; Recente, Antilhas. -- U. S. Geol. Surv. Prof. Paper 191, 1939, p. 55, pl. 15, figs. 1-3; Referências. - Renz Geol. Soc. Am., Mem. 32. 1948, p. 132, pl. 6, fig. 7; Mioceno, formação Luciano, Venezuela.

Elphidium sagra (d'Orbigny), Bermudez, Cush. Lab. Foram. Res., Sp. Publ. 25, 1949, p. 171, pl. 11, fig. 25; Mioceno Superior, formação Las Salinas, São Domingos.

Elphidium sagrai (d'Orbigny), Galloway e Heminway, New York Acad. Sci., vol. 3, pt. 4, 1941, p. 365, pl. 15, fig. 3; Oligoceno e Mioceno, Pôrto Rico. Cushman e Eltisor, Jour. Pal., vol. 19, 1945, p. 561. p!. 75, fig. 8; Oligoceno Médio, formação Anahuac, Texas. - Bermudcz, Mem. Soc. Cubana Hist. Nat. vol. XIX, n. 3 , 1950, p. 339; Oligoceno Superior - Recente, Cuba.

Descriçĩo - Testa de tamanho pequeno para o gênero; periferia arredondada, margem inteira, não lobulada; lados convexos em vista periferal, sendo a porção mais nora mais larga que o resto da testa; região umbilical deprimida, câmaras distintas, de 10 a 12 na última volta do corpo; suturas bem distintas, niveladas com o resto da testa excepto entre as últimas câmaras onde é ligeiramente deprimida; processos retrais, cêrca de 12 de cada lado entre as áltimas câmaras, curtos e largos, contínuos na porção mais antiga da testa formando cristas; parede regularmente espêssa ; face apertural subtrapesoidal; a abertura consiste de uma série de pequenos orificios arredondados na base da face apertural. 
OCORRÊnCIA - Esta espécie é relativamente rara no poço $\mathrm{CR}$. 1-PA, ocorrendo em amostras de calha, nos seguintes intervalos: $264 \mathrm{~m}-289 \mathrm{~m}, 331 \mathrm{~m} 335 \mathrm{~m}, 344 \mathrm{~m} 350 \mathrm{~m}, 386 \mathrm{~m} \quad 423 \mathrm{~m}, 535 \mathrm{~m}$ $541 \mathrm{~m}$.

Dimensões - Os diâmetros são em média, $0.28 \mathrm{~mm}$ e $0.22 \mathrm{~mm}$ e espessura $0.16 \mathrm{~mm}$.

Discussĩo - A ornamentação e os processos retrais dos espécimes brasileiros são menos desenvolvidos que nos espécimes figurados por d'Orbigny e por Cushman (1939 Est. 15, fig. 1-3).

A espécie $E$. sagrai (d'Orbigny) é uma forma vivente, habitando a província caraíbica tendo sido registrada desde a costa brasileira do Rio de Janeiro até a costa de Flórida. Como fóssil ocorre do Oligoceno a Recente.

$$
\text { Plesiótipos - L. P - C. N. P. 1-42. }
$$

Elphidium sagrai (d'Orbigny) var. cururuensis Petri var. nov.

Est. 5 - Figs. 13-16

DESCRIÇÃo - A presente variedade distingue-se da forma típica por ser mais bojuda, possuir esbôço mais eircular, câmaras em número menor (9 a 10 na última volta do corpo), suturas niveladas com o resto da testa apenas mareadas pelos processos retrais, cêrca de 10 de cada lado entre as 2 últimas câmaras e pela face apertural que é semi-lunar enquanto que na forma típica da espécie é trapesoidal.

OCORRÊncIa - Esta variedade é muito comum no poço CR-1$\mathrm{PA}$, sendo muito mais freqüente que a forma típica da espécie. Ocorre, nas amostras de calha, de $258 \mathrm{~m}$ a $1243 \mathrm{~m}$ de profundidade.

Dimensões - Os diâmetros são em média, $0.32 \mathrm{~mm}$ e $0.30 \mathrm{~mm}$ e a espessura $0.29 \mathrm{~mm}$.

Discussĩo - A variedade aqui descrita se assemelha a variedade percrassum (Galloway e Heminway) da mesma espécie, descrita por aquêles autores como variedade crassum mas que Thalmann (1951 p. 222) mostrou ser homônima de E. crispum (Lineu) var. crassa (Möbius). Contudo o número de câmaras por volta do corpo é menor na variedade paraense e os processos retrais são curtos e largos enquanto na variedade de Pôrto Rico são longos e estreitos. o número de processos retrais é também menor na variedade brasileira.

$$
\text { HoLótiPo - L. P. - C. ‥ P 1-43. }
$$




\section{Elphidium tropicalis Petri sp nor.}

Est. 5 - Figs. 17-18

Descriçio - Testa deprimida de tamanho morlerado para o gênero, ligeiramente alongada, completamente involuta; periferia largamente arredondada; região umbilical nivelada com o resto da testa; eâmaras em número variável, geralmente 12 na última volta do corpo, aumentando um tanto bruscamente em largura e gradativamente em comprimento, não infladas, mesmo as últimas eâmaras; suturas distintas, não limbadas, niveladas com o resto da testa, apenas ligeiramente curvas, ornamentadas por pequenos grânulos nem sempre visíveis; os processos retrais são curtos, cêrca de 6 visíveis adjacentes a abertura; umbílico preenchido e confluente com as suturas, pequeno e pouco visível; a parede é distintamente perfurada e com frágil ornamentação longitudinal, visivel só em casos excepcionais; a face apertural tem a forma semi-lunar; a abertura não é clara mas parece ser constituída por uma série de orifícios na base da face apertural.

OCorRêncla - Esta espécie ocorre no poço CR-1-PA, em amostras de ealha, nos seguintes intervalos : $264 \mathrm{~m}-286 \mathrm{~m}, 313 \mathrm{~m}-316 \mathrm{~m}$, $331 \mathrm{~m} 334 \mathrm{~m}, 356 \mathrm{~m} 359 \mathrm{~m}$. Ela ocorre também no testemunho $n^{\circ}$ 7 do mesmo poço, intervalo de $503 \mathrm{~m}$ a $506 \mathrm{~m}$.

Dinensões - Diâmetros do exemplar figurado, $0.62 \mathrm{~mm}$ e $0.55 \mathrm{~mm}$ e espessura $0.26 \mathrm{~mm}$.

Discussĩo - Esta espécie pela frágil ornamentação longitudinal e aumento brusco da largura das câmaras, as quais não são infladas, mesmo a ńltima câmara, é muito característica, distinguindo-se perfeitamente das espécies descritas do gênero.

$$
\begin{array}{r}
\text { Holótipo - L. P. }- \text { C. N. P 1-44. } \\
\text { Elphidium sp } \\
\text { Est. } 6 \text { - Figs. } 1-2
\end{array}
$$

A presente espécie é distinta de tôdas as outras que ocorre no poço CR-1-PA. Não conseguimos também identifiéa-la com nenhuma espécie conhecida de Elphidium.

A espécie é apenas figurada no presente trabalho. Não associamos a ela nenhum nome específico devido a raridade de individuos coletados. Achamos nas amostras de calha do citado poço sòmente 2 indivíduos, um correspondente ao intervalo $274 \mathrm{~m} 277 \mathrm{~m}$, e outro 
correspondente ao intervalo $362 \mathrm{~m} 365 \mathrm{~m}$. Pela presenga de uma carena estreita na periferia a presente espécie se assemelha a Elphidium advenum (Cushman) também encontrada no poço CR1-PA. Contudo o umbílico é deprimido faltando a rôlha característica de $E$. advenum. A forma da face apertural e a atitude dos septos são também diferentes.

O diâmetro máximo medido no exemplar figurado (intervalo $362 \mathrm{~m} 365 \mathrm{~m}$ ) foi de $0.25 \mathrm{~mm}$ e espessura $0.09 \mathrm{~mm}$.

TrPo - L. P - C. N. P $1-45$.

Peneroplis carinatus d'Orbigny

Est. 5- Figs. 19-20 - Est. 6 - Figs. 3-4

Peneroplis carinatus d'Orbigny, Voy. Amẻr. Mérid., vol. 5, pt. 5, Foraminifères, 1839, p. 33, pl. 3, figs. 7, 8; Recente, Patagonia. - Cushman, U. S. Nat. Mus., Bull. 104, pt. 7, 1930, p. 36, pl. 12, figs. 7-10; pl. 14, fig. 1; Recente, Antilhas. Bermudez, Cush. Lab. Foram, Res., Sp. Publ. 25, 1949, p. 173; Mioceno Médio, formação Gurabo, São Domingos. - Mem. Soc. Cubana Hist. Nat. vol. XIX, n.o 3, 1950, p. 352, Plioceno - Recente, Cuba.

Descrição - Testa completamente involuta com periferia aguda a subaguda; câmaras, de 12 a 15 por volta do corpo, baixas e largas, distintas; suturas distintas, deprimidas, não limbadas; parede lisa, não estriada; a abertura consiste em uma série de póros na face apertural.

Ocorkêcria - Esta espécie é rara no poço CR-1-PA, ocorrendo em amostras de calha, nos seguintes intervalos: $255 \mathrm{~m} 261 \mathrm{~m}$, $288 \mathrm{~m} 304 \mathrm{~m}, 330 \mathrm{~m} 336 \mathrm{~m}, 355 \mathrm{~m} 361 \mathrm{~m}$.

Dnmessóns - Os diâmetros e espessuras, medidos em diversos espécimes, são: 1) Diâmetro maior $0.60 \mathrm{~mm}$, diâmetro menor $0.48 \mathrm{~mm}$, espessiura $0.35 \mathrm{~mm}$; 2) Diâmetro maior 0.81 mum, diâmetro menor $0.76 \mathrm{~mm}$, espessura $0.19 \mathrm{~mm}$; 3) Diâmetro maior $0.64 \mathrm{~mm}$, diâmetro menor $0.56 \mathrm{~mm}$, espessura $0.43 \mathrm{~mm}$.

Discussĩo - Os exemplares adultos são num tanto deprimidos e carenados se identificando, desta maneira, com a espécie en consideração. Os exemplares jovens são bojudos e com a periferia subarredondada.

Plesiótupos - L. P - C. N. P 1-81. 


\section{Spirolina sp}

Est. 6 - Figs. 8-9

Descriçĩo - A testa é inicialmente bem enrolada porém parcialmente evoluta, um tanto comprimida; a porção mais jovem é desenrolada, com tendência a se tornar cireular em secção transversal; suturas distintas, deprimidas; câmaras um tanto infladas; parede lisa; abertura indistinta.

OConR̂̂ncla - Êste gênero está representado no poço CR-1-PA, por apenas 4 indivíduos distribuídos, em amostras de calha dos seguintes intervalos: $283 \mathrm{~m} 286 \mathrm{~m}, 299 \mathrm{~m} 302 \mathrm{~m}, 442 \mathrm{~m}-461 \mathrm{~m}$.

Dimensões - As dimensões medidas nos 3 espécimes melhor conservados são as seguintes: 1) Comprimento $0.90 \mathrm{~mm}$, largura $0.76 \mathrm{~mm}$, espessula $0.18 \mathrm{~mm}$; 2) Comprimento $0.50 \mathrm{~mm}$, largura $0.39 \mathrm{~mm}$, espessura $0.20 \mathrm{~mm}$; 3) Comprimento $0.46 \mathrm{~mm}$, largura $0.31 \mathrm{~mm}$, espessura $0.20 \mathrm{~mm}$.

$$
\text { TIPOS - L. P. - C. N. P 1-100. }
$$

\section{Archaias angulata (Firhtel a Moll)}

Est. 6 - Figs. 5-7, 13-14

Nautilus angulatus Fichtel e Moll, Test. Micr., 1803, p. 112, pl. 21.

Archaias angulatus (Fichtel e Moll) Cushman, U. S. Nat. Mus., Bull. 104, pt. 7 , 1930, p. 46, pl. 16, figs. 1-3; pl. 17, figs. 3-5; Referências, Recente. Galloway e Heminway, New York Acad. Sci., vol. 3, pt. 4, 1941, p. 318, pl. 5, fig. 9; Oligoceno - Mioceno, Pôrto Rico. - Bermudez, Cush. Lab. Foram. Res., Sp. Publ, 25. 1949, p. 174; Oligoceno Superior - Mioceno Inferior, São Domingos. - Mem. Soc. Cubana Hist. Nat. vol. XIX, n. ${ }^{\circ} 3$, 1950, p. 328; Oligoceno Superior - Recente, Cuba.

Descrição - Testa ponco comprimida; os estágios jovens são formados por testa plano-espiral, alongada e involuta; as câmaras posteriormente se estendem cada rez mais até se tornarem quase circulares; periferia carenada; as câmaras são dotadas de pilares ("pillars") que as dividem incompletamente; êsses pilares aparecem desde os estágios mais jovens; existem, no nosso material, indivíduos jovens, onde se rê, perfoitamente, as camarazinhas secundárias formadas por êsses pilares; suturas dlistintas, deprimidas; abertura crivada.

OCorrtincia - Esta é a espécie de Peneroplidae mais comum 110 poco (R-1-PA. Ocorre em amostras de callua dos seguintes intervalos: $250 \mathrm{~m} 335 \mathrm{~m}, 342 \mathrm{~m} 370 \mathrm{~m}, 405 \mathrm{~m} 420 \mathrm{~m}, 440 \mathrm{~m} 475 \mathrm{~m}$, $510 \mathrm{~m} 670 \mathrm{~m}, 780 \mathrm{~m} 800 \mathrm{~m}$. 
Dimensões - Os diâmetros e espessuras medidos em espécimes considerados representativos, são: 1) Diâmetro maior $1.97 \mathrm{~mm}$, diâmetro menor $1.68 \mathrm{~mm}$, espessura $0.3 \pm \mathrm{mm}$; 2) Diâmetro maiol $1.17 \mathrm{~mm}$, diâmetro menor $1.12 \mathrm{~mm}$, espessura $0.23 \mathrm{~mm}$; 3) Diâmetro maior $1.14 \mathrm{~mm}$, diâmetro menor $0.95 \mathrm{~mm}$, espessura $0.31 \mathrm{~mm}$; 4 ) Diâmetro maior $0.95 \mathrm{~mm}$, diâmetro menor $0.87 \mathrm{~mm}$, espessura $0.23 \mathrm{~mm}$; 5) Diâmetro maior $0.86 \mathrm{~mm}$. diâmetro menor $0.37 \mathrm{~mm}$, espessura $0.24 \mathrm{~mm}$; 6) Diâmetro maior $0.55 \mathrm{~mm}$, diâmetro menor. $0.22 \mathrm{~mm}$, espessura $0.21 \mathrm{~mm}$; 7 ) Diâmetro maior $0.55 \mathrm{~mm}$, diâmetro menor $0.50 \mathrm{~mm}$, espessura $0.26 \mathrm{~mm}$; 8) Diâmetro maior $0.50 \mathrm{~mm}$, diâmetro menor $0.31 \mathrm{~mm}$, espessura $0.18 \mathrm{~mm}$.

Discussĩo - Os indivíduos do Marajó, se assemelham mais aos espécimes figurados por Fichtel e Moll como Nautilus angulatus (Em Ellis e Messina, Catalogue of Foraminifera) do que aos espécimes figurados por Cushman (1930 a Est. 16, figs. 1-3, Est. 17. figs. 3-5) o qual figura individuos mais compridos, assemelhando-se aos espécimes figurados por Fichtel e Moll como Nautilus aduncus (Em Ellis e Messina, Catalogue of Foraminifera). Existem, não obstante, certos indivíduos mais compridos que o normal no nosso material. Cushman (Idem, p. 46), descrevendo os indivíduos da espécie, provenientes do mar das Caraíbas, adlianta que as primeiras câmaras são simples, só as últimas sendo divididas em camarazinhas secundárias. Entretanto, em nosso material, observamos a presenca dessas câmaras secundárias em indivíduos bem jovens.

Devemos a Henson o esclarecimento, em publicação datada de 1950, da estrutura de Archaias e de outros gêneros de Peneroplidae.

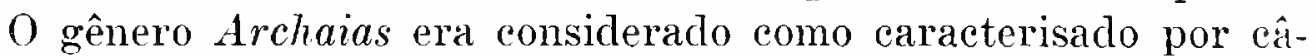
maras sub-divididas por septos secundários, em camarazinhas de segunda ordem. Henson (Em Éllis e Messina, Catalogue of Foramìnifera) mostrou que existem realmente, em lugar dos septos secundários, pilares, os quais são espessamentos da parede da câmara e que só incompletamente dividem a câmara. Os pilares de uma câmara correspondem aos das câmaras anteriores e posteriores. Henson verificou ainda que espécies até então referidas ao gênero Archaias deveriam ser referidas a outros gêneros, visto possuírem diferentes estruturas, aparecendo, em lugar dos pilares ou simultâneamente com êstes, septos secundários. Fxaminando os espécimes das Antilhas, os quais costmmam ser referidos a 3 espécies: Archaias angulata (Fichtel e Moll), L. adunca (Fichtel e Moll) remida por Cushman a A. angulata e A. compressa (d'Orbigny), Henson chegon a conchusão que $A$. angulata e $A$. adunca devem ser conservadas no gênero Archaias devido a estrutura em pilares, enquanto 1. compressa deve ser subdividida em 3 espécies, uma das quais ainda pertencente ao gênero Archaias e as outras duas, referidas aos gêneros Meandropsina e Taberina. 
Os indivíduos aqui referidos a espécie Archaias angulata (Fichtel e Moll) se enquadram no gênero Archaias de acôrdo com o conceito de Henson. A espécie é dotada ùnicamente de pilares que só incompletamente dividem as câmaras. Existem, em nossa coleção, alguns moldes internos referidos a espécie, os quais, a primeira vista, parecem pertencer ao gênero Peneroplis, isto porque as cûmaras aparecem sob a forma de cilindros curvos, cheios e inteiriços, sem divisões. Nota-se apenas ondulações na borda dêsses cilindros, em contacto com os septos, que aqui aparecem sob a forma de sulcos. Essas ondulações representam os pilares.

A presença de pilares e o desenvolvimento ontogenético, distinguem esta espécie dos indivíduos pertencentes ao gênero Peneroplis, provenientes do mesmo porg. Existe na coleção, uma série de indivíduos joveus de ambos os gềieros. Os indivíduos jovens de Peneroplis são obesos e com cầmaras simples; os individuos jovens de Archaias são deprimidos, alongados e já mostram a estrutura em pilares.

A espécie em consideração se distingne dos indivíduos aqui referidos a Taberina sp por ser mais bojuda, as câmaras nunca se tornarem completamente envolventes e circulares como neste último gênero e pela estrutura, em Archairs, formada por pilares que se correspondem nas voltas sncessivas, enquanto em Taberina ela é formada por partições que se alternam nas voltas sucessivas. Nos moldes internos de Tabcrina, as câmaras aparecen sob a forma de grânulos separados por sulcos que constituem as partições secundárias, as quais as rêzes são incompletas. Êsses grânulos, que são prodnzidos pelo preenchimento das camarazinhas secundárias comunicam-se com as voltas anteriores e posteriores por canais, que aparecem nos moldes internos sob a forma de condutos sólidos.

() gênero Archaias tinha, como fóssil, distribuição muito mais ampla que atualmente. Êle é citado desde o Oligoceno, tanto no Pacífico como no Atlântico, mas se extingue no Pacífico, só vivendo, atualmente, no mar das Antilhas.

Os Peneroplidae são característicos de águas rasas e quentes, de regiões próximas a recifes.

$$
\text { Plesiótipos - L. P - C. N. P. 1-7 }
$$

\section{Tabcrina sp}

Est. 6 - Fig. 10

Desckição - Testa circular em esbôço, muito comprimida; as primeiras câmaras possuem enrolamento involuto e são simples; posteriormente as câmaras se estendem, tornando-se circulares e se 
subdividindo en câmaras secundárias por pilares e possìvelmente por septos secundários; a parte involuta forma pouco mais de uma volta do corpo e possui cêrca de 10 câmaras eln uma volta; a maior espessura da testa é formada pela parte neânica involuta; abertura formada por uma série de póros na periferia da testa.

OCorrência - Esta espécie é relativamente rara no poço C'R1-PA, ocorrendo nos seguintes testemunhos de sondagem: Testemunho $n 0^{\circ} 6$, intervalo $500 \mathrm{~m} 503 \mathrm{~m}$, test. n. $^{\circ} 7$, intervalo $503 \mathrm{~m}$ $506 \mathrm{~m}$. Ocorre, também, em amostras de calha dos seguintes intervalos: $250 \mathrm{~m} 270 \mathrm{~m}, 285 \mathrm{~m} 290 \mathrm{~m}, 305 \mathrm{~m} \quad 310 \mathrm{~m}, 320 \mathrm{~m} \quad 339 \mathrm{~m}$. $355 \mathrm{~m} 368 \mathrm{~m}, 735 \mathrm{~m} \quad 760 \mathrm{~m}, 800 \mathrm{~m} 815 \mathrm{~m}$.

DInensões - O diâmetro medido em $u m$ indivíduo, relativamente jovem, é de $1.04 \mathrm{~mm}$ e a espessura $0.09 \mathrm{~mm}$. (I diâmetro de um espécime maior é de $4.25 \mathrm{~mm}$.

Discussio - A forma aqui en consideração tem sido descrita pelos autores como Archaias compressa (d'()rbirny). Henson (Em Ellis e Messina, Catalogue of Foraminifera, Tabcrina) mostrou que A. compressa anct. é formada por indivíduos pertencentes a 3 gêेneros: Archaias, Meandropsina, Taberina. Aste último gênero é definido por Henson como Peneroplidae com pilares a partiçóes subepidérmirads, sendo os pilares confinados a zona central das câmaras. () conceito do gênero que antigamente só compreendia formas que passavam do estágio espiral para cilíndrico-serial possuindo, neste sentido, somente representantes fósseis (Cretaceo Superior-Paleoceno), foi ampliado por Henson para incluir formas com a mesma estrutura essencial, mas exibindo uma escala de variação da forma da testa e arranjo das câmaras ig̣ual ao observado em outros gêeneros de Peneroplidae isto é, completamente espiral para cíclico, comprimido on lenticular, evoluto ou involuto. Nesse conceito o gênero compreende também formas do Terciário e Recente.

Os indivíduos aqui referidos a êste gênero, se distingruem de Archaias angulata (Fichtel a Moll) proveniente do mesmo poco, por serem mais comprimidos, sendo que as partições são alternantes de câmara para câmara, ao contrário dos pilares correspondentes de Archaias. Essias partiçoes são também muito mais claras e simétricas que os pilares de Archaias.

"A. compressa" foi descrita por d'Orbigny da região das Caraíbas. Como fóssil ocorre no Terciário Superior de Jamaica, Flórida e Panamá. Bermudez (1950 p. 328$)$ cita a espécie como ocorrendo em Cuba, do Oligoceno Superior a Recente, sendo rara no Oligoceno Superior, só se tornando commu do Mioceno a Recente

Tipos - L. P - C. N. P 1-103. 


\section{Gïmbelina globulosa (Ehrenberg)}

Est. 6 - Figs. 11-12

Textularia globulosa Ehrenberg, Alhhandl. preuss. Akad. Wiss., Berlin, 1838, p. 135, pl. 4, fig. B - Cretaceo. Inglaterra.

Güembelina globulosa (Ehrenberg) - Cushman, Cush. Lab. Foram. Res., Contr. vol. 7 , pt. 2,1931 , p. 39 , pl. 5 , figs. 7 a, b; Cretaceo, Antigua.

Gümbelina globulosa Egger, Abhandl. Kön. bay. Akad. Wiss., München, cl. II, vol. 21, pt. 1, 1899, p. 32, pl. 14, fig. 43. - Cushman, Cush. Lab. Foram. Res., Contr. vol. 14, pt. 1, 1938, p. 6, pl. 1, figs. 28-33; Cretaceo, Referências. - Cushman e Hedberg, Cush. Lab. Foram. Res., Contr. vol. 17, pt. 4, 1941, p. 92, pl. 22, fig. 15; Cretaceo Superior, formação Colon, Colômbia. - Cushman e Todd, Cush. Lab. Foram. Res., Contr. vol. 19, n. ${ }^{\circ}$ 3, 1943, p. 64, pl. 11, fig. 12; Cretaceo Superior, Texas.

Descriçio - Testa pequena, bisserial, um tanto deprimida; periferia lobada, largamente arredondada; câmaras distintas, muito infladas, aumentando ràpidamente, os últimos 2 pares ocupando dois têrços do comprimento da testa; suturas distintas, muito deprimidas; a abertura não está clara no nosso material mas parece ser relativamente grande e em forma de areo na base da última câmaræa ; a parede é finamente punctada, lisa e transparente.

OCorrência - A espécie é rara no pogo CR-1-l'A, ocorrendo nos testemunhos $11 .{ }^{\circ} 51,2082 \mathrm{~m} 2085 \mathrm{~m}$ e n. ${ }^{\circ} 65,2376 \mathrm{~m} 2379 \mathrm{~m}$.

Dianssões - As dimensoes, medidas no espécime firumalo, foram as seguintes: Comprimento 0.2.) mm, largura $0.22 \mathrm{~mm}$, espessura $0.06 \mathrm{~mm}$.

Discussĩo - (Is nossos espécimes se assemelham a G. globulosa (Ehrenberg) pelo número de câmaras visíveis no adulto, cêreà de 6 pares e pelo aumento brusco do tamanho das camaras. () ammento das últimas câmaras é mais brusco que na maioria dos representantes eocênicos do gênero; ao contrário, G. wilcorensis Cushman e Ponton, também do Eoceno, possui anmento das câmaras muito mais brusco que na espécie em consideração.

Os espécimes aqui considerados talvez provenham de sedimentos do Cretaceo, tendo sido, possivelmente, redepositados.

Plesiótipos - L. P - C. N. P 1-66.

\section{Bulimina ef marginata d'()rbigny}

Est. 3 - Fig. 23; Est. 6 - Fig. 1.5

Bulimina marginata d'Orbigny, Inn. Sci. Nat. vol. 7. 1826, p. 269, pl. 12. figs. 10-12, Recente, Rimini. Itália.-Cushman, U. S. Nat. Mus.. Bull. 104. pt. 3. 
1922, p. 91, pl. 21, figs. 4, 5; Referências, Recente, Atlântico. - Coryell e Rivero, Jour. Pal. vol. 14, 1940, p. 341; Mioceno Médio, Port-au-Prince, Haiti. - Palmer, Bull. Am. Pal. vol. 29. n." 115, 1945. p. 46; Mioceno Médio, formação Bowden, Jamaica. - Cushman e Todd, Cush. Lab. Foram. Res., Sp. Publ. 15, 1945, p. 39, pl. 6, fig. 8; Mioceno, Buff Bay, Jamaica. -- Bermudez, Cush. Lab. Foram. Res., Sp. Publ. 25, 1949, p. 182, pl. 12, fig̣. 11; Mioceno Médio, formação Gurabo, São Domingos.

Descriç.̃o - Testa pequena, com comprimento cêrca de 2 vêzes a largura, afinando-se gradualmente a partir do meio da testa onde a largura é máxima, consistindo de cêrea de 4 voltas, a última volta ocupando cêrca de metade da testa; câmaras distintas, ligeiramente infladas; suturas distintas, deprimidas; parede lisa, perfurada, a margem das câmaras cortada por pecqueno denteado regular, nem sempre bem visível; abertura alongada e curva em forma de gancho.

Ocorrêscia - Esta espécie ocorre no poco CR-1-PA, nos seguintes testemunhos de sondagem: Testemunho n. ${ }^{\circ} 5,497 \mathrm{~m} 500 \mathrm{~m}$, test. n. ${ }^{\circ} 6,500 \mathrm{~m} 503 \mathrm{~m}$. Ocorre também, em amostras de calha, nos seguintes intervalos : $262 \mathrm{~m} \quad 293 \mathrm{~m}, 302 \mathrm{~m} 305 \mathrm{~m}, 323 \mathrm{~m} \quad 326 \mathrm{~m}$, $335 \mathrm{~m}-338 \mathrm{~m}, 366 \mathrm{~m} \quad 375 \mathrm{~m}, 549 \mathrm{~m} \quad 555 \mathrm{~m}$.

Dranexsóss - As dimensões medidas no espécime figurado são as seguintes: Comprimento $0.22 \mathrm{~mm}$, largura $0.1 \mathrm{~mm}$, espessura $0.08 \mathrm{~mm}$.

Discressio - Esta espécie foi referida com dúvida a $B$. marginata d'Orbigny. Contudo ela se distingue desta última espécie, entre outros caracteres, por possuir apenas sugestões de truncamento na base das câmaras. As seguintes diferenças a afastam de B. aculeata d Orbigny espécie esta que se assemelha, de certo modo, ao nosso material. As câmaras não são tão infladias, a testa é bem menor e não aparecem os espinhos da porção mais antiga que são aracterísticos de $B$. aculeata l'Orbigny. Ela apresenta algumas semelhanças com formas do Cretaceo e Eoceno, tais como $B$. spinata Cushman e Campbell, B. macilenta Cushman e Parker, B. stalacta cushman e Parker', ete., distinguindo-se, contudo, pela forma geral e caráter menos ornamentado da testa.

E possível que tenhamos aqui uma nova espécie. Contudo como a espécie $B$. marginata d'Orbigny é muito variável, preferimos manter os nossos espécimes, ainda que com dúvida, dentro desta última.

$$
\text { Plesiótipos - L. P - C. N. P 1-18. }
$$




\section{Virgulina ef compressa (Bailey)}

$$
\text { Est. } 3 \text { - Fig. } 22 \text {; Est. } 6 \text { - Fig. } 16
$$

Bulimina compressa Bailey, Smithsonian Contr., vol. 2. art. 3, 1851, p. 12, pl., figs. 35-37.

Virgulina compressa (Bailey). Cushman, L. S. Nat. Mus., Bull. 104, pt. 3, 1922, p. 116. pl. 24, figs. 2, 3; Referências.

Descrição - O gênero Virgulina é representado no poço CR1-PA, por uma única espécie. que parece pertencer a $V$ compressa (Bailey). A testa é fusiforme alongada, um tanto comprimida, com a periferia largamente arredondada, extremidade inicial obtusa; câmaras distintas, ligeiramente infladas, a porção inicial da testa torcida espiralmente e as últimas câmaras arranjadas bisserialmente; suturas distintas, deprimidas, oblíquas; parede lisa, finamente perfurada: abeltura alongada, estreita.

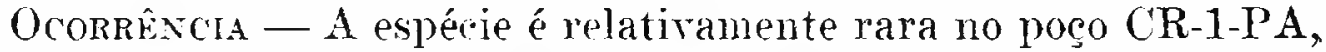
veorrendo em amostras de calha do intervalo $258 \mathrm{~m} 276 \mathrm{~m}$.

Drinscíes - As dimensóes, medidas no espécime figurado, foram as seguintes: Comprimento $0.31 \mathrm{~mm}$, largura $0.11 \mathrm{~mm}$, espessura $0.06 \mathrm{~mm}$.

Discessio - A espécie Virgulina compressa (Bailey) é uma espécie vivente no Atlântico léste, estendendo-se da Nova Inglaterra ao gôlfo do México. Fla não tern sido citada como fóssil. Contudo as espécies $r$ pontoni Cushman e $r$ punctata d'orbigny, intimamente relacionadas com $T$ compressa (Bailey), ocorren, na proríncia caraíbica, descle o Mioceno.

$$
\text { Plesiótipos - L. P - C. N. I 1-114. }
$$

\section{Bolicina alata (Seguenza)}

Est. 6 - Figs. 19-20

Vulvulina alata Seguenza, Atti Accad. Gioenia Sci. Nat.. ser. 2, rol. 18, 1862, p. 115, pl. 2, figs. 5, 5 a; Pleisioceno, Itália.

Bolivina alata (Seguenza), Fornasini, Mem. Accad. Sci. Instit. Bologna, ser. 5, vol. 9. 1901, p. 12. Pleistoceno, Itália. - Cushman, Cush. Lab. Foram. Res., Sp. Publ. 9, 1937. p. 106, pl. 13, figs. 3-11; Referências; Terciário e Recente. -- Palmer, Bull. Am. Pal., vol. 29, n. ${ }^{\circ}$ 115, p. 47; Mioceno Médio, formaçāo Bowden. Jamaica. -- Cusńman e Todd, Cush. Lab. Foram. Res., Sp. Publ. 15, 1945, p. 42, pl. 6, fig. 25; Mioceno, Buff Bay. Jamaica. - Renz, Geol. Soc. Am.. Mem. 32. 1948. p. 116, pl. 6, fig. 26; pl. 12, fig. 12; Mioceno Mnferior. Venezuela. - Bermudez, Cush. Lab. 
Foram. Res., Sp. Publ. 25, 1949, p. 187, pl. 12, fig. 25; Oligoceno e Mioceno, São Domingos. - Mem. Soc. Cubana Hist. Nat. vol. XIX, n." 3, 1950, p. 329; Oligoceno - Recente, Cuba.

Descriçĩo - Testa alongada, muito deprimida; periferia agudamente carenada; a porção basal de cada câmara é representada por projecõos espinhosas da carena, viradas bruscamente para a extremidade inicial ; câmaras distintas, largas e baixas, ligeiramente infladas; suturas distintas um tanto limbadas.

OCorrêxcia - A espécie é relativamente rara no poģo CR-1-PA, ocorrendo em amostras de calha dos seguintes intervalos: $270 \mathrm{~m}$ $273 \mathrm{~m}, 276 \mathrm{~m} 279 \mathrm{~m}, 288 \mathrm{~m} 291 \mathrm{~m}$.

Dimensões - As dimensões, medidas no espécime figurado, foram as seguintes: Comprimento $0.31 \mathrm{~mm}$, largura $0.17 \mathrm{~mm}$, espessura $0.08 \mathrm{~mm}$.

Discussĩo - (Os espécimes, provenientes do poço CR-1-PA, referidos a $B$. alata (Seguenza), concordam muito bem com a descrição e ilustração desta última espécie. Tivemos oportunidade de comparar diretamente, os nossos espécines, com exemplares recentes provenientes do Gôlfo do México.

Os tipos provém do Pleistoceno de Catania, Itália. Contudo a espécie é espalhada, atualmente, tanto nos oceanos Atlântico como P’acífico.

Plesiótipos - L. P - C. N. P 1-11.

\section{Bolivina plicatella Cushman}

Est. 4 - Figs. 22-25

Bolivina plicala Brady, Parker e Jones (Non d'Orbigny), Trans. Zool. Soc. London, vol. 12, 1888, p. 221. - Cushman, Amer. Geol. vol. 33, 1904, p. 264.

Bolivina plicatella Cushman, Flórida St. Geol. Surv., Bull. 4, 1930, p. 46. pl. 8. figs. 10 a. b; Mioceno, formação Choctawhatchee, Flórida. - Cole, Idem, Bull. 6. 1931, p. 41; Plioceno, Flórida. - Cushman e Parler, Proc. U. S. Nat. Mus., vol. 80, art. 3, 1931, p. 15, pl. 3, fig. 19; Recente, costa atlântica da América do Sul. Cushman e Ponton, Flórida St. Geol. Surv., Bull. 9. 1932, p. 82; Mioceno. Flórida. - Cushman e Cahill, U. S. Geol. Surv. Prof. Paper 175-A, 1933. p. 26, pl. 8, figs. 12 a. b; Mioceno. Flórida. - Cushman e Todd, Cusl. Lab. Foram. Res., Sp. Publ. 15, 1945, p. 46, pl. 7, fig. 10; Mioceno, Buff Bay, Jamaica. - Redmond, Jour. Pal., vol. 27 , n. 5 , 1953, p. 721, pl. 75, figs. 13 a. b; Mioceno Médio, formação Tubara. Colômbia.

Descriçio - A testa é pequena, comprimida, com a maior largrura na extremidade apertural; periferia subaguda; parede perfurada e com ornamentação caracteristica a qual constitui de 2 
cristas longitudinais ligadas por barras transversais; superfície da testa coberta por depressões irreculares que obscurecem as suturas; abertura alongada.

OCORRÊNCIA - Ela é comum em amostras de calha do intervalo $296 \mathrm{~m} 332 \mathrm{~m}$, sendo inexistente mais abaixo, com excecão de 2 indivíduos no intervalo $417 \mathrm{~m} 420 \mathrm{~m}$, e $\mathrm{mm} \mathrm{cm}$ cada $11 \mathrm{~m}$ dos seguintes intervalos : $497 \mathrm{~m} \quad 503 \mathrm{~m}, 503 \mathrm{~m} \quad 512 \mathrm{~m}, 512 \mathrm{~m} \quad 524 \mathrm{~m}, 610 \mathrm{~m} \quad 616 \mathrm{~m}$. É possivel que as ocorrências desta espécie abaixo de $332 \mathrm{~m}$, tenham sido produzidas por contaminação das amostras de calha provenientes do intervalo $292 \mathrm{~m} 332 \mathrm{~m}$, pois elas tornam-se bruscamente muito raras nestes intervalos inferiores.

Dranensões - As dimensões, medidas nos espécimes figurados, foram as seguintes: 1) Comprimento $0.28 \mathrm{~mm}$, largura $0.20 \mathrm{~mm}$, espessura $0.07 \mathrm{~mm}$; 2) Comprimento $0.20 \mathrm{~mm}$, largura $0.17 \mathrm{~mm}$, espessura $0.06 \mathrm{~mm}$.

Discussĩo - Os indivíduos provenientes do poço CR-1-PA, referidos a esta espécie, concordam perfeitamente com a descrição e ilustração de $B$. plicatclla Cushman. Tivemos também oportunidade de fazer comparaçoos diretas com espécies provenientes do Mioceno de Buff Bay, Jamaica.

É possível que esta espécie possa ser, no futuro, ótimo fóssil índice para correlacoões na estratigrafia da fóssa do Marajó; é o que sugere a sua abundância em um pacote restrito da coluna geológica do Marajó.

() tipo da espécie provém do Mioceno de Flórida. Contudo ela é muito comum na província caraíbica, em sedimentos que se distribuem do Mioceno a Recente. F́ interessante notar que esta espévie, ao contrário do que geralmente acontece com os foraminíferos da província caraíbica, se estende bem para o Sul, até as ilhas Falklands. Cushman (1937 b, p. 89) cita a espécie como ocorrendo na baía de Guanabara a Brady, Parker a Jones (Em Cushman, idem. idem) a citam na ilha dos Ábrolhos.

Não se conhece a espécie fora da costa atlântica das Américas.

Plesiótipos - L. P - C. N. P' 1-12.

Bolvina rhombica Petri sp nov.

Est. 6 - Figs. $17-18$

Descriçio - Testa curta e larga, teminada em extremidade obtusa, com vistas dorsal e ventral um tanto romboides, mais espêssa na regrão mediana e dai se arlelgadgando para a periferia a 
qual possui carena um tanto indistinta; a secẹão transversal é rômbica deprimida; câmaras distintas, curvas, muito mais largas que altas; suturas distintamente limbadas, geralmente fundidas na parte mediana da testa formando uma faixa longitudinal larga; parede finamente perfurada; abertura estreita e alongada.

Ocorrêncra - Esta espécie ocorre em amostras de calha do poço CR-1-PA, nos seguintes intervalos: $268 \mathrm{~m}-280 \mathrm{~m}, 290 \mathrm{~m} 293 \mathrm{~m}$, $341 \mathrm{~m} 344 \mathrm{~m}, 803 \mathrm{~m} 821 \mathrm{~m}$.

Dimensões - As dimensões, medidas no espécime figurado, são as seguintes: Comprimento $0.22 \mathrm{~mm}$, largura $0.14 \mathrm{~mm}$, espessura $0.05 \mathrm{~mm}$.

Discussĩo - Esta espécie é afin a $\boldsymbol{B}$. alazanensis Cushman do Oligoceno do México. O ângulo da sutura das câmaras com a sutura mediana é, aproximadamente, o mesmo e o caráter da parede é o mesmo; contudo a espécie paraense é mais curta, mais larga e mais deprimida. B. simplex Phleger e Parker é mais alongada e possui as suturas mais retas.

$$
\text { Holóthro - L. P - C. N. P 1-13. }
$$

\section{Bolvina ef rhomboidalis (Millett)}

$$
\text { Est. } 7 \text { - Figs. 1-2 }
$$

Textularia rhomboidalis Millett, Jour. Roy. Micr. Soc., 1899, p. 559, pl. 7, fig. 4; Recente, Malaia. - Sidebottom, Manchester Lit. Philos. Soc., vol. 49, n. ${ }^{\circ}$, 1905, p. 8, pl. 2, figs. 2. 3; Recente, tha de Delos.

Bolivina rhomboidalis (Millett), Cushman, Carnegie Instit. Washington, Publ. 311, 1922, p. 28; Recente, Tortugas. - U. S. Nat. Mus.. Bull. 104, pt. 3, 1922, p. 44, Recente, Atlântico. - Cush. Lab. Foram. Res., Sp. Publ. 9, 1937, p. 138, pl. 18, fig. 7; Referências, Recente. - Palmer, Bull. Am. Pal., vol. 29, n.' 115, 1945, p. 47; Mioceno Médio. formação Bowden, Jamaica. - Cushman e Todd, Cush. Lab. Foram. Res.. Sp. Publ. 15, 1945, p. 47. pl. 7, fig. 19; Mioceno, Buff Bay, Jamaica. Bermudez, Cush. Lab. Foram. Res., Sp. Publ. 25. 1949, p. 194, pl. 12, fig. 44; Mioceno Superior, formação Las Salinas, São Domingos.

Descriçĩo - Foi encontrado no poço CR-1-PA. um único individuo (ujos caracteres parecem pertencer a espécie $B$. rhomboidalis (Millett). A testa é aproximadamente triangular em vista frontal, ligeiramente mais longa que larga, aumentando bruscamente em largura; extremidade inicial um tanto truncada e periferia obliquamente truncada; vista apertural quadrangular, tendendo para rômbica. 
OCorrêncla - O indivíduo aqui referido a esta espécie, provém de amostra de calha do poço CR-1-PA, intervalo $276 \mathrm{~m} 279 \mathrm{~m}$.

Dinensões - Comprimento $0.17 \mathrm{~mm}$, largura $0.14 \mathrm{~mm}$, espessura $0.06 \mathrm{~mm}$.

Plesiótipo - L. P - C. N. P 1-14.

Bolivina striatula Cushman rar. angulata Petri var. nov.

Est. 6 - Figs. 21-22

Desc'RIÇĩo - Testa alongada, comprimida, terminada em extremidade aguda; a maior largura da testa está situada na zona mediana, mais para a abertura; periferia angular; carena ausente ou ligeiramente esboçada; câmaras numerosas, um tanto indistintas, não se projetando; suturas um tanto indistintas formando ângulo quase reto com o eixo mediano e, a partir dêste, curvando-se ligeiramente para a frente e depois para traz; parede fina, grosseiramente punctada; as punctações são restritas a parte inferior das câmaras; a testa mostra sugestões de costas longitudinais principalmente na sua porção mais antiga; a abertura é alongada.

Existem, na coleção, espécimes microsféricos, os quais se afinam gradualmente, e espécimes megalosféricos com a parte adulta da testa subparalela.

OCORRÊNCIA - Esta espécie ocorre em amostras de calha do poço CR-1-PA, nos seguintes intervalos : $259 \mathrm{~m} 293 \mathrm{~m}, 308 \mathrm{~m} \quad 311 \mathrm{~m}$. $335 \mathrm{~m} 344 \mathrm{~m}, 363 \mathrm{~m}-375 \mathrm{~m}, 460 \mathrm{~m}-479 \mathrm{~m}, 803 \mathrm{~m} 820 \mathrm{~m}$.

Dinensões - As dimensões medidas nos dois espécimes foram: Espécime figurado: Comprimento $0.31 \mathrm{~mm}$, largura $0.14 \mathrm{~mm}$, espessura $0.06 \mathrm{~mm}$. Outro espécime: Comprimento $0.14 \mathrm{~mm}$, largura $0.05 \mathrm{~mm}$, espessura $0.04 \mathrm{~mm}$.

Discussão - A forma brasileira difere da forma típica de $B$. striatula Cushman pelas câmaras que não se projetam, por ser, proporcionalmente, mais larga, e pela periferia, angular em tôda a extensão. Ela se assemelha mais a variedade spinata da mesma espécie faltando, contudo, o espinho da extremidade aboral.

A forma típica vive atnalmente, na província caraíbica. de Flórida ao Brasil, sendo encontrada, na mesma província. como fóssil, desde o Mioceno.

Holótipo da variedade - L. P - C. N. P 1-15. 


\section{Bolivina of tortuosa Brady}

Est. 7 - Figs. 3-4

Bolivina tortuosa Brady, Quart. Jour. Micr. Soc., vol. 21, 1881, p. 57. - Rep. Voy. Challenger, Zool. vol. 9, 1884, p. 420, pl. 52, figs. 31, 32 (Non figs. 33, 34); Recente, Ithas Admiralty. - Cushman e Parker, Proc. U. S. Nat. Mus., vol. 80, art. 3, 1931, p. 16, pl. 3, figs. 22 a, b; Recente, costa atlântica da América do Sul. - Cushman, Cush. Lab. Foram. Res., Sp. Publ. 9. 1937, p. 133, pl. 17, figs. 11-19; Referências. - Palmer, Bull. Am. Pal., vol. 29, n. ${ }^{\circ} 115$, 1945, p. 48; Mioceno Médio, formação Bowden, Jamaica. - Bermudez, Cush. Lab. Foram. Res., Sp. Publ. 25, 1949, pp. 195, 196, pl. 12, fig. 45; Mioceno Inferior, Membro Higuerito, São Domingos. - Mem. Soc. Cubana Hist. Nat., vol. XIX, n. ${ }^{\circ}$ 3, 1950, p. 330; Oligoceno Superior, Recente, Cuba. - Redmond, Jour. Pal., vol. 27. n. ${ }^{\circ}$ 5, 1953, p. 721, pl. 75, figs. 14 a, b; Mioceno Médio, formação Tubara, Colômbia.

Descriçĩo - Referimos, com dúvida, à espécie acima, um indivíduo proveniente do poço CR-1-PA. As câmaras são relativamente altas e a periferia é inteira, não lobulada; as suturas são distintas, não deprimidas; a parede é grosseiramente perfurada; a abertura tende a se tornar terminal, alongada, elítica.

OCORRÊNCIA - O exemplar em consideração foi encontrado em amostra de calha do intervalo $268 \mathrm{~m} 271 \mathrm{~m}$, poço CR-1-PA.

Dimensões - $O$ espécime em consideração tem as seguintes dimensões : Comprimento $0.32 \mathrm{~mm}$, largura $0.09 \mathrm{~mm}$.

Discussĩo - O nosso excmplar é torcido como a espécie acima, mas é mais alongado, assomelhando-se, neste senticlo, a rariedade atlantica, da mesma espécic, descrita por Cushman. Conturlo a periferia não é lobuladia como naquela variedade. Como na espécie acima, o nosso exemplar é muito deprimido, com periferia aguda mas não carenada. Conseguimos coletar diversos exemplares provenientes de um afloramento de calcáreo da formação Pirabas (Mioceno Inferior do Estado do Pará). O afloramento fica em um corte entre as estações de Peixe-Boi c Tamarí, da estrada de ferro Belém-Bragança. Os exemplares da formaşão Pirabas diferem do de Curnrú, por serem mais largos, aproximando-se mais, neste sentido, da forma típica.

Plesiótipo - L. P - C. N. P 1-16.

\section{Bolivina sp}

$$
\text { Est. } 7 \text { - Figs. 5-6 }
$$

Descriçio - Os espéeimes aqui referidos como $B$. sp se assemelham um tanto a $B$. ihombica Petri diferindo por serem mais curtos e laresos, pela presença de mina crista saliente na região mediana e por serem menos deprimidos. 
OCorrêxcia - Esta espécie ocorre no poço CR-1-PA, nos intervalos de $268 \mathrm{~m}-280 \mathrm{~m}, 290 \mathrm{~m} 293 \mathrm{~m}, 341 \mathrm{~m} 344 \mathrm{~m}$.

Dimensões - Dimensões do exemplar figurado: Comprimento $0.20 \mathrm{~mm}$, largura $0.14 \mathrm{~mm}$, espessura $0.09 \mathrm{~mm}$.

Discussĩo - Esta espécie se assemelha a B. alazanensis Cushman, do Oligoceno do México, possuindo, como naquela espécie, uma crista longitudinal na região mediana. Contudo os nossos exemplares são mais curtos e mais largos.

$$
\text { Tipos - L. P. - C. N. P. 1-17. }
$$

\section{Renssella spinulosa (Reuss) \\ Est. 7 - Figs, $7-8$}

Vernetilina spinulosa Reuss, Denkschr. Akad. Wiss. Wien, vol. 1, 1850, p. 374, pl. 47, fig. 12; Terciário, Alemanha. - Brady, Rep. Voy. Challenger, Zool., vol. 9, 1884, p. 384, pl. 47, figs. 1-3; Recente, Ilhas Admiralty e Papua. -- Cushman, Carnegie Instit. Washington, 1919, p. 34; Mioceno, Matanzas, Cuba.

Reussella spinulosa (Reuss), Bermudez, Mem. Soc. Cubana Hist. Nat., vol 9, 1935, p. 197, Recente, Cuba. - Palmer e Bermudez, Idem, vol. 9, 1936, p. 240, Mioceno Superior, Matanzas, Cuba. - Palmer, Bull. Am. Pal., vol. 29, n. ${ }^{\circ} 115$, p. 49; Mioceno Médio. formação Bowden, Jamaica. - Cushman, Cush. Lab. Foram. Res., Contr. vol. 21, 1945, p. 33, pl. 6, figs. 8, 9; Referências. - Renz, Geol. Soc. Am., Mem. 32, 1948, p. 156. pl. VII, figs. 16, 17; Mioceno, Venezuela, Colômbia. Bermudez, Cush. Lab. Foram. Res., Sp. Publ. 25, 1949, p. 198, pl. 12, fig. 59; Mioceno Inferior, formação Cercado, São Domingos. - Mem. Soc. Cubana Hist. Nat., vol. XIX, n. ${ }^{\circ} 3$, 1950, p. 357; Oligoceno Superior - Recente, Cuba.

Descriçĩo - Testa piramidal, triangular, tricarenada, trisserial com cêrea de 7 séries visíveis; câmaras ponteagudas, projetantes para a extremidade inicial.

OCoRrência - Esta espécie é relativamente rara no pogo CR1-PA, ocorrendo em amostras de calha, nos seguintes intervalos: $262 \mathrm{~m} 293 \mathrm{~m}, 332 \mathrm{~m} 360 \mathrm{~m}, 588 \mathrm{~m}-594 \mathrm{~m}, 783 \mathrm{~m} 801 \mathrm{~m}$.

Drmensões - As dimensões, medidas em 2 espécimes foram as seguintes: Espécime figurado: Comprimento $0.28 \mathrm{~mm}$, largura $0.25 \mathrm{~mm}$, espessura $0.20 \mathrm{~mm}$. Outro espécime: Comprimento $0.07 \mathrm{~mm}$, largura $0.05 \mathrm{~mm}$, espessura $0.05 \mathrm{~mm}$.

Discussĩo - Os espécimes do poço CR-1-PA pertencentes ao gênero Reussella parecem ser referiveis a $R$. spinulosa (Reuss). Cushman (1945 pp. 33-34) em sua monografia sôbre a subfamília Reusselinae da família Buliminidae considera a espécie $R$. spinulosa (Reuss) como característica do Mioceno da Europa. Esta é uma 
espécie que tem sido frequientemente citada na literatura, do EocenoRecente, em todo o mundo. Cushman (idem, idem) mostrou que a maior parte dessas referências dizem respeito a espécies diferentes. Contudo a espécie ocorre, em sua forma típica, desde o Oligoceno na província caraíbica.

Pi.esiótipos - L. P - C. N. P 1-93.

\section{Uvigerina $\mathrm{sp}$}

Est. 7 - Figs. 9-10

Descricio - Testa pequena subfusiforme, não deprimida; câmaras distintas, infladas; suturas distintas, deprimidas; parede ornamentada por costas inteiras e finas (aproximadamente 10 por câmara), as quais tornam-se indistintas nas 2 últimas câmaras; as costas de cada câmara são independentes das costas das câmaras adjacentes; abertura terminal, pequena, sôbre um pescoço relativamente longo e dotado de um colarinho bem visivel.

OCorRềcia - Esta espécie é rara, no poço CR-1-PA, ocorrendo em amostra de calha do intervalo: $271 \mathrm{~m}-274 \mathrm{~m}$.

Druensões - As dimensões medidas no espécime figurado, são as seguintes: Comprimento $0.36 \mathrm{~mm}$, largura $0.25 \mathrm{~mm}$, espessura $0.25 \mathrm{~mm}$.

Discussĩo - Esta espécie mostra certa semelhança com $U$. subperegrina Cushman e Kleinpell do Mioceno da Califórnia, diferindo pelo pescoço mais largo, pelo tamanho menor e pelas câmaras relativamente menos infladas.

Além desta espécie de Uvigerinc ainda existem outras formas cuja classificação não foi tentada derido a raridade das mesmas.

Plesiótipos - L. P - C. X. P. 1-111.

\section{Angulogerina illingi Cushman e Renz}

Est. 7 - Figs. 11-1:3

Angulogerina illingi Cushman e Renz, Cush. Lah. Foram. Res., Contr. vol. 17, 1941, p. 21, pl. 3, figs. 19, 20; Oligoceno. formação Agua Salada, Venezuela. Cushman e Todd, Cush. Lab. Foram. Res., Sp. Publ. 15, 1945. p. 52, pl. 8, fig. 2; Mioceno, Buff Bay, Jamaica. - Renz, Geol. Soc. Am., Mem. 32, 1948, p. 114, pl. 7, figs. 31, 32; Oligoceno Superior, Venezuela. - Bermudez, Cush. Lab. Foram. Res., Sp. Publ. 25, 1949, pp. 216.217, pl. 13, fig. 52; Oligoceno Médio, formação Sombrerito, São Domingos.

Angulogerina yumuriana Palmer. Mem. Soc. Cubana Hist. Nat., vol. 15, 1941, p. 186, pl. 15, fig. 8; Oligoceno Superior, formação Cojimar, Cuba. 
Descriçĩo - Testa fusiforme a elítica em vista frontal, triangular em secção; periferia com carenas fortes nos ângulos; lados côncavos ; câmaras distintas, ligeiramente infladas e triangulares em secção ; suturas distintas, deprimidas na parte mais jovem da testa; parede lisa; abertura arredondada, terminal, sôbre um peseoço curto, com um lábio distinto.

OCORRÊNCIA - A espécie é rara no poço CR-1-PA, ocorrendo, em amostras de calha, nos seguintes intervalos: $274 \mathrm{~m} 277 \mathrm{~m}$, $317 \mathrm{~m}-320 \mathrm{~m}, 347 \mathrm{~m}-350 \mathrm{~m}, 501 \mathrm{~m}-510 \mathrm{~m}$. Os espécimes abaixo de $277 \mathrm{~m}$ são raros e talvez provenham de contaminação de sedimentos superiores.

Dimensões - As dimensões, medidas em 3 espécimes, são: 1) Comprimento $0.45 \mathrm{~mm}$, largura $0.25 \mathrm{~mm}$, espessura $0.19 \mathrm{~mm}$;

2) Comprimento. $0.31 \mathrm{~mm}$, largura $0.22 \mathrm{~mm}$, espessura $0.10 \mathrm{~mm}$; 3) Comprimento $0.14 \mathrm{~mm}$, largura $0.09 \mathrm{~mm}$, espessura $0.08 \mathrm{~mm}$.

Discussĩo - Os espécimes brasileiros concordam bem com a descrição e ilustração de $A$. illingi Cushman e Renz a qual foi deserita do Mioceno da Venezuela. (Formação Agula Saladia Superior).

$$
\text { Plesiótipos - L. P - C. N. P 1-4. }
$$

Angulogerina ef jamaicensis Cushman e Todd

$$
\text { Est. } \bar{\imath} \text { - Figs. 14-17 }
$$

Angulogerina jamaicensis Cushman e Todd, Cush. Lab. Foram. Res.. Sp. Publ. 15, 1945, p. 53, pl. 8. fig. 3; Mioceno Médio, Buff Bay, Jamaica. - Redmond, Jour. Pal., vol. 27, n. ${ }^{\circ}$, 1953, p. 723, pl. 75, figs. 29 a, b; Mioceno Médio, formação Tubara, Colômbia.

Descriçĩo - Testa pequena para o gênero, alongada, duas a duas vêzes e meia mais longa que larga; periferia lobulada em vista frontal, triangular em vista apertural, com faces planas ou ligeiramente convexas; câmaras não unidas intimamente, com a parte superior um tanto excavada e a parte inferior se projetando ligeiramente; suturas muito deprimidas; parede ornamentada por costas longitudinais altas, cêrca de 5 para cada câmara, independentes, não se unindo com as dlas câmaras adjacentes; abertura sôbre um pescoço longo e estrcito e dotado de um lábio.

OCorrêncta - A espécie ocorre, no poco CR-1-PA. em amostras de calha, nos seguintes intervalos : $262 \mathrm{~m} 293 \mathrm{~m}, 329 \mathrm{~m} 347 \mathrm{~m}$, $365 \mathrm{~m}-369 \mathrm{~m}, 50: 3 \mathrm{~m} \quad 524 \mathrm{~m}, 658 \mathrm{~m} \quad 668 \mathrm{~m}, 707 \mathrm{~m} \quad 725 \mathrm{~m}$. Contudo os espécimes provenientes de cotas inferiores a $293 \mathrm{~m}$. são raros e 
talvez provenham de contaminação de sedimentos de cotas superiores.

Dimensões - As dimensões, medidas em 3 espécimes são: 1) Espécime figurado: Comprimento $0.25 \mathrm{~mm}$, largura $0.11 \mathrm{~mm}$, espessura $0.11 \mathrm{~mm}$; 2) Outro espécime figurado: Comprimento $0.32 \mathrm{~mm}$, largura $0.18 \mathrm{~mm}$, espessura $0.12 \mathrm{~mm}$; 3) Espécime não figurado: Comprinento $0.23 \mathrm{~mm}$, largura $0.15 \mathrm{~mm}$, espessura $0.12 \mathrm{~mm}$.

Discussĩo - Os espécimes brasileiros se assemelham a descrição e ilustração de A. jamaicensis Cushman e Todd, a qual foi descrita do Mioceno de Jamaica (Buff Bay), diferindo, contudo, por serem menos alongados e pela projeção das câmaras menos acentuada. A vista apertural é, em nossos exemplares, mais arredondada que em A. iamaicensis. É possível que tenhamos aqui nova espécie.

$$
\text { TIPOS - L. P - C. N. P 1-5. }
$$

Angulogerina ef rugoplicata Cushman

Est. 7 - Figs. 18-19

Angulogerina rugoplicaia Cushman, Cush. Lab. Foram. Res., Contr. vol. 11, 1935. p. 33. p3. 5. figs. 5 a, b; Oligoceno Inferior, Mississippi.

Descriçĩo - Testa alongada, com o comprimento 2 a 3 vêzes a largura, triangular em vista apertural ; lados ligeiramente côneavos e os ângulos, no adulto, truncados; um tanto fusiforme em vista lateral, com o maior diâmetro, aproximadamente, no meio da testa; câmaras distintas, fortemente côncavas na base e no lado interno, irregulares, aumentando de tamanho para a extremidade apertural; suturas fortemente deprimidas; parede distintamente perfurada com ligeiros traços de estrias longitudinais sòmente na porção mais antiga da testa, o restante da testa com parede lisa; abertura circular, terminal, com um pesçoço cilíndrico muito curto e um peyueno lábio arredondado.

Ocorrência - Esta espécie ocorre, no poco CR-1-PA, em amostras de calha, nos seguintes intervalos: $262 \mathrm{~m} 293 \mathrm{~m}, 335 \mathrm{~m} 338 \mathrm{~m}$, $503 \mathrm{~m}-524 \mathrm{~m}, 543 \mathrm{~m}-549 \mathrm{~m}, 707 \mathrm{~m} 725 \mathrm{~m}, 844 \mathrm{~m}-857 \mathrm{~m}$, Contudo as ocorrências abaixo de $293 \mathrm{~m}$, são esporádicas e talvez sejam provenientes de contaminação das amostras de calha.

Dimensões - As dimensões, medidas em 2 espécimes foram: Espécime figurado: Comprimento $0.28 \mathrm{~mm}$, largura $0.14 \mathrm{~mm}$, espessura $0.08 \mathrm{~mm}$. Outro espécime: Comprimento $0.12 \mathrm{~mm}$, largura $0.05 \mathrm{~mm}$, espessura $0.05 \mathrm{~mm}$. 
Discussão - A espécie A. rugoplicata Cushman foi descrita do Oligoceno de Mississippi, Estados Unidos da América do Norte. Os espécimes brasileiros se assemelham as descrições e ilustrações desta espécie. Tivemos oportunidade de comparar diretamente o nosso material com espécimes provenientes de Mississippi, verificando a semelhança dos dois materiais. Não obstante o pescôço em nossos espécimes é mais alongado e a testa é também mais alongada.

Tanto quanto é de nosso conhecimento esta espécie não aparece em sedimentos posteriores ao Oligoceno. A. hughesi (Galloway e Wessler) difere de nosso material por possuir as câmaras mais entumescidas, não tão excavadas como em nossos indivíduos.

$$
\text { Tipos - L. P. - C. X. P. 1-6. }
$$

\section{Discorbis floridensis (Cushman)}

Est. 7 - Figs. 20-21; Est. 8 - Fig. 1

Discorbis bertheloti (d'Orbigny) var. floridensis Cushman, U. S. Nat. Mus., Bull. 104, pt. 8, 1931, p. 17, pl. 3, figs. 3-5; Recente, Flórida. - Bermudez, Mem. Soc. Cubana Hist. Nat. vol. 9, 1935, p. 201; Recente, Cuba. - Palmer e Bermudez, Idem, vol. 9, 1936, p. 240; Mioceno, Cuba. - Palmer, Bull. Am. Pal., vol. 29, n. ${ }^{\circ}$ 115, 1945, p. 54; Mioceno Médio, formação Bowden, Jamaica. - Cushman e Todd, Cush. Lab. Foram. Res., Sp. Publ. 15, 1945, p. 56, pl. 8, figs. 15, 16; Mioceno, Buff Bay, Jamaica.

Discorbis floridensis (Cushman). Bermudez, Cush. Lab. Foram. Res., Sp. Publ. 25, 1949, p. 238, pl. 15, fiğs. 19-21; Mioceno Médio, formação Gurabo, São Domingos. -- Mem. Soc. Cubana Hist. Nat., vol. XIX, n. ${ }^{\circ} 3$, p. 337; Oligoceno Superior - Recente, Cuba. - Redmond, Jour. Pal., vol. 27, n. ${ }^{\circ}$ 5, 1953, p. 724, pl. 75. figs. 32 a, c; Mioceno Superior, Colômbia.

Descrição - Testa pequena, um tanto alongada, côneavoconvexa, deprimida, lado ventral côneavo, lado dorsal convexo, sendo a superfície uniformemente convexa a partir do proloculum; periferia aguda carenada; câmaras em número de 4 na última volta do corpo, aumentando ràpidamente de tamanho, largas; suturas ligeiramente deprimidas, tanto no lado dorsal como ventral, um tanto limbadas e ligeiramente oblíquas no lado dorsal, aproximadamente radiais no lado ventral; parede grosseiramente perfurada; a abertura consiste de uma estreita fenda na base da face apertural, próxima ao umbílico, com um prolongamento da última câmara sôbre ela.

OcorrêncIa - Esta espécie ocorre, no poço CR-1-PA, em amostras de calha dos seguintes intervalos: $262 \mathrm{~m}-277 \mathrm{~m}, 287 \mathrm{~m}-299 \mathrm{~m}$, $311 \mathrm{~m}-314 \mathrm{~m}, 332 \mathrm{~m}-353 \mathrm{~m}, 375 \mathrm{~m}-387 \mathrm{~m}, 512 \mathrm{~m}-542 \mathrm{~m}, 555 \mathrm{~m}-$ $561 \mathrm{~m}, 658 \mathrm{~m}-668 \mathrm{~m}$. 
Dinensões - As dimensões medidas em 2 espécimes são as seguintes: 1) Espécime figurado: Diâmetro maior $0.28 \mathrm{~mm}$, diâmetro menor $0.22 \mathrm{~mm}$, espessura $0.07 \mathrm{~mm}$; 2) Outro espécime: Diâmetro maior $0.13 \mathrm{~mm}$, diâmetro menor $0.12 \mathrm{~mm}$, espessura $0.07 \mathrm{~mm}$.

Plesiótipos - L. P - C. N. P 1-30.

\section{Discorbis orbicularis (Terquem)}

Est. 8 -- Figs. 2-4

Rosalina orbicularis Terquem, Essai. Class. Anim. Dunkerque, pt. 2, 1876. p. 75 , pl. 9, fig. 4; Recente, França.

Discorbis orbicularis (Terquem). Cushman, U. S. Nat. Mus., Bull. 104, pt. 8, 1931, p. 27, pl. 6. fig. 3; Referências, Recente. - Cushman e Ponton, Flórida Geol. Surv., Bull. 9, 1932, pp. 89-90, pl. 13, figs. 6 a, c; Mioceno Inferior, formação Choctawhatchee, Flórida. - Cushman e Cahill, U. S. Geol. Surv., Prof. Paper 175-A, 1933, p. 29. pl. 10, figs. 1 a, c; Mioceno Inferior, formação Choctawhatchee, Fló. rida. - Bermudez, Mem. Soc. Cubana Hist. Nat., vol. 9, 1935, p. 205; Recente, Cuba. - Palmer e Bermudez, Mem. Soc. Cubana Hist. Nat., vol. 9, 1936, p. 240: Mioceno Superior, Cuba. - Palmer, Bull. Am. Pal., vol. 29, n.॰ 115, 1945, p. 56; Mioceno Médio, formação Bowden. Jamaica. -- Bermudez, Cush. Lab. Foram. Res., Sp. Publ. 25, 1949, pp. 239-240, pl. 15, figs. 31-33; Mioceno Médio, formação Gurabo, São Domingos.

Descriçĩo - A testa é um cone baixo cujo lado dorsal é convexo e o ventral plano ou ligeiramente côncavo; o esbôco é circular. as câmaras alongradas e a parede grosseiramente perfuradla.

Ocorrêscia - Esta espécie é rara no poço CR-1-PA, ocorrendo em amostra de calha do seguinte intervalo: $268 \mathrm{~m} 277 \mathrm{~m}$.

Dinensões - As dimensões, medidas em 2 espécimes, foram: 1) Espécime figurado: Diâmetro maior $0.27 \mathrm{~mm}$, diâmetro menor $0.26 \mathrm{~mm}$, espessura $0.07 \mathrm{~mm}$; 2) Outro espécime: Diâmetro maior $0.08 \mathrm{~mm}$, diâmetro menor $0.07 \mathrm{~mm}$, espessura $0.04 \mathrm{~mm}$.

Discussio - Os nossos indivíduos concordam perfeitamente com as descrições e ilustrações da espécie D. orbicularis (Terquem). Recentemente Bermudez (1952 p. 34), reviveu o gênero Rosalina creado por d'Orbigny em 1826 e pôsto posteriormente em sinonímia do gênero Discorbis, colocando a espécie em consideração sob o gềnero Rosalina, como na descrição original de Terquem. Redmond (1953 p. 724) dá, para esta espécie, o nome Discorbis terquemi (Rzehak), lembrando que Rzehak já em 1888 deu novo nome a esta espécie (Discorbina terquemi Rzehak = Rosalina orbicularis Terquem) por estar, o nome Rosalina orbicularis preocupado por uma espécie de d'Orbigny. Infelizmente não houve timpo de alterarmos o nome da espécie no título e nas figuras. 
Esta é uma espécie característica de águas quentes (Cushman e Cahill, 193:3, p. 29).

Plesiótipos - L. P - C. N. P 1-31.

Discorbis patelliformis (Brady)

Est. 8 - Figs. 5-7

Discorbina patelliformis Brady, Rep. Voy. Challenger, Zool., vol. 9, 1884, p. 650, pl. 88, fig. 10; Recente, Ilhas Admiralty e Papua, Pacífico.

Discorbis ef patelliformis (Brady), Bermudez, Cush. Lab. Foram. Res., Sp. Publ. 25, 1949, p. 240, pl. 15, figs. 34-36; Mioceno Médio, formação Gurabo, São Domingos.

Descriçĩo - Testa cônica, lado dorsal altamente cônico, lado rentral plano; periferia aguda; cêrea de 3 voltas do corpo visíveis no lado dorsal, com cêrca de 3 câmaras longas e baixas por volta do corpo; há sugestóes de ornamentação no lado ventral.

OCorrência - Esta pequena espécie é rara no pogo CR-1-PA, ocorrendo, em amostras de calha dos seguintes interralos: $295 \mathrm{~m}$ $301 \mathrm{~m}, 385 \mathrm{~m} 391 \mathrm{~m}, 688 \mathrm{~m} 694 \mathrm{~m}$.

Draensões - As dimensões, medidas no espécime figurado, foram: Diâmetros $0.40 \mathrm{~mm}$, espessura $0.18 \mathrm{~mm}$.

Discussão - (os espécimes brasileiros são menores e possuem menos câmaras por rolta do corpo que os exemplares típicos descritos por Brady, porém êles concordam em outros cdracteres. Esta espécie vive atualmente na região Inclo-Pacífica; não tem sido confirmadas as supostas ocorrências no ()ceano Atlântico, oncle ela aparece somente como fóssil.

O espécime figurado é de 1 in indivíluo “uja altur’a é média, sem atingir o extremo de outros indivíduos, os duais se parecem mais com as ilustrações de Bermudez (1949, pl. 15, figs. 34-36).

Recentemente Bermudez (1952, p. 37 ) refere a espécie aqui em consideração, com dúvida, ao gềnero Comonblla crado por Hofker em 1951.

Piesiótipos - L. P - C. X. P 1-32.

Discombis is

Est. 8 - Figrs. 11-13

Descreçio - A testa tem a forma de mun alco. cuja convexidade é formada pelo lado dorsal ; as câmaras são regularmente distintas 
em ambos os lados, as suturas limbadas e niveladas no lado dorsal, deprimidas no lado ventral; cêrca de 6 câmaras compreende a última volta do corpo; as câmaras, no lado dorsal, aumentam ràpidamente em largura e gradativamente em comprimento.

Ocorrência - A raridade dêsse fóssil nas amostras de calha do poço CR-1-PA, não permite uma identificação segura. Sòmente 4 indivíduos foram coletados, distribuídos em amostras de calha dos seguintes intervalos: $262 \mathrm{~m} 268 \mathrm{~m}, 290 \mathrm{~m} 293 \mathrm{~m}, 299 \mathrm{~m}-302 \mathrm{~m}$,

Dimensões - As dimensões, medidas no espécime figurado, são: Diâmetro maior $0.87 \mathrm{~mm}$, diâmetro menor $0.67 \mathrm{~mm}$, espessura $0.37 \mathrm{~mm}$.

Discussĩo - Esta espécie mostra sinais de ter sido, em vida, séssil, prêsa ao substratum pelo lado ventral. Isto causou uma diversificação dos lados dorsal e ventral fazendo com que ela adquirisse o aspecto das testas do gênero Lamarckina. Contudo o lado ventral não se mostra polido como é característico daquêle gênero. $O$ aspecto do lado dorsal lembra a espécie Discorbis bertheloti (d'Orbigny).

TiPos - L. P. - C. N. P 1-33.

Valuulineria aff scrobiculata (Schwager)

Est. 8 -- Figs. 8-10

Anomalina scrobiculata Schwager, Palaeontogr. vol. 30,1883, p. 129, pl. 29, (6), figs. 18 a, d; Eoceno Médio, África do Norte.

Valvulineria scrobiculata (Schwager), Cushman e Ponton, Cush. Lab. Foram. Res., Contr. vol. 8, pt. 3, 1932, p. 70, pl. 9, figs. 5 a-c; Eoceno, Alabama.

DEScriçĩo - Testa pequena, biconvexa, evoluta no lado dorsal, involuta no lado ventral; periferia arpedondada, inteira, não lobulada; as câmaras em número de 7 a 8 na última volta do corpo, não são infladas; suturas $1 \mathrm{~m}$ tanto indistintas, aproximadamente radiais, ligeiramente curvas, não limbadas, ligeiramente deprimidas; parede lisa, polida; abertura sob uma ligeira extensão da última câmara sôbre a região umbilical; testa fortemente umbilicada.

Oconkência - Esta espécie é rara no poço CR-1-PA, ocorrendo, em amostras de calha dos sequintes intervalos: $262 \mathrm{~m} 277 \mathrm{~m}$, $290 \mathrm{~m} 293 \mathrm{~m}$.

Dimensões - As dimensões, medidas em 2 espécimes são as seguintes: 1) Espécime figurado: Diâmetro maior $0.31 \mathrm{~mm}$, diâ- 
metro menor $0.22 \mathrm{~mm}$, espessurd $0.13 \mathrm{~mm}$; 2) Outro espécime : Diâmetro maior $0.08 \mathrm{~mm}$, diâmetro menor $0.07 \mathrm{~mm}$, espessura $0.04 \mathrm{~mm}$.

Discussio - Esta espécie é afim a $V$ scrobiculata (Schwager) descrita do Eoceno do Velho e Novo Mundo. Os espécimes brasileiros, apesar de não serem provenientes de material do Eoceno, se assemelham a espécie de Schwager pelas descriçoes e ilustraçóes. Êles são menores, mas a periferia é caracteristicamente inteira, não lobulada, as suturas deprimidas a a testa umbilicada ventralmente; o número de câmaras parece ser, contudo, ligeiramente menor, e a testa também é bem mais alongada no nosso material.

$$
\begin{aligned}
& \text { TIPos - I. P - C. N. P 1-113. } \\
& \text { Gyroidina aff parra Cushman e Renz } \\
& \text { Est. } 8 \text { - Figs. 14-16; Est. 9- Figs. 1-3 }
\end{aligned}
$$

Gyroidina parva Cushman e Renz, Cush. Lab. Foram. Res., Contr. vol. 17, pt. 1, 1941, p. 23, pl. 4, fig. 2; formação Agua Salada, Inferior e Superior, Oligoceno Superior - Mioceno Médio, Venezuela.

Descriçio - Testa pequena, plano-convexa, lado dorsal plano, lado ventral muito convexo; umbílico preenchido; periferia arredondada, lobulada; câmaras distintas, 5 a 6 na última volta do corpo; suturas distintas, deprimidas, aproximadamente radiais tanto no lado dorsal como ventral; parede espêssa, lisa e polida; a abertura é constituída por uma fenda alongada na base da face apertural, entre a região umbilical e a periferia.

Ocorrêncta - Fsta espécie é lara no poço CR-1-PA, ocorrendo, em amostras de calha dos seguintes intervalos: $271 \mathrm{~m} 280 \mathrm{~m}$, $366 \mathrm{~m} 369 \mathrm{~m}$.

Dinensões - As dimensões medidas nos espécimes figurados, são as seguintes: 1) Diâmetro maior $0.25 \mathrm{~mm}$, diâmetro menor $0.22 \mathrm{~mm}$, espessura $0.12 \mathrm{~mm}$; 2) Diâmetro $0.17 \mathrm{~mm}$, espessura $0.07 \mathrm{~mm}$.

Discussĩo - Esta espécie, pelo número de câmal’as, espessura da testa e periferia arredondada, se aproxima de G. parva Cushman e Renz, do Oligoceno e Mioceno da Tenezuela, diferindo, contudo, pela atitude aproximadamente radial dos septos dorsais e pela última volta do corpo que não é deprimida em relação as outras. Possivelmente trata-se aqui de uma espécie nova, devido a raridade de exemplares (4 indivíduos) todos de pequeno tamanho, sendo, provàvelmente, formas jovens, preferimos não descrevê-los como tal. 
Outras espécies com o mesmo número de câmaras por volta do corpo, tais como G. chirana Cushman, do Eoceno do Perú, diferem por mostrar, parcialmente, na região umbilical do lado ventral, as câmaras anteriores. Gr. byramensis Cushman e Todd difere por possuir a testa mais alongada e as câmaras, proporcionalmente, mais alongadas.

Tipos - L. P - C. N. P 1-68.

\section{Gyroidinoides sp}

Est. 9 - Figs. $4-6$

Descriçio - Testa formada por cêred de 2 roltas, pequena, um tanto deprimida, lado ventral bem convexo, lado dorsal ligeiramente convexo; umbílico claro, estreito mas profundo; periferia arredondada; câmaras distintas, cêrca de 7 na última volta do corpo; suturas distintas, um tanto deprimidas, radiais tanto no lado ventral como dorsal, ligeiramente curvas no lado dorsal; parede lisa, polida; a abertura consiste de uma fenda alongada na base da face apertural, a partir do umbílico, dotada de um lábio.

OCORRÊNCIA - Esta espécie é muito rara no poco CR-1-PA, tendo sido encontrados 3 indivíduos, razão porque não lhes refelimos a nenhuma espécie em particular. Êsses indivíduos foram encontrados em amostras de calha dos seguintes interralos: $262 \mathrm{~m}$ $265 \mathrm{~m}, 317 \mathrm{~m}-320 \mathrm{~m}$.

Dinensóes - As dimensões, medidas no espécime figurado, foram: Diâmetro maior $0.17 \mathrm{~mm}$, diâmetro menor $0.14 \mathrm{~mm}$, espessura $0.06 \mathrm{~mm}$.

Discussĩo - Esta espécie pelo fato de ser biconvexa, distintamente umbilicada e deprimida, se aproxima de $G$. planulata (Cushman e Renz) do Mioceno da Venezuela. Distingue-se desta última espécie pelo menor número de câmaras.

O gênero Gyvoidinoides foi criado por Brotzen (1942 p. 35 ) o qual foi separado de Gyroidina pelo umbílico aberto e pela presença de lábio sôbre a abertura. Cushman em seu tratado de foraminíferos, 4." edição (1948 p. 290) considera o gênero válido, contudo, em seus artigros, êle tem sempre referidlo as espécies de Gyroidinoides, ao gênero Gyroidina, o que tem sido seguido por diversos antores. Outros como Renz (1948 p. 1399) mantém o gênero de Brotzen em suas publicaçóes.

$$
\text { Tipos - L. P - C. \. P. 1-69. }
$$




\title{
Eponides repandus (Fichtel e Moll)
}

\author{
Est. 9 - Figs. $7-9$
}

Pulvinulina repanda (Fichtel e Moll), Brady, Rep., Voy. Challenger, Zool., vol. 9, 1884, p. 684, pl. 104, figs. 18 a, c; Recente.

Eponides repanda (Fichtel e Moll), Cushman, U. S. Nat. Mus., Proc. vol. 75, art. 25,1929 , p. 11 , pl. 4 , figs. 7 a, c; Recente.

Eponides repandus (Fichtel e Moll), Cushman e Ponton, Flórida Geol. Surv. Bull. 9, 1932, p. 92, pl. 13, figs. 9 a, c; Mioceno Inferior, Flórida - Recente, Flórida e Antilhas. - Galloway e Heminway, New York Acad. Sci., vol. 3, pt. 4, 1941, p. 375, pl. 17, fig. 3; Mioceno Inferior, formação Quebradillas, Pôrto Rico. Bermudez, Cush. Lab. Foram. Res., Sp. Publ. 25, 1949, p. 248, pl. 17, figs. 13-15; Mioceno Médio, formação Gurabo, São Domingos. - Redmond, Jour. Pal., vol. 27, n..$^{\circ}$, 1953, p. 726, pl. 76, figs. 8 a, c; Mioceno Médio e Superior, Colômbia.

Descrição - Testa subcircular em vista lateral, de tamanho normal para o gênero, biconvexa, havendo tendência para o lado ventral ser mais convexo que o dorsal; periferia inteira, não lobulada, aguda, ligeiramente carenada; câmaras em número de 7 a 8 na última volta do corpo; suturas dorsais um tanto indistintas, oblíquas em relação a periferia e retas; elas não são nem deprimidas e nem elevadas mas contínuas com o resto da testa e limbadas; suturas ventrais radiais, mais distintamente limbadas e, também, nem deprimidas e nem elevadas mas contínuas com o resto da testa; as primeiras voltas do corpo, no lado dorsal, são difíceis de se perceber, formando, o seu conjunto, um umbo distinto; o lado ventral mostra uma pequena área central formada pela fusão das suturas limbadas; parede espêssa, finamente punctada, lisa; face apertural um tanto côncava, triangular, sendo que o lado externo, que vai do umbo a periferia, é o lado maior, e o menor é formado pela periferia; abertura alongada na base da face apertural.

Ocorrência - Esta espécie ocorre, no poço CR-1-PA, em testemunhos de sondagem e em amostras de calha. Ela aparece nos seguintes testemunhos: Test. n. ${ }^{0}$ 6, $500 \mathrm{~m} 503 \mathrm{~m}$, test. ${ }^{\circ}{ }^{\circ} 7,503 \mathrm{~m}$ $506 \mathrm{~m}$. Ocorre também em amostras de calha dos seguintes intervalos : $259 \mathrm{~m}-326 \mathrm{~m}, \quad 340 \mathrm{~m} 423 \mathrm{~m}, 478 \mathrm{~m} \quad 485 \mathrm{~m}, 497 \mathrm{~m} 555 \mathrm{~m}$, $573 \mathrm{~m} 582 \mathrm{~m}, \quad 594 \mathrm{~m} \quad 600 \mathrm{~m}, 658 \mathrm{~m} 667 \mathrm{~m}$.

Dimensões - As dimensões medidas em 2 espécimes são as seguintes: 1) Espécime figurado: Diâmetro maior $0.76 \mathrm{~mm}$, diâmetro menor $0.70 \mathrm{~mm}$, espessura $0.37 \mathrm{~mm}$; 2) Outro espécime: Diâmetro maior $0.34 \mathrm{~mm}$, diâmetro menor $0.29 \mathrm{~mm}$, espessura $0.18 \mathrm{~mm}$.

Discussão - Os representantes paraenses de $E$. repandus (Fichtel e Moll) não se identificam perfeitamente com as descrições e ilustrações desta espécie. Os nossos espécimes são mais circulares, e o lado dorsal mostra, 3 ou 4 voltas. Esta espécie tem 
sido muito citada nd literatura. Contudo muitas dessas citacooes devem ser referidas a outras espécies. Ela é muito comum, como forma vivente, na província caraíbica. Como fóssil, ela ocorre na província caraíbica no Mioceno de Flórida, São Domingos e Pôrto Rico.

Redinond (1949 pp. 19-21) chamou a atenção para a confusão a respeito desta espécie, que também é o genótipo de Eponides propôsto por Montfort em 1808. Secuindo o uso geral a espécie $E$. repandus é aqui considerada como idêntica a Pulvinulina repanda Brady (Non Nautilus repandus Fichtel e Moll).

Outras espécies de Eponides aparecem no poço CR-1-PA, as quais não foram descritas devido a raridade de exemplares.

Plestótipos - L. P. - C. N. P 1-46.

"Rotalia"' beccarii (Lineu) var. angulata Petri var. nov.

Est. 9 - Figs. 10-12

Descriçĩo - Testa aproximadamente circular, em espiral deprimida, biconvexa a plano-convexa, sendo que o lado dorsal tende a ser mais projetante que o ventral; periferia angular e não lobulada; o indivíduo adulto é formado por cêrea de 4 voltas do corpo; o número de câmaras, na última volta do corpo, é em tôrno de 11; as suturas do lado dorsal são niveladas com o resto da testa e marcadas pelas linhas largas e claras dos septos espêssos; as suturas do lado ventral são excavadas e largas, limbadas; a rôlha que aparece no lado ventral é bem visível e perfeitamente separada das câmaras, as quais, no contacto com ela, são lobuladas; a parede é finamente perfurada, geralmente de uma côr amarelada, e a abertura é mediana, na base da face apertural.

Ocorrîncin - Esta espécie ocorre, no poço CR-1-PA, nos seguintes testemumhos de sondagem: Test. ${ }^{0}{ }^{0} 6,500 \mathrm{~m} 503 \mathrm{~m}$, test. n. ${ }^{\circ} 8,614 \mathrm{~m} 617 \mathrm{~m}$, test. ${ }^{\circ}{ }^{\circ} 10,620 \mathrm{~m}-623 \mathrm{~m}$. Ocorre também, em amostras de calha dos seguintes intervalos: $259 \mathrm{~m}-485 \mathrm{~m}, 497 \mathrm{~m}$ $567 \mathrm{~m}, 588 \mathrm{~m} 606 \mathrm{~m}, 658 \mathrm{~m} 668 \mathrm{~m}, 738 \mathrm{~m} 765 \mathrm{~m} .783 \mathrm{~m} 820 \mathrm{~m}$, $844 \mathrm{~m} 857 \mathrm{~m}, 1000 \mathrm{~m} 1009 \mathrm{~m}, 1064 \mathrm{~m} 1073 \mathrm{~m}, 1253 \mathrm{~m} 1262 \mathrm{~m}$.

Dimensões - As dimensões medidas nos espécimes figurados são as seguintes: 1) Diâmetro maior $0.62 \mathrm{~mm}$, diâmetro menor $0.59 \mathrm{~mm}$, espessura $0.28 \mathrm{~mm}$; 2) Diâmetro maior $0.56 \mathrm{~mm}$, diâmetro menor $0.53 \mathrm{~mm}$, espessura $0.21 \mathrm{~mm}$; 3) Diâmetro maior $0.34 \mathrm{~mm}$, diâmetro menor $0.31 \mathrm{~mm}$, espessura $0.21 \mathrm{~mm}$. 
Discussĩo - A presente variedade possue o aspecto geral, número de câmaras, caráter das suturas, ete. de "Rotalia" bcccarii (Lineu). Contudo, difere da forma típica, por possuir periferia angular, e, pelo lado dorsal mais distintamente abaulado que o ventral, o qual, as vêzes, é plano on mesmo côncaro. Tanto pela periferia angular as vêzes carenada como pelo lado dorsal distintamente abaulado, a nossa forma se aproxima de R. rosea d'Orbigny; contudo a abertura não é bordejada por um lábio superior, não existindo também reentrâncias nas suturas ventrais de nossos espécimes. O caráter abaulado do lado dorsal é também menos acentuado em nossos espécimes.

Bermudez (1952 pp. 70-7 7 ) define diversos gêneros intimamenlte relacionados a Rotalia, sistematisando os trabalhos de diversos autores a respeito. Baseado no referido trabalho de Bermudez, apresentamos aqui diversas retificaçoes relativas aos exemplares descritos como "Rotalia" beccarii (Lineu) var. angulata Petri, retificaçoes estas infelizmente muito tardias para aparecer nas descrições e nas tabelas aqui apresentadas.

Dos exemplares figurados, o da Est. 9, figs. 10-12, representando uma concha com rôlha bem distinta, pertence realmente a variedade aqui chamada de angulata, a qual deve ser mais pròpriamente referida ao gênero streblus, portanto, ela deve ser denominada da seguinte maneira: Streblus beccarii (Lineu) var. angnlata Petri var. nov.

O segundo e o terceiro exemplares figurados, sem rôlha distinta e com carena bem distinta na periferia (Est. 9, figs. 13-18) parecem pertencer a outra espécie de streblus que julgamos ser nova, representando o exemplar nenor, uma forma joven. Propomos para êsses exemplares a denominação śtreblus marajoara Petri sp nov. A forma jovem possui 7 câmaras na última volta do corpo, enquanto a forma adulta, 11.

Streblus beccarii (Lineu) var. angulata Petri var. nor. possui o lado ventral distintamente convexo, se bem que muito menos que o lado dorsal, a rôlha bem grande, as suturas ventrais distintamente limbadas e a periferia subangular.

Esta variedade talvez seja idêntica a deserita por Cushman e Cahill (1933 p. 31) com o nome de Rotalia beccarii (Lineu) var. parkinsoniana (d'Orbigny) e proveniente do Mioceno de Flórida e Carolina do Sul. Contudo ela não é idêntica a espér.ie original descrita por d'Orbigny como Rosalina parkinsomiana, a qual, segundo Bermudez (1952 p. 73) não aparece nas Antilhas o sim no Norte da Europa.

Existe ainda uma terceira espécie de Streblus no poço CR-1PA caracterisada por uma rôlha pequena, pelo lado ventral quase plano, pelas suturas ventrais simples, não limbadas, e pela perife- 
ria fortemente angular, sendo além disso, menor que $S$. beccarii (Lineu) var. angulata Petri var. nov. O número de câmaras na última rolta do corpo é 8 . Ela parece ser idêntica a $S$. bassleri Cushman e Cahill proveniente do Mioceno de Maryland. Esta espécie é muito comum em muitos afloramentos da formação Pirabas. Voltaremos a ela quando tratarmos dos fósseis dessa formação.

" $R$.' beccarii (Lineu), originalmente descrita entre as formas recentes do Adriático, foi depois reconhecida como vivente em todos os oceanos, inclusive na província caraíbica, onde ela é conhecida desde o Oligoceno.

HoLótıpos - O holótipo de $S$. beccarii (Lineu) var. angulata Petri var. nov., está representado na Est. 9, figs. 10-12, e o de $S$. marajoara Petri sp nov., na Est. 9, figs. 13-15. Ambos estão depositados na coleção do Laboratório de Paleontologia do Conselho Nacional do Petróleo, em Belém, Estado do Pará, sob os números, respectivamente, $1-96$ e 1-102.

\section{siphonina pulchra Cushman}

$$
\text { Est. } 10 \text { - Figs. 1-3 }
$$

Siphonina pulchra Cushman, Carnegie Instit. Washington, Publ. 291, 1919, p. 42, pl. 14, fig. 7; Proc. U. S. Nat. Mus., vol. 72, 1927, p. 8, pl. 2, fig. 5; Mioceno, Matanzas, Cuba. - Bermudez, Mem. Soc. Cubana Hist. Nat., vol. 9, n. ${ }^{\circ}$ 3, 1935, p. 211; Recente, Cuba. - Palmer e Bermudez, Idem, vol. 9, n. ${ }^{\circ}$ 4, 1936, p. 240; Mioceno Superior. Cuba. - Coryell e Rivero, Jour. Pal., vol. 14, 1940, p. 337, pl. 43, fig. 23; Mioceno Médio. Port-au-Prince, Haití. - Palmer, Mem. Soc. Cubana Hist. Nat., vol. 15, 1941, p. 196; Oligoceno Superior, formação Cojimar, Cuba. - Bull. Am. Pal., vol. 29, n. ${ }^{\circ}$ 115. 1945, p. 61, Mioceno Médio, formação Bowden. Jamaica. -- Cushman e Stainforth, Cush. Lab. Foram. Res.. Sp. Publ. 14, 1945, p. 62, pl. 11, fig. 6; Oligoceno, formação Cipero, Trinidad, B. W. I. - Cushman e Todd, Cush. Lab. Foram. Res., Sp. Publ. 15, 1945, p. 59, pl. 9, fig. 12, Mioceno, Buff Bay, Jamaica. - Bermudez, Cush. Lab. Foram. Res., Sp. Publ. 25, 1949, pp. 243-244. pl. 16. figs. 34-36; Mioceno Médio e Superior, São Domingos. - Mem. Soc. Cubana Hist. Nat., vol. XIX, n.o 3, 1950, p. 361; Oligoceno Superior - Recente, Cuba. - Redmond. Jour. Pal., vol. 27, n. ${ }^{\circ} 3$, 1953, p. 726, pl. 76, figs. 12 a-c; Mioceno Médio e Superior, Colômbia.

Descriçio - Os espécimes acpui referidos a esta espécie concordam bem com os exemplares típicos, tendo o mesmo gran de convexidade da testa, forma da periferia carenada, tendendo para arredondada, ornamentação da testa produzida por perfurações bem distintas en ângulo reto rom a superfície da testa no meio das câmaras, tornando-se gradativamente mais oblíquas a medida que se dirigem para a periferia, de maneira que na zona da carena elas aparecem sob a forma de pequenos tubos bem distintos, cêrca de 12 por câmara, cortando transversalmente a área da carena; os 
nossos espécimes, em relação a espécie S. pulchra Cushman, possuem o mesmo tipo e número de câmaras por volta do corpo, caráter das suturas, posição da abertura e grau de desenvolvimento do pescoço.

OCORRÊNCia - Esta espécie é rara no poço CR-1-PA, ocorrendo em amostras de calha dos seguintes intervalos: $268 \mathrm{~m} 283 \mathrm{~m}$. $316 \mathrm{~m} 319 \mathrm{~m}, 443 \mathrm{~m} 460 \mathrm{~m}, 496 \mathrm{~m} \quad 502 \mathrm{ml}$.

Dramensões - As dimensões medidas no espécime figurado são: Diâmetro maior $0.33 \mathrm{~mm}$. diâmetro menor $0.30 \mathrm{~mm}$, espessura $0.21 \mathrm{~mm}$.

Plesiótipos - L. P - C. X. P. 1-98.

Cancris sagrai (d'orbigny)

Est. 10 - Figs. 4-9

Rotalina sagra d'Orbigny, in De La Sagra, Hist. Phys. Pol. Nat. Cuba, Fora. minifères, 1839, p. 77. pl. 5, figs. 13.15; Recente, Cuba e Jamaica.

Cancris sagra (d'Orbigny), Cushman, U. S. Nat. Mus., Bull. 104. pt. 8, 1931, p. 74, pl. 15, fig. 2; Referências, Recente, Atlântico. - Cushman e Parker, Idem, Proc., vol. 80, art. 3, 1931, p. 20; Recente, costa Atlântica da América do Sul. Palmer e Bermudez, Mem. Soc. Cubana Hist. Nat., vol. 9, 1936, p. 240; Mioceno Superior, Cuba. - Palmer, Idem, vol. 15, 1941, p. 198; Oligoceno Superior, formacão Cojimar, Cuba. - Bull. Am. Pal., vol. 29, n. ${ }^{\circ} 115$, 1945, p. 62; Mioceno Médio, formação Bowden, Jamaica. - Bermudez, Cush. Lab. Foram. Res., Sp. Publ. 25, 1949, p. 256, pl. 18, figs. 28-30; Mioceno Médio e Superior. São Domingos. Redmond, Jour. Pal., vol. 27, n. ${ }^{\circ}$ 5, 1953. p. 727, pl. 76, figs. 13 a, b; Mioceno Médio e Superior, Colômbia.

Cancris sagrai (d'Orbigny), Bermudez, Mem. Soc. Cubana Hist. Nat., vol. XIX, n." 3. 1950, p. 332; Plioceno - Recente, Cuba.

Descriçio - Testa ligeiramente mais longa que larga, convexa no lado ventral, quase plana no lado dorsal; periferia aguda, carenada, ligeiramente lobulada; câmaras no lado dorsal miformes, aumentando ràpidamente cm largura e gradualmente em comprimento, seralmente 6 na niltima rolta do corpo, uniformemente arqueadas e com o maior comprimento tendendo para o lado distal, infladas no lado ventral, çom a última câmara dotada de um lobo projetante sôbre o umbílico; esta câmara é envolvente no lado ventral, de maneira que, neste lado, a última câmara compreende cêrca de metade da superfície ventral da testa; suturas curvas e limbadas no lado dorsal, deprimidas e aproximadamente radiais no lado ventral; parede lisa, $1 \mathrm{~m}$ tanto grosseiramente perfurada, excepto pela presença de uma área oval clara, cêrca de metade da altura da cômara no lado ventral, na base da última câmara; aber- 
tura constituída de uma fenda baixa, no lado ventral, sob o lobo dà última rêtmara.

OCorrềcia - Esta espécie é relativamente rara no poço CR1-PA, ocorrendo, em amostras de calha, dos seguintes intervalos: $259 \mathrm{~m} 27 \mathrm{~m}, 357 \mathrm{~m} 360 \mathrm{~m}, 442 \mathrm{~m} 460 \mathrm{~m}$.

Drmessões - As dimensões, medidas nos espécimes figurados são: 1) Diâmetro maior $0.47 \mathrm{~mm}$, diâmetro menor $0.37 \mathrm{~mm}$, espessura $0.22 \mathrm{~mm}$; 2) Diâmetro maior $0.25 \mathrm{~mm}$, diâmetro menor $0.17 \mathrm{~mm}$, espessura $0.10 \mathrm{~mm}$.

Plesiótipos - L. P - C. N. P 1-19.

\section{Amphistegina lessonii d'Orbigny'}

Est. 10 - Figs. 10-16; Est. 11 - Figs. 1-6

Amphistegina lessonii d'Orbigny, Ann. Sci. Nat., vol. 7, 1826. p. 304, pl. 17, figs. 1-4 (A. quoii, na descrição das estampas); Recente, França. - Cushman, U. S. Nat. Mus., Bull. 104, pt. 8. 1931, p. 79, pl. 16, figs. 1-3; Recente, Antilhas. Cushman e Cahil!, U. S. Geol. Surv., Prof. Paper 175-A, 1933, p. 32, pl. 11, fig. 6; Mioceno, Flórida. - Coryell e Rivero, Jour. Pal., vol. 14, 1940, p. 339; Mioceno Médio, Port-Au-Prince, Haití. - Palmer, Mem. Soc. Cubana Hist. Nat., vol. 15, 1941, p. 198; Oligoceno Superior, formação Cojimar, Cuba. - Cushman e Todd, Cush. Lab. Foram. Res., Sp. Publ. 15, 1945, p. 60, pl. 10, fig. 2; Mioceno, Buff Bay, Jamaica. - Renz, Geol. Soc. Am., Mem. 32, 1948, p. 113, pl. 9. fig. 4; Mioceno, Venezuela. - Bermudez, Cush. Lab. Foram. Res., Sp. Publ. 25, 1949, pp. 263-264, pl. 19, figs. 1-3; Mioceno Médio e Superior, São Domingos. - Mem. Soc. Cubana Hist. Nat., vol. XIX, n. ${ }^{\circ} 3$, 1950, p. 327; Mioceno - Recente. Cuba. - Redmond, Jour. Pal.. vol. 27. n. ${ }^{\circ}$ 5, 1953. p. 727, pl. 77, figs. 1 a-c; Mioceno Médio e Superior, Colômbia.

Descrição e Discussĩo - Esta é a espécie mais numerosa do poço CR-1-PA. Como em outras regiões é aqui também muito variada. Essas variações se distribuem em uma escala que abrange muitos caracteres descritos para espécies diferentes de Amphistegina. Ainda não se conseguiu caracteres seguros para a distinção das diversas espécies sem ornamentação. Quanto as ornanentadas por yianulos e contas ou por áreas elevadas da superficie da testa, formas estas não encontradas na fóssa do Marajó, elas são muito distintas, a maior parte proveniente do Eoceno. São mesmo caractelísticas do Eoceno as formas com grossos grânulos na região umbilical como A. lopeztrigoi Palmer.

Dos indivíduos encontractos no poco CR-1-PA consideramos como típicos, os que apresentam os seguintes caracteres: Testa lenticular, carenada, completamente involuta tanto no lado dorsal 
como ventral, dotada de muitas câmaras (cêrca de 18 na última volta do corpo); suturas dorsais sinnosas dirigindo-se para a frente até próximo a periferia quando curvam bruscamente para traz cortando a periferia eni $11 m$ ângulo bem açudo. Apesar da mudança de direção da sutura se dar próximo a periferia ela demora para atingi-la, percorrendo uma distância maior que a primeira parte da sutura devido ao ângulo bem agudo com que ela procura a periferia. Intercalados entre os septos no meio das câmaras dêste lado, aparecem, as rêzés, suturas incompletas. Realmente estas suturas são apenas aparentemente incompletas visto serem a continuação das suturas dorsais normais, tomando êste aspecto incompleto devido a erosão da testa e aparecendo intercaladas devido a forte sinuosidade das suturas. No lado ventral as câmaras secundárias são irregulares, tendendo para a forma de losângulo.

Existe grande número de variações dêste tipo fundamental, as quais, geralmente, não estão em relação com o tamanho da testa, existindo diversificações tanto em formas jovens como adultas. Infelizmente o número de testemunhos de sondagem tirados na zona fossilifera onde parece êste fóssil é muito pequeno, tornaudo impossível $\mathrm{um}$ estudo estratigráfico destas variações. É difícil também dizer se estas variações estão em relação com a alternância de gerações microsférica e macrosférica devido a absorção das câmaras iniciais na zona do umbílico, muito comum nos exemplares paraenses.

A variedade que chamamos tumida se distingue da forma típica por ser bojuda no lado rentral, enquanto o lado dorsal é plano ou ligeiramente côncaro. Tma zrande rôlha, projetando-se muito para fora cobre o umbo do lado rentral, enquanto o umbo do lado dorsal é coberto por nua área transparente menor. As câmaras secundárias do lado ventral possuem a forma de losângulo mais regularmente delineada. As suturas du lado dorsal são menos sinnosas. O ângulo da suturà dorsal aparece mais para o meio da testa. O número de septos na última rolta do corpo, em média, também é menor (cêrca de 12). Esta variedade compreende tanto formas jovens como adultas, portanto não temos aqui variações de ordem ontogenética. Esta variedade pode ser comparada com a variedade gibba descrita por d'Orbigny da qual se distingue pela forma mais regular das cânuaras secundárias do lado ventral e pelo angnlo das suturas dorsais que está a meia distância do umbo a periferia. Nestes caracteres ela se aproxima da variedade bowdenensis descrita por Palmer de que se distingue pelo fato de o lado ventral ser o lado mais convexo, ao contrário da variedade de 


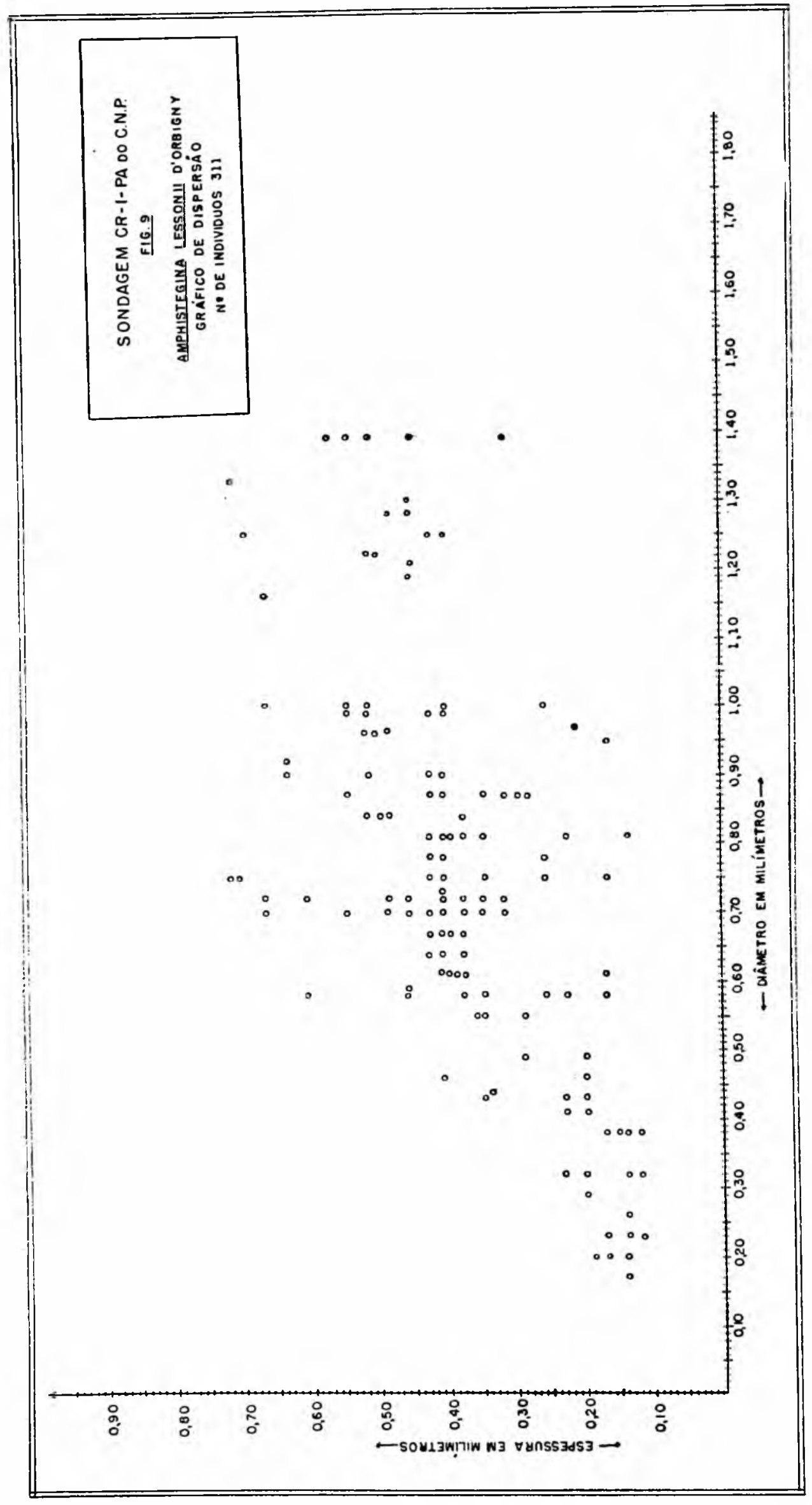


Jamaica. Ela se assemelha também a A. anyulata (Cushman), contudo temos, no nosso material, passagem gradativa da forma típica para a variedade, não podenclo, esta, sel separada daquela como entidade a parte.

A variedade que chamamos conica, como a variedade tumida, possue o lado ventral bem convexo, e o dorsal plano. Distingue-se desta última variedade por ser mais promunciadamente planoconvexa e por não possuir uma rôlha tão distinta e projetante no lado ventral. As câmaras secundárias dêste lado são bem regulares e em forma de losângo. As suturas dorsais são mais simples e menos angulosas. As vêzes a testa é evoluta no lado dorsal. O declive da testa no lado ventral, não é regular como na variedade anterior, mas cai bruscamente do umbo para a periferia, tornandose cada vez mais suave a medida que se aproxima da periferia. Como na forma típica e na variedade anterior, testas pequenas e grandes se incluem aqui. Contudo a tendência desta variedade é para incluir indivíduos menores.

Além das variedades aqui descritas, existem outras as quais não foram tratadas mais extensamente devido a raridade de representantes. Assim por exemplo, existe uma testa lenticular, parcialmente evoluta de ambos os lados e dotada de suturas limbadas. Pelo caráter parcialmente evoluto, esta testa se aproxima de $A$. floridana Cushman e Ponton e pelo earáter limbado das suturas ela se aproxima de A. taberina Bermudez. Existe ainda outra testa caracterisada por ser grandemente entumescida dorsalmente, com declive uniforme e uma rôlha pequena, sendo côncava no lado ventral. Pela forma fortemente côncavo-convexa ela se aproxima de A. rotundata (Cushman) contudo nesta última espécie o lado convexo é o ventral.

Algums indivíduos tanto da forma típica como das variedades mostram-se parcialmente erodidos, aparecendo então a área granular das aberturas das câmaras anteriores. O aspecto então é de uma testa granular lembrando por exemplo, A. foveolata Egger. Talvez esta espécie não passe de uma Amphistegina parcialmente erodida.

OCorrênCIA - Esta espécie foi encontrada nos seguintes testemunhos de sondagem: Testemunho n. ${ }^{\circ} 6,500 \mathrm{~m}-503 \mathrm{~m}$, test. n. ${ }^{\circ} \mathrm{T}$, $503 \mathrm{~m} 506 \mathrm{~m}$, test. n. ${ }^{\circ} 9,617 \mathrm{~m} 620 \mathrm{~m}$, test. ${ }^{\circ}{ }^{\circ} 10,620 \mathrm{~m} 623 \mathrm{~m}$. Ocorre também, em amostras de calha, nos seguintes intervalos:

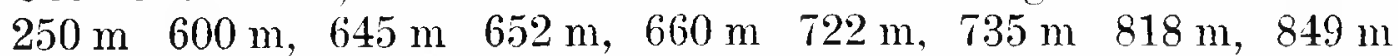
$928 \mathrm{~m}, 958 \mathrm{~m} 970 \mathrm{~m}, 1100 \mathrm{~m} 1119 \mathrm{~m}, 1134 \mathrm{~m} 1140 \mathrm{~m}$. $1278 \mathrm{~m}$ $1282 \mathrm{~m}, 1465 \mathrm{~m} 1477 \mathrm{~m}, 1560 \mathrm{~m} 1585 \mathrm{~m}$. 


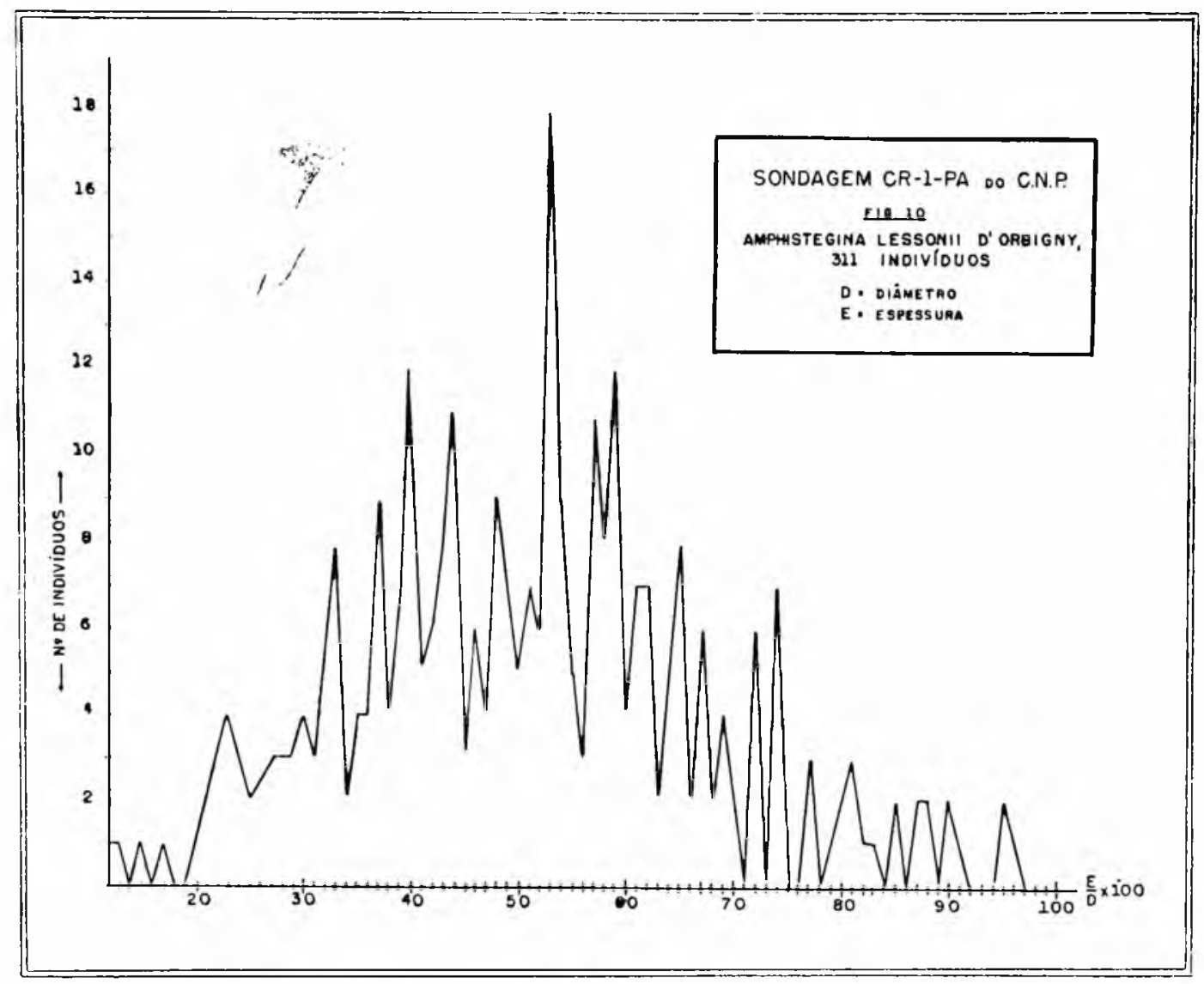

Dimensões - Devido ao grande número de indivídnos pertencentes a espécie em consideração na fauna do Mioceno de Cururú, organizamos um gráfico de dispersão (Fiğ. 9) e um polígono de frequiência (Fig. 10) desta espécie. Não podemos falar para a associação de Anthistegina do poço de Cururú, em população mesmo no sentido paleontológico, visto que os fósseis não provêm de $u m$ horizonte ou camada, mas de $11 \mathrm{~m}$ intervalo que vai de $250 \mathrm{~m}$ a $740 \mathrm{~m}$. Os gráficos foram obtidos tomando-se o conjunto da espécie $A$. lessonii d'Orbigny e as variedades tumida a conica e demonstram, a nosso_ver, que essas 3 entidades contituem uma única espécie, havendo passagem gradativa para as rariedades. () número de indivíduos examinados foi de 311.

O wráfico de dispersão foi obtido tomando-se nas ordenadas a espessura das testas e nas abcissas o diâmetro máximo das mesmas. O polígono de frecuiênecia foi obtido tomando-se nas ordenadas o número de indivíduos e nas abcissas a relação entre a espessura e o diâmetro multiplicado por 100.

Apesar de algumas discrepâncias devido, possivelmente, ao fato dos fósseis provirem de cotas diferentes do intervalo $250 \mathrm{~m}$ 
$740 \mathrm{~m}$, a regularidade das curvas é, a nosso ver, significativa. Não foi possível separar os indivíduos das diversas cotas devido, como já foi dito, a escassez de testemunhagem.

Piesiótipos - L. P - C. N. P 1-1.

Holótipos das variedades conica e tumida - L. P - C. X. P., respectiramente, 1-2 e 1-3.

\section{Tretomphalus atlanticus Cushman}

Est. 11 - Figs. 7-9

Cymbalopora (Tretomphalus) bulloides Brady, (Parte) (Non d'Orbigny), Rep. Voy. Challenger, Zool., vol. 9, 1884, p. 638, pl. 102, figs. 10, 11 (Non figs. 7-9, 12); Recente, Bermudas.

Tretomphalus atlanticus Cushman, Cush. Lab. Foram. Res., Contr., vol. 10, 1934, p. 86. pl. 11, fig. 3; pl. 12, fig. 7; Recente, Tortugas e Antilhas. - Bermudez, Mem. Soc. Cubana Hist. Nat., vol. 9, 1935, p. 214; Recente, Cuba. - Palmer, Idem, vol. 15, 1941, p. 281; Oligoceno Superior, formação Cojimar, Cuba. - Bull. Am. Pal., vol. 29, n. ${ }^{\circ} 115,1945$, p. 65; Mioceno Médio. formação Bowden, Jamaica. - Bermudez, Cush. Lab. Foram. Res., Sp. Publ. 25. 1949. p. 267, pl. 19, figs. 43-45; Plioceno, formação Jimani, São Domingos. - Mem. Soc. Cubana Hist. Nat., vol. XIX, n. ${ }^{\circ} 3$, 1950, p. 363; Plioceno - Recente, Cuba.

Descriçio - Testa globular, nos indiriduos adultos hemisférica; nas formas jovens irregularmente concaro-convexa, trocoide, intimamente enrolada; lado ventral ligeiramente concavo, lado dorsal bem convexo; periferia discretamente lobada, subangular; câmalas no adulto arranjadas ladialmente em orden de 4 , com candis profundos entre elas, bem visíveis no lado ventral onde são planas ou ligeiramente convexas, infladas dorsalmonte, ammentando gradualmente de tamanho, em numero de 6 por rolta nas testas jovens; no adulto tornando-se radiais e ligeiramente triangulares no lado ventral; suturas ventral e dorsal deprimidas, irregularmente distribuidas no lado dorsal, aproximadamente radiais no lado ventral; parede grosseiramente perfurada no lado ventral, finamente perfurada no lado dorsal ; as aberturas aparecem como orifírios tubulares, dotados de um lábio distinto, ceralmente um de cada lado dis câmaras.

Ocorrîxcia - Esta espécie é relativamente rara no poço CRI-PA, ocorrendo, em amostra de calha do segrinte intervalo: $265 \mathrm{~m}$ $297 \mathrm{~m}$.

Dinexsones - As dimensões, medidas no espécime figurado, são: Diâmetro $0.31 \mathrm{~mm}$, altura $0.21 \mathrm{~mm}$. 
Discussão - A simetria tetraradial é bem característica da espécie em consideração. Não foram encontrados indivíduos no estágio de desenvolvimento da câmara grande, flutuadora, característica do gênero.

Plesiótipos - L. P - C. N. P 1-107.

\section{Cassidulina laevigata d'Orbigny}

Est. 11 - Figs. 13-15

Cassidulina laevigata d'Orbigny, Ann. Sci. Nat., vol. 7, 1826, p. 282, pl. 15, figs. 4-5; Modèles n.o 41; Recente. - Brady, Rep. Voy. Challenger Zool., vol. 9, 1884, p. 428, pl. 54, figs. 1-3; Recente. - Cushman, U. S. Geol. Surv. Bull. 676, 1918, p. 9, pl. 1, fig. 5; Plioceno, Carolina do Norte. - Galloway e Heminway, New York Acad. Sci., vol. 3, pt. 4, 1941, p. 424, pl. 32, fig. 1; Oligoceno, Pôrto Rico. - Cushman e Todd, Cush. Lab. Foram. Res., Sp. Publ. 15, 1945, p. 62 pl. 10, fig. 10; Mioceno, Buff Bay, Jamaica. - Renz, Geol. Soc. Am., Mem. 32, 1948, p. 125, pl. IX, figs. 9 a, b; Oligoceno e Mioceno da Venezuela. - Bermudez, Cush. Lab. Foram. Res., Sp. Publ. 25, 1949, p. 268, pl. 20, figs. 16-21; Oligoceno e Mio. ceno, São Domingos.

Descriçĩo - Os indivíduos do poço CR-1-PA, referidos a esta espécie, concordam bem com os exemplares típicos de C. laevigata d'Orbigny. A testa é igualmente biconvexa, biumbonada, aproximadamente circular em vista lateral; lenticular em vista periferal; área umbilical distinta; periferia lisa, carenada; adulto com 4 pares de câmaras aumentando gradativamente de tamanho; suturas niveladas com o resto da testa, limbadas, retas, encontrando a periferia em um ângulo bem aberto; parede lisa, distintamente perfurada; a abertura é quase paralela a periferia, alongada.

OCorrêNCIA - Esta espécie é rara no poço CR-1-PA, ocorrendo em amostras de calha dos seguintes intervalos: $271 \mathrm{~m} 283 \mathrm{~m}$. $292 \mathrm{~m} 298 \mathrm{~m}, 341 \mathrm{~m} 344 \mathrm{~m}$.

Dimensões - As dimensões medidas em 2 espécimes são: 1) Espécime figurado: Diâmetro maior $0.30 \mathrm{~mm}$, diâmetro menor $0.28 \mathrm{~mm}$, espessura $0.16 \mathrm{~mm}$; 2) Outro espécime: Diâmetro maior $0.24 \mathrm{~mm}$, diâmetro menor $0.20 \mathrm{~mm}$, espessura $0.12 \mathrm{~mm}$.

Plesiótipos - L. P - C. N. P 1-20.

\section{Cassidulina subglobosa Brady}

Est. 11 - Fig. 16

Cassidulina subglobosa Brady, Rep. Voy. Challenger Zool., vol. 9, 1884, p. 430. pl. 54, fig. 17; Recente. - Cushman, U. S. Nat. Mus., Bull. 104, pt. 3, 1922, p. 127, pl. 24, fig. 6; Recente, Atlântico. - Palmer e Bermudez, Mem. Soc. Cubana Hist. 
Nat., vol. 10, 1936, p. 306, Referências; Mioceno Superior, Cuba. - Hedberg, Jour. Pal., vol. 11, 1937, p. 680, pl. 92, fig. 5; Oligoceno Superior. formação Carapita, Venezuela. - Palmer, Mem. Soc. Cubana Hist. Nat., vol. 15, 1941. p. 282; Oligoceno Superior, formação Cojimar, Cuba. - Bull. Am. Pal., vol. 29, n. ${ }^{\circ} 115,1945$, p. 66; Mioceno Médio, formação Bowden, Jamaica. - Cushman e Stainforth, Cush. Lab. Foram. Res., Sp. Publ. 14, 1945, p. 63, pl. 12, fig. 1; Oligoceno, formação Cipero, Trinidad. B. W. I. - Cushman e Todd, Cush. Lab. Foram. Res., Sp. Publ. 15, 1945, p. 61, pl. 10, fig. 8; Mioceno, Buff Bay, Jamaica. - Renz, Geol. Soc. Am., Mem. 32, 1948, p. 125, pl. 9, figs. 11, 12; Oligoceno Superior e Mioceno Inferior, Venezuela. -- Bermudez, Cush. Lab. Foram. Res., Sp. Publ. 25, 1949, p. 269, pl. 20, figs. 1-3; Oligoceno e Mioceno, São Domingos.

Descrição - Os exemplares aqui referidos a esta espécie concordam bem com os típicos; a testa é subglobular, não deprimida; a periferia, largamente arredondada; as câmaras são em pequeno número, geralmente 3 pares; as snturas limbadas e niveladas; a parede lisa. finamente perfurada, e a abertura, relativamente grande, tendo a forma de uma vírgula, ao longo da face apertural, na região mediana.

OCorrência - Esta espécie é relativamente rara no poço CR1-PA, ocorrendo, em amostras de calha, nos seguintes intervalos: $262 \mathrm{~m} 291 \mathrm{~m}, 311 \mathrm{~m} \quad 314 \mathrm{~m}, 320 \mathrm{~m} 323 \mathrm{~m}, 351 \mathrm{~m} 354 \mathrm{~m}, 479 \mathrm{~m}-$ $485 \mathrm{~m}, 531 \mathrm{~m} 537 \mathrm{~m}$.

Dinifnsões - As dimensões, medidas em 2 espécimes são: 1) Espécime figurado: Diâmetro maior $0.25 \mathrm{~mm}$, diâmetro menor $0.21 \mathrm{~mm}$, espessura $0.17 \mathrm{~mm}$; 2) Ontro espécime: Diâmetro maior $0.21 \mathrm{~mm}$, dî̀metro menor $0.17 \mathrm{~mm}$, espessura $0.14 \mathrm{~mm}$.

$$
\begin{aligned}
& \text { Plesiótipos }- \text { L. P - C. N. P. 1-21. } \\
& \text { Cassidulinoides bradyi (Norman) }
\end{aligned}
$$

Est. 11 - Figs. 10-12

Cassiduitna bradyi Norman. in Wright, Proc. Belfast. Nat. Field. Club., App., 1880, p. 152, Recente.

Cassidulinoides bradyi (Norman), Cushman e Cahill, U. S. Geol. Surv., Prof. Paper 175-A. 1933, p. 33, pl. 12. fig. 4. - Palmer e Bermudez, Mem. Soc. Cubana Hist. Nat., vol. 10, 1936, p. 306; Referências; Mioceno Superior, Cuba. - Palmer, Idem, vol. 15, 1941, p. 283. Oligoceno Superior formação Cojimar, Cuba. - Cushman e Stainforth, Cush. Lab. Foram. Res., Sp. Publ. 14, 1945, p. 65, pl. 12, fig. 6; Oligoceno, formação Cipero, Trinidad, B. W. I. - Cushman e Todd, Cush. Lab. Foram. Res., Sp. Publ. 15, 1945, p. 63, pl. 10. fig. 14; Mioceno, Buff Bay, Jamaica. -Bermudez, Cush. Lab. Foram. Res., Sp. Publ. 25, 1949, p. 270. pl. 20, figs. 29-31; Oligoceno Médio - Mioceno Superior. São Domingos.

Descrição - Os indivíduos do poço referidos a êste gênero, podem ser afiliados a espécie $C$. bradyi (Norman), pela forma lar- 
gamente oval da testa, pelo earáter incipiente do desenrolamento da testa, pelas câmaras em pequeno numero e ammentando ràpidamente em lareura e menos rapidamente em comprinento, e pela abertura relativamente grande, em forma de vírgula e situada no meio da face apertural e alongada distalmente; a parede é lisa, finamente perfurada e as suturas são miveladas em relação ao resto da testa.

Oconkêrcia - A espécie é rara no poco CR-1-PA, ocorrendo em amostras de walha nos seguintes intervalos: $262 \mathrm{~m} 274 \mathrm{~m}$. $280 \mathrm{~m} 283 \mathrm{~m}$.

Drmensõs - As dimensões, medidas no exemplar figurado são: Comprimento $0.25 \mathrm{~mm}$, largura $0.16 \mathrm{~mm}$, espessura $0.1 \pm \mathrm{mm}$.

P'Lesiótipos - L. P - C. N. P 1-22.

\section{Pullenia quinqueloba (Reuss)}

Est. $11-$ Figs. 17-18

Nonionina quinqueloba Reuss, Zeitschr. deutsch. geol. Ges.. vol. 3, 1851, p. 71. pl. 5, fig. 31;'Oligoceno, Alemanha.

Pullenia quinqueloba (Reuss), Brady, Rep. Voy. Challenger Zool., vol. 9. 1884. p. 617, pl. 84, figs. 14, 15; Recente, Atlântico e Pacífico. - Cushman, U. S. Nat. Mus., Bull. 104, pt. 5, 1924, p. 42, pl. 8, figs. 5-9, 11; Recente. Atlântico. Galloway e Morrey, Bull. Am. Pal., vol. 15, n. ${ }^{\circ}$ 55, 1929, p. 44, pl. 6, fig. 17; Eoceno Superior, Manta. Equador. - Cushman e Todd, Cush. Lab. Foram. Res., Contr. vol. 19, 1943, p. 10. pl. 2, fig. 5; pl. 3, fig. 8; Referências. - Cushman e Stainforth, Cush. Lab. Foram. Res., Sp. Publ. 14, 1945, p. 66, pl. 12. fig. 9; Oligoceno. formação Cipero, Trinidad, B. W. I. -- Colom., Bull. Instit. Geol. Lucas Mallada, n. ${ }^{\circ} 3$, 1946, p. 59, pl. 3, fig. 89; Mioceno. Ithas Baleares, Espanha. -Bermudez, Cush. Lab. Foram. Res.. Sp. Publ. 25, 1949. p. 276, pl. 21, figs. 32. 33; Mioceno Superior, formação Mao, São Domingos. - Mem. Soc. Cubana Hist. Nat.. vol. XIX, n. ${ }^{\circ} 3,1950$, p. 355 ; Eoceno - Oligoceno, Cuba.

Descriç̃̃o - T'm único exemplar pertencente ao gênero Pullenia foi coletado no poço CR-1-PA. Apesar de só dispormos de um úmico exemplar, êle apresenta os caracteres de $I$ ' quinqueloba (Reuss) de maneira a não deixar dúvida a respeito. A testa é um tanto deprimida para o rênero, periferia ligeiramente lobulada, arredondada; as câmaras são em número de j) na íltima volta do corpo, aumentando gradualmente de tamanho; as suturas são ligeiramente deprimidas, aproximadamente radiais; a abertura é constituída por uma fenda baixa estendendo-se para o mbílico em ambos os lados; a face apertural é relativamente alta com a altura maior no meio da testa; parede lisa, finamente perfurada.

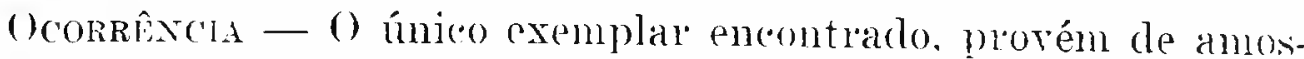
tra de caiha (lo intervalo: $2 T+m$ 2 $T$ T $\mathrm{m}$. 
Dimensões - As dimensões são as seguintes: Diâmetro maior $0.25 \mathrm{~mm}$, diâmetro menor $0.22 \mathrm{~mm}$, espessiura $0.21 \mathrm{~mm}$.

\author{
Plesiótipo - L. P - C. N. P 1-85. \\ Globigerina bulloides d'Orbigny
}

Est. 12 - Figrs. 1-3

Globigerina bulloides d'Orbigny, Ann. Sci. Nat.. vol. 7, 1826, p. 277; Modèles, ns. 17, 76; Recente, Adriático. - Voy. Am. Mèrid., vol. 5, pt. 5, Foraminifères, 1839, p. 37; Recente. - Palmer e Bermudez, Mem. Soc. Cubana Hist. Nat., vol. 10, 1936, p. 310; Oligoceno Inferior, Cuba. - Palmer, Idem, vol. 15, 1941, p. 285; Oligoceno Superior, formação Cojimar, Cuba. - Bull. Am. Pal., vol. 29, n.o 115, 1945, p. 67; Mioceno Médio, formação Bowden, Jamaica. - Cushman e Stainjorth, Cush. Lab. Foram. Res., Sp. Publ. 14, 1945, p. 68, pl. 13, fig. 4; Oligoceno, formação Cipero, Trinidad, B. W. I. - Colom, Instit. Geol. Lucas Mallada, n. ${ }^{\circ} 3$, 1946, p. 56, pl. 3, fig $\leqq .63-65$; Mioceno, llhas Baleares, Espanha. - Bermudez, Cush. Lab. Foram. Res., Sp. Publ. 25, 1949, p. 278, pl. 21, fig. 49; Oligoceno e Mioceno, São Domingos. - Mem. Soc. Cubana Hist. Nat., vol. XIX, n. ${ }^{\circ}$ 3, 1950, p. 341; Oligoceno - Recente, Cuba. - Phleger e Parker, Geol. Soc. Am., Mem. 46. pt. II, 1951, pp. 33-34; Recente, Gôlfo do México.

Descriçio - Testa subglobosa, trocoide deprimida, composta de poucas câmaras infladas, subsféricas; tôdas as roltas do corpo são visíveis do lado dorsal, somente 4 câmaras são visíveis do lado ventral; as câmaras aumentam rapidamente de tamanho de maneira que a última volta do corpo forma quase que a totalidade da testa; suturas profundas; parede grossamente perfurada; a abertura se situa na base da face apertural, alargada em direção ao umbílico.

Ocorrêtera - Esta espécie ocorre, em amostras de calha do poço (R-1-PA, nos secruintes intervalos: $265 \mathrm{~m} 305 \mathrm{~m}, 320 \mathrm{~m}$ $460 \mathrm{~m} \quad 497 \mathrm{~m} \quad 503 \mathrm{~m}, 512 \mathrm{~m} 555 \mathrm{~m}, 707 \mathrm{~m} \quad 725 \mathrm{~m}, 912 \mathrm{~m} 930 \mathrm{~m}$, $972 \mathrm{~m} 981 \mathrm{~m}, 1100 \mathrm{~m} 1109 \mathrm{~m}, 1253 \mathrm{~m} 1279 \mathrm{~m}, 1405 \mathrm{~m} 1457 \mathrm{~m}$.

Dimensões - Diâmetros, medidos no exemplar figurado, $0.33 \mathrm{~mm}$ e $0.26 \mathrm{~mm}$. Espessura $0.24 \mathrm{~mm}$.

Discussio - A presente espécie se distingue de Globigerinoides triloba (Reuss) por ser mais deprimida, pela ausência de aberturas múltiplas, pelas suturas mais profundas a pela abertura mais alargrada em direção ao umbílicon.

G. bulloides tem sido citada romo vivendo, atualmente, em águas do Pacífico Norte. Brady considera-a, como espécie cosmopolita. Contudo o conceito de Brady sôbre esta espécie era muito lato. Cushman, am 1924, em sula monografia sôbre os foraminíferos do Oceano Atlântico adianta que $G$ bulloides, se existente, é muito rara no Atlantico Oéste. Contudo Phleger e Parker (1951 pp. 33- 
34, Est. 19, figs. 6. T) citam à espécie (como vivendo atualmente no Gôlfo do México. As ilustraçies fornecidas por êles concordam bem com a descrição da espécie. Eles ressaltam (idem, p. 73) que a presente espérie se distribue em águas cujas temperaturas variam. Contudo ela é nulito mais frequiente en regiões árticas e subárticas. Na fauma da parte inferior dos testemunhos provenientes do Gôlfo do México (Pleistoceno) ela não aparece aom frequiência tão alta como nos mares atuais de água fria. Globigerinoides rubra (d'Orbigny) a qual é inexistente no poço CR-1-PA. quando em abundância, ao contrário, parece ser característica dos mares atuais. de águas quentes e tropicais. Schott (1935 pp. 95 e seguintes), mostrou que a espécie $G$. bulloides l'Orbigny é abundante entre o material coletado pela Expediça "Meteor" na zona equatorial do Atlântico, se bem que ela predomine nesta região em águas profundas, portanto, mais frias.

\section{PLESÓTIPO - I. P - C. N. P 1-52. \\ Gibbigerina cretarea dorbigny}

Est. 12- Figs. $4-6$

Globigerina cretacea d'Orbigny. Mem. Soc. Géol. France. scr. 1, vol. 4, 1840, p. 34. pl. 3, figs 12.14; Cretaceo. França. - Cushmun, Cush. Lab. Foram. Res., Contr. vol. T, 1931. p. 44. pl. 6. fig. 6; Cretaceo Superior. Antigua. B. W. I. Sandidge, Amer. Mitiland Nat. vol. 13. 1932. p. 366, pl. 33, figs. 13. 15; Cretaceo Superior. formação Ripley Alabama.

Globigerina ef cretacea d'Orbigny. Bermudez. Cush. Lab. Foram. Res., Sp. Publ. 25. 1949, pp. 278-279. pl. 21. fig. 43; Eoceno Inferior. formaçāo Abruillot, São Domingos. - Mem. Soc. Cubana Hist. Nat.. vol. XIX, n. 3. 1950. p. 341; Creiaceo - Eoceno. Cuba.

Descrição - Testa em espiral trocoide muito baixa. ‘om esbôço lobulado ligeiramepte angular; umbílico distinto, um tanto profundo. cercakle por 5 chnuras: o lado dorsal mostra 2 voltas rom um total de cêrca de 12 cânaras, ammentando gradualmente de tamanho; as câmaras são ligeiramente deprimidas, em forma de elípse, arredondadas a ligeiramente subangulares; as suturas são retas e profundas; a abeltura não é clara; a parede é finamente perfinada e a superfície é ormamentada por papilas minúsculas, sem arranjo regular; enrolamento em ambos os lados foram observados, sendo que o número de indivíduos é pequeno para se tirar uma conclusão definitiva sôbre a predominância de un dos enrolamentos.

Ocorrencia - Esta espécie ocorre no poco CR-1-PA, somente no testemmono n. ${ }^{0} 65$, intervalo de $2376 \mathrm{~m} 2379 \mathrm{~m}$, sendo contudo rarísima mesmo neste intervalo. 
Dimessōes - As dimensões, medidas no espécime figurado, foram: Diâmetro maior $0.37 \mathrm{~mm}$, diâmetro menor $0.33 \mathrm{~m}$, espessura $0.19 \mathrm{~mm}$.

Discussĩo - Os espécimes de Cururú concordam bem com a espécie G. cretacea d'Orbigny. possuindo os caracteres críticos que identificam esta espécie, tais como a testa trocoidal baixa com esbôço distintamente lobular, um tanto subangular e ornamentação em papilas minúsculas sem arranjo regular. A espécie tem sido referida do Cretaceo a Recente; parece, todaria, que diferentes espécies foram incluídas sob esta denominação. Ela parece ser limitada ao Cretaceo e Eoceno. É possível que os espécimes encontrados no testemunho n. ${ }^{\circ} 65$, de Cururú tenham sido redepositados.

Plesiótipos - L. P - C. N. P 1-53.

Globigerina of triangularis White

Est. 12 - Fig. 7

Globigerina bulloides Woodward e Thomas (Parte) (Non d'Orbigny), Geol. and Nat. Hist. Surv of Minn. vol. 3. pi. 1. $1885-92$, p. 40 pl. d. figs. 16, 17; (Sòmente).

Globigerina triangularis White Jour. Pal., vol. 2. pt. I, 1928, p. 195, pl. 28. figs. 1 a. b; Cretaceo Superior, formação Velascco. México.

Descrição - As globigerinas aqui descritas são referidas com Gúvida a espécie $G$. triangularis White, cujo holótipo foi descrito da formacão Velasco, Cretaceo Superior do México. Os espécimes estão pèssimamente conservados e provàvelmente estão redepositados; a testa é triangular e composta, do que parece, de 2 voltas arranjadas em uma espiral trocoide baixa; as câmaras são infladas; a ńltima volta do corpo é composta por 3 câmaras subiguais; as suturas são profundas e a abertura não é visível devido ao estado de conservarão; a parede parece ser papilosa.

Oconkêtcia - Esta espécie é rara no testemmuho n. ${ }^{\circ} 56$, do pog̣o CR-1-PA, intervalo $2198 \mathrm{~m} 2201 \mathrm{~m}$, tendo sido, provàvelmente, redepositada.

Dinensões - As dimensões. medidas no espécime figurado, são: Diâmetro $0.33 \mathrm{~mm}$, espessura $0.21 \mathrm{~mm}$.

Tipos - L. P - C. N. P $1-54$. 


\section{Globigerina sp}

Est. 12 - Figs. 8-9

Descriçĩo - Testa eireular, trocoide nm tanto deprimida, composta de poucas camaras infladas, subesféricas; tôdas as voltas do corpo são visíveis do lado dorsal, somente a última volta do corpo, formada por 5 câmaras, visivel do lado ventral; as câmaras aumentam gradativamente de tamanho; parede grosseiramente perfurada; a abertura bem visivel, aproximadamente circular, e se situa na região umbilical.

OCorrência - Esta espécie ocolre nos seguintes testemunhos de sondagem: Test. n. ${ }^{\circ} 9$, intervalo $617 \mathrm{~m}$ 620, test. n. ${ }^{\circ} 12,731 \mathrm{~m}$ $738 \mathrm{~m}$. Ocorre também, em amostras de calha, nos seguintes intervalos: $258 \mathrm{~m} 292 \mathrm{~m}, 313 \mathrm{~m} 335 \mathrm{~m}, 343 \mathrm{~m} 362 \mathrm{~m}, 368 \mathrm{~m} 424 \mathrm{~m}$. $442 \mathrm{~m} 460 \mathrm{~m}, 479 \mathrm{~m}-485 \mathrm{~m}, 497 \mathrm{~m} 535 \mathrm{~m}, 594 \mathrm{~m}, 607 \mathrm{~m}, 658 \mathrm{~m}$ $668 \mathrm{~m}, 689 \mathrm{~m} 707 \mathrm{~m}, 738 \mathrm{~m} \quad 765 \mathrm{~m}, .912 \mathrm{~m}-930 \mathrm{~m}, 1472 \mathrm{~m} 1484 \mathrm{~m}$, $1673 \mathrm{~m} 1686 \mathrm{~m}$.

Dianensões - Diâmetros do exemplar figurado: $0.25 \mathrm{~mm}$, e $0.20 \mathrm{~mm}$, espessura $0.16 \mathrm{~mm}$.

Discussio - Esta espécie se assemelha a G. eggeri Rhumbler e G. concinma Reuss, de que difere pelo tipo de abertura que é circular enquanto naquelas espécies ela é alongada. Além disso $G$. eggeri possui uma espiral mais alta que a nossa espécie. Talvez tenhamos aqui uma espécie nova. Contudo evitamos dar-lhe $11 \mathrm{~m}$ nome específico devido ao estado caótico em que está a sistemáticad do gênero Globigerina para as espécies do Terciário.

As espécies de globigerinas do Terciário da província caraíbica são incompletamente conhecidas, havendo necessidade de mua revisão das espécies conhecidas e de monografias do gênero para o Terciário, do tipo das monografias das espécies do Cretaceo e do Paleoceno e Eoceno de Trinidad publicadias, por Brommimann, em 1952 .

Tilos -- L. P - C. N. P 1-5.5.

Globigerimoides triloba (Reuss)

Est. 12 - Figs. 10-11

Globigerina triloba Reuss, K. Akad. Wiss. Wien, Math. - Nat. Cl. Denkschr., Viena, Austria, Bd. 1, 1850, p. 374. pl. 17. figs. 11 a-e.-Cushman, U. S. Nat. Mus., Bull. 103, 1918, p. 65; Mioceno, zona do Canal do Panamá. - U. S. Geol. Surv.. Prof. Paper 129-E. p. 95. Oligoceno, Mississippi. 
Globigerina bulloides d'Orbigny var. triloba Brady, Rep. Voy. Challenger Zool., vol. 9, 1884, p. 595, pl. 81, figs. 2, 3; Recente, Pacífico.

Globigerina trilocularis d'Orbigny, Fornasini, Rend. R. Accad. Sci. Instit. Bologna n. s., vol. 2, fasci. 1, 1897, pl. 1, figs. 6, 7-7 a (Figuras inéditas de d'Orbigny, de $G$. trilocularis, creada por d'Orbigny em 1826 , sem ilustração e descrição, considerada agora nomen nudum.). - cf Galloway e Morrey, Bull. Am. Pal., vol. XV, n. ${ }^{\circ}$ 55, 1929, p. 10, pl. 3, fig. 9; Eoceno Superior, Equador.

Globigerina bulloides Cushman, (Non d'Orbigny), U. S. Geol. Surv., Prof. Paper 128-B, 1920, p. 69, pl. XI, fig. 6; Mioceno Inferior, Flórida.

Globigerinoides trilocularis (d'Orbigny), Cushman, Cush. Lab. Foram. Res., Contr. vol. 17, pt. 2, 1941, pp. 39-40, pl. 10, figs. 14-17; pl. 11, fig. 1 .

Globigerinoides triloba (Reuss), Cushman, Cush. Lab. Foram. Res., Contr. vol. 22 , pt. 1 , 1946, pp. $20-21$; pl. 3 , fig. 8 ; pl. 4, figs. 16-18.

DescriçÃo - Testa aproximadamente oval, com poucas voltas do corpo, sendo que as câmaras aumentam ràpidamente de tamanho; a última volta do corpo é composta de 3 grandes câmaras, as vêzes com parte da quarta câmara; à última câmara é pouco maior que as 2 precedentes; suturas deprimidas porém um tanto rasas para o gênero; as últimas 3 câmaras em conjunto formam uma estrutura assaz compacta; as voltas anteriores do corpo as quais são $1 \mathrm{~m}$ tạto indistintas podem ser vistas do lado dorsal como $\mathrm{um}$ conjunto de camaras de muito menor tamanho e separadas por suturas deprimidas mas rasas para o gênero; parede grosseiramente perfurada; a abertura principal é pequena para o gênero, elítica, situada na base da última câmara, na região mediana e dotada de um pequeno lábio, cêréa de $1 / 4$ da base da última câmara; aberturas suplementares são constituídas de pequenas fendas suturais, geralmente não visíveis no nosso material; o umbílico é indistinto.

Oconktisca - Esta é a espécie de grobigerinídeo mais frequiente do poco (R-1-PA, ocorrendo nos seguintes testemunhos de sondagem: Test. $10^{\circ} 6$, intervalo $500 \mathrm{~m} 503 \mathrm{~m}$, test. $11 .^{\circ} 7,503 \mathrm{~m}$ $506 \mathrm{~m}$, test. $110^{\circ} 8,614 \mathrm{~m} 617 \mathrm{~m}$, test. $10^{\circ} 9,617 \mathrm{~m} 620 \mathrm{~m}$. Algums indivíluos também foram achados nos testemumhos n. ${ }^{\circ} 17,1038 \mathrm{~m}$ $1041 \mathrm{~m}$ e $11 .^{0} 26,1237 \mathrm{ml} 1241 \mathrm{~m}$. Contudo é duvidosa a exata filiação específica dêsses indiríduos. Não obstante parece fora de dúvida que esta espécie tem grande distribuição estratigráfica. Ela ocorre também em amostras de calha dos secruintes intervalos: $250 \mathrm{~m}$ $485 \mathrm{~m}, 497 \mathrm{~m} 607 \mathrm{~m}, 646 \mathrm{~m} 655 \mathrm{~m}, 689 \mathrm{~m} \quad 707 \mathrm{~m}, 738 \mathrm{~m}-820 \mathrm{~m}$, $844 \mathrm{~m} \quad 8.57 \mathrm{~m}, 876 \mathrm{~m} \quad 894 \mathrm{~m}, 930 \mathrm{~m} \quad 948 \mathrm{~m}, 960 \mathrm{ml} \quad 972 \mathrm{~m}, 1012 \mathrm{~m}$ $1020 \mathrm{~m}, 1247 \mathrm{~m} 127+\mathrm{m}$.

Dinfansones - Diametros do espécime figurado, cể('a de 0.25 mm e $0.22 \mathrm{~mm}$; espessural, cêrea de $0.21 \mathrm{~mm}$.

D)rscussio - A maior parte dos globigerinídeos moveniontes do poco CR-1-PA é formada pelo grmpo de formas constituído pelo 
predomínio das 3 últimas câmaras as quais formam a última volta do colpo e constituem a maior parte da testa a que se junta as vêzes a quarta câmal’a. Existe na literatura grande confusão com referência a êste grupo de formas. Muitas dessas formas foram referidas a Globigerina bulloides d'Orbigny. Contudo G. bulloides é mais deprimida, con situras mais profundas, com abertura mais alarçarla para o umbílico e não possui aberturas múltiplas sendo, portanto. Globigerina "sensu strictu" Por ontro lado "Globigerina triloba Reuss" possui aberturas suplementares devendo porianto ser referida ao gênero Globigcrinoides.

1 espécie que mais se aproxima da presente é Globigerina tribeulinoides Phummer (Em Ellis e Messina, Catalogue of Foraminifera), descrita do Eoceno do Texas. Esta espécie, além de ter uma única abertura sendo portanto Globigerina "sensu strictu', possui a abertura constitinda por estreita fenda arqueada na base da uitima câmarà em contacto com um lábio proeminente que se estende para a região umbilical, enquanto na espécie aqui considerada, a abertma é elítica situada na base da última camara, na retrião mediana e sem a cobertura labial.

A presente espécie se distingue de Globigerina tricanerata Tolmachoitf, do Mioceno da Colómbia. por mostrar as voltas anteriores do corpo no lado dorsal. enquanto na espécie colombiana as roltas do corpo são invisiveis de ambos os lados. Redmond (1953 p. 730) mostrou que esta espécie possui aberturas suplementares, devendo, portanto, também ser referida ao gênero Globigerinoides.

Tolmathoff (1934 pp. 326-328, Est. 22-23). cita. do Mioceno da Colombia, "Giobigerina trilocularis d'Orbigny'" a qual, segundo as ilustrações dadas por êle. parrece ser idêntica a espécie em consideração. Segundo êste autor. a abertura é singular e aparentemente pequend. Talvez tenham escapado a êle as aberturas suplementares por serem muito peouenas, on então êle tivesse examinado formas jorens onde as aberturas suplementares não tivessem ainda se desentolvido. Como mostrou Cushman (19+1 pp. 39-40, Est. 10, figs. 13-17; Est. 11, fig. 1: 1946 pp. 20-2], Est. 3. fig. 8, Est. 4, fiess. 16-18; estudando material proveniente do Mioceno da França, da região de onde provém o holótipo de "Globigevina trilocularis". esta espécie possui aberturas múltiplas devendo, portanto, ser refexida ao gênero (rlobigerinoides; é possível que ela seja idêntica a Globigerinoides triloba (Reuss). Cushman (1946 pp. 20-21), salienta "que. apesar da expécie "Globigerina trilocularis d Orbigny" ter sido criada por lorbigny em 1826, êle não a figurou ou descreveu e referências a espécie anterior a 1850 não são coespecíficas com a de d'Orbigny. Parece portanto, gue o nome dado por d'Orbigny é uin "momen muium" devendo ser usado o de Reuss que descreveu a mesnia espécip em 1850. Como mostrou ainda Cushman (1941 
pp. 39-40) as aberturas suplementares não aparecem nas formas jovens. A maioria dos espécimes de C'ururú são pequenos e sem aberturas suplementares. Isto é devido provàvelmente ao transporte que sofxeram por correntes que selecionaram os espécimes jovens.

Segundo Tolmachoff (1934 pp. 322-328) a espécie ocorre, como forma vivente, no Pacífico Norte, sendo encontrada em quase todos os lugares onde aparece $G$. bulloides d'Orbigny, porém parece ser muito menos comum. No Oceano Atlântico, de acôrclo com Cushman, ela falta quase que totalmente.

A julgar pelos dados da literatura a respeito das associações de foraminíferos planctônicos, vemos que a associação de globigerinídeos de Cururú, difere da associação hoje encontrada na província caraíbica faltando, em Cururú, espécies como Globigerinella aequilateralis (Brady), Globigerinoides rubra (d'Orbigny), $G$. sacculifera (Brady), etc., tão comuns nas associações recentes desta províneia. Baseados nos dados de literatura seríamos levarlos a comparar a associação de globigerinídeos de Cururú com associações do Mioceno como por exemplo do rio Atrato na Colombia, descrita por Tolmachoff (1934 pp. 322-332). Devemos recordar, não obstante, que associações de globigerinídeos do Plioceno e Pleistoceno são ponco conhecidas na província caraíbica. É possível que a espécie Globigerinoides triloba (Reuss) tenha sido descrita, entre material recente, como Globigcrina bulloides d'Orbigny, espécie esta que costuma ser tomada por muitos com um conceito muito amplo. Contudo mesmo com esta ressalva existe diferença real entre as associações de globigerinídeos recentes da província caraíbica e a associação de Cururú.

$$
\text { Plesiótipos - L. P - C. X. P 1-5i }
$$

Globigerinoides triloba (Renss) ral. aspera Petri 'rar. nor.

Est. 12 - Fig's. 12-13

Descriçio - Testa aproximadamente oval, com poucas roltas do corpo, senclo que as câmaras anmentam ràpidamente de tamanho; 3 grandes câmaras formam a última rolta do corpo, a qual constitue quase a totalidade da testa; as roltas anteriores, visíveis do lado dorsal, constituem como que $\mathrm{um}$ apêndice da testa; a última câmara é bem maior que as 2 precedentes; suturas deprimidas porém um tanto rasas para o gênero ; parede ọrosseiramente perfurada, com grossas reticulações formando depressões hexagonais; as aberturas, geralmente em número de 2, são estreitas e situadas na liuha de sutura da áltima câmara, nos pontos de união das suturas for- 
madas pelas 2o câmaras precedentes, com a sutura formada pela ńltima cânuara; 0 umbílico é indistinto.

Ocorrência - Esta variedade é muito commm no poço CR-1PA, formando justamente com a forma Globigcrinoides triloba (Reuss) aqui considerada como típicar, a massa predominante clos globigerinídeos daquêle poço. Ocorre nos seguintes testemumhos de sondagem: Test. n. ${ }^{\circ}$ (i, intervalo $500 \mathrm{~m} 503 \mathrm{~m}$, test. ${ }^{\circ}{ }^{\circ} 7,503 \mathrm{~m}$ $506 \mathrm{~m}$, test. $11 .{ }^{0} 8.614 \mathrm{~m} 617 \mathrm{~m}$. ()oorre também em amostras de (alha, dos seguintes intervalos: $250 \mathrm{~m} 607 \mathrm{~m}, 637 \mathrm{~m}-668 \mathrm{~m}, 707 \mathrm{~m}-$ $725 \mathrm{~m}, 738 \mathrm{~m} 802 \mathrm{~m}, 844 \mathrm{~m} \quad 857 \mathrm{~m}, 960 \mathrm{~m} \quad 981 \mathrm{~m}, 1064 \mathrm{~m} \quad 1085 \mathrm{~m}$, $1253 \mathrm{~m} 1262 \mathrm{~m}$.

Dinksõ̃s - Diâmetros do exemplar figurado: $0.28 \mathrm{~mm}$ e $0.22 \mathrm{~mm}$ : espessiura, cêrca de $0.21 \mathrm{~mm}$.

Drscussio - A presente variedade se distingue da forma típica de (r. triloba (Reuss) pela ornamentação da parede com grossas reticulacooes hexagonais e pelas aberturas em estreitas fendas, não existindo uma abertura principal. Com referência a ornamentação, se aproxima de Globigerina heragona Nattland, de que se distingue pelas aberturas múltiplas e pelo arranjo e numero de câmaras por volta do corpo.

HoLóTIPO DA VARIEDADE - L. P - C. ․ P 1-58.

\section{Globigerimoides sp}

Est. 12 - Figr. 14

Descriçio - Entre os fósseis do poço CR-1-PA, existe unt úmico espécime pertencente ao gênero Globigcrinoides que difere de outros do mesmo gênero por ser subglobular, com as câmaras arlanjadas rompartamente, e com as aberturas suplementares relativamente grandes, um tanto alongadas. As ńltimas câmaras são grandes e infladas.

Ocorrêncha - o único espécinme encontrado provém de amostra de (alha do intervalo $280 \mathrm{~m} 283 \mathrm{~m}$.

Dimexsōes - () citado espécime mede $0.70 \mathrm{~mm}$ de diâmetro.

Discussio - Esta espécie se assemelha a (r. comglobata (Brady); evitamos, contudo, dar-lhe nome esperifico devido a ansência de maior número de exemplares.

$$
\text { TIPO - L.P - C. \. P 1-5.9. }
$$




\section{Orbulina suturalis Bromnimamn}

$$
\text { Est. 12 - Figrs. 15-16 }
$$

Orbulina universa d'Orbigny, de vários autores (Non d'Orbigny, 1839).

Candorbulina universa Jedlitschka, Naturforsch. Vereinigung Brünn, Verh., vol. 65, 1934, p. 21. - Cushman e Dorsey, Cush. Lab. Foram. Res., Contr. vol. 16, pt. 2, 1940, pp. 40-42; pl. 8, figs. 1-7 (Non 8, 9) Mioceno da Tchecoslovaquia, Hungria, Austria, Egito, Plano costal americano de Maryland a Flórida, Panamá e Venezuela. - Cushman e Stainforth, Cush. Lab. Foram. Res., Sp. Publ. 14, 1945, pp. 69-70, pl. 13, fig. 10; Oligoceno Superior, formação Cipero, Trinidad.

Candeina trilobata Jedlitschka, Naturforsch. Vereinigung Brïnn Verh., vol. 65, 1934, p. 24.

Orbulina suturalis Bronnimann, Cush. Found. Foram. Res., Contr. vol. II, pt. 4, 1951, p. 135, fig. do texto II, figs. 1-5; III, figs. 3-8, 11, 13-16, 18, 20-22; IV, figs. 2-4, 7-12, 15-16, 19-22.

Descriçio e Discussio - A Orbulina que ocorre no poco CR1-PA, se filia à espécie O. suturalis Bronnimann. Esta espécie foi criada por Bromnimamn para incluir os indivíduos antes filiados ao gênero Candorbulina. Como bem mostrou Bronnimann (1951 pp. 132-138), não é aconselhável manter êste gênero devido a sua íntima relação com o gênero Orbulina.

Os espécimes brasileiros mostram bem a última câmara não inteiramente envolvente, deixando a mostra o estágio de Globigerina e os orifícios que circundam as câmaras.

"Candorbulina" foi descrito originamente por Jedlitschka; êle foi reconhecido para espécimes do Mioceno da Tchecoslovaquia e reconhecido subseqüentemente no Mioceno da Austria, Hungria, Egito, no plano costal dos Estados [Tnidos de Maryland a Flórida, no Panamá e Venezuela, e no Oligoceno Superior de Trinidad. Bronnimam apresenta, em detalhe, a distribuição estratigráfica da espécie no Oligoceno e Mioceno de Trinidad.

Pelo expôsto conclui-se que, a julgar pela espécie orbulina suturalis Bromnimamn, os sedimentos do poço C'R-1-PA que contém a riea fauna marinha de foraminíferos devem sel colocados no Mioceno, visto que ela possui certos fósseis que excluem a sua colocação no Oligoceno.

Ocorrência - A espécie é regularmente freqüiente no poro CR-1-PA, ocorrendo no test. $11 .^{\circ} 7$, intervalo $503 \mathrm{~m} 506 \mathrm{~m}$. ()corre também em amostras de calha do mesno poço, nos seguintes intervalos: $258 \mathrm{~m}-357 \mathrm{~m}, \quad 435 \mathrm{~m} \quad 459 \mathrm{~m}, \quad 502 \mathrm{ml} \quad 535 \mathrm{~m}, \quad 574 \mathrm{~m} \quad 582 \mathrm{~m}$, $1090 \mathrm{~m} 1105 \mathrm{ml}, 1180 \mathrm{ml} 1200 \mathrm{~m}$.

Dnuesonos - () diâmetro do maior indivíduo roletado é de $0.45 \mathrm{~mm}$, o diâmetro do menor indivíduo coletado é de $0.25 \mathrm{~mm}$.

Piesiótipos - L. P - C. N. P 1-78. 


\section{Globorotalia compressa (Plumer)}

$$
\text { Est. } 13 \text { - Figs. 1-3 }
$$

Globigerina compressa Plummer, Lniv. Texas, Bull. 2644, 1927, p. 135, pl. 8, fig. 11; Eoceno, formação Midway, Texas. - Jennings, Bull. Am. Pal., vol. 23, n. ${ }^{\circ}$ 78, 1936, p. 193, pl. 31, fig. 8; Eoceno, formação Hornerstown, New Jersey. Glaessner, Problems of Paleontology, Moscow Univ., vols. 2-3, 1937, p. 382, pl. 4, fig. 32; Eoceno, Cáucaso. - Toulmin, Jour. Pal., vol. 15, 1941, p. 607, pl. 82, figs. 1-2; Eoceno, Calcáreo Salt Mountain, Alabama. -- Cushman e Todd, Cush. Lab. Foram. Res., Contr., vol. 18, pt. 2, 1942, p. 44, pl. 8, figs. 5, 6; Eoceno, formação Naheola, Alabama.

Globorotalia compressa (Plummer), Bermudez, Mem. Soc. Cubana Hist. Nat., vol. XIX, n. ${ }^{\circ} 3,1950$, p. 342; Cretaceo Superior - Paleoceno, Cuba. - Bronnimann, Bull. Am. Pal., vol. 34, n. ${ }^{0}$ 143, 1952, p. 173, pl. 2, figs. 19-24; Paleoceno, formação Lizard Springs, Trinidad.

Descriçĩo - Testa pequena, intimamente enrolada, biconvexa, comprimida; periferia lobulada angular com uma carena distinta em nossos exemplares pelo menos na última câmara; câmaras aumentando gradualmente de tamanho, 5 na última volta do corpo, infladas; suturas bem deprimidas; parede fina, lisa, finamente punctada; a abertura não está clara mas parece ser alongada na base da face apertural e dirigida para o umbílico, o qual é distintamente deprimido; o pequeno número de indivíduos coletados possui enrolamento dextral.

OCoRrência - Os espécimes encontrados, provém do poco CR1-PA, testemunho n. ${ }^{\circ}$ 65, intervalo $2376 \mathrm{~m} 2379 \mathrm{~m}$.

Drmensões - As dimensões, medidas no espécime figurado, foram as seguintes: Diâmetro maior: $0.37 \mathrm{~mm}$, diâmetro menor: $0.34 \mathrm{~mm}$, espessura: $0.15 \mathrm{~mm}$.

Discussio - Esta espécie é muito característica pelas câmaras deprimidas produzindo uma periferia angular, pelo enrolamento en espiral deprimida e principalmente pelo caráter da parede que é fina transparente e lisa. A espécie foi descrita como pertencente ao gênero Globigerina. Cushman e Todd (1942 a p. 44) observaram que esta espécie deveria possivelmente ser colocada no gênero Globorotalia devido a testa deprimida e câmaras obtusamente angulares. Bromimann ( 1952 b p. 26) aceita esta espécie como pertencente ao gênero Globorotalia não só pelos caracteres apontados como também pelo caráter da abertura interiomarginal, tìpicamente desenvolvida em Globorotalia menardii (d'Orbigny). A presença de uma carena distinta em nosso material rem confirmar o diagnóstico genérico de Globorotalia.

Esta é uma espécie característica do Cretaceo Superior-Eoceno.

$$
\text { Plesiótipos - I. P - C. N. P 1-60. }
$$




\section{Globorotalia ef crassata (Cushman)}

Est. 13 - Figs. 4-6

Pulvinulina crassata Cushman, Bull. Am. Ass. Petr. Geol., vol. 9, 1925, p. 300, pl. 7, fig. 4; Eoceno, México.

Globorotalia crassata (Cushman), Cole, Bull. Am. Pal., vol. 14, n. ${ }^{\circ}$ 51, 1927, p. 34, pl. 1, figs. 7-8. - Cushman e Applin, Cush. Lab. Foram. Res., Contr., vol. 19, pt. 2, 1943, pp. 44-45; Referências; Eoceno, formação Yegua, Texas. - Selli, Ann. Mus. Geol. Bologna, ser. 2, vol. 17, 1944, p. 75. - Cushmon e Herrick, Cush. Lab. Foram. Res., Contr., vol. 21, 1945, p. 71; Eoceno Superior, formação Mc Bean, Georgia, U. S. A. - Cushman e Renz, Cush. Lab. Foram. Res., Sp. Publ. 24, 1948, p. 40, pl. 8, figs. 5, 6; Eoceno Superior, formação Hospital Hill, Trinidad, B. W. I. - Bermudez, Mem. Soc. Cubana Hist. Nat., vol. XIX, n.o 3, 1950, p. 342; Eoceno, Cuba.

Descriç̃o - Testa pequena, plano-convexa, lado dorsal plano, lado ventral fortemente convexo; íltima volta do corpo com 5 câmaras; periferia subaguda, distintamente carenada; câmaras infladas, especialmente no lado ventral, suturas distintas, ligeiramente deprimidas no lado dorsal, fortemente no lado ventral; a abertura não é elara no nosso material.

OCorrîncia - Esta espécie é rara no poço CR-1-PA, ocorrendo sòmente no testemunho $\mathrm{n}^{\circ}$ 弓̆ 6 , intervalo $2198 \mathrm{~m} 2201 \mathrm{~m}$.

Dumensões - As dimensões, medidas no espécime fignrado, são as seguintes: Diâmetro maior $0.37 \mathrm{~mm}$, diâmetro menor $0.34 \mathrm{~mm}$, espessura $0.16 \mathrm{~mm}$.

Discussĩo - O estado de conservação do material não permite a verificação se a parede é ornamentada por espinhos curtos, como no holótipo, o que torna $\mathrm{mm}$ tanto duvidosa a exata afiliação especifica de nosso material. Esta espécie é característica do Eoceno.

$$
\text { Tipos - I. P - C. N. P 1-61. }
$$

\section{Globorotalia menardii (d'orbigny)}

Est. 13 - Figs. 7-9

Rotalir menardii d'Orbigny, Ann. Sci. Nat., vol. 7, 1826, p. 273; Modèles n. ${ }^{\circ}$ 10, Recente, Adriático.

Pulvinulina menardii (d'Orbigny), Brady, Rep. Voy. Challenger, Zool., vol. 9. 1884, p. 690, pl. 103, figs. 1, 2; Recente, Pacífico.

Globorotalia menardii (d'Orbigny), Cushman, U. S. Nat. Mus., Bull. 104. pt. 8, 1931, pp. 91-91, pl. 17. fig. 1; Referências; Recente, Atlântico. - Nuttali, Jour. Pal., vol. 6, 1932, p. 29, pl. 4. fig. 16: Olignceno Inferior, formação tlazan, México. 
Hadley, Bull. Am. Pal., vol. 20. n. ${ }^{\circ}$ 70-A, 1934, p. 25, pl. 3, figs. 12, 13; Oligoceno Superior, Cuba. - Bermudez, Mem. Soc. Cubana Hist. Nat., vol. 9, 1935, p. 278; Recente, Cuba. - Coryell e Rivero, Jour. Pal., vol. 14, 1940, p. 336, pl. 42, figs. 34, 35; Mioceno Médio, Port-au-Prince, Haití. - Palmer, Mem. Soc. Cubana Híst. Nat., vol. 15, 1941, p. 291; Oligoceno Superior, formação Cojimar, Cuba. - Bull. Am. Pal., vol. 29, n. ${ }^{\circ} 115,1945$, p. 70; Mioceno Médio, formação Bowden, Jamaica. Renz, Geol. Soc. Am., Mem. 32, 1948, p. 137, pl. X, figs. 3 a-c; Mioceno, Venezuela. - Bermudez, Cush. Lab. Foram. Res., Sp. Publ. 25, 1949, pp. 286-287, pl. 22, figs. 9-11; Oligoceno Médio - Mioceno Superior, São Domingos. - Mem. Soc. Cubana Hist. Nat., vol. 19, n. ${ }^{\circ}$ 3, 1950, p. 342; Mioceno - Recente, Cuba. - Redmond, Jour. Pal., vol. 27, n. ${ }^{\circ} 5,1953$, p. 731, pl. 77, figs. 11 a-c; Mioceno, formação Tubara, Colômbia.

Descriç̃̃o - Testa biconvexa, deprimida, alongada, com 6 câmaras na última volta do corpo; câmaras projetantes na zona central do lado ventral; lado ventral com um umbílico pequeno; periferia carenada; suturas deprimidas no lado ventral e limbadas e curvas no lado dorsal; abertura bem desenvolvida na base da face apertural com um lábio projetante.

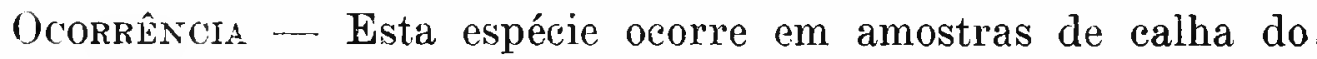
poço CR-1-PA, nos seguintes intervalos: $258 \mathrm{~m} 264 \mathrm{~m}, 270 \mathrm{~m}$ $290 \mathrm{~m}, 332 \mathrm{~m} 335 \mathrm{~m}, 431 \mathrm{~m}-434 \mathrm{~m}, 512 \mathrm{~m}-524 \mathrm{~m}, 658 \mathrm{~m} 668 \mathrm{~m}$, $784 \mathrm{~Hz} \quad 802 \mathrm{~m}$.

Dimensiões - Os diâmetros são, em média, cêrca de $0.39 \mathrm{~mm}$ e $0.31 \mathrm{~mm}$ e a espessura $0.15 \mathrm{~mm}$. Foi medido um indivíduo excepcionalmente mais circular; os seus diâmetros são de $0.31 \mathrm{~mm} \mathrm{e}$ $0.27 \mathrm{~mm}$ e a espessura $0.17 \mathrm{~mm}$.

Discussío -... Os indivíduos pertencentes a esta espécie concordam bem com as descrições e ilustrações de $G$. menardii (d'Orbigny). Segundo Cushman (1931 p. 92) a testa é plano-convexa com o lado ventral plano. Entretanto êle ilustra (Idem, Est. 17, figs. 1 a, e) uma forma biconvexa. A ilustração original (Ellis e Messina, Catalogue of Foraminifera) também mostra uma forma biconvexa.

Esta espécie é muito espalhada atualmente em águas do Oceano Atlântico. Ela ocorre como fóssil no plano costal dos Estados Unidos e na região caraíbica, do Oligoceno Superior a Recente (Trinidad, Cuba, São Domingos, Haití, Jamaica, México). Ela não é abundante no material brasileiro. Todos os indivíduos observados, os quais aliás são em pequeno número (17), mostram enrolamento sinistrógiro. É interessante salientar que todos os espécimes colhidos são muito pequenos em relação a espécie, representando formas: jovens.

Plesiótipos - L. P - C. N. P. 1-62. 


\section{Globorotalia sp}

Est. 13 - Figs. 10-11

Descrição - Foram separados entre os representantes do gênero Globorotalia, provenientes do poço CR-1-PA, diversos exemplares, cujos caracteres se aproximam dos da espécie $G$. tumida (Brady). Como nesta espécie, a parede é espêssa, a testa é biconvexa, um tanto entumescida e alongada, o número de câmaras na última volta do corpo é de 6 e a carena é larga e arredondada; tôdas as câmaras são granulosas próximo a periferia da testa; os espécimes são erodidos parecendo ser material transportado, extranho a fauna aqui descrita.

OCORRÊNCIA - Os exemplares encontrados provém de amostra de calha, do intervalo $274 \mathrm{~m}-277 \mathrm{~m}$.

Dimensões - Os diâmetros do exemplar figurado são: $0.39 \mathrm{~mm}$ e $0.28 \mathrm{~mm}$ e a espessura $0.17 \mathrm{~mm}$. A relação entre a espessura e o diâmetro maior é de 0.43 , enquanto nos representantes de $G$. menardii (d'Orbigny) do poço CR-1-PA, a relação é em tôrno de 0.38 .

TIPOS - L. P. C. N. P. 1-63.

Globoquadrina quadraria (Cush. e Ellisor) var. advena Bermudez

Est. 13 - Figs. 15-16; Est. $14-$ Fig. 1

Globoquadrina quadraria (Cushman e Ellisor) var. advena Bermudez, Cush. Lab. Foram. Res., Sp. Publ. 25, 1949, p. 287, pl. 22, figs. 36-38; Mioceno Médio, formação Gurabo, São Domingos.

DEscriçĩo - Testa pequena, subquadrada tanto em vista dorsal como ventral, lado dorsal plano ou ligeiramente convexo, lado ventral muito convexo; tôdas as voltas do corpo vistas do lado dorsal (cêrca de 2 ), sòmente a última volta vista do lado ventral; a última volta do corpo é constituída por 4 câmaras; as câmaras aumentam ràpidamente em espessura e largura mas não muito em comprimento, de maneira que a última eâmara é saliente. Elas, especialmente a última câmara, tem um esbôço quadrado; a face apertural que é plana ou ligeiramente côncava, forma um ângulo agudo com a periferia; esta é larga e plana, formando ângulo reto com as faces dorsal e ventral; as suturas são distintas e dispostas radialmente; eîâs são bem deprimidas no lado ventral mas ligeiramente deprimidas no lado dorsal; parede grosseiramente perfurada excepto na face apertural a qual é finamente perfurada, de maneira que a 
referida face mostra, nos espécimes bem conservados, um anel extermo na periferia que constitui o reflexo das grossas perfurações das paredes da periferia e dos lados; a abertura é alongada na base da face apertural, se extendendo do umbílico para a periferia, e parcialmeṇte escondida por um lábio suspenso sôbre ela; o umbílico é largo e distinto.

Ocorrência - Esta espécie não é comum no poço CR-1-PA, ocorrendo em amostras de calha, dos seguintes intervalos: $253 \mathrm{~m}$ $256 \mathrm{~m}, 271 \mathrm{~m} 293 \mathrm{~m}, 299 \mathrm{~m} 302 \mathrm{~m}, 314 \mathrm{~m} 317 \mathrm{~m}, 341 \mathrm{~m} 344 \mathrm{~m}$, $360 \mathrm{~m}-364 \mathrm{~m}, 366 \mathrm{~m} 369 \mathrm{~m}, 387 \mathrm{~m}-405 \mathrm{~m}, 497 \mathrm{~m}, 503 \mathrm{~m}, 530 \mathrm{~m}$ $536 \mathrm{~m}$.

Dinensões - Os diâmetros, medidos no espécime figurado são: $0.29 \mathrm{~mm}$ e $0.25 \mathrm{~mm}$ e a espessura $0.24 \mathrm{~mm}$.

Discussio - O gênero Globoquadrina foi criado por I'inlay em 1947 para incluir espécies que costumaram ser enlocadas no gênero Globorotalia. Certas espécies incluídas no ęênero Globigerina também foram aqui colocadas por Finlay, porém não são típicas. Êste gênero é caracterisado por câmaras comprimidas com lados ventral. dorsal e periferal achatados on ligeiramente convexos; o contacto entre as faces forma aproximadamente um ângulo de $90^{\circ}$, de maneira a se obter $1 \mathrm{~m}$ esbôço quadrangular; a face apertural é lisa e plana ou ligeiramente côncava, encontrando outras faces em $\mathrm{um}$ ângulo agudlo; a abertura é formada por estreita fenda na base da face apertural, parcialmente escondida por $11 \mathrm{~m}$ lábio pendente; êstes caracteres são muito claros nos espécimes do Marajó. Como salientou Finlay (Ellis e Messina, Catalogue of Foraminifera). "Most Miocene off - shore famnas seem to contain a representative and it is possible that typical forms may be limited to upper Oligocene and Miocene",

Finlay inclui neste gênero as seguintes espécies:

1 - Globorotalia dehiscens Chapman, Parr e Collins, o genotipo, do Oligoceno da Australia.

2- G. quadraria - Cushman e Ellisor - Mioceno de Louisiana.

3 - Globigerina altispira - Cushman e Jarvis - Mioceno de - Jamaica. Finlay se baseou no umbílico característico a nos caracteres da face apertural para incluir esta ńltima espécie no gênero citado. Contudo esta espécie, a nosso ver, não deve ser incluíla no gênero por ter zilaior número de câmaras por volta do corpo e, principalmente. pelo esboco arredondako das câmaras. 
4 - Globigerina venezuelana Hedberg, do Oligoceno Superiur da Venezuela. Esta espécie também não é típica por serem as câmaras arredondadas, pelo esbôȩo circular da testa tomada em conjunto, e pela abertura que é citada como se localisando em uma profunda depressão triangular entre as últimas câmaras.

Além das 4 espécies citadas, Finlay cita como possível, que Globigerina helicina d'Orbigny, do Plioceno de Rimini, Itália, figurada por Cushman (1941 p. 41) possa ser incluída no gênero. Contudo aqui as câmaras são arredondadlas, e a abertura parece ser característica do gênero Globigerina. Vê-se, portanto, que das 4 espécies citadas por Finlay, somente Globorotalia dehiscens Chapman, Parr e Collins e G. quadraria Cushman e Ellisor podem ser colocadas, sem discussão, no gênero. Além destas 2 espécies, Finlay ainda descreveu mais 2 espécies, $G$. primitiva que se distribui do Cretaceo Superior ao Eoceno Médio da Nova Zelândia e G. subdehiscens que se distribui do Oligoceno Médio ao Mioceno Superior da Nora Zelândia.. Bermudez (1949) p. 287 ) descreveu G. quadraria var. advena do Mioceno Médio da República Dominicana (Forma(cão Gurabo).

A espécie $G$. primitiva mostra certos caracteres interpretados como primitivos, isto é, vista lateral um tanto triangular ou suboval e apesar da vista ventral mostrar 4 câmaras, a quarta aparece só incompletamente, formando as outras 3 a maior parte da volta do corpo; a ornamentação é formada por fortes espinhos; estas particularidades tornam a espécie menos característica, fàcilmente se diferenciando de outras espécies mais características, inclusive a que ocorre em Cururú.

Na espécie $G$. subdehiscens as câmaras se juntam obliqüamente, uma sucedendo a outra com torcedura para baixo e para traz, de maneira que a última câmara se inclina para dentro e encobre a câmara de baixo; a rista ventral mostra, portanto, 3 grandes câmaras procminentes, a quarta ficando parcial, ou totalmente escondida. As câmaras são infladas tendendo para subglobular, não sendo também espécie característica, diferenciando-se fàcilmente las outras.

As espécies G. dehiscens (Chapman, Parr e Collins) e G. quadraria (Cushman e Ellisor) são as que apresentam os caracteres do gênero sob a forma mais típica.

$G$. dehiscens possui suturas mais perfeitamente radiais que $G$. cuadraria (Cushman e Ellisor) a vista periferal mais cilíndrica. A forma das câmaras é também diferente sendo que os espécimes brasileiros se aproximam mais de G. quadraria (Cushman e Ellisor). Cremos que a forma brasileira deve ser referida a $G$. quadraria (Cushman e Ellisor) var. advena Bermudez, do Mioceno Médio (Formação Gurabo) de São Domingos. Como naquela rariedade, 
ela é mais elevada ventralmente que a forma típica e também possui a superfície completamente perfurada em contraste com a forma típica, onde metade de cada câmara é lisa.

Plesiótipos - L. P - C. N. P 1-64.

\section{Planulina sp}

Est. 13 - Figs. 12-14

DESCRIÇ̃̃o - Sòmente um indivíduo pertencente a êste gênero foi achado no poço CR-1-PA. A testa é quase planospiral, muito deprimida; a periferia é truncada, em ângulo reto com os lados da testa; tôdas as voltas do corpo, cêrca de duas e meia, visíveis de ambos os lados; a testa é completamente evoluta de um lado e quase completamente evoluta do outro lado; oito câmaras bem distintas formam a última volta do corpo; suturas fortemente convexas para a face apertural, bem distintas e limbadas em ambos os lados; parede lisa, um tanto grosseiramente perfurada; abertura periferal extendendo-se para o lado menos evoluto.

OCORRÊncIa - O indivíduo aqui citado aparece no poço CR1-PA, em amostra de calha do intervalo $271 \mathrm{~m} 274 \mathrm{~m}$.

Dinensões - As dimensões do espécime em consideração são as seguintes: Diâmetro maior $0.40 \mathrm{~mm}$, diâmetro menor $0.34 \mathrm{~mm}$ e espessura $0.10 \mathrm{mn}$.

Discussĩo - Esta espécie lembra P. foveolata (Brady) tendo. contudo, menos câmaras por volta do corpo. Evitamos a diagnóse específica por têrmos a mão sòmente um indivíduo.

$$
\text { TiPo - L. P. - C. N. P } 1-82 .
$$

\section{Laticarinina sp}

Est. 14-Figs. 8-9

Descrição - Testa plano-convexa, lado dorsal achatado, ventral fortemente convexo; uma volta e meia visível; quilha larga e relativamente grossa; primeiras câmaras subesféricas tornando-se, as adultạs, mais largas que compridas; 7 câmaras na última volta do corpo; suturas deprimidas; parede lisa, finamente perfurada; a abertura não está clara.

OCORRÊncia - O único indivíduo encontrado no poco CR-1PA, provém de amostra de calha do intervalo $594 \mathrm{~m} 600 \mathrm{~m}$. 
Drmẹsões - As dimensões são as seguintes: Diâmetro maior $0.38 \mathrm{~mm}$, diâmetro menor $0.24 \mathrm{~mm}$, espessura $0.12 \mathrm{~mm}$.

Discussĩo - Apesar de representado sòmente por um indivíduo, a presença dêste gênero constitui em elemento a mais na fauna estudada para corroborar a idade dos sedimentos que a contém. Como salientam Cushman e Todd (1942 b, p. 14), apesar de se ter registro dêste gênero desde o Cretaceo, espécimes característicos, onde o gênero se mostra bem desenvolvido, só se encontram do Mioceno a Recente. Posteriormente ao trabalho de Cushman e Todd, Colom em 1945 (Catalogue of Foraminifera sob Laticarinina hispanica) e Ten Dam e Sigal em 1950 (1950 p. 37), descreveram 2 espécies do gênero em consideração, respectivamente $L$. hispanica Colom e L. prima Ten Dam e Sigal provenientes, respectivamente, de sedimentos do Oligoceno Inferior e do Cretaceo-Paleoceno. Contudo êsses fósseis pré-miocênicos não apresentam os caracteres de Laticarinina completamente desenvolvidos, tendo uma carena bem menor, lado dorsal bem distinto e lado ventral mostrando sòmente parte das voltas anteriores. O nosso espécime possui a quilha relativamente grossa o que a aproxima de $L$. crassicarinata Cushman e Todd, contudo êle é distintamente plano-convexo o que o afasta tanto desta espécie como de L. pauperata (Parker e Jones) de que o nosso espécime se aproxima pela forma das câmaras.

$$
\text { Plesiótipo - L. P - C. N. P. 1-73. }
$$

Cibicides americanus (Cushman) var. paraensis Petri var. nov.

$$
\text { Est. } 14 \text { - Figs. } 2-4
$$

DESCRIÇão - Testa plano-convexa, lado dorsal plano, lado ventral convexo; periferia aguda, dotada de carena pouco desenvolvida mas distinta; câmaras cêrca de 7 a 8 na última volta do corpo, aumentando gradualmente de tamanho; suturas distintas, limbadas em ambos os lados, curvas para a abertura; no lado ventral a região umbilical é preenchida por material freqüentemente transparente, formando um pequeno nódulo central; parede lisa, finamente perfurada; abertura periferal e extendendo-se para o lado dorsal, dotada de um ligeiro lábio.

OCORRÊncia - Esta espécie é comum no poço CR-1-PA, ocorrendo em testemunhos de sondagem e em amostras de calha. Ocorre nos seguintes testemunhos: Test. $n^{\circ} 6,500 \mathrm{~m} 503 \mathrm{~m}$, test. ${ }^{\circ}{ }^{0} 9$, $617 \mathrm{~m}-620 \mathrm{~m}$. Em amostras de calha ela ocorre nos seguintes intervalos : $270 \mathrm{~m}-475 \mathrm{~m}, 495 \mathrm{~m} \quad 564 \mathrm{~m}, 585 \mathrm{~m} \quad 597 \mathrm{~m}, 689 \mathrm{~m} 707 \mathrm{~m}$, $783 \mathrm{~m} 820 \mathrm{~m}, 844 \mathrm{~m} 870 \mathrm{~m}$. 
Dinensões - As dimensões, medidas em 2 espécimes, são as seguintes: 1) Espécime figurado: Diâmetro maior $0.49 \mathrm{~mm}$, diâmetro menor $0.45 \mathrm{~mm}$, espessura $0.18 \mathrm{~mm}$; 2) Outro espécime: Diâmetro maior $0.16 \mathrm{~mm}$, diâmetro menor $0.13 \mathrm{~mm}$, espessura $0.07 \mathrm{~mm}$.

Discussĩo - A presente variedade difere da forma típica de C. anericanus (Cushman) por possuir as suturas mais limbadas e muito mais curvas e pelo menor número de câmaras por volta do corpo. Por êstes caracteres ela se aproxima da variedade antiquus da mesma espécie, descrita por Cushman e Applin e proveniente do Eoceno do Texas, ocorrendo também no Eoceno da Carolina do Sul, Alabama e Mississippi. Distingue-se desta variedade principalmente pela periferia dotada de carena bem distinta.

C. americanus (Cushman) foi deserita do Mioceno da zona do Canal do Panamá, sendo uma espécie comum no Mioceno e Oligoceno da região do Plano Costal dos Estados Unidos, extendendo-se também para o norte da América do Sul, onde ocorre no Mioceno e Oligoceno da Venezuela, Colombia e Trinidad (Renz 1948 p. 127). Aparece também em camadas idênticas no México, Pôrto Rico, São Domingos e Cuba.

A espécie afim C. yazooensis Cushman difere da espécie em consideração pelas suturas muito mais limbadas e elevadas e pelas câmaras mais largas, enquanto $C$. concentricus (Cushman) possuj as suturas deprimidas, não limbadas e menos curvas.

$$
\text { HoLớtiPo - L. P - C. N. P 1-23. }
$$

Cibicides cururuensis Petri sp nov.

$$
\text { Est. } 14 \text { - Figs. 5-7 }
$$

Descrição - Testa relativamente grande, alongada, biconvexa deprimida, com convexidade aproximadamente igual em ambos os lados, involuta no lado ventral, evoluta no lado dorsal; a última volta do corpo neste lado é nitidamente separada das voltas anteriores por uma profunda sutura espiral; a superfície lateral das câmaras é mais convexa na parte proximal, caindo em declive um tanto íngreme para a parte distal; periferia aguda, ligeiramente carenada; câmaras distintas, ligeiramente projetantes produzindo periferia lobada, cêrca de 8 na última volta do corpo, aumentando ràpidamente $\mathrm{em}$ comprimento, altura e largura, de maneira que a parte central da testa é ligeiramente deprimida em relação a última volta do corpo; parte central da testa fechada, sem umbílico mas sem se projetar em umbo; suturas distintas, deprimidas, aproximadamente radiais; parede lisa, finamente perfurada; abertura exten- 
dendo-se da periferia para a região dorsal em certa extensão, dotada de um ligeiro lábio.

Ocorrência - Esta espécie é rara no poço CR-1-PA, ocorrendo, em amostras de calha dos seguintes intervalos: $261 \mathrm{~m} 268 \mathrm{~m}$, $280 \mathrm{~m} 290 \mathrm{~m}, 323 \mathrm{~m} 326 \mathrm{~m}, 334 \mathrm{~m}-346 \mathrm{~m}$.

Dimensões - As dimensões, medidas em 2 espécimes, são: 1) Espécime figurado: Diâmetro maior $1.29 \mathrm{~mm}$, diâmetro menor $0.95 \mathrm{~mm}$, espessura $0.62 \mathrm{~mm}$. 2) Outro espécime: Diâmetro maior $0.81 \mathrm{~mm}$, diâmetro menor $0.71 \mathrm{~mm}$, espessura $0.38 \mathrm{~mm}$.

Discussão - Esta espécie é muito característica e perfeitamente distinta de outras espécies de Cibicides descritas; pelos lados sem umbos projetantes, pelo lado dorsal evoluto, pela testa alongada e com câmaras aumentando ràpidamente de tamanho e pela periferia lobada, ela se aproxima de C. lobatus (d'Orbigny), da qual se distingue por ser biconvexa e por possuir suturas deprimidas em ambos os lados e pelo caráter da parede da testa, finamente perfurada.

$$
\text { Holótrio - L. P - C. N. P 1-24. }
$$

\section{Cibicides lobatus (d'Orbigny)}

Est. 14 - Figs. 10-12

Truncatulina lobata d'Orbigny, in Barker - Webb e Berthelot, Hist. Nat. iles Canaries, vol. 2, pt. 2, Foraminifères, 1839, p. 134, pl. 2, figs. 22-24; Recente, Canaries.

Cibicides lobatus (d'Orbigny), Galloway e Heminway, New York Acad. Sci., vol. 3, pt. 4, 1941, p. 393, pl. 24, fig. 4; Oligoceno e Mioceno, Pôrto Rico. Palmer, Bull. Am. Pal., vol. 29, n. ${ }^{\circ}$ 115, p. 73; Mioceno Médio, formação Bowden, Jamaica. - Bermudez, Cush. Lab. Foram. Res., Sp. Publ. 25, 1949, p. 301, pl. 25, figs. 46-48; Mioceno Superior, formação Mao, São Domingos.

Truncatulina lobatula (Walker e Jacob), Cushman, U. S. Geol. Surv., Bull. 676, 1918, pp. 16, 60; pl. 1, fig. 10; pl. 17, figs. 1-3; Mioceno, Plano costal do leste dos Estados Unidos. - Publ. 291, Carnegie Instit., Washington, 1919, p. 41; Mioceno Inferior, formação Cercado, São Domingos. - Nuttall, Quart. Jour. Geol. Soc., vol. 84, 1928, p. 98; Mioceno, Trinidad, B. W. I.

Cibicides lobatulus (Walker e Jacob) (Non Nautilus lobatulus Walker e Jacob), Cole, Flórida St. Geol. Surv., Bull. 6, 1931, p. 56; Plioceno e Pleistoceno, Flórida. - Palmer, Mem. Soc. Cubana Hist. Nat., vol. 15, 1941, p. 294, pl. 29, fig. 4; Oligoceno Superior, formação Cojimar, Cuba.

Descrição - Testa alongada, côncavo-convexa; lado ventral involuto, convexo, deprimido próximo a periferia; lado dorsal incompletamente evoluto, ligeiramente côncavo; periferia aguda; câmaras aumentando um tanto ràpidamente em altura e espessura, 
gradualmente em largura, cêrea de 8 na última volta do corpo; suturas do lado ventral radiais, deprimidas e curvas; suturas dorsais contínuas com o resto da testa ou ligeiramente deprimidas, um tanto limbadas, aproximadamente radiais, curvas; parede finamente perfurada no lado ventral, um tanto grosseiramente no lado dorsal; abertura periferal, extendendo-se bem para o lado dorsal.

OCORRÊNCIA - Esta espécie é rara no poço CR-1-PA, ocorrendo, em amostras de calha dos seguintes intervalos: $277 \mathrm{~m} 289 \mathrm{~m}$, $332 \mathrm{~m} \quad 335,543 \mathrm{~m} \quad 549 \mathrm{~m}, 646 \mathrm{~m} \quad 655 \mathrm{~m}$.

Dimensões - As dimensões, medidas no espécime figurado, são: Diâmetro maior $0.42 \mathrm{~mm}$, diâmetro menor $0.31 \mathrm{~mm}$, espessura $0.07 \mathrm{~mm}$.

Discussio - Os espécimes brasileiros, como os espécimes típi$\cos$ de $C$. lobatus (d'Orbigny) mostram sinais de terem sido aderentes pelo lado dorsal a um substratum. Êles parecem ser idênticos a espécie acima. Devemos lembrar que esta espécie de d'Orbigny tem sido confundida com a espécie "Nautilus lobatulus Walker e Jacob" que também deve ser referida ao mesmo gênero. "Nautilus lobatulus Walker e Jacob" difere, contudo, da espécie de d'Orbigny. A espécie de Walker e Jacob que foi referida por Cushman (1931 pp. 118-120, Est. 21, figs. 3 a-c.) no Oceano Atlântico, foi descrita anteriormente a de d'Orbigny, e se bem que os nomes específicos sejam diferentes, lobatulus para a espécie de Walker e Jacob e lobatus para a de d'Orbigny, cremos que talvez fôsse mais conveniente dar um novo nome para a espécie de d'Orbigny para evitar confusões a respeito. Aparecem ainda, no poço CR-1-PA, outras formas de Cibicides, cuja raridade desaconselha tentativa de diagnóstico específico.

$$
\text { Plesiótipos - L. P - C. N. P 1-25. }
$$

\section{Cibicides pseudoungerianus (Cushman)}

Est. 14 - Figs. 16-18

Truncatulina ungeriana Brady (Non Rotalina ungeriana d'Orbigny), Rep. Voy. Challenger, Zool., vol. 9, 1884, pl. 94, fig. 9; Recente, Irlanda. - Cushman, U. S. Nat. Mus., Bull. 103, 1918, p. 69, pl. 24, fig. 1; Oligoceno, formação Culebra, Panamá.

Truncatulina pseudoungeriana Cushman, U. S. Geol. Surv., Prof. Paper 129, 1922, pp. 97, 136, pl. 20, fjg. 9; Oligoceno, formação Byram Marl, Mississippi.

Cibicides ungeriana (d'Orbigny), Galloway e Morrey, Bull. Am. Pal., vol. XV, n. ${ }^{\circ}$ 55, 1929, p. 31, pl. 4, fig. 10; Eoceno Superior, Equador. 
Cibicides pseudoungerianus (Cushman), Cole e Gillespie, Bull. Am. Pal., vol. 15, n. 57 b, 1930, p. 15, pl. 3, figs. 10, 11; Oligoceno Médio, formação Meson, México. - Ellisor, Bull. Am. Ass. Petr. Geol., vol. 17, n. ${ }^{\circ}$ 11, 1933, pl. 5, figs. 3, 4; Eoceno, formação Jackson, Texas. - Tolmachoff, Ann. Carnegie Mus., vol. 23. 1934, p. 335, pl. 42, figs. 4, 6; Mioceno, Colômbia. - Cushman, U. S. Geol. Surv., Prof. Paper 181, 1935, p. 52, pl. 23, fig. 1; Eoceno Superior, Sudeste dos Estados Unidos. - Galloway e Heminway, New York Acad. Sci., vol. 3, pt. 4, 1941, p. 395, pl. 23, fig. 5; Mioceno Inferior, formação Los Puertos, Pôrto Rico. - Palmer, Bull. Am. Pal., vol. 29, n.o 115, p. 74; Mioceno Médio, formação Bowden, Jamaica. Cushman e Todd, Cush. Lab. Foram. Res., Sp. Publ. 15, 1945, pp. 70-71, pl. 12, fig. 7; Referências; Mioceno, Buff Bay, Jamaica. - Bermudez, Cush. Lab. Foram. Res., Sp. Publ. 25, 1949, pp. 304-305, pl. 24, figs. 28-30; Mioceno Médio, formação Sombrerito, São Domingos. - Mem. Soc. Cubana Hist. Nat., vol. XIX, n. ${ }^{\circ} 3$, 1950, p. 334; Eoceno - Recente, Cuba.

Descrição - Testa circular, plano-convexa; lado dorsal plano ou ligeiramente convexo, evoluto; lado ventral convexo, porém deprimido próximo a periferia, as vêzes com o umbo ocupado por matéria conchífera clara; periferia subcarenada; câmaras distintas no lado ventral, um tanto indistintas no lado dorsal, cêrca de 7 a 9 na última volta do corpo; suturas contínuas com o resto da testa, não deprimidas, ligeiramente limbadas tanto no lado dorsal como ventral; parede lisa, grosseiramente perfurada no lado dorsal e finamente perfurada no lado ventral; abertura periferal, extendendo-se para o lado dorsal.

OCORRÊncia - A presente espécie é relativamente abundante no poço CR-1-PA, ocorrendo tanto em amostras de calha como em testemunhos de sondagem. Ela aparece nos seguintes testemunhos de sondagem: Test. $\mathrm{n} .{ }^{\circ}$ 6, $500 \mathrm{~m} 503 \mathrm{~m}$, test. ${ }^{\circ}{ }^{\circ} 8,614 \mathrm{~m} 617 \mathrm{~m}$. Em amostras de calha, ocorre nos seguintes intervalos: $261 \mathrm{~m}-301 \mathrm{~m}$, $310 \mathrm{~m}-313 \mathrm{~m}, 334 \mathrm{~m} \quad 423 \mathrm{~m}, 442 \mathrm{~m}-479 \mathrm{~m}, 497 \mathrm{~m}-512 \mathrm{~m}, 524 \mathrm{~m}$ $541 \mathrm{~m}, 658 \mathrm{~m} 668 \mathrm{~m}$.

Dinensões - As dimensões, medidas em 2 espécimes, são: 1) Espécime figurado: Diâmetro maior $0.47 \mathrm{~mm}$, diâmetro menor $0.39 \mathrm{~mm}$, espessura $0.22 \mathrm{~mm}$; 2) Outro espécime: Diâmetro maior $0.24 \mathrm{~mm}$, diâmetro menor $0.23 \mathrm{~mm}$, espessura $0.12 \mathrm{~mm}$.

Discussĩo - A presente espécie concorda bem com os caracteres de C. pseudoungerianus (Cushman); tivemos oportunidade de comparar os nossos espécimes diretamente com espécimes provenientes do Mioceno de Buff Bay, Jamaica. Êles são em relação aos citados espécimes de Buff Bay bem menores e mais distintamente plano-covexos.

Plesiótipos - L. P - C. N. P 1-26. 


\section{Dyocibicides sp}

Est. 14 - Figs. 13-15

Descrição - Foram encontrados no poço CR-1-PA, 3 indivíduos, pertencentes ao gênero Dyocibicides, os quais parecem pertencer a espécie $D$. biserialis Cushman e Valentine; contudo a raridade do material não permite uma classificação segura; a testa é comprimida, sendo a parte mais antiga intimamente enrolada e a parte mais jovẹm bisserial; câmaras um tanto infladas, um tanto indistintas em nosso material devido ao estado de conservação; parede grosseiramente perfurada.

OCORRÊncia - Os 3 indivíduos citados, provém de amostras de calha dos seguintes intervalos: $274 \mathrm{~m} 277 \mathrm{~m}, 332 \mathrm{~m} 335 \mathrm{~m}, 353 \mathrm{~m}-$ $358 \mathrm{~m}$.

Dimensões - O diâmetro máximo medido no espécime figurado é $0.32 \mathrm{~mm}$.

Discussĩo - Êste gênero aparece em sedimentos que se distribuem do Eoceno até hoje. A espécie D. biserialis Cushman e Valentine, aparece no Mioceno do plano costal dos Estados Unidos, Flórida, Jamaica e São Domingos. Em Cuba ela tem sido citada do Oligoceno ao Plioceno. Vive atualmente no Oceano Atlântico.

A espécie D. perforatus Cushman e Valentine com a qual os nossos espécimes mostram também alguma semelhança, foi citada por Bermudez (1949 pp. 310-311) no Mioceno de São Domingos. O tipo é uma forma vivente descrita da costa da Califórnia.

$$
\text { Tipos - L. P - C. N. P 1-34. }
$$




\section{B I B L I O G R A F I A}

Bermudez, P. J. - 1949 - Tertiary smaller Foraminifera of the Dominican Republic - Cush. Lab. Foram. Res., Special Publ. n. ${ }^{\circ}$ 25, 322 pp., 6 figs., $26 \mathrm{t}, 1 \mathrm{tab}$.

Bermudez, P. J. - 1950 - Contribución al estudio del Cenozoico cubano - Mem. Soc. Cubana Hist. Nat., vol. XIX, n. ${ }^{\circ} 3$, pp. 205-375, 2 tab.

Bermudez, P. J. - - 1952 - Estudio sistemático de los foraminiferos rotaliformes - Bol. Geol. Ministerio de Minas e Hidrocarburos - vol. 2, n. ${ }^{\circ} 4$, Venezuela, 230 pp., 35 t.

Bronnimann, P. - 1951 - The genus Orbulina d'Orbigny in the Oligo-Miocene of Trinidad, B. W. I. - Cush. Found. Foram. Res., Contr., vol. 2, pt. 4, pp. 132-138, $4 \mathrm{t}$.

Bronnimann, P. - 1952 a - Glohigerinidae from de Upper Cretaceous (CenomianMaestrichtian) of Trinidad, B. W. I. - Bull. Am. Pal., vol. 34, n. ${ }^{\circ} 140$, 30 figs., 70 pp., 4 t.

Bronnimann, P. - 1952 b - Trinidad Paleocene and Lower Eocene Globigerinidae - Bull. Am. Pal., vol. 34, n.0 143, 34 pp., 13 t., 1 tab.

Brotzen, F. - 1942 - Die Foraminiferengattung Gavelinella nov. gen. und die Systematik der Rotalliformes - Sverges Geologiska Undersokning, ser. C., n. ${ }^{\circ} 451$, Arsbox $36, \mathrm{~N}: 0$ 8, $60 \mathrm{pp}$.

Cushman, J. A. 1929 a - The Foraminifera of the Atlantic Ocean - U. S. Nat. Mus., Bull. 104, pt. 6, 129 pp., 22 t.

Cushman, J. A. -- 1929 b - On Quinqueloculina seminula (Linné) - Cush. Lab. Foram. Res., Contr. vol. 5, pt. 3, pp. 59-60.

Cushman, J.A. - 1930 a - The Foraminifera of the Atlantic Ocean - U. S. Nat. Mus., Bull. 104, pt. 7, 79 pp., 8 t.

Cushman, J. A. - $1930 \mathrm{~b}$ - The Foraminifera of the Choctawhatchee formation of Flórida - Florida St. Geol. Surv., Bull. 4, 89 pp., 12 t.

Cushman, J. A. -- 1931 - The Foraminifera of the Atlantic Ocean - U. S. Nat. Mus., Bull. 104, pt. 8, 179 pp., 26 t.

Cushman, J. A. - 1932 - The Foraminifera of the Tropical Pacific collections of the "Albatross" 1899-1900 - U.S. Nat. Mus., Bull. 161, pt. 1, 87pp., 17 t.

Cushman, J. A. - 1937 a - A monograph of the Foraminiferal family Valvulinidae -- Cush. Lab. Foram. Res., Special Publ. n. ${ }^{\circ}$ 8, 210 pp., 1 fig., 24 t.

Cushman, J.A. - $1937 \mathrm{~b}$ - A monograph of the subfamily Virgulininae of the Foraminiferal family Buliminidae - Cush. Lab. Foram. Res., Special Publ. n. ${ }^{\circ}$ 9, 228 pp., 24 t.

Cushman, J.A. - 1939 - A monograph of the Foraminiferal family Nonionidae - U. S. Geol. Surv., Prof. Paper 191, 100 pp., 20 t.

Cushman, J. A. - 1941 - The species described as Globigerina by d'Orhigny in 1926 - Cush. Lab. Foram. Res., Contr. vol. 17, pt. 2. pp. 38-42, 2 t. 
Cushmon, J. A. - 1945 - The species of the subfamily Reusselinae of the foraminiferal family Buliminidae - Cush. Lab. Foram. Res., Contr. vol. 21, pt. 2 , pp. $27-54,4$ tab.

Cushman, I. A. - 1946 -- The species of Globigerina described between 1839 and 1850 - Cush. Lab. Foram. Res., Contr. vol. 22, pt. 1, pp. 15-21, 2 t.

Cushman, J. A. - 1948 -.- Foraminifera - Their classification and economic use - 4.a ed. - Harvard Univ. Press, 605 pp., 31 figs., 55 t.

Cushman, J. A. e Cahill, E. D. - 1933 - Miocene Foraminifera of the Coastal Plain of the Eastern United States - U. S. Geol. Surv., Prof. Paper 175-A, 50 pp., 13 t., 1 tab.

Cushman, J. A. e Gray, H. B. - 1946 - A Foraminiferal fauna from the Timms Point, Califórnia - Cush. Lab. Foram. Res., Special Publ. 19, 46 pp., 8 t.

Cushman, J. A. e Parker, F. L. - 1931 - Recent Foraminifera from the Atlantic Coast of South America - U. S. Nat. Mus., Proc. vol. 80, Art. 3, 24 pp., $4 \mathrm{t}$.

Cushman, J. A. e Ponton, G. M. - 1932 - Foraminifera of the Upper Middle and part of the Lower Miocene of Flórida -. Flórida St. Geol. Surv., Bull. 9, 147 pp., 17 t.

Cushman, J. A. e Todd, R. - 1942 a - The Foraminifera of the type locality of the Naheola formation - Cush. Lab. Foram. Res., Contr. vol. 18, pp. $23 \cdot 46,4 \mathrm{t}$.

Cushman, J. A. e Todd, R. - $1942 \mathrm{~b}$ - The recent and fossil species of Laticarinina - Cush. Lab. Foram. Res., Contr. vol. 18, pt. 1, pp. 14-20, 1 t.

Cushman, J.A. e Todd, R. - 1944 - The genus Spiroloculina and its species Cush. Lab. Foram. Res., Special Publ. 11, 82 pp., 9 t.

Cushman, J. A. e Todd, R. - 1945 - Miocene Foraminifera from Buff Bay, Jamaica - Cush. Lab. Foram. Res., Special Publ. 15, 73 pp., 12 t.

Cuvillier, J. e Szakall, V - 1949 - Foraminifères d'Aquitaine - pt. 1 -- Soc. Nat. des Petroles d'Aquitaine, 113 pp., 32 t.

Ellis, B. F e Messina, A. R. - 1940 - Catalogue of Foraminifera - Am. Mus. Nat. Hist. New York.

Galloway, J. J. e Heminway, C. E. - 1941 - The Tertiary Foraminifera of Pôrto Rico - Sci. Surv. of Pôrto Rico and the Virgin Islands, vol. III, pt. 4, 490 pp., 36 t., 4. tab., 1 mapa geol. Pôrto Rico.

Moura, P. - 1938 - Geologia do Baixo Amazonas - Serv. Geol. Miner., Bol. n.o 91, 94 pp., 1 mapa.

Parker, F. L. - 1948 - Foraminifera of the Continental shelf from the Gulf of Maine to Maryland - Bull. Mus. Comp. Zool. Harvard College, vol. 100, n. ${ }^{\circ}$ 2, 4 figs., 241 pp., 7 t., 10 tab.

Parr, $W$ J. - 1947 -- The Lagenid Foraminifera and their relationship - Proc. Roy. Soc. Victeria, vol. LVIII new series, 1 fig., pp. 116-130, 2 t.

Petri, S. - 1952 - Ocorrências de Foraminíferos fósseis no Brasil - Bol. Geol. VII, Fac. Fil. Ciên. Lt., Univ. S. Paulo, pp. 21-42, 2 figs. 3 fotos, 4 t.

Phleger, F. B. - 1951 - Ecology of Foraminifera, Northwest Gulf of México Geol. Soc. Am., Mem. 46, pt. 1 - Fotaminifera Distribution, 88 pp., 33 figs.

Phleger, F. B. e Parker, F. L. - 1951 - Ecology of Foraminifera, Northwest Gulf. of México - Geol. Soc. Am., Mem. 46, pt. II - Foraminifera species, 64 pp., 20 t.

Redmond, C. D. - 1949 - What is the genus Eponides? - The Micropaleontologist, vol. III, n. ${ }^{\circ} 4$, pp. 19-21, 1 t. 
Redmond, C. D. - 1953 - Miocene Foraminifera from the Tubara Beds of Northern Colombia - Jour. Pal., vol. 27, n. ${ }^{\circ}$ 5, pp. 708-733, t. 74-77, 1 fig.

Renz, H. H. - 1948 - Stratigraphy and fauna of the Agua Salada group, State of Falcon, Venezuela - Geol. Soc. Am., Mem. 32, 219 pp., 12 t., 19 tab.

Schott, W. - 1935 - Die Foraminiferen in dem Äquatorialen Theil des Atlantischen Ozeans - Wissenschaftliche Ergebnisse der deutschen atlantischen Expedition auf dem Forschungsund Vermessungsschiff "Meteor" 192527, Bd. 3, pt. 3, section B., pp. 43-134, text. - figs. 18-75, mapas.

Silva, S. O. e Petri, S. - 1952 - Reconhecimento geológico na área de exposição da formação Pirabas, Estado do Pará, Brasil - Rev. Esc. Minas Ouro Prêto, Ano XVII, n. ${ }^{\circ}$ 1, pp. 9-15, 3 mapas, 2 perfís.

Ten Dam, A. e Sigal, J. - 1950 - Some new species of Foraminifera from the Dano-Montian of Algeria - Cush. Found. Foram. Res., Contr. vol. 1, pt. 1-2.

Thalmann, H. E. - 1951 - Mitteilungen über Foraminiferen IX - Weitere Homonyme bei den Foraminiferen - Eclogae Geol. Helv., vol. 43, n. 2.

Tolmachoff, I. P. - 1934 - A Miocene Microfauna and Flora from the Atrato River, Colombia, South America - Ann. Carnegie Mus., vol. 23, pp. 275-356, t., XXXIX-XLIV. 1 mapa. 
(Todos os fósseis desta e das estampas seguintes provém da sondagem de Cururú)

Fig. 1 - Textularia curta Petri, sp. nov., vista lateral do holótipo, amostra calha $335 \mathrm{~m}-338 \mathrm{~m}-30 \mathrm{x}$.

Fig. 2 - Mesmo espécime, vista apertural - $30 \mathbf{x}$.

Fig. 3 - Textularia marajoara Petri, sp. nov., vista lateral do holótipo, amostra calha $280 \mathrm{~m} \cdot 283 \mathrm{~m}-40 \mathrm{x}$.

Fig. 4- Mesmo espécime, vista apertural - $40 \mathrm{x}$.

Fig. 5 - Textularia? sp., vista lateral, amostra calha $268 \mathrm{~m} \cdot 271 \mathrm{~m}-50 \mathrm{x}$.

Fig. 6 - Clavulina tricarinata d'Orbigny, vista lateral, amostra calha $286 \mathrm{~m}$. $289 \mathrm{~m}-45 \mathrm{x}$.

Fig. 7 - Mesmo espécime, vista apertural $-45 \mathrm{x}$.

Fig. 8 - Ditto, vista lateral, amostra calha $317 \mathrm{~m} \cdot 320 \mathrm{~m}-100 \mathbf{x}$.

Fig. 9 - Mesmo espécime, vista apertural - $100 \mathrm{x}$.

Fig. 10 - Cribrobulimina? sp. vista lateral, amostra calha $512 \mathrm{~m}-524 \mathrm{~m}-55 \mathrm{x}$.

Fig. 11 - Mesmo espécime, vista apertural - 55 x.

Fig. 12 - Quinqueloculina lamarcliana d'Orbigny, vista de 3 câmaras, amostra calha $259 \mathrm{~m} \cdot 262 \mathrm{~m}-50 \mathrm{x}$.

Fig. 13 - Mesmo espécime. vista de 4 câmaras - $50 \mathrm{x}$.

Fig. 14 - Mesmo espécime, vista apertural - $50 \mathrm{x}$.

Fig. 15 - Ditto, vista de 3 câmaras, amostra calha $262 \mathrm{~m} \cdot 265 \mathrm{~m}-100 \mathrm{x}$.

Fig. 16 - Mesmo espécime, visıa de 4 câmaras - 100 x.

Fig. 17 - Mesmo espécime, vista apertural - $100 \mathrm{x}$.

Fig. 18 - Quinqueloculina seminula (Lineu), vista de 3 câmaras, amostra calha $317 \mathrm{~m}-320 \mathrm{~m}-25 \mathrm{x}$.

Fig. 19 - Mesmo espécime, vista de 4 câmaras - $25 \mathbf{x}$.

Fig. 20 - Mesmo espécime, vista apertural - $25 \mathrm{x}$.

Fig. 21 - Ditto, vista de 4 câmaras, amostra calha $317 \mathrm{~m}-320 \mathrm{~m}-55 \mathrm{x}$.

Fig. 22 - Mesmo espécime, vista de 3 câmaras - $55 \mathbf{x}$.

Fig. 23 - Mesmo espécime, vista apertural - $55 \mathrm{x}$.

Fig. 24 - Quinquelocuiina sp. vișı de 3 câmaras, amostra calha $594 \mathrm{~m}$ - $600 \mathrm{~m}$ $55 \mathrm{x}$. 


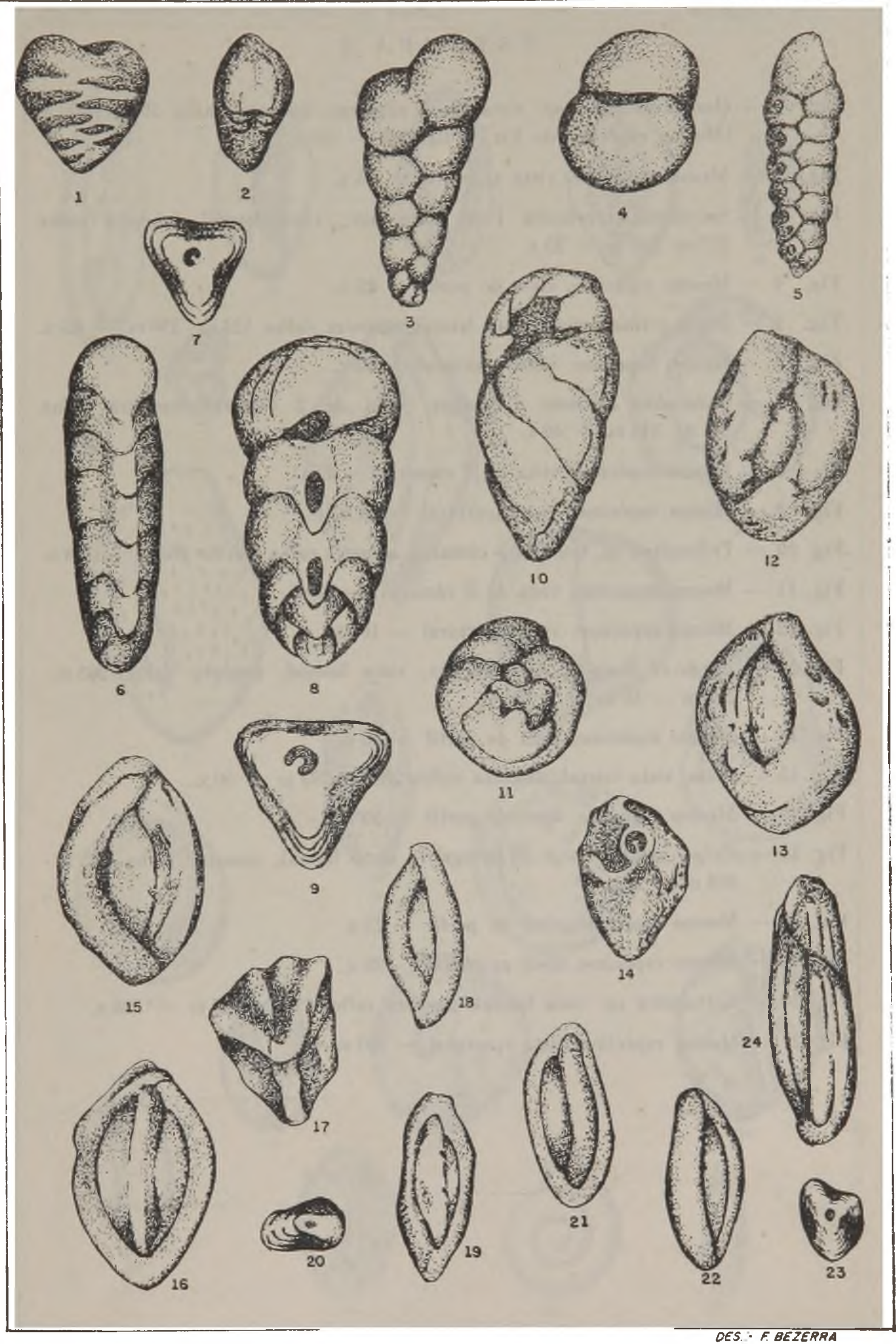




\section{E S T A M P A 2}

Fig. 1 -- Quinqueloculina sp. vista de 4 câmaras, amostra calha $594 \mathrm{~m}-600 \mathrm{~m}$ (Mesmo espécime de Est. 1, fig. 24) - 55 x.

Fig. $2-$ Mesmo espécime, vista apertural $-55 \mathrm{x}$.

Fig. 3 - Spiroloculina concava Petri nom. nov., vista lateral, amostra calha $317 \mathrm{~m} \cdot 320 \mathrm{~m}-25 \mathrm{x}$.

Fig. $4-$ Mesmo espécime, vista de perfíl $-25 \mathbf{x}$.

Fig. 5 - Ditto, forma jovem, vista lateral, amostra calha $524 \mathrm{~m}-530 \mathrm{~m}-65 \mathrm{x}$.

Fig. 6 - Mesmo espécime, vista apertural $-65 x$.

Fig. 7 - Triloculina carinata d'Orbigny, vista de 2 câmaras, amostra calha $341 \mathrm{~m} \cdot 344 \mathrm{~m}-40 \mathrm{x}$.

Fig. 8 - Mesmo espécime, vista de 3 câmaras $-40 \mathbf{x}$.

Fig. 9 - Mesmo espécime, vista apertural - $40 \mathbf{x}$.

Fig. 10 - Triloculina sp. vista de 3 câmaras, amostra calha $265 \mathrm{~m}-268 \mathrm{~m}-100 \mathrm{x}$.

Fig. 11 - Mesmo espécime, vista de 2 câmaras - $100 \mathbf{x}$.

Fig. 12 - Mesmo espécime, vista apertural - $100 \mathrm{x}$.

Fig. 13 - Pyrgo of inornata (d'Orbigny), vista lateral, amostra calha $265 \mathrm{~m}$ $268 \mathrm{~m}-50 \mathrm{x}$.

Fig. 14 - Mesmo espécime, vista de perfíl $-50 \mathrm{x}$.

Fig. 15 - Ditto, vista lateral, amostra calha $289 \mathrm{~m}-293 \mathrm{~m}-50 \mathrm{x}$.

Fig. 16 - Mesmo espécime, vista de perfíl - $50 \mathbf{x}$.

Fig. 17 - Pyrgo subsphaerica (d'Orbigny), vista lateral, amostra calha $265 \mathrm{~m}$ $268 \mathrm{~m}-25 \mathrm{x}$.

Fig. 18 - Mesmo espécime, vista de perfíl $-25 \mathrm{x}$.

Fig. 19 - Mesmo espécime, vista apertural - $25 \mathrm{x}$.

Fig. 20 - Cornuspira sp. vista lateral, amostra calha $259 \mathrm{~m}-262 \mathrm{~m}-100 \mathrm{x}$.

Fig. 21 - Mesmo espécime, vista apertural $-100 \mathrm{x}$. 


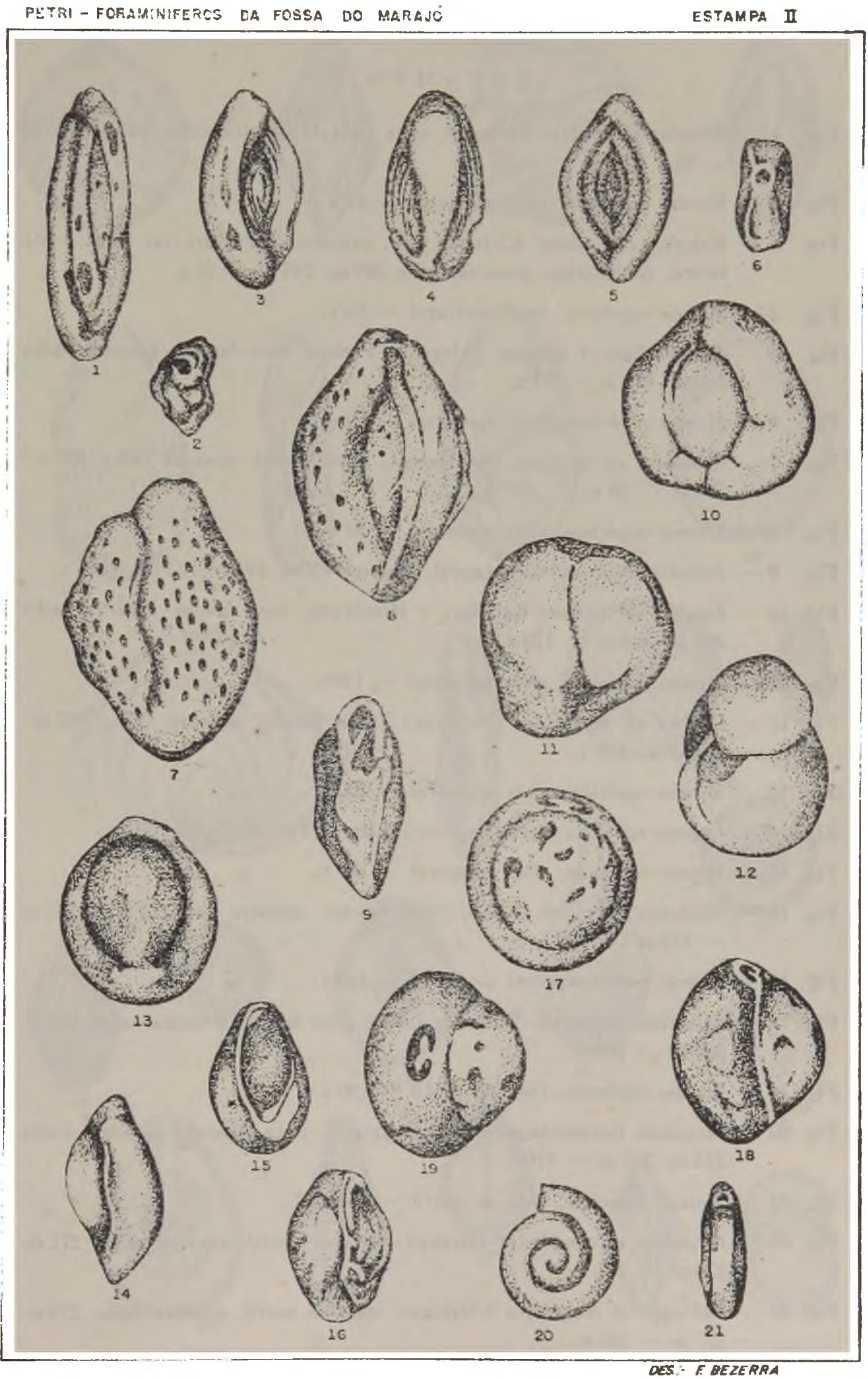




\section{E S T A V P A 3}

Fig. 1 - Robulus of smileyi Kleinpell, vista lateral, amostra calha $253 \mathrm{~m}$ - $256 \mathrm{~m}$ $-25 \mathrm{x}$.

Fig. $2-$ Mesmo espécime, vista apertural $-25 \mathrm{x}$.

Fig. 3-Robulus of smileyi Kleinpell var. pauciloculata Petri var. nov., vista lateral do holótipo, amostra calha $289 \mathrm{~m} \cdot 293 \mathrm{~m}-25 \mathrm{x}$.

Fig. 4- Mesmo espécime, vista apertural - $25 \mathrm{x}$.

Fig. 5-Marginulina cf planata Phleger e Parker, vista lateral, amostra calha $268 \mathrm{~m}-271 \mathrm{~m}-70 \mathrm{x}$.

Fig. $6-$ Mesmo espécime, vista apertural - 70x.

Fig. 7 - Astacolus ef insolitus (Schwager), vista lateral, amostra calha $387 \mathrm{~m}$. $406 \mathrm{~m}$ - $70 \mathrm{x}$.

Fig. 8 - Mesmo espécime, vista apertural - $70 \mathrm{x}$.

Fig. 9 - Frondicularia sp. vista lateral, amostra calha $249 \mathrm{~m}-253 \mathrm{~m}-25 \mathrm{x}$.

Fig. 10 - Lagena aff bullosa Galloway e Heminway, vista lateral, amostra calha $262 \mathrm{~m} \cdot 265 \mathrm{~m}-110 \mathrm{x}$.

Fig. 11 - Mesmo espécime, vista apertural - $110 \mathbf{x}$.

Fig. 12 - Lagena ef perlucida (Montagu), vista lateral, amostra calha $265 \mathrm{~m}$. $268 \mathrm{~m}$ - $100 \mathrm{x}$.

Fig. 13 - Mesmo espécime, vista apertural - $100 x$.

Fig. 14 - Lagena sp. vista lateral, amostra calha $271 \mathrm{~m}-274 \mathrm{~m}-145 \mathrm{x}$.

Fig. 15 - Mesmo espécime, vista apertural - $145 \mathrm{x}$.

Fig. 16 - Fissurina laevigata Reuss, vista lateral, amostra calha $274 \mathrm{~m} \cdot 277 \mathrm{~m}$ - $110 \mathrm{x}$.

Fig. 17 - Mesmo espécime, vista de perfíl - $110 \mathrm{x}$.

Fig. 18 - Fissurina marginata Walker e Jacob, vista lateral, amostra calha $262 \mathrm{~m}$ $265 \mathrm{~m}-100 \mathrm{x}$.

Fig. 19 - Mesmo espécime, vista de perfíl -- $100 \mathrm{x}$.

Fig. 20 - Fissurina marginato-perjurata Seguenza, vista lateral. amostra calha $274 \mathrm{~m}-277 \mathrm{~m}-110 \mathrm{x}$.

Fig. 21 - Mesmo espécime, vista de perfíl - $110 \mathrm{x}$.

Fig. 22 -Virgulina cf compressa (Bailey), vista de perfíl, amostra calla $271 \mathrm{~m}$ $274 \mathrm{~m}-135 \mathrm{x}$.

Fig. 23 - Bulimina cf marginata d'Orbigny. vista de perfil, amostra calha $274 \mathrm{~m}$. $277 \mathrm{~m}-125 \mathrm{x}$. 


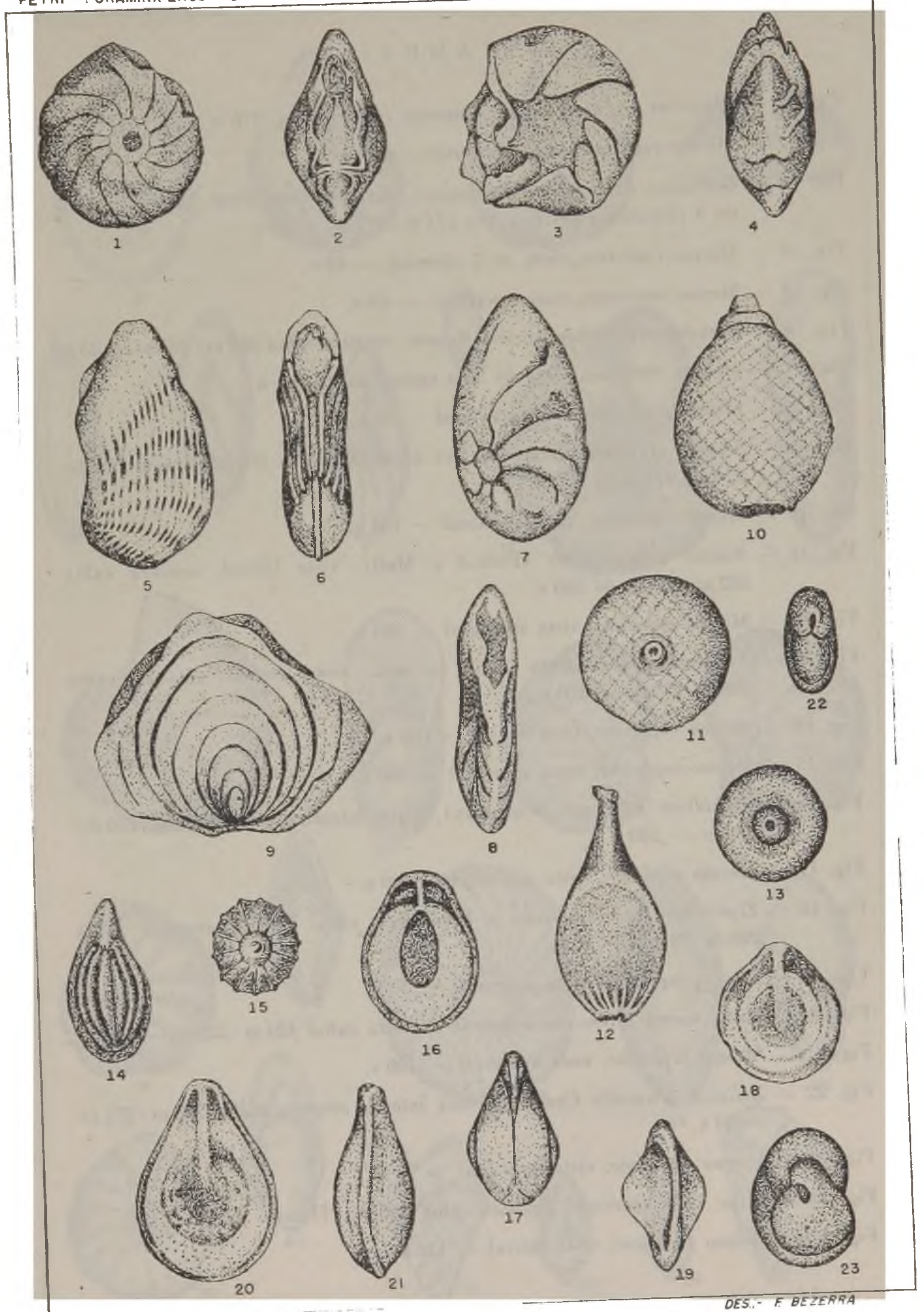




\section{E S T A M P A 4}

Fig. 1 -- Fissurina sp. vista lateral, amostra calha $267 \mathrm{~m}-276 \mathrm{~m}-100 \mathrm{x}$.

Fig. 2 - Mesmo espécime, visla de perfíl - $100 \mathrm{x}$.

Fig. 3 - Guttulina irregularis (d'Orbigny), var. contraria Petri var. nov., vista de 4 câmaras, amostra calha $274 \mathrm{~m} \cdot 277 \mathrm{~m}-45 \mathrm{x}$.

Fig. 4 -... Mesmo espécime, visìa de 3 câmaras - $45 \mathbf{x}$.

Fig. 5 -- Mesmo espécime, vista apertural - $45 \mathrm{x}$.

Fig. $6-$ Pseudopolymorphina sp vista lateral, amostra calha $262 \mathrm{~m} 265 \mathrm{~m}-25 \mathrm{x}$.

Fig. 7 - Mesmo espécime, vista do lado opôsto ao da fig. $6-25 \mathrm{x}$.

Fig. 8 - Mesmo espécime, vista apertural $-25 \mathrm{x}$.

Fig. 9 - Nonion of depressulum (Walker e Jacob), vista lateral, amostra calha $274 \mathrm{~m}-277 \mathrm{~m}-135 \mathrm{x}$.

Fig. 10 - Mesmo espécime, vista apertural - $135 \mathrm{x}$.

Fig. 11 - Nonion pompilioides (Fichtel e Moll), vista lateral. amostra calha $332 \mathrm{~m} \cdot 335 \mathrm{~m}-100 \mathrm{x}$.

Fig. 12 - Nesmo espécime, vista apertural -- $100 \mathrm{x}$.

Fig. 13 - Nonionella curvisulcata Petri sp. nov., vista ventral, amostra calha $286 \mathrm{~m}-289 \mathrm{~m}-100 \mathrm{x}$.

Fig. 14 -..- Mesmo espécime, vista dorsal - $100 \mathrm{x}$.

Fig. 15 - Nesmo espécime, vista apertural - $100 \mathrm{x}$.

Fig. 16 - Elphidium advenum (Cushman). vista Iateral, amostra calha $286 \mathrm{~m}$ $289 \mathrm{~m}-100 \mathrm{x}$.

Fig. 17 - Mesmo espécime, vista apertural - $100 \mathrm{x}$.

Fig. 18 -- Elphidium lens Galloway e Heminway, vista lateral, amostra calha $230 \mathrm{~m} \cdot 283 \mathrm{~m}-50 \mathrm{x}$.

Fig. 19 - Mesmo espécime, vista apertural - $50 \mathrm{x}$.

Fig. 20 - Ditto, forma jovem, vista lateral, amostra calha $329 \mathrm{~m}-332 \mathrm{~m}-120 \mathrm{x}$.

Fig. 21 - Mesmo espécime, vista apertural - $120 \mathrm{x}$.

Fig. 22 - Bolivina plicatella Cushman. vista lateral, amostra calha $268 \mathrm{~m}-271 \mathrm{~m}$ $-95 \mathrm{x}$.

Fig. 23 - Mesmo espécime, visıa apertural - $95 \mathrm{x}$.

Fig. 24 -- Ditto, vista apertural, amostra calha $268 \mathrm{~m}-271 \mathrm{~m}-120 \mathrm{x}$.

Fig. 25 - Nesmo espécime, vi.la lateral -- $120 \mathrm{x}$. 


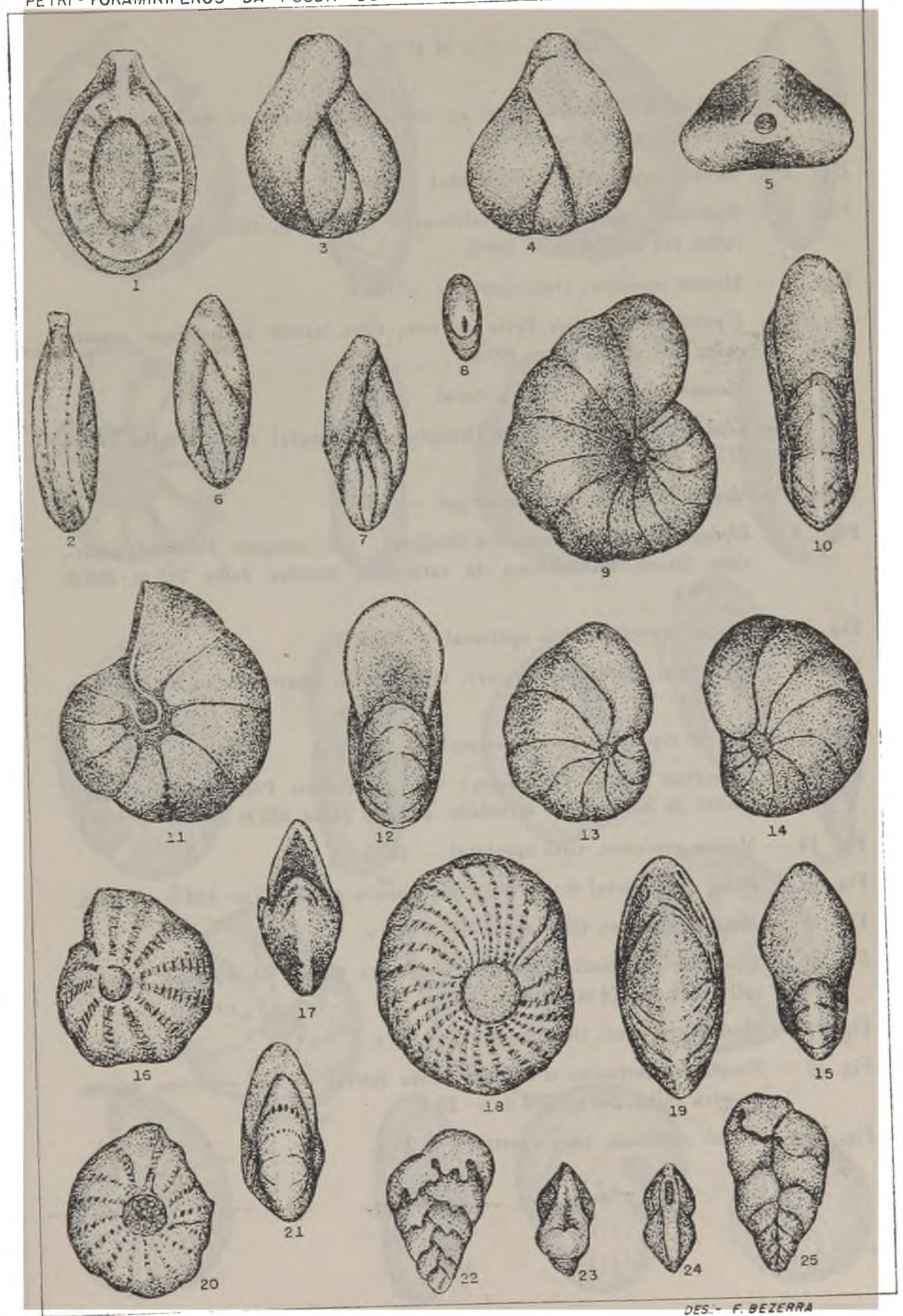




\section{E S T A M P A 5}

Fig. 1 - Elphidium? limbatus Petri sp. nov., vista lateral do holótipo, amostra calha $271 \mathrm{~m} \cdot 274 \mathrm{~m}--80 \mathrm{x}$.

Fig. 2 -- Mesmo espécime, vista apertural - $80 \mathrm{x}$.

Fig. 3 - Elphidium nautiloideum Galloway e Heminway, vista lateral, amostra calha $271 \mathrm{~m} \cdot 274 \mathrm{~m}-100 \mathrm{x}$.

Fig. $4-$ Mesmo espécime, vista apertural - $100 \mathrm{x}$.

Fig. 5 - Elphidium paraensis Petri sp. nov., vista lateral do holótipo, amostra çalha $329 \mathrm{~m} \cdot 332 \mathrm{~m}-100 \mathrm{x}$.

Fig. 6 -- Mesmo espécime, visia apertural - $100 \mathbf{x}$.

Fig. 7 - Elphidium cf poeyanum (d'Orbigny), vista lateral, amostra calha $274 \mathrm{~m}$ $277 \mathrm{~m}-100 \mathrm{x}$.

Fig. 8 - Mesmo espécime, vista aperiural - $100 \mathbf{x}$.

Fig. 9 - Elphidium ef poeyanum (d'Orbigny), var. elongata Petri var. nov., vista lateral do holótipo da variedade, amostra calha $265 \mathrm{~m} \cdot 268 \mathrm{~m}$ $-130 x$.

Fig. 10 - Mesmo espécime, vista apertural - $130 \mathrm{x}$.

Fig. 11 - Elphidium sagrai (d'Orbigny), vista lateral, amostra calha $280 \mathrm{~m}-286 \mathrm{~m}$ $-110 \mathrm{x}$.

Fig. 12 - Mesmo espécime, vista apertural - $110 \mathrm{x}$.

Fig. 13 - Elphidium sagrai (d'Orbigny) var. cururuensis Petri var. nov., vista lateral do holótipo da variedade, amostra calha $335 \mathrm{~m}-338 \mathrm{~m}-100 \mathrm{x}$.

Fig.. 14 - Mesmo espécine, vista apertural - $100 \mathrm{x}$.

Fig. 15 - Ditto, vista lateral de um parátipo. amostra calha $335 \mathrm{~m} \cdot 338 \mathrm{~m}-100 \mathrm{x}$.

Fig. 16 - Mesmo espécime, vista apertural - $100 \mathbf{x}$.

Fig. 17 - Elphidium tropicalis Petri sp. nov., vista lateral do holótipo, amostra calha $271 \mathrm{~m} \cdot 274 \mathrm{~m}-50 \mathrm{x}$.

Fig. 18 - Mesmo espécime, vista apertural - $50 \mathrm{x}$.

Fig. 19 - Peneroplis carinatus d'Orbigny, vista lateral de um espécime adulto, amostra calha $298 \mathrm{~m}-302 \mathrm{~m}-25 \mathrm{x}$.

Fig. 20 - Mesmo espécime, vista apertural $-25 \mathbf{x}$. 


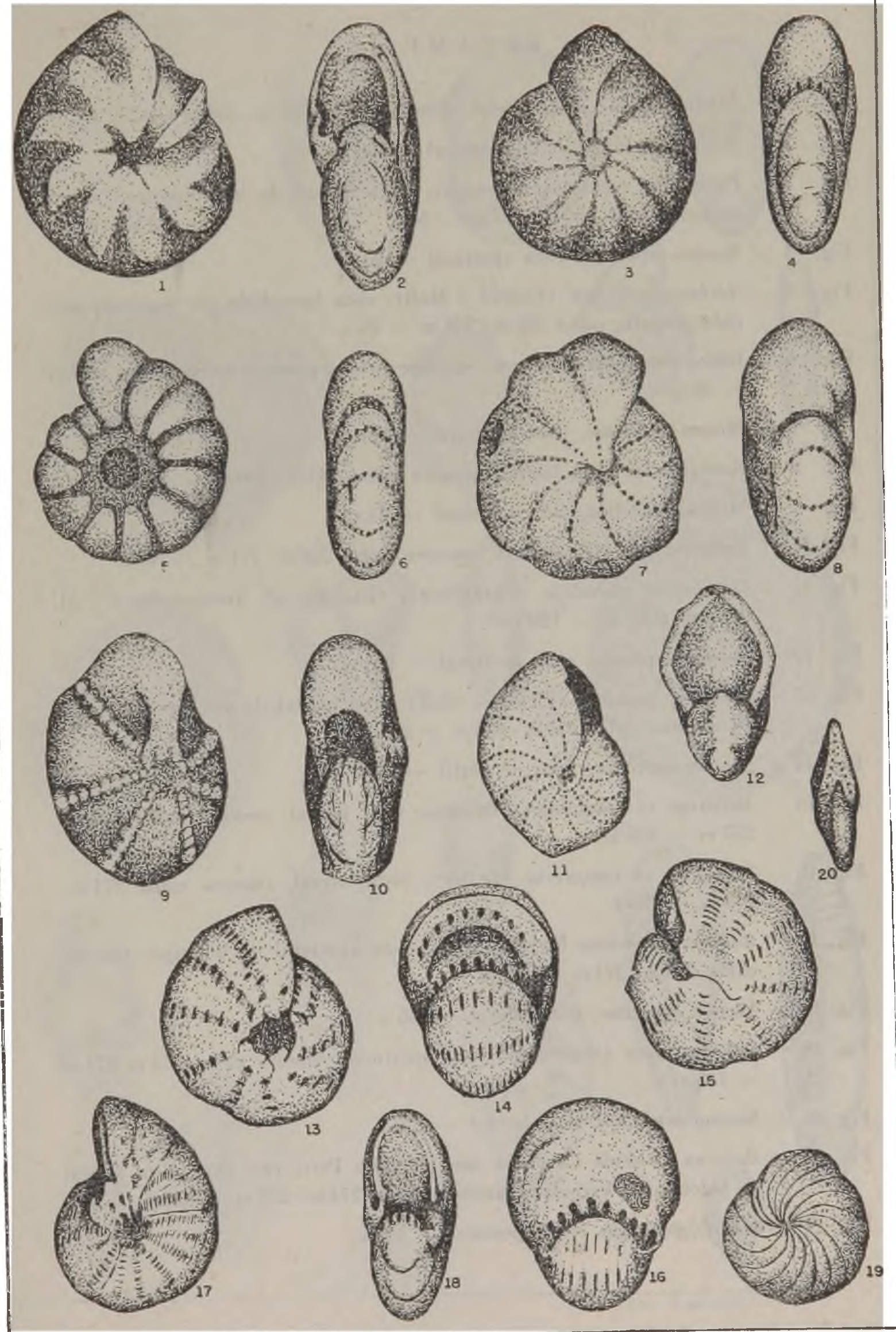

Des - F Bererro 


\section{ESTA MPA 6}

Fig. 1 - Elphidium sp., vista lateral, amostra calha $363 \mathrm{~m}-366 \mathrm{~m}-200 \mathbf{x}$.

Fig. 2 - Mesmo espécime, vista apertural $-200 \mathrm{x}$.

Fig. 3 - Peneroplis carinatus d'Orbigny, vista lateral de um espécime jovem, amostra calha $256 \mathrm{~m} \cdot 259 \mathrm{~m}-50 \mathrm{x}$.

Fig. 4- Mesmo espécime, vista apertural $-50 \mathrm{x}$.

Fig. 5 - Archaias angulata (Fichtel e Moll), vista lateral de um espécíme erodido, amostra calha $253 \mathrm{~m} \cdot 256 \mathrm{~m}-25 \mathrm{x}$.

Fig. 6 - Ditto, vista lateral de um espécime jovem, amostra calha $341 \mathrm{~m}-347 \mathrm{~m}$ $-50 \mathrm{x}$.

Fig. 7 -- Mesmo espécime, vista apertural - 50x.

Fig. 8 -- Spirolina sp. vista lateral, amostra calha $283 \mathrm{~m}-286 \mathrm{~m}-25 \mathrm{x}$.

Fig. $9-$ Mesmo espécime, vista apertural $-25 \mathrm{x}$.

Fig. 10 - Taberina sp., vista lateral, amostra calha $268 \mathrm{~m}-271 \mathrm{~m}-40 \mathrm{x}$.

Fig. 11 - Gümbelina globulosa (Ehrenberg), vista lateral, Testemunho n. ${ }^{\circ} 51$, $2082 \mathrm{~m}-2085 \mathrm{~m}-120 \mathrm{x}$.

Fig. 12 - Mesmo espécime, vista apertural $-120 \mathrm{x}$.

Fig. 13 - Archaias angulata (Fichte] e Moll), vista lateral de um espécime adulto, amostra calha $249 \mathrm{~m} \cdot 253 \mathrm{~m}-25 \mathrm{x}$.

Fig. 14 - Mesmo espécime, vista de perfíl -- $25 \mathrm{x}$.

Fig. 15 - Bulimina ef marginata d'Orbigny, vista lateral, amostra calha $274 \mathrm{~m}$ $277 \mathrm{~m}-125 \mathrm{x}$.

Fig. 16 - Virgulina cf compressa (Bailey), vista lateral, amostra calha $271 \mathrm{~m}$. $274 \mathrm{~m}-135 \mathrm{x}$.

Fig. 17 - Bolivina rhombica Petri sp. nov., vista apertural do holótipo, amostra calha $268 \mathrm{~m} \cdot 271 \mathrm{~m}-135 \mathrm{x}$.

Fig. 18 - Mesmo espécime, vista lateral -- $135 \mathrm{x}$.

Fig. 19 - Bolivina alata (Seguenza), vista apertural, amostra calha $274 \mathrm{~m} .277 \mathrm{~m}$ $-135 \mathrm{x}$.

Fig. 20 - Mesmo espécime, vista lateral -- $135 \mathrm{x}$.

Fig. 21 - Bolivina striatula Cushman var. angulata Petri var. nov., vista lateral do holótipo da variedade, amostra calha $274 \mathrm{~m} \cdot 277 \mathrm{~m}-135 \mathrm{x}$.

Fig. $22-$ Mesmo espécime, vista apertural - $135 \mathrm{x}$. 


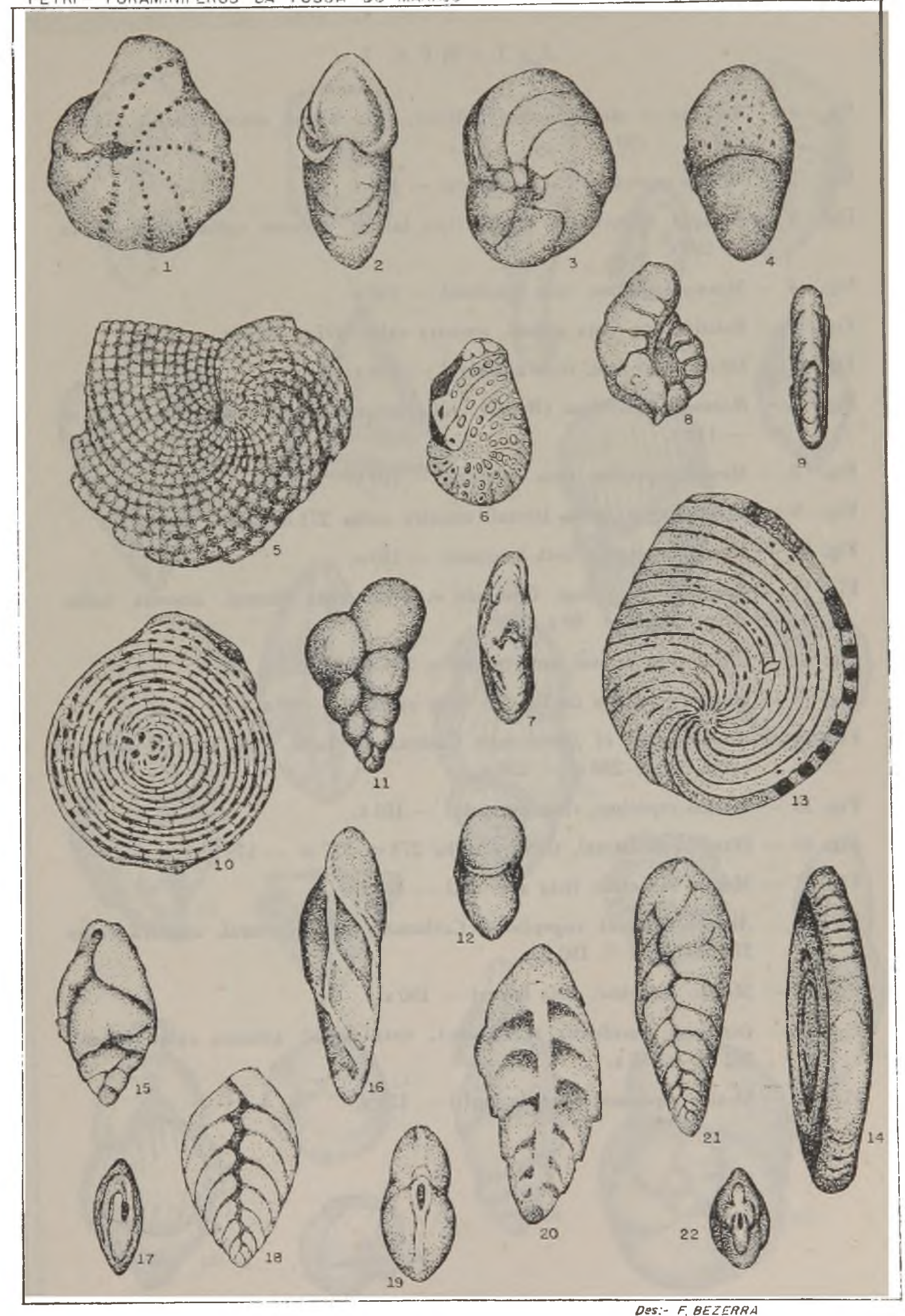


Fig. 1 - Bolivina cf rhomboidlais (Millett), vista lateral, amostra calha $274 \mathrm{~m}-$ $277 \mathrm{~m}-190 \mathrm{x}$.

Fig. 2 - Mesmo espécime, vista apertural - $190 \mathbf{x}$.

Fig. 3-Bolivina ef tortuosa Brady, vista lateral, amostra calha $268 \mathrm{~m} \cdot 271 \mathrm{~m}$ $-150 \mathrm{x}$.

Fig. 4- Mesmo espécime, vista apertural - $150 \mathbf{x}$.

Fig. 5 - Bolivina sp., vista lateral, amostra calha $497 \mathrm{~m}-512 \mathrm{~m}-150 \mathbf{x}$.

Fig. 6 - Mesmo espécime, vista apertural - $150 \mathrm{x}$.

Fig. 7 - Reussella spinulosa (Reuss), vista lateral, amostra calha $366 \mathrm{~m} \cdot 369 \mathrm{~m}$ - $110 \mathrm{x}$.

Fig. 8 - Mesmo espécime, vista apertural - $110 \mathrm{x}$.

Fig. 9 - Uvigerina sp., vista lateral, amostra calha $271 \mathrm{~m} \cdot 274 \mathrm{~m}-110 \mathrm{x}$.

Fig. 10 - Mesmo espécime, visia apertural - $110 \mathrm{x}$.

Fig. 11 - Angulogerina illingi Cushman e Renz, vista lateral, amostra calhá$503 \mathrm{~m} \cdot 512 \mathrm{~m}-80 \mathrm{x}$.

Fig. 12 - Ditto, vista lateral, amostra calha $274 \mathrm{~m}-277 \mathrm{~m}-130 \mathrm{x}$.

Fig. 13 - Mesmo espécime da fig. 11, vista apertual - $80 \mathrm{x}$.

Fig. 14 - Angulogerina cf jamaicensis Cushman e Todd, visła lateral, amostra calha $277 \mathrm{~m}-280 \mathrm{~m}-150 \mathrm{x}$.

Fig. 15 - Mesmo espécime, vista apertural - $150 \mathbf{x}$.

Fig. 16 - Ditto, vista lateral, amostra calha $274 \mathrm{~m} \cdot 277 \mathrm{~m}-175 \mathrm{x}$.

Fig. 17 - Mesmo espécime, vista apertural - $175 \mathrm{x}$.

Fig. 18 - Angulogerina cf rugoplicata Cushman, vista apertural, amostra calha $274 \mathrm{~m}-277 \mathrm{~m}-150 \mathrm{x}$.

Fig. 19 - Mesmo espécime, vista lateral - $150 \mathrm{x}$.

Fig. 20 - Discorbis floridensis (Cushman), vista dorsal, amostra calha $555 \mathrm{~m}$ $561 \mathrm{~m}-135 \mathrm{x}$.

Fig. $21-$ Mesmo espécime, vista de perfíl -135 x. 
PETRI-FORAMINIFEROS DAN-FOSSA DO MARAJO
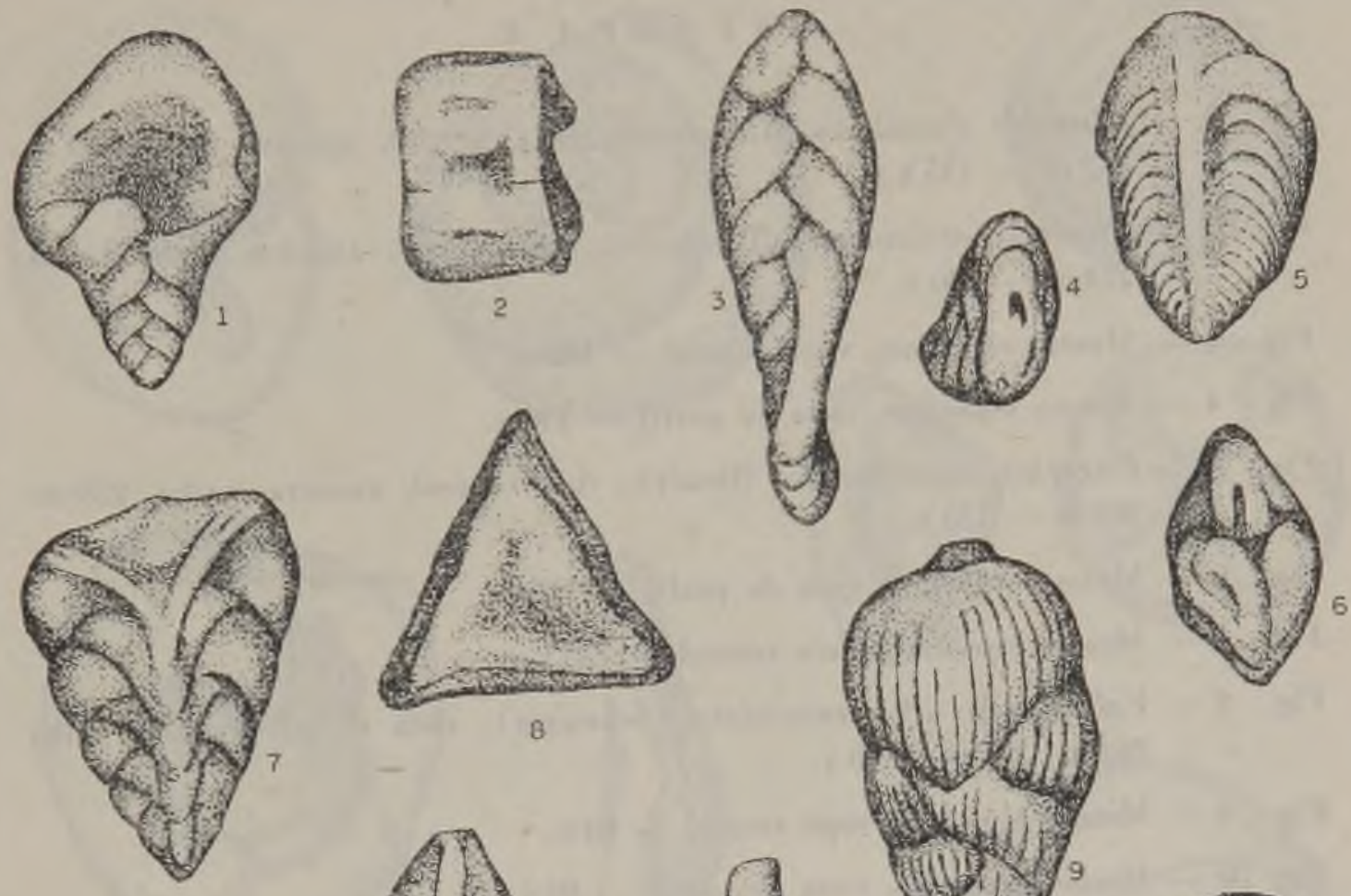

8
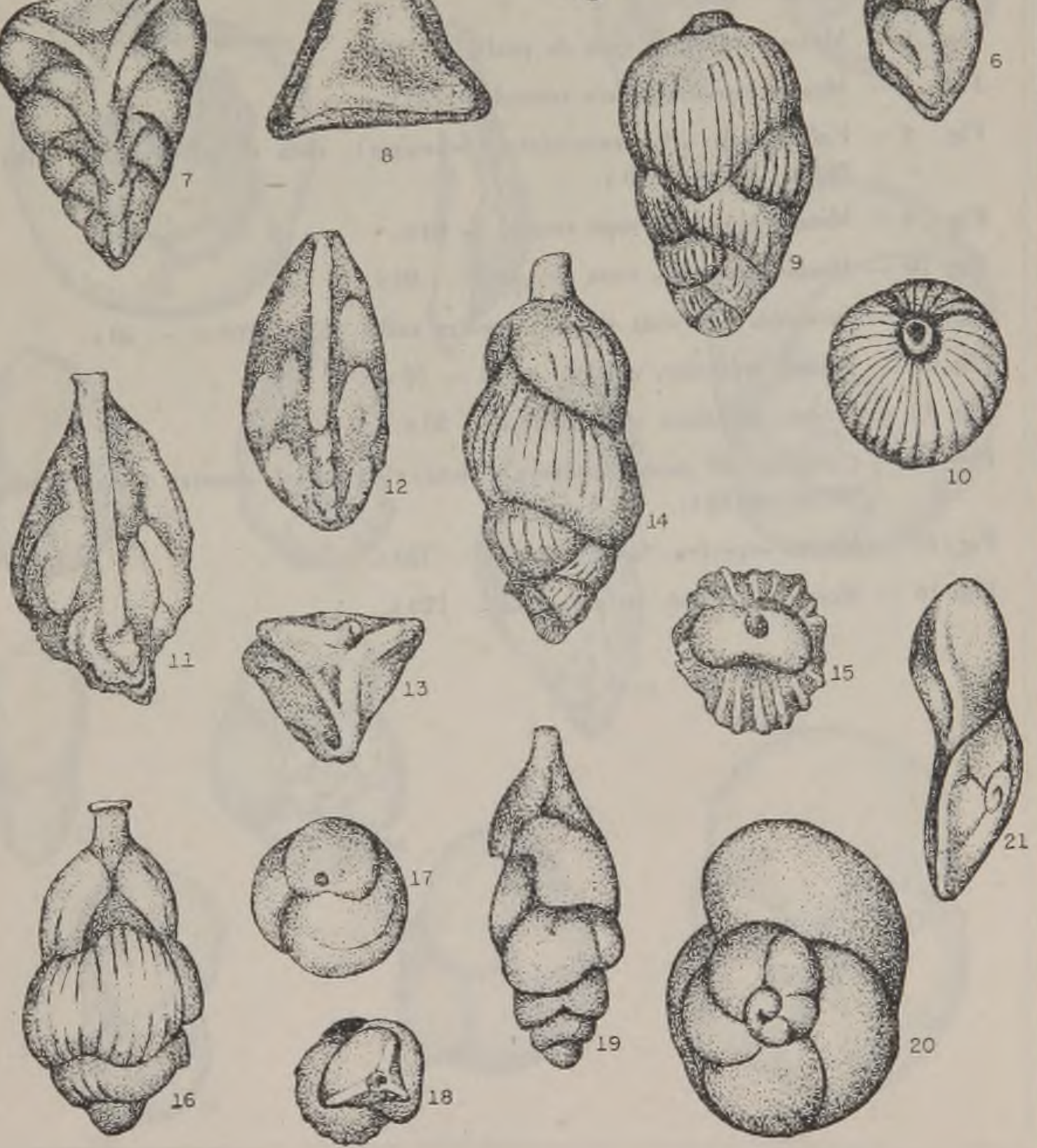


\section{E S T A M P A 8}

Fig. 1 - Discorbis floridensis (Cushman), vista ventral, amostra calha $555 \mathrm{~m}$ $561 \mathrm{~m}-135 \mathrm{x}$.

Fig. 2 - Discorbis orbicularis (Terquem), vista dorsal, amostra calha $271 \mathrm{~m}$ $274 \mathrm{~m}-140 \mathrm{x}$.

Fig. 3 - Mesmo espécime, vista ventral $-140 \mathrm{x}$.

Fig. 4 - Mesmo espécime, vista de perfíl - $140 \mathrm{x}$.

Fig. 5-Discorbis patelliformis (Brady), vista dorsal, amostra calha $259 \mathrm{~m}$ $262 \mathrm{~m}-135 \mathrm{x}$.

Fig. 6 - Mesmo espécime, vista de perfíl - $135 \mathrm{x}$.

Fig. 7 - Mesmo espécime, vista ventral - $135 \mathrm{x}$.

Fig. 8 - Valvulineria aff scrobiculata (Schwager), vista dorsal, amostra calha $262 \mathrm{~m} \cdot 265 \mathrm{~m}-90 \mathrm{x}$.

Fig. 9 - Mesmo espécime, vista ventral - $90 \mathrm{x}$.

Fig. 10 - Mesmo espécime, vista de perfíl - $90 \mathbf{x}$.

Fig. 11 - Discorbis sp., vista dorsal, amostra calha $265 \mathrm{~m}-268 \mathrm{~m}-50 \mathrm{x}$.

Fig. 12 - Mesmo espécime, vista de perfíl - $50 \mathrm{x}$.

Fig. 13 -- Mesmo espécime, vista ventral - $50 \mathrm{x}$.

Fig. 14 - Gyroidina aff parva Cushman e Renz, vista dorsal, anıstra calha $277 \mathrm{~m}$ $280 \mathrm{ml}-120 \mathrm{x}$.

Fig. 15 - Mesmo espécime, vista de perfíl - $120 \mathrm{x}$.

Fig. 16 - Mesmo espécime, vista ventral $-120 \mathrm{x}$. 


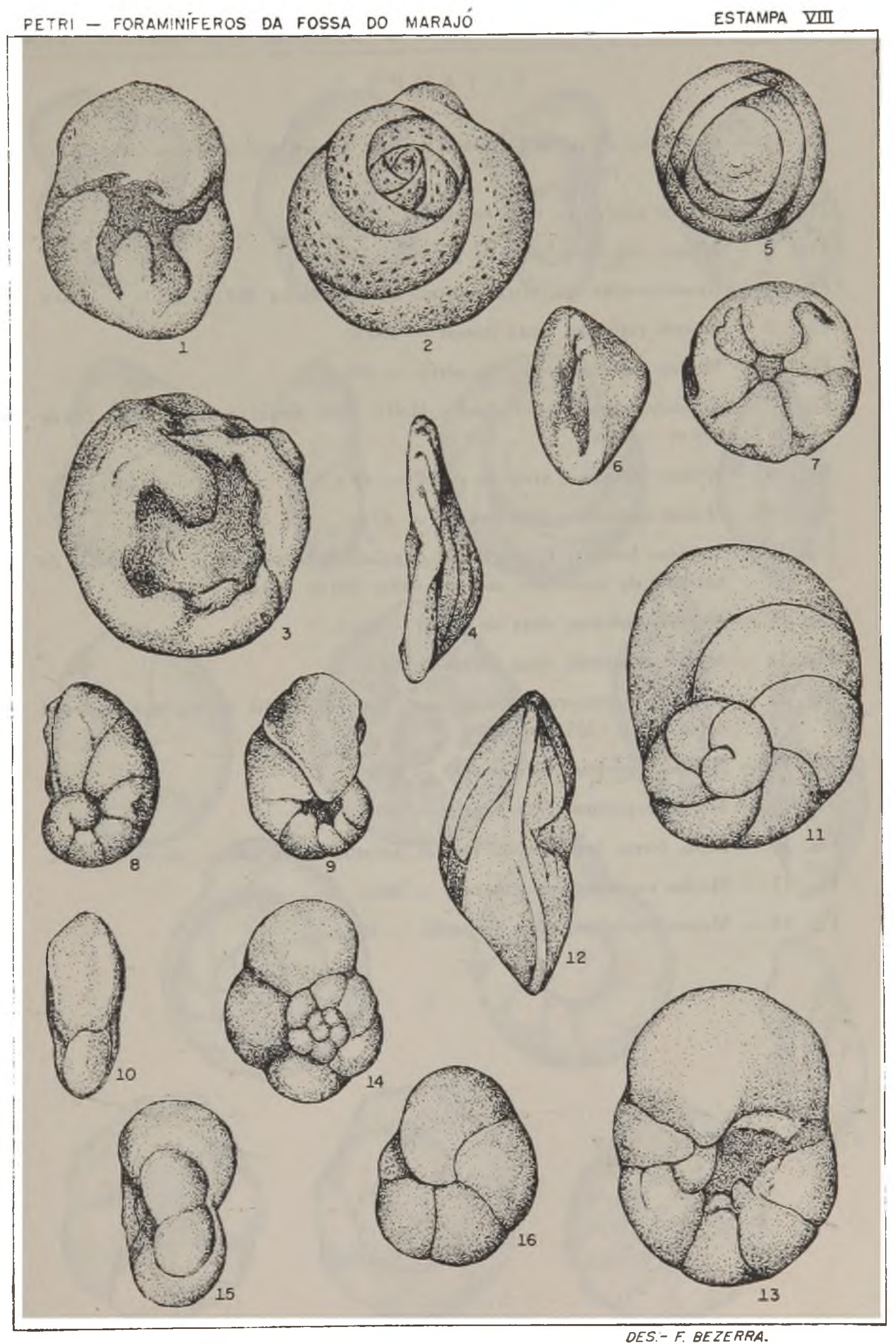




\section{EST A IIP \& 9}

Fig. 1 - Gyroidina aff parta Cuslman e Renz, vista dorsal, amostra calha $283 \mathrm{~m}$ $286 \mathrm{~m}-190 \mathrm{x}$.

Fig. 2 - Mesmo espécime, vista ventral - $190 \mathrm{x}$.

Fig. 3 - Mesmo espécime, vista cle perfíl - $190 \mathrm{x}$.

Fig. 4-Gyroidinoides sp., vista ventral, amestra calha $262 \mathrm{~m} \cdot 265$ m $-190 \mathrm{x}$.

Fig. 5 - Mesmo espécime, vista dorsal - $190 \mathrm{x}$.

Fig. 6 - Mesmo espécime, vista de perfil - $190 \mathrm{x}$.

Fig. 7 - Eponides repandus (Fichtel e Moll), vista dorsal, amostra calha $286 \mathrm{~m}$ $289 \mathrm{~m}-45 \mathrm{x}$.

Fig. 8 -- Mesmo espécime, vista de perfíl - 45x.

Fig. 9 - Mesmo espécime, vista ventral - $4.5 \mathrm{x}$.

Fig. 10 - Streblus beccarii (Lineu) var. angulata Petri var. nov., vista ventral do holótipo da variedade, amostra calha $289 \mathrm{~m}-293 \mathrm{~m}-65 \mathrm{x}$.

Fig. 11 - Mesmo espécime, vista de perfíl - $65 \mathrm{x}$.

Fig. 12 - Mesmo espécime, vista dorsal - $65 \mathrm{x}$.

Fig. 13 - Streblus marajoara Petri sp. nov., vista de perfíl do holótipo, amostra calha $332 \mathrm{~m}-335 \mathrm{~m}-60 \mathrm{x}$.

Fig. 14. - Mesmo espécime, vista dorsal $-60 \mathrm{x}$.

Fig. 15 - Mesmo espécine, vista ventral - $60 \mathrm{x}$.

Fig. 16 - Ditto, forma jovem, vista ventral, amostra calha $530 \mathrm{~m}-536 \mathrm{~m}-100 \mathrm{x}$.

Fig. 17 - Mesmo espécime, vista dorsal - $100 \mathrm{x}$.

Fig. 18 - Mesmo espécime, vista de perfíl - $100 \mathrm{x}$. 


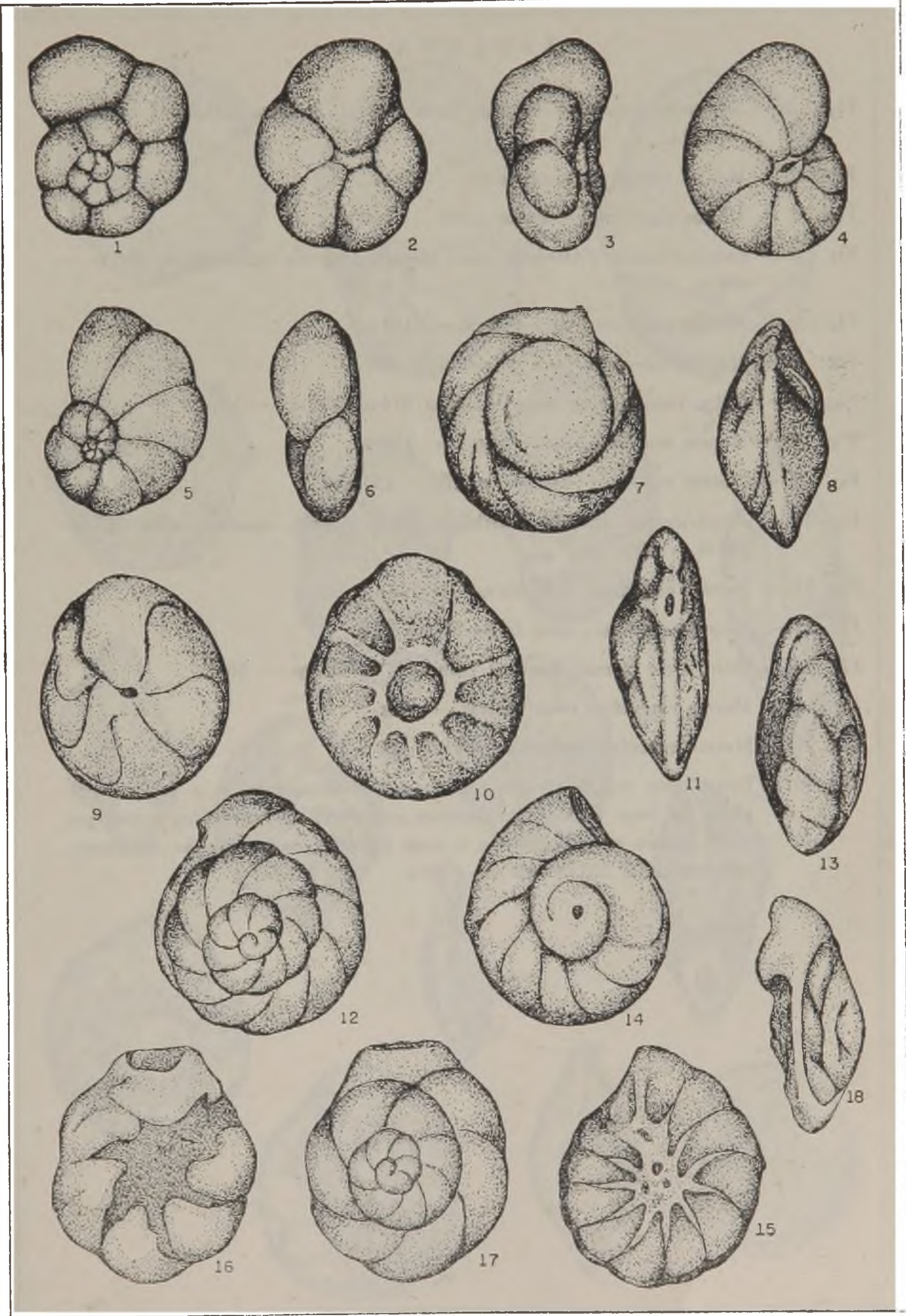

DES:- F. BEZERRA. 


\section{ES TA M P $\triangle 10$}

Fig. 1 - Siphonina pulchra Cushman, vista ventral, amostra calha $442 \mathrm{~m} \cdot 460 \mathrm{~m}$ $-100 \mathrm{x}$.

Fig. 2 - Mesmo espécime, vista dorsal - $100 \mathrm{x}$.

Fig. 3 -- Mesmo espécime, vista de perfíl - $100 \mathbf{x}$.

Fig. 4. Cancris sagrai d'Orbigny, vista dorsal. amostra calha $265 \mathrm{~m} \cdot 268 \mathrm{~m}-$ 100.x.

Fig. $5-$ Mesmo espécime. vista ventral $-100 \mathrm{x}$.

Fig. 6 - Mesmo espécime. vista de perfíl - $100 \mathrm{x}$.

Fig. 7 - Ditto. vista dorsal, amostra calha $274 \mathrm{~m}-277 \mathrm{~m}-150 \mathrm{x}$.

Fig. 8 - Mesmo espécime, vista ventral - $150 \mathrm{x}$.

Fig. 9 - Mesmo espécime. vista de perfíl - $150 \mathrm{x}$.

Fig. 10 - Amphistegina lessonii d'Orbigny, vista ventral, amostra calla $265 \mathrm{~m}$ $268 \mathrm{~m}-50 \mathrm{x}$.

Fig. 11 - Mesmo espécime, vista dorsal - $50 \mathrm{x}$.

Fig. 12 -- Meşmo espécime. vista de perfíl - $50 \mathrm{x}$.

Fig. 13 - Dirto, vista dorsal, amostra calha $277 \mathrm{~m}-280 \mathrm{~m}-50 \mathrm{x}$.

Fig. 14 - Mesmo espécime, vista ventral - $50 \mathrm{x}$.

Fig. 15 -- Mesmo espécime, vista de perfíl - $50 \mathrm{x}$.

Fig. 16 - Ditto, vista ventral de um espécime erodido mostrando o aspecto granular da zona próximo a abertura extendido em uma área maior por ter a erosão pôsto à moștra à área granular das aberturas anteriores. amostra calha $280 \mathrm{~m}-283 \mathrm{~m}-50 \mathrm{x}$. 

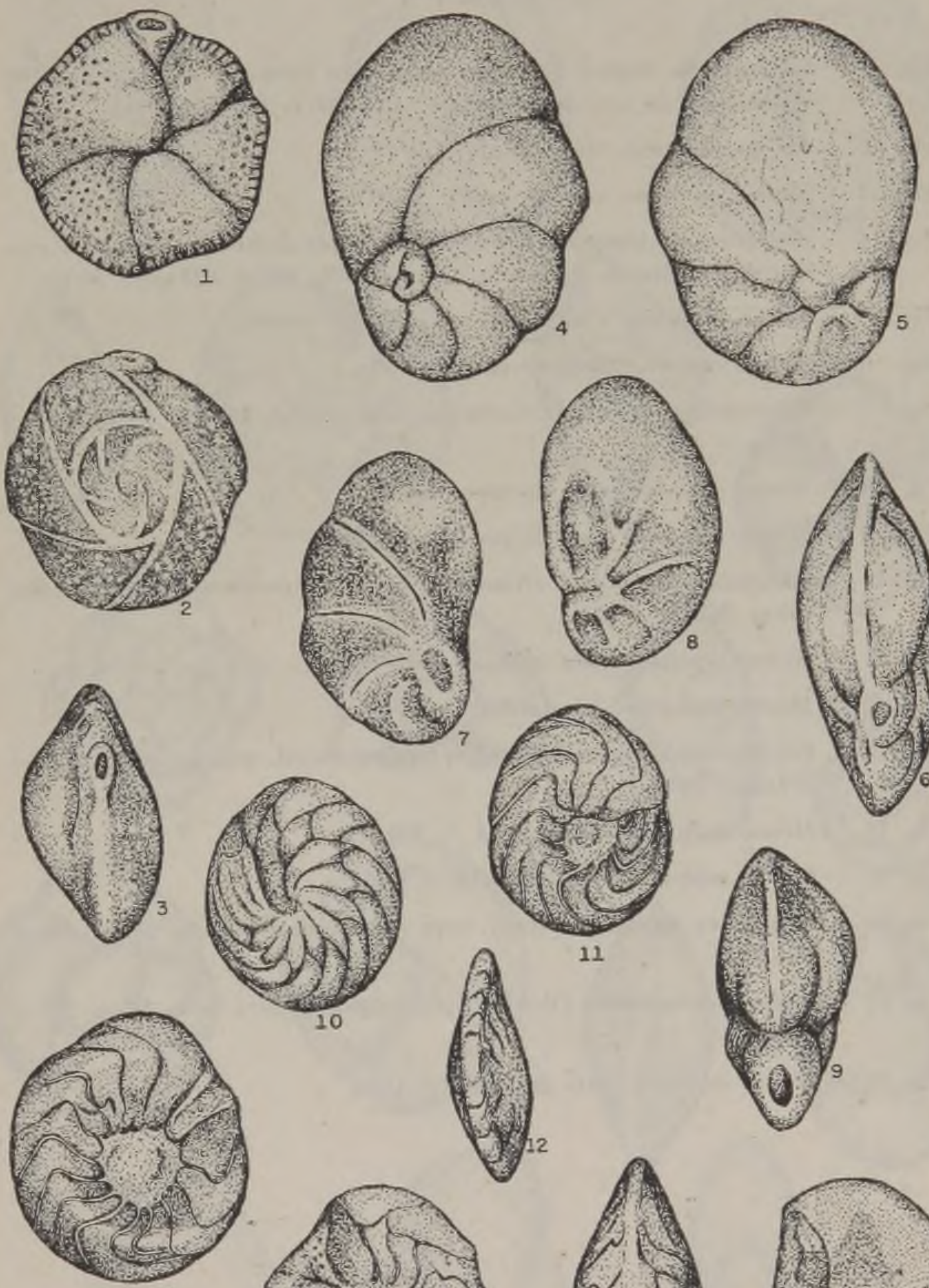

13
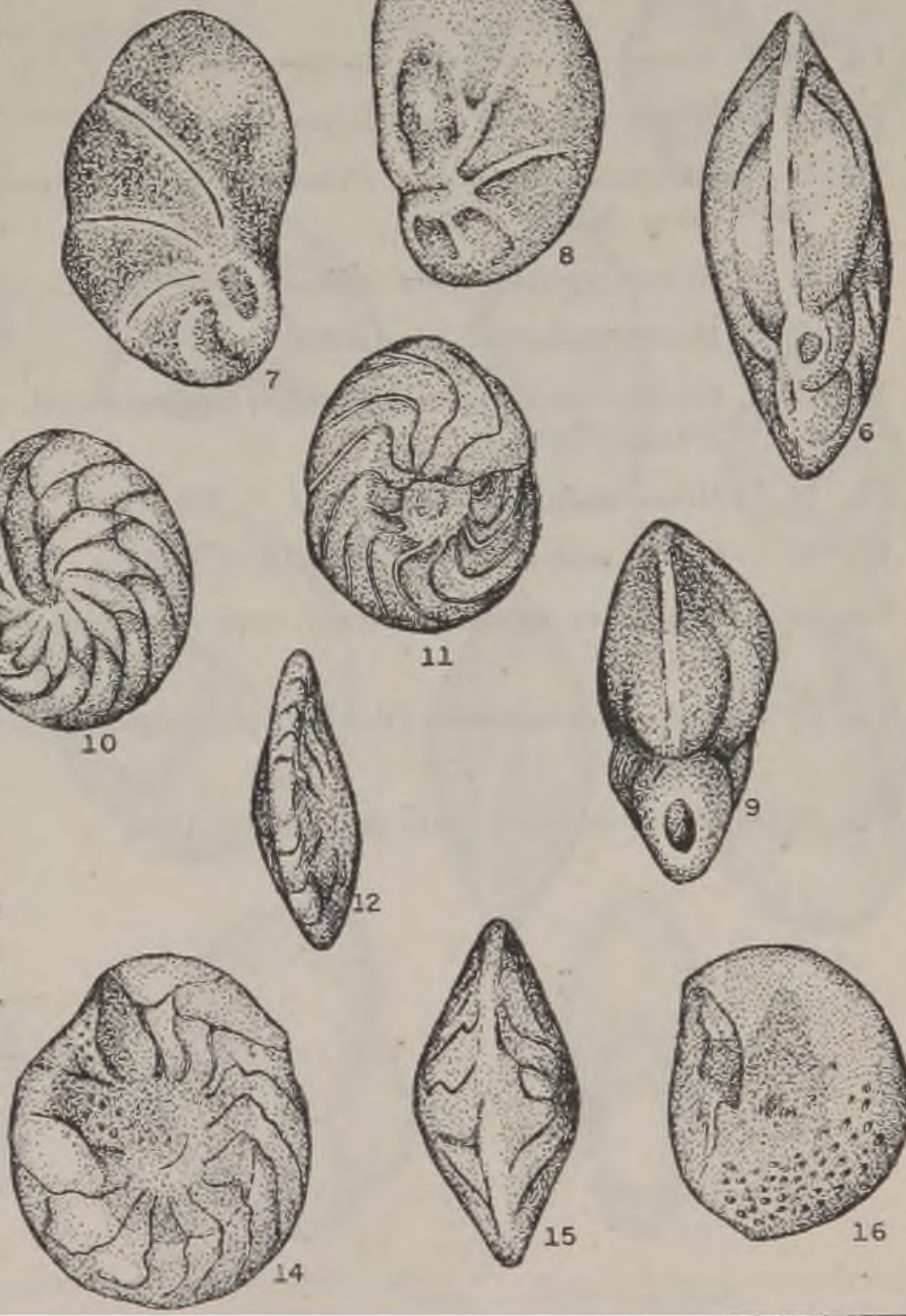

OES: F. BEZERRA 
Fig. 1 -Amphistegina lessonii d'Orbigny var. conica Petri var. nov., vista ventral do holótipo da variedade, amostra calha $280 \mathrm{~m} \cdot 28.3 \mathrm{~m}-50 \mathrm{x}$.

Fig. 2 - Mesmo espécime, vista dorsal $-50 \mathbf{x}$.

Fig. 3 - Mesmo espécime, vista de perfíl - $50 \mathrm{x}$.

Fig. 4 - Amphistegina lessonii d'Orbigny var. tumida Petri var. nov., vista ventral do holótipo da variedade, amostra calha $320 \mathrm{~m}-323 \mathrm{~m}-50 \mathrm{x}$.

Fig. 5 - Mesnıo espécime, vista dorsal - $50 \mathrm{x}$.

Fig. 6 - Mesmo espécime, visıa de perfíl - $50 \mathrm{x}$.

Fig. 7 - Tretomphalus allanticus Cushman, vista ventral, amostra calha $277 \mathrm{~m}$ $280 \mathrm{~m}-100 \mathrm{x}$.

Fig. 8 - Mesmo especime, vista dorsal - $100 \mathrm{x}$.

Fig. 9 - Mesmo espécime, vista de periferia - $100 \mathrm{x}$.

Fig. 10 - Cassidulinoides bradyi (Norman). vista de periferia, amostra calla $265 \mathrm{~m}-268 \mathrm{~m}-125 \mathrm{x}$.

Fig. 11 - Mesmo espécime, vista apertural - $125 \mathrm{x}$.

Fig. 12 - Mesmo espécime, vista lateral - $125 \mathrm{x}$.

Fig. 13 - Cassidulina laevigata (d'Orhigny), vista dorsal, amostra calha $271 \mathrm{~m}$ $274 \mathrm{~m}-150 \mathrm{x}$.

Fig. 14 - Mesmo espécime, vista ventral - $150 \mathrm{x}$.

Fig. 15 - Mesmo espécime, vista de perfíl - $150 \mathrm{x}$.

Fig. 16 - Cassidulina subglobosa Brady, vista ventral, amostra calha $280 \mathrm{~m}-283 \mathrm{~m}$ $-125 \mathbf{x}$.

Fig. 17 - Pallenia quinqueloba (Reuss), vista lateral, amo-tra calha $274 \mathrm{~m} \cdot 277 \mathrm{~m}$ $-130 \mathrm{x}$.

Fig. 18 - Mesmo espécine, vista de perfíl - 130x. 

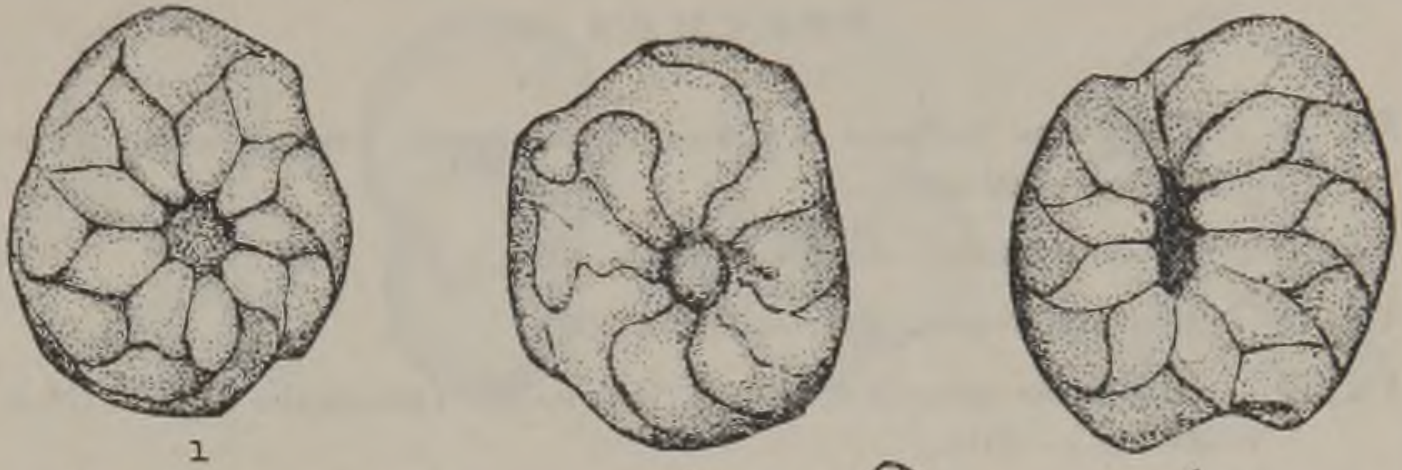

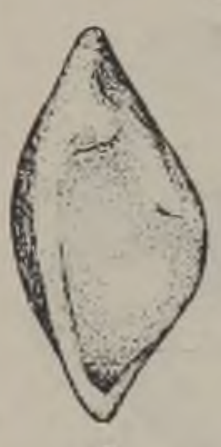

3
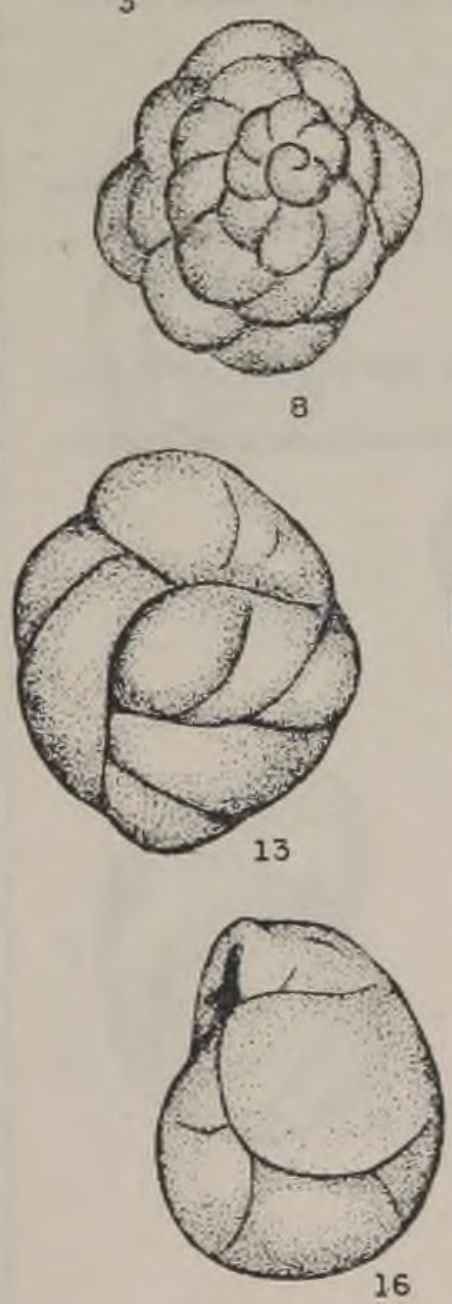

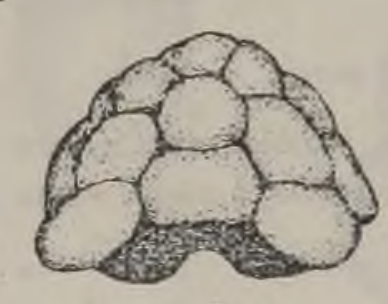

9
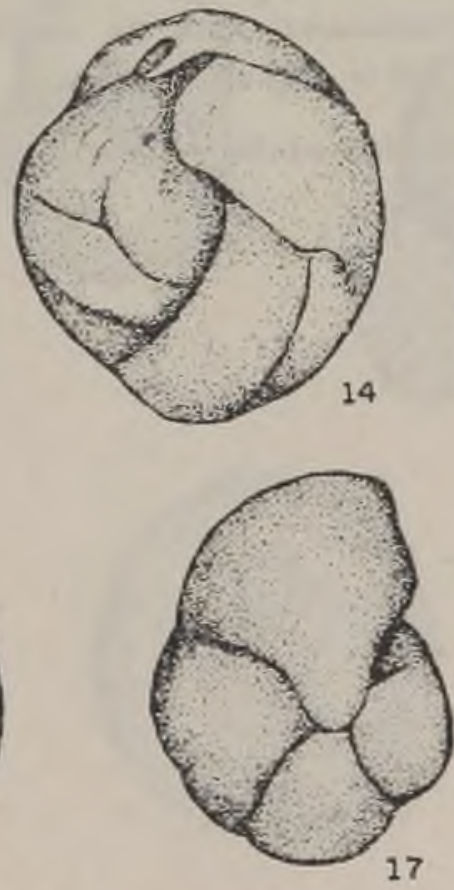

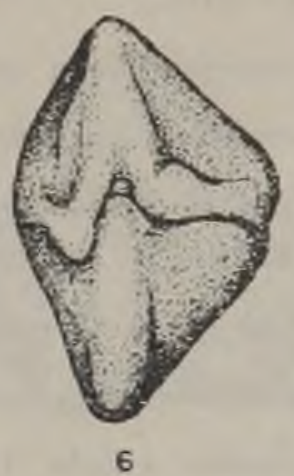

4
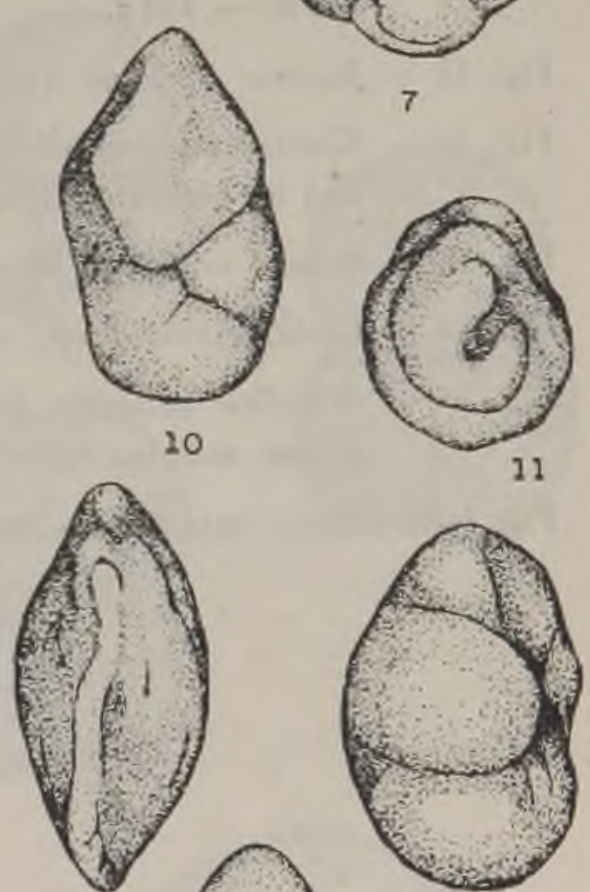

15

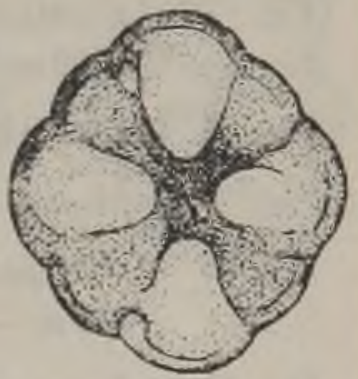

11

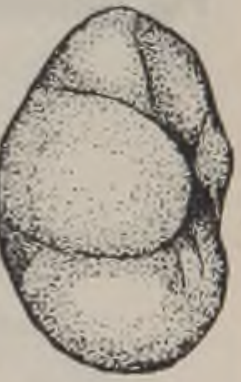

12 


\section{E S I A M P A 12}

Fig. 1 - Globigerina bulloides d'Orbigny, vista dorsal, amostra calha $283 \mathrm{~m}$ $286 \mathrm{~m}-100 \mathrm{x}$.

Fig. 2 - Mesmo espécime, vista de perfíl - $100 \mathrm{x}$.

Fig. 3 - Mesmo espécime, vista ventral -- $100 \mathrm{x}$.

Fig. 4 - Globigerina cretacea d'Orbigny, vista dorsal, Testemunho n. ${ }^{\circ} 65,2376 \mathrm{~m}$ $2379 \mathrm{~m}-100 \mathrm{x}$.

Fig. 5 - Mesmo espécime, vista ventral $-100 x$.

Fig. 6 - Mesmo espécime, vista de perfíl - $100 \mathrm{x}$.

Fig. 7 - Globigerina of triangularis White, vista lateral, Testemunho n. ${ }^{\circ} 56$, $2198 \mathrm{~m}-2201 \mathrm{~m}-100 \mathrm{x}$.

Fig. 8 - Globigerina sp., vista ventral, amostra calha $524 \mathrm{~m} \cdot 530 \mathrm{~m}-120 \mathrm{x}$.

Fig. 9 - Mesmo espécime, vista dorsal - $120 \mathrm{x}$.

Fig. 10 - Globigerinoides triloba (Reuss), vista ventral, amostra calha $329 \mathrm{~m}$ $332 \mathrm{~m}-110 \mathrm{x}$.

Fig. 11 - Mesmo espécime, vista dorsal - $110 \mathbf{x}$.

Fig. 12 - Globigerinoides triloba (Reuss) var. aspera Petri var. nov., vista ventral do holótipo da variedade, amostra calha $265 \mathrm{~m} \cdot 268 \mathrm{~m}-120 \mathrm{x}$.

Fig. 13 - Mesmo espécime, vista dorsal - $120 \mathrm{x}$.

Fig. 14 - Globigerinoides sp., vista lateral, amostra calha $280 \mathrm{~m}-283 \mathrm{~m}-50 \mathbf{x}$.

Fig. 15 - Orbulina suturalis Bronnimann, vista de um indivíduo relativamente jovem, amostra calha $262 \mathrm{~m} \cdot 265 \mathrm{~m}-125 \mathrm{x}$.

Fig. 16 - Ditto, vista de um indivíduo adulto - $-75 \mathbf{x}$. 

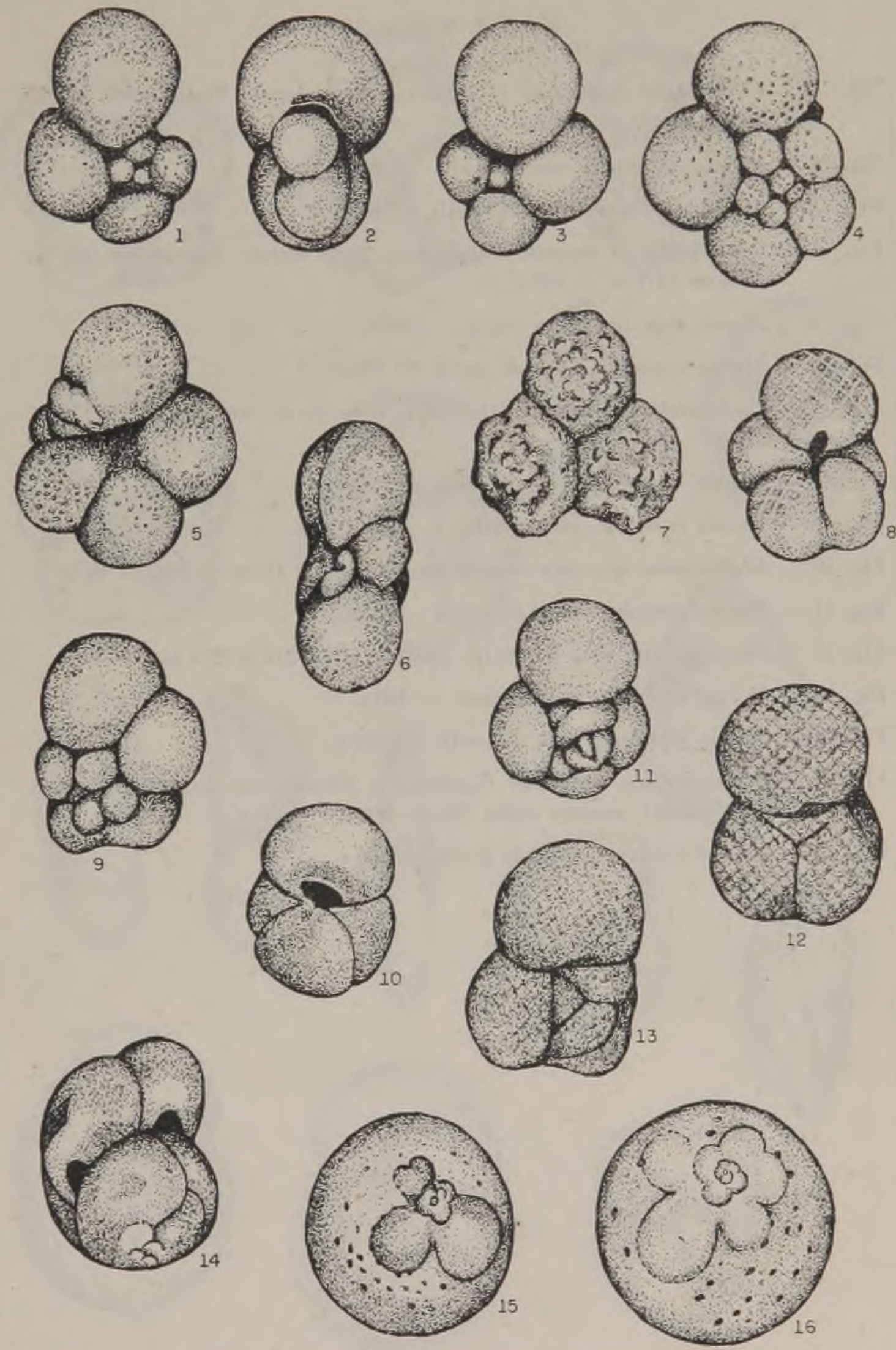

OES.:- F. BEZERRA 


\section{E S T A M P A 13}

Fig. 1 - Globorotalia compressa (Plummer), vista dorsal, Testemunho n." 65, $2376 \mathrm{~m} \cdot 2379 \mathrm{~m}-100 \mathrm{x}$.

Fig. $2-$ Mesmo espécime, vista ventral - $100 \mathbf{x}$.

Fig. 3 - Mesno espécime, vista de perfíl - $100 \mathbf{x}$.

Fig. 4-Globorotalia cf crassata (Cushman), vista ventral, Testemunho n. ${ }^{0} 65$. $2376 \mathrm{~m}-2379 \mathrm{~m}-100 \mathrm{x}$.

Fig. 5 - Mesmo espécime, vista dorsal $-100 \mathbf{x}$.

Fig. 6 - Mesmo espécime, vista de perfíl - $100 \mathrm{x}$.

Fig. 7 - Globorotalia menardii (d'Orbigny), vista dorsal, amostra calha $274 \mathrm{~m}$ $277 \mathrm{~m}-80 \mathrm{x}$.

Fig. 8 - Mesmo espécime, vista de perfíl - $80 \mathrm{x}$.

Fig. 9 - Mesmo espécime, vista ventral -- $80 \mathrm{x}$.

Fig. $10-$ Globorotalia sp., vista ventral, amostra calha $274 \mathrm{~m}-277 \mathrm{~m}-90 \mathrm{x}$.

Fig. 11 - Mesmo espécime, vista de perfíl - $90 \mathrm{x}$.

Fig. $12-$ Planulina sp., vista de perfíl, amostra calha $271 \mathrm{~m} \cdot 274 \mathrm{~m}-100 \mathrm{x}$.

Fig. 13 - Mesmo espécine, vista ventral $-100 \mathbf{x}$.

Fig. 14 - Mesmo espécime, vista de perfíl - $100 \mathrm{x}$.

Fig. 15 - Globoquadrina quadraria (Cushman e Ellisor) var. advena Bermudez. vista ventral, amosira calha $283 \mathrm{~m} \cdot 286 \mathrm{~m}-100 \mathrm{x}$.

Fig. 16 - Mesmo espécime, vista de perfíl - $100 \mathrm{x}$. 


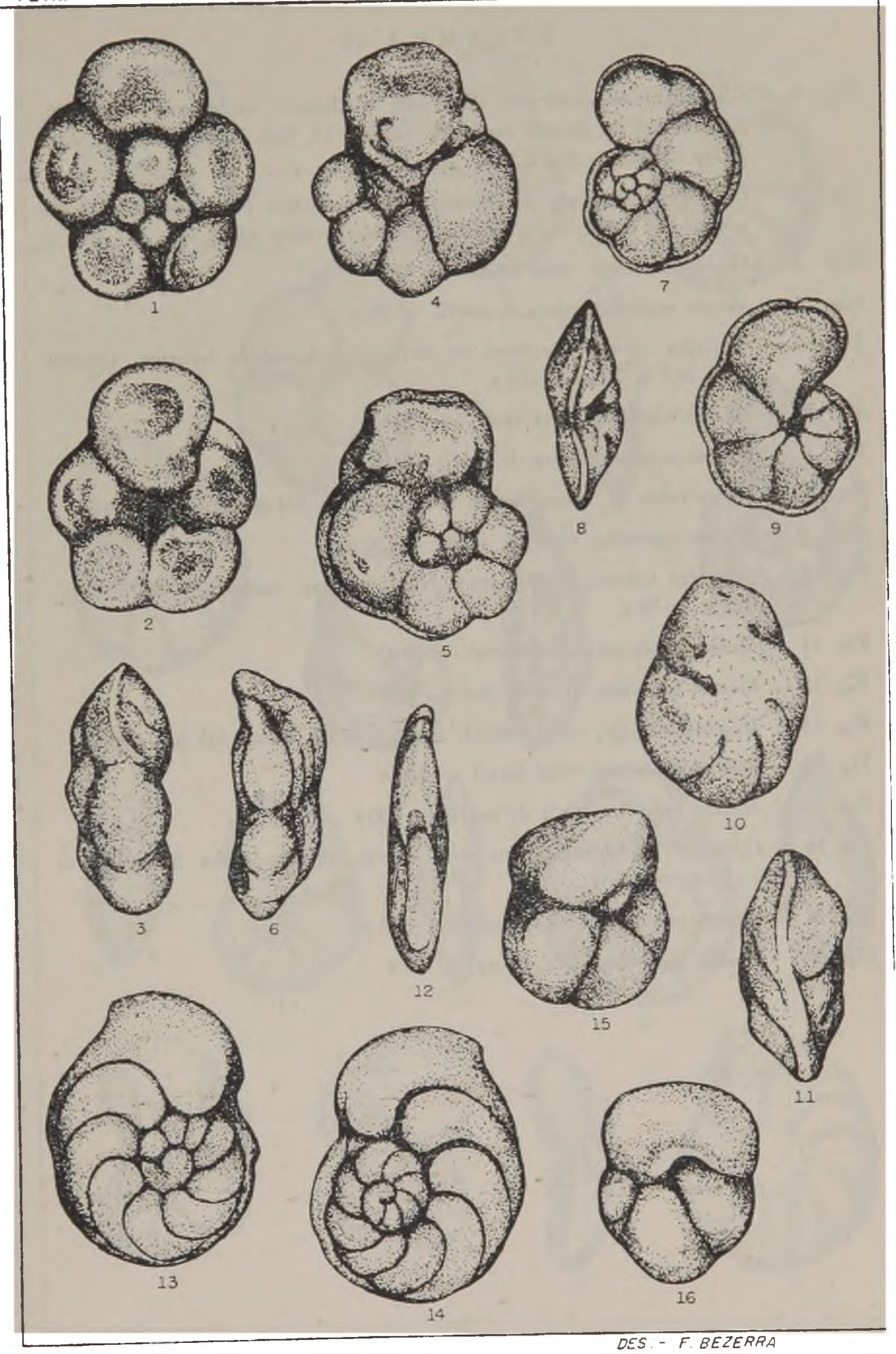




\section{E S T A M P A 14}

Fig. 1 - Globoquadrina quadraria (Cushman e Ellisor) var. advena Bermudez, vista dorsal do mesmo espécime da Est. 13, figs. 15-16, amostra calha $283 \mathrm{~m} \cdot 286 \mathrm{~m}-100 \mathrm{x}$.

Fig. 2 - Cibicides americanus (Cushman) var. paraensis Petri var. nov., vista ventral do holótipo da variedade, amostra calha $332 \mathrm{~m}-335 \mathrm{~m}-70 \mathrm{x}$.

Fig. 3 - Mesmo espécime, vista dorsal $-70 \mathrm{x}$.

Fig. 4-Mesmo espécime, vista de perfíl - $70 \mathrm{x}$.

Fig. 5 - Cibicides cururuensis Petri sp. nov., vista dorsal do holótipo, amostra calha $262 \mathrm{~m} \cdot 265 \mathrm{~m}-25 \mathrm{x}$.

Fig. 6 - Mesmo espécime, vista ventral $-25 \mathrm{x}$.

Fig. 7 - Mesmo espécime, vista de perfíl - $25 \mathrm{x}$.

Fig. 8 - Laticarinina sp., vista dorsal, amostra calha $594 \mathrm{~m} \cdot 600 \mathrm{~m}-100 \mathrm{x}$.

Fig. 9 - Mesmo espécime, vista de perfíl - $100 \mathrm{x}$.

Fig. 10 - Cibicides lobatus (d'Orbigny), vista ventral, amostra calha $542 \mathrm{~m}$ $549 \mathrm{~m}-70 \mathrm{x}$.

Fig. 11 - Mesmo espécime, vista dorsal $-70 \mathrm{x}$.

Fig. 12 - Mesmo espécime, vista de perfíl - $70 \mathrm{x}$.

Fig. 13 - Dyocibicides sp., vista ventral, amostra calha $332 \mathrm{~m}-335 \mathrm{~m}-100 \mathrm{x}$.

Fig. 14 - Mesmo espécime, vista dorsal - $100 \mathrm{x}$.

Fig. 15 - Mesmo espécime, vista de perfíl - $100 \mathrm{x}$.

Fig. 16 - Cibicides pseudoungerianus vista dorsal, amostra calha $268 \mathrm{~m}-271 \mathrm{~m}$ $-75 \mathrm{x}$.

Fig. 17 - Mesmo espécime, vista de perfíl $-75 \mathbf{x}$.

Fig. $18-$ Mesmo espécime, vista ventral $-75 x$. 


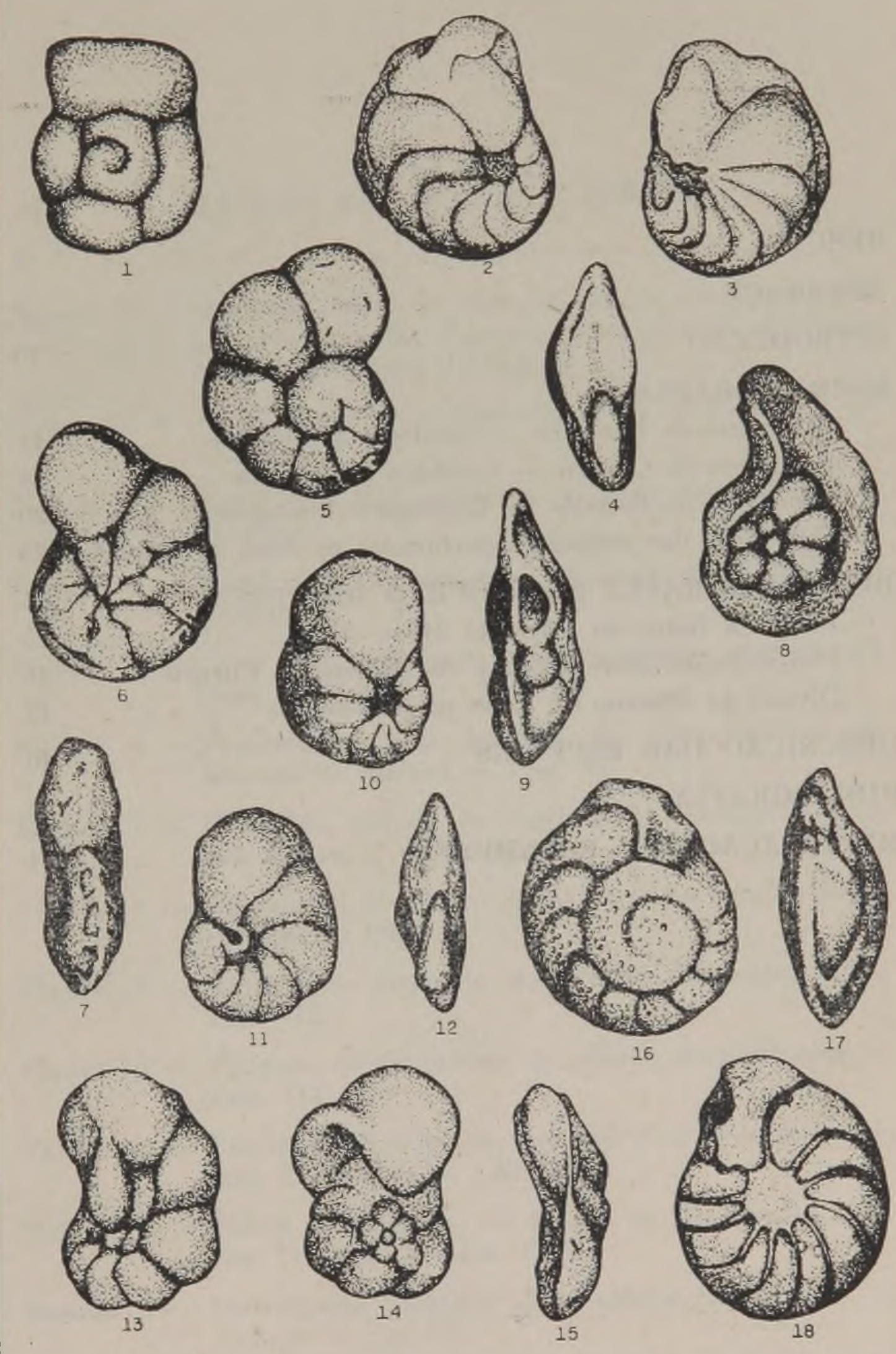

OES - F. BEZERRA 


\section{I $\mathbf{N}$ D I C E}

RESUMO .

ABSTRACT . .

INTRODUÇÃO 10

ESTRATIGRAFIA

Sondagem de Limoeiro. - Litologia e Litótopos . 11

Sondagem de Cururú. - Litologia e Litótopos 14

Sondagem de Badajós. -- Litologia e Litótopos 20

Correlação das sondagens perfuradas na fossa do Marajó 22

BIOSTRATIGRAFIA DO MIOCENO DE CURURÚ 25

Idade da fauna do intervalo $245 \mathrm{~m}$. $740 \mathrm{~m}$. 25

Considerações sôbre a fauna do Mioceno de Cururú 36

Divisão do Mioceno em zonas paleontológicas 42

DESCRIÇÃO DAS ESPÉCIES 46

BIBLIOGRAFIA . 141

EXPLICAÇNO DAS ESTAMPAS 144 


\section{RELAÇÃo dos MAPAS E PERFís}

Figura 1 - Mapa da fossa do Marajó com a localização dos poços de Limoeiro, Cururú e Badajós e as principais feições estruturais - Pág. 9.

Figura 2 -- Perfil Lito-Paleontológico do poço de Limoeiro (Anexo).

Figura 3 - Perfil Lito-Paleontológico do poco de Cururú -(Anexo),

Figura 4 - Perfil Lito-Paleontológico do poço de Badajós (Anexo).

Figura 5 - Carta das correlações possíveis entre os poços da fóssa do Marajó - Pág. 24.

Figura 6 - Porcentagens das famílias de Foraminíferos do Mioceno de Cururú - Pág. 35.

Figura 7 - Curva do número de espécies de foraminíferos de acôrclo com a profundidlade - Pág. 36.

Figura 8 - Frequência do gênero Amphisteg.na e família Peneropliclae - Pág. 3 T.

Figura 9 - Gráfico de dispersão don gênero Amphistcgina Pág. 112.

Figura 10 - Polígono de frequência do gênero Amphistegina Pág. 114.

Tabela 1 - Tabela de clistribuiegão estratigráfica dos fósseis do poco de Cururú - (Anexo).

Tabela 2 - Trabela comparativa dos fósseis do Mioceno da América Tropical — Págs. 29.3?3.

Tabela 3 - Distribuição geológica das espéecies do Mioceno de Cururú - P’ág. :34. 
SONDAGEM BJ-1-PA do C.N.P

-fig.4-

PERFIL LITO - PALEONTOLÓGICO

AREIA FINA, CAOLIINICA

FRIAVEL VARIEGADA + ARGILA

MARRON-AVERMELHADA ESCURA

LADA ESGURA + SILTITO GINZA-

AMARELO + ARGILA CINZA - OLIVA

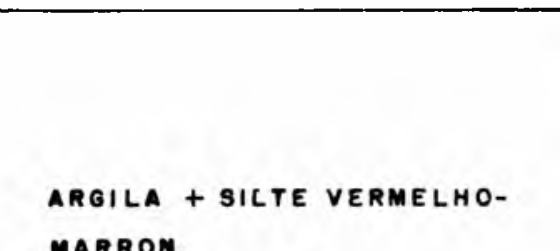

MARRON.

ARENITO FINO VERDE-AMARELO

AGINZENTADO + SILTITO GIN -

ZENTO GLARO.

(ARGILITO SUBORDINADO).

ARENITO FINO CASTANHO PÁLIDO + SILTITO CINZEN-

TO ESCURO
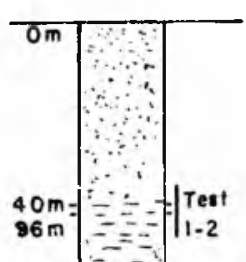

$\left.\underset{168 \mathrm{~m}}{16 \mathrm{~m}}\right|_{3.4} ^{T+2.4}$

${ }_{283 \mathrm{~m}}^{27 m}=-\left.\right|_{5.7} ^{T 03 t}$

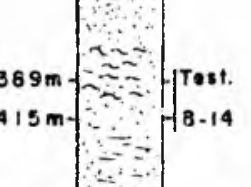

(175m

${ }_{576 \mathrm{~m}}^{563 \mathrm{~m}}=0$.

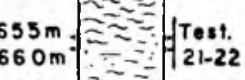

$721 \mathrm{~m}$
$724 \mathrm{~m}$
$726 \mathrm{~m}$

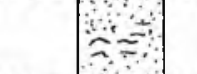

${ }_{795 m}^{789 m}=0 .=||_{26-27}^{T e s 1 .}$

$853 \mathrm{~m}$
$862 \mathrm{~m}$

(a)

${ }_{933 \mathrm{~m}}^{927 \mathrm{~m}}=\mid \begin{aligned} & \text { Test. } \\ & 31.33\end{aligned}$

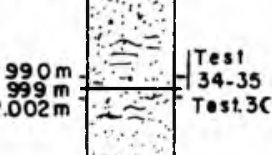

$1.067 \mathrm{~m} / \mathrm{m}$

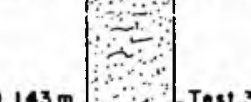

$.143 \mathrm{~m}-\mathrm{m}^{\text {Test } 39}$

$210 \mathrm{~m}$. Trest. 40

$1.243 \mathrm{~m}=$ Test.

$1.320 \mathrm{~m}=$ Test.42

$1320 \mathrm{~m}=2 \mathrm{~T}$

$1380 \mathrm{~mm} / \mathrm{T}-\mathrm{Tes} 1.43$

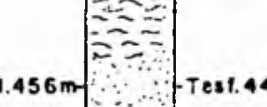

$456 \mathrm{~m}={ }^{\text {Test. }} 4 \mathrm{~T}^{2}$

$1.507 \mathrm{~m}-\mathrm{t} \mathrm{r}$-Test 45

$592 \mathrm{~m}-\mathrm{Tes1} 46$

$1.612 \mathrm{~m}=$ Test.47

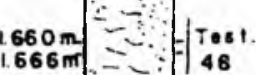

$1.66 \mathrm{~m}$
$1.692 \mathrm{~m}$

$780 \mathrm{~m}$ -

$1804 \mathrm{~m}=-\mathrm{Test} .51$

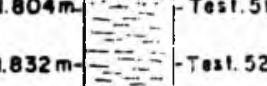

$1.869 \mathrm{~m}$ Test.53

ARENITO MÉDIO A GROSSEI-

RO, BRANGO A VERDE-AMARE-

LADO COM SILTITO E FOLHE LMO ARENOSO GINZENTO.
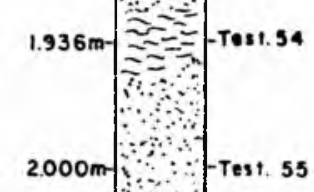

$2000 \mathrm{~m}-\mathrm{fos}$ Tr. 55

$2052 \mathrm{~m}-\mathrm{T}$ Test.56

$2.112 \mathrm{~m}-\mathrm{T}=\mathrm{Tes1} .57$

.

DIABÁBIO

ATUAL OU PLEISTOCENO (?)

ESPICULAS DE ESPONJAS SILL-

COSAS E ALGUNS FRAGMENTOS

DE VEGETAIS.

POSSIVELMENTE AGUA DOCE

PELO LOG ELÉTRICO.

CENOZOICO SUPERIOR(?)

OSSOS E DENTES DE PEIXEE

RESTOS VEgETAIS. -AMBIENTE

POSSIVE LNENTE AGUA DOCE

LOG ELÉTRICO-AGUA DOCE

CENOZOICO SUPERIOR (?) SILI-

SELAOE DENTES DE PEIXES

CENOZOICO SUPERIOR

OSTRACODA + OOGONIAS DE CHA-

ROPHYTA NUTELLA. - AMBIENTE:

AGUA SALOBRA.

LOG ELÉTRICO-ÁgUa SALOBRa

IDADE IN DETERMINADA

RESTOS E ESPOROS DE PLANTAS,

COMUNS

LOG ELÉtrico água doce.

IDADE INDETERMINADA

UNICO FÓSSIL ENCONTRADO

Dente, possivelmente de

REPTIL, NO TEST. 44

LOG ELETRICO - AGUA SALGADA

Dade INDETERMINADa.

RASTROS E TUBOS OE VERMES,

RI PPLE MARKS E GRETAS DE

CONTRAGÃO.

LOQ ELÉTRICO - ÁGUA DOCE.

QUARTzITO 
PERFIL LITO - PALEONTOLÓGICO

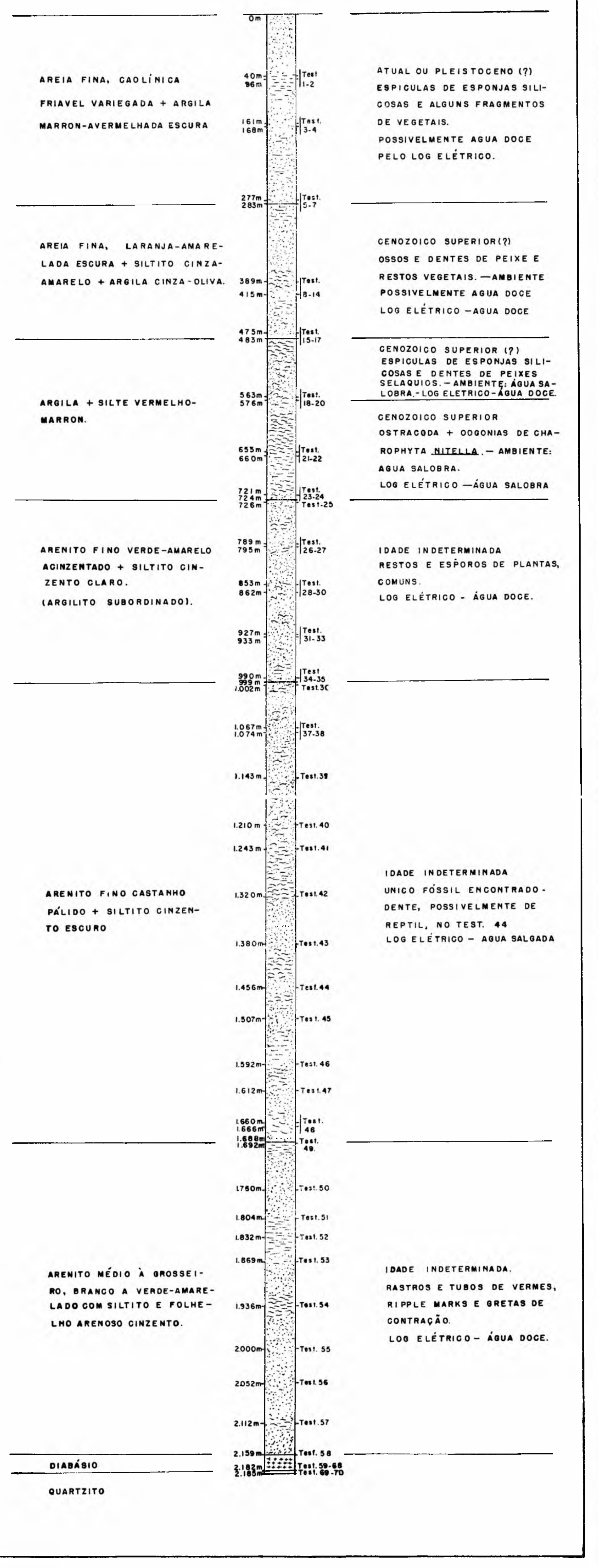




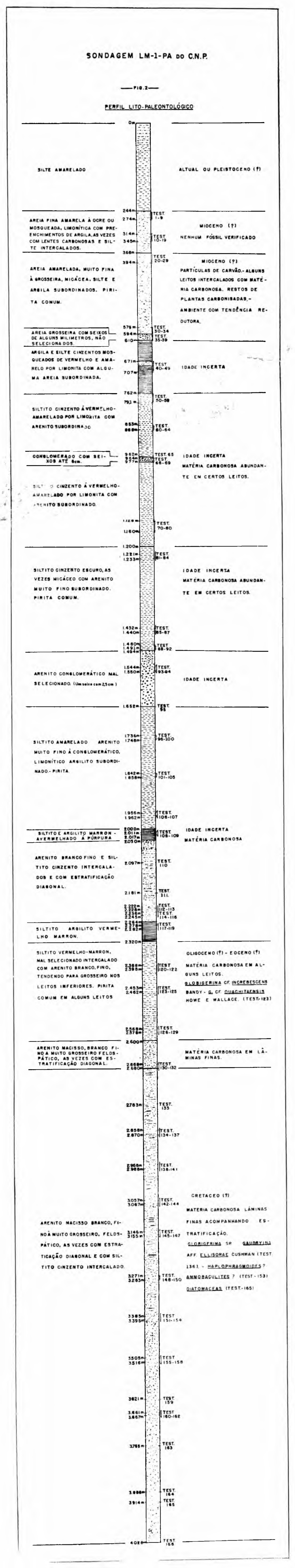




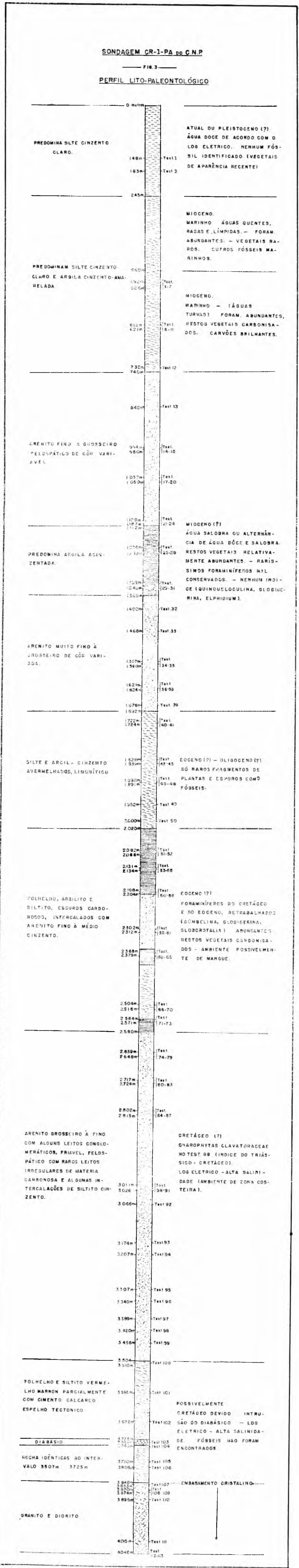


TABELA № 1

DISTRIBUICQÃO ESTRATIGRÁFICA DE FORAMINIFEROS

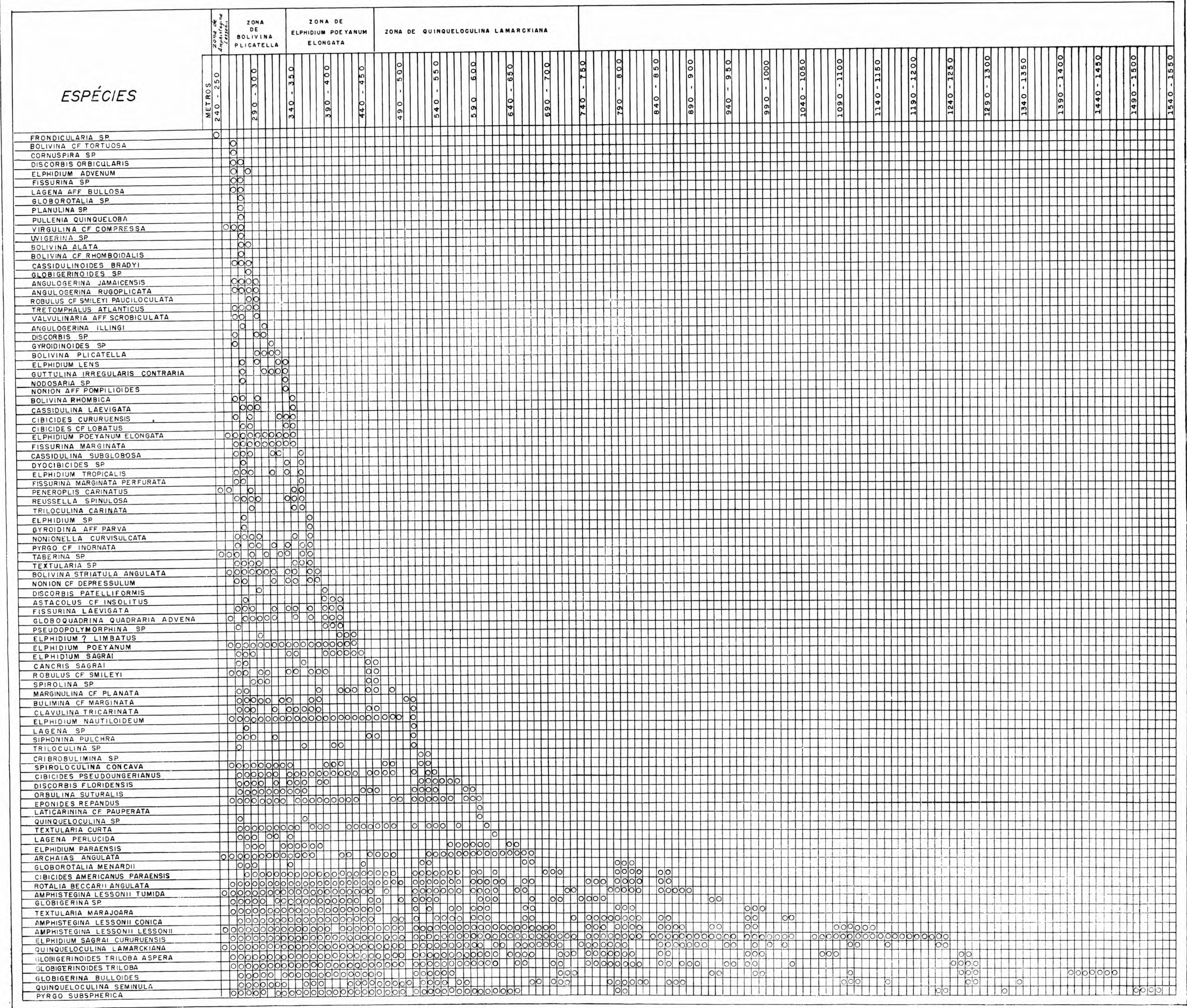


